\title{
Tectonic Summaries of Magnitude 7 and Greater Earthquakes from 2000 to 2015
}

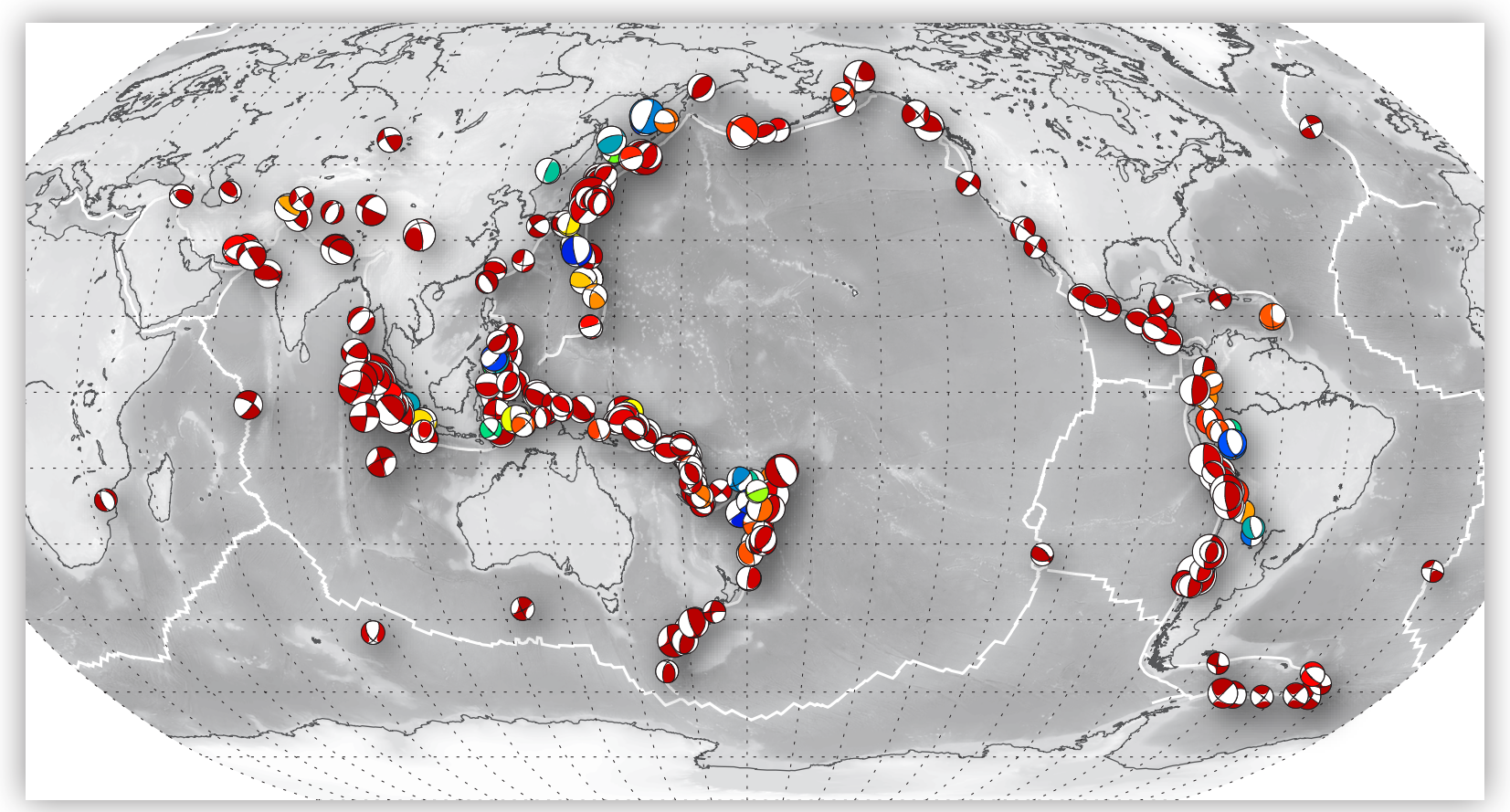

Open-File Report 2016-1192 



\section{Tectonic Summaries of Magnitude 7 and Greater Earthquakes from 2000 to 2015}

By Gavin P. Hayes, Emma K. Myers, James W. Dewey, Richard W. Briggs, Paul S. Earle, Harley M. Benz, Gregory M. Smoczyk, Hanna E. Flamme, William D. Barnhart, Ryan D. Gold, and Kevin P. Furlong

Open-File Report 2016-1192 


\section{U.S. Department of the Interior SALLY JEWELL, Secretary}

\section{U.S. Geological Survey Suzette M. Kimball, Director}

\section{U.S. Geological Survey, Reston, Virginia: 2017}

For more information on the USGS - the Federal source for science about the Earth, its natural and living resources, natural hazards, and the environment—visit http://www.usgs.gov or call 1-888-ASK-USGS.

For an overview of USGS information products, including maps, imagery, and publications, visit http://store.usgs.gov/.

Any use of trade, firm, or product names is for descriptive purposes only and does not imply endorsement by the U.S. Government.

Although this information product, for the most part, is in the public domain, it also may contain copyrighted materials as noted in the text. Permission to reproduce copyrighted items must be secured from the copyright owner.

Suggested citation:

Hayes, G.P., Myers, E.K., Dewey, J.W., Briggs, R.W., Earle, P.S., Benz, H.M., Smoczyk, G.M., Flamme, H.E., Barnhart, W.D., Gold, R.D., and Furlong, K.P., 2017, Tectonic summaries of magnitude 7 and greater earthquakes from 2000 to 2015: U.S. Geological Survey Open-File Report 2016-1192, 148 p., https://doi.org/10.3133/ofr20161192. 


\section{Acknowledgments}

The knowledge and information expressed in these tectonic summaries is compiled by the authors and often utilizes a wealth of geological and geophysical literature, too numerous to list here. The authors thank all researchers who have worked to improve our understanding of global tectonics, historic earthquakes, and seismotectonic problems.

All relative tectonic plate velocities were calculated using the UNAVCO Plate Motion Calculator and the MORVEL 2010 model (https://www.unavco.org/software/geodetic-utilities/platemotion-calculator/plate-motion-calculator.html).

\section{Contents}

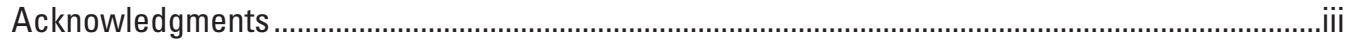

Abstract

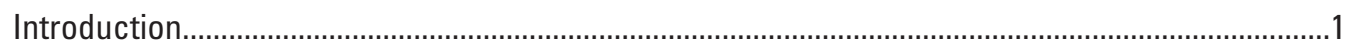

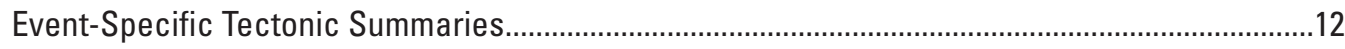

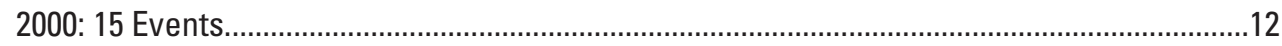

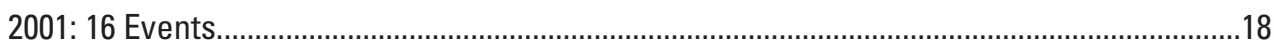

2002: 13 Events.

2003: 15 Events.

2004: 16 Events.









2009: 17 Events.

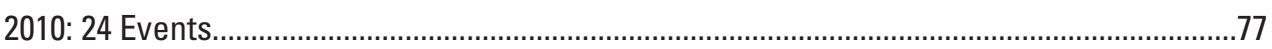

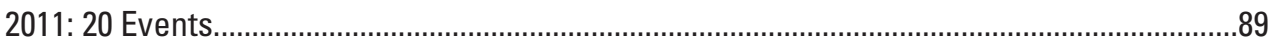

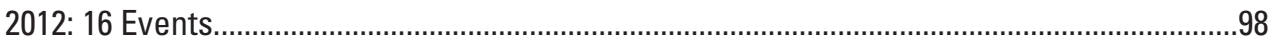

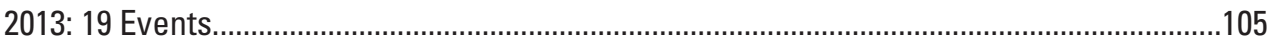

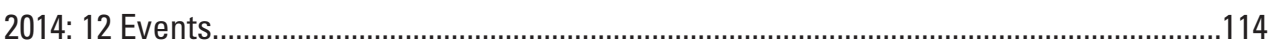

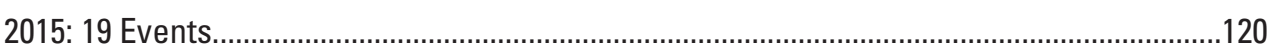

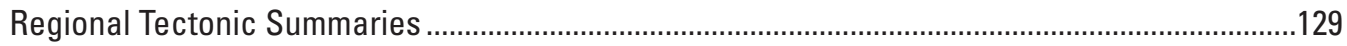

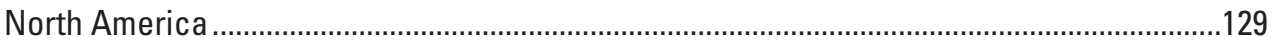

Aleutian Arc and Vicinity .......................................................................................129

Offshore British Columbia - Southeastern Alaska and Vicinity.....................................131



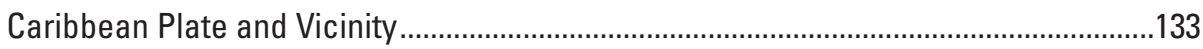

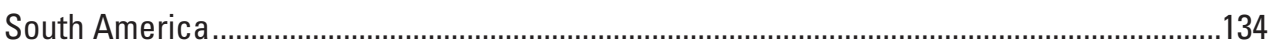

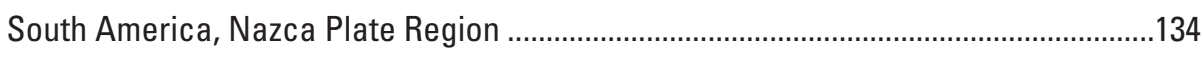

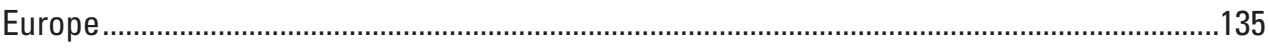

Mediterranean Sea and Vicinity............................................................................. 


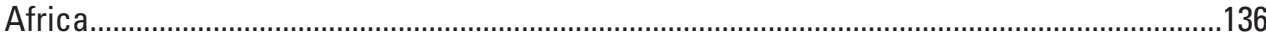

East African Rift .................................................................................................... 136

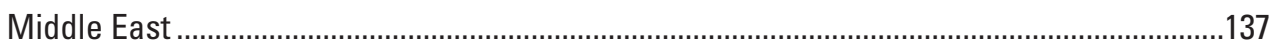



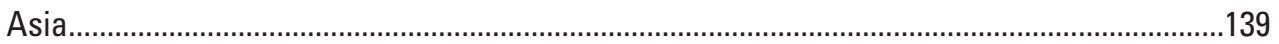



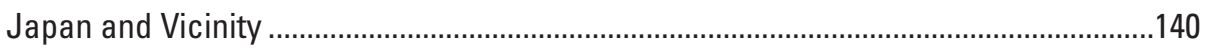

Kuril-Kamchatka Arc and Vicinity ..........................................................................141



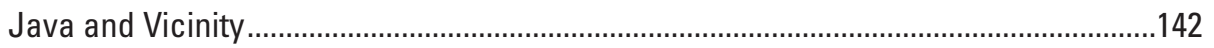

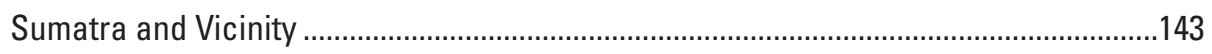

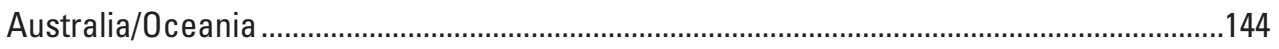

Australia Plate and Vicinity ....................................................................................... 144

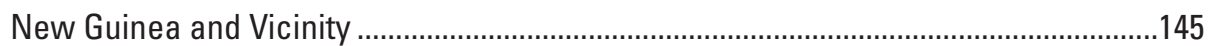

Eastern Margin of the Australian Plate.......................................................................146

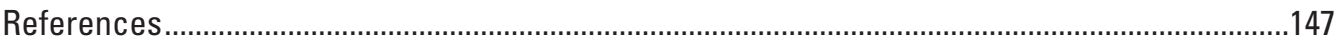

\section{Figure}

1. Map showing earthquakes of magnitude 7 or greater, 2000-2015. In $(A)$, earthquake locations are colored by depth and sized according to their magnitude. In $(B)$, earthquake focal mechanism solutions (derived via moment tensor inversion) are plotted and are also colored by depth and sized according to their magnitude

\section{Table}

1. Earthquakes of magnitude 7 or greater, 2000-2015

\section{Conversion Factors}

International System of Units to U.S. customary units

\begin{tabular}{lcl}
\hline \multicolumn{1}{c}{ Multiply } & By & \multicolumn{1}{c}{ To obtain } \\
\hline & Length & \\
\hline centimeter $(\mathrm{cm})$ & 0.3937 & inch (in.) \\
millimeter $(\mathrm{mm})$ & 0.03937 & inch (in.) \\
meter $(\mathrm{m})$ & 3.281 & foot $(\mathrm{ft})$ \\
kilometer $(\mathrm{km})$ & 0.6214 & mile (mi) \\
kilometer $(\mathrm{km})$ & 0.5400 & mile, nautical $(\mathrm{nmi})$ \\
meter $(\mathrm{m})$ & 1.094 & yard $(\mathrm{yd})$ \\
\hline & Area & \\
\hline square kilometer $\left(\mathrm{km}^{2}\right)$ & 0.3861 & square mile $\left(\mathrm{mi}{ }^{2}\right)$ \\
\hline & Flow rate & \\
\hline millimeter per year $(\mathrm{mm} / \mathrm{yr})$ & 0.03937 & inch per year $(\mathrm{in} / \mathrm{yr})$ \\
\hline
\end{tabular}




\section{Datum}

Horizontal coordinate information is referenced to the World Geodetic System of 1984 (WGS84) reference frame.

\section{Abbreviations}







\title{
Tectonic Summaries of Magnitude 7 and Greater Earthquakes from 2000 to 2015
}

\author{
By Gavin P. Hayes, ${ }^{1}$ Emma K. Myers, ${ }^{2}$ James W. Dewey, ${ }^{1}$ Richard W. Briggs, ${ }^{1}$ Paul S. Earle, ${ }^{1}$ Harley M. Benz, \\ Gregory M. Smoczyk, ${ }^{1}$ Hanna E. Flamme, ${ }^{1}$ William D. Barnhart, ${ }^{3}$ Ryan D. Gold, ${ }^{1}$ and Kevin P. Furlong ${ }^{4}$
}

\begin{abstract}
This paper describes the tectonic summaries for all magnitude 7 and larger earthquakes in the period 2000-2015, as produced by the U.S. Geological Survey National Earthquake Information Center during their routine response operations to global earthquakes. The goal of such summaries is to provide important event-specific information to the public rapidly and concisely, such that recent earthquakes can be understood within a global and regional seismotectonic framework. We compile these summaries here to provide a long-term archive for this information, and so that the variability in tectonic setting and earthquake history from region to region, and sometimes within a given region, can be more clearly understood.
\end{abstract}

\section{Introduction}

The U.S. Geological Survey (USGS) National Earthquake Information Center (NEIC) generates event-specific tectonic summaries for global earthquakes having magnitudes of 7 or larger to provide key event information to the public in a concise format, focusing on the tectonic context of that particular event and how it relates to the historical seismicity of the region. Such information includes the type of faulting that caused the event, the depth of the hypocenter, the tectonic plates involved and their relative velocities, information on the orientation of the causative fault, and a brief discussion of regional tectonics and nearby historically significant earthquakes. Some summaries also include reports of fatalities or economic loss estimates, but information about event impact usually can be found on Web pages associated with the earthquake in the USGS NEIC Comprehensive Catalog (ComCat - http://earthquake.usgs.gov/earthquakes/search/). ComCat is the source of all event-based information used in this report, and is the long-term archive for event-based tectonic summaries.

An earthquake of magnitude 7 (M 7) typically involves an average displacement of 1 meter (m) or more across a fault surface with linear dimensions of several tens of kilometers, and earthquakes with larger magnitudes involve larger displacements over larger fault areas. Not all large to great earthquakes produce a significant effect on human society, but the energy released by a M 7+ earthquake is capable of producing widespread and serious damage if the event is centered at shallow depth (less than 70 kilometers $[\mathrm{km}]$ ) beneath a populated region. Some large earthquakes occurring at intermediate depth (between $70 \mathrm{~km}$ and $300 \mathrm{~km}$ ) also produce serious damage. Each year there are typically 10 to $20 \mathrm{M} 7+$ earthquakes globally. Lists of most of these earthquakes, as well as smaller magnitude events that produced appreciable damage or generated substantial media interest, are kept on the USGS NEIC Web site in the Significant Earthquakes Archive (http://earthquake.usgs.gov/earthquakes/browse/significant.php).

This report provides tectonic summaries for $250 \mathrm{M} 7+$ earthquakes that occurred in the period 2000-2015. The events are listed in table 1. Time spans discussed in all tectonic summaries are relative to the event in question, rather than being relative to the present day. So, for example, if an earthquake in June of 2004 discusses earthquakes over the past 40 years, the time span referenced is June 1964-June 2004. In the following text, seismotectonic summaries for each event are provided in chronological order.

\footnotetext{
${ }^{1}$ U.S. Geological Survey.

${ }^{2}$ Formerly U.S. Geological Survey, now at: Deparment of Earth and Space Sciences, University of Washington, Johnson Hall Rm-070, Box 351310, 4000 15th Avenue NE, Seattle, WA 98195.

${ }^{3}$ Formerly U.S. Geological Survey, now at: Department of Earth and Enviromental Sciences, The University of Iowa, 115 Trowbridge Hall, Iowa City, IA 52242 .
}

${ }^{4}$ Department of Geosciences, Pennsylvania State University, 413 Deike Building, University Park, PA 16802. 
In most cases, tectonic summaries for individual events are based on characteristics of the earthquakes that are inferred from standard analyses of global seismographic data and that are interpreted in light of broad-scale tectonic processes of the earthquake regions. Summaries commonly allude to the fact that seismic moment-tensor analyses using seismographic data identify two alternatives for the orientation of an earthquake's fault plane: although both orientations correspond to the same mode of faulting (for example, strike-slip, normal, reverse), the two alternative planes are orthogonal to each other. Given the two alternative planes identified in the moment-tensor analysis of an earthquake, the orientation of the causative fault plane is sometimes inferred by a finite-fault model of the seismic-wave radiation pattern, by the location of the earthquake being on or close to a previously mapped fault or well-defined plate boundary, or by the distribution of early aftershocks. We either explicitly note the ambiguity that is inherent in the moment-tensor analysis, or we identify the independent evidence that we used to favor one of the moment-tensor analysis planes as the likely causative fault plane.

We describe the tectonic environments of most individual earthquakes in terms of the relative motions of tectonic plates that are identified in the global MORVEL model of DeMets and others (2010). Summaries for earthquakes that occurred prior to the release of this model have been updated to reflect MORVEL velocities for consistency. Plate boundary regions between some of the plates are complex, however, so individual earthquakes may have focal mechanism solutions that seem inconsistent with the motions of the plates of the global model. Scientists studying these regions commonly have success explaining the characteristics of individual seismic zones by modeling the boundary regions between global-model plates as consisting of microplates that move relative to each other in a way that accommodates the broad-scale relative motions of the larger plates. For tectonic summaries that pertain to these regions, we identify the global-model plates whose relative motions determine the regional tectonics and also note that the broader plate boundary regions are subdivided into microplates. In some instances, the India and Australia tectonic plates are described together as the "IndoAustralia plate" because they primarily move as a single block with a broad zone of convergent deformation between them.

Many of the earthquakes described in these summaries were significant enough that they have been subject to special scientific studies that have inferred more on characteristics of the rupture process and sequence seismotectonics than we have inferred from our routine analyses or that focused on properties of the earthquake source that we do not consider in the summaries. The conclusions of these studies are reported in scientific journals and in special papers. The On-Line Event Bibliography of the International Seismological Centre (2016; http://www.isc.ac.uk/event_bibliography/) can be used to find reports of many such studies.

Following the tectonic summaries corresponding to specific M 7+ events during 2000-2015, the section, "Regional Tectonic Summaries," contains tectonic summaries for many of the regions of high seismicity, discussed in a broader context and published as part of a series of USGS Seismicity of the Earth Open-File Reports (http://earthquake.usgs.gov/earthquakes/world/ seismicity_maps/).

A Google Earth keyhole markup language (KML) file is provided at https://doi.org/10.3133/ofr20161192, by means of which the events, related information from table 1, and associated summaries may be graphically displayed. A global map of events listed in table 1 is also provided in figure 1. 


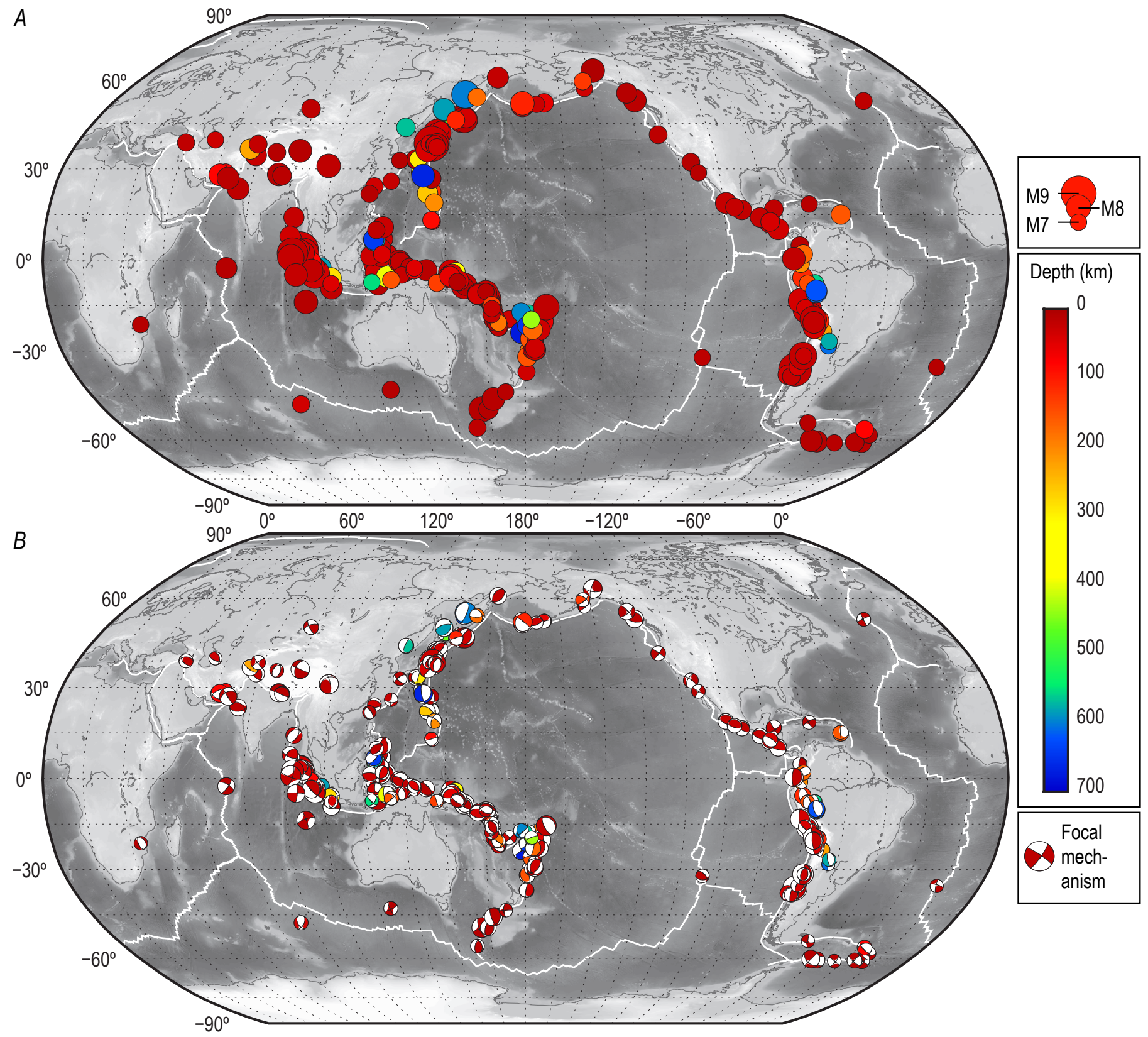

Figure 1. Earthquakes of magnitude 7 or greater, 2000-2015. In (A), earthquake locations are colored by depth and sized according to their magnitude. $\ln (B)$, earthquake focal mechanism solutions (derived via moment tensor inversion) are plotted and are also colored by depth and sized according to their magnitude. 
Table 1. Earthquakes of magnitude 7 or greater, 2000-2015.

[Date/Time (UTC) - Date and time of the onset of the earthquake, expressed in Coordinated Universal Time.

$\mathrm{Mw}$ - Moment magnitude of the earthquake that is used by the NEIC as the preferred measure of earthquake size. Moment magnitudes that are computed by different procedures sometimes differ by 0.1-0.2 units of magnitude: accordingly, Mw listed for some earthquakes may differ slightly from Mw listed for the same earthquakes in other scientific reports. While tectonic summaries typically list magnitude with the notation "M", to denote a generic magnitude, the size of all earthquakes in this report have been calculated with moment tensor analyses and are accordingly moment magnitude estimates.

Region - Source region of the earthquake, described in very general geographic terms.

Faulting Style - Mode of faulting, whether predominantly strike-slip, normal, reverse, or containing major components of both strike-slip and reverse or normal faulting (respectively oblique/reverse and oblique/normal). The term "thrust-fault," used in some of the tectonic summaries, is commonly used to describe a shallowly dipping $\left(<30^{\circ}\right)$ reverse fault. In the table below, reverse faulting events occurring on the shallow megathrust interfaces of subduction zones are noted with an additional "thrust" label. Events thought to be located on subduction zone interfaces, but via more moderately dipping reverse faulting, are labeled with an additional “*”.

Focal depth - General description of the depth of the earthquake beneath the earth's surface:

Shallow - focal depth less than 70 kilometers $(\mathrm{km})$.

Intermediate - focal depth between $70 \mathrm{~km}$ and $300 \mathrm{~km}$.

Deep - focal depth greater than $300 \mathrm{~km}$.

ComCat EventID -Identification number that directly links to the event specific page in ComCat, when used as "EVENTID" in the following address: http:// earthquake.usgs.gov/earthquakes/eventpage/EVENTID. Italicized IDs correspond to events whose tectonic summaries were created as part of this report.]

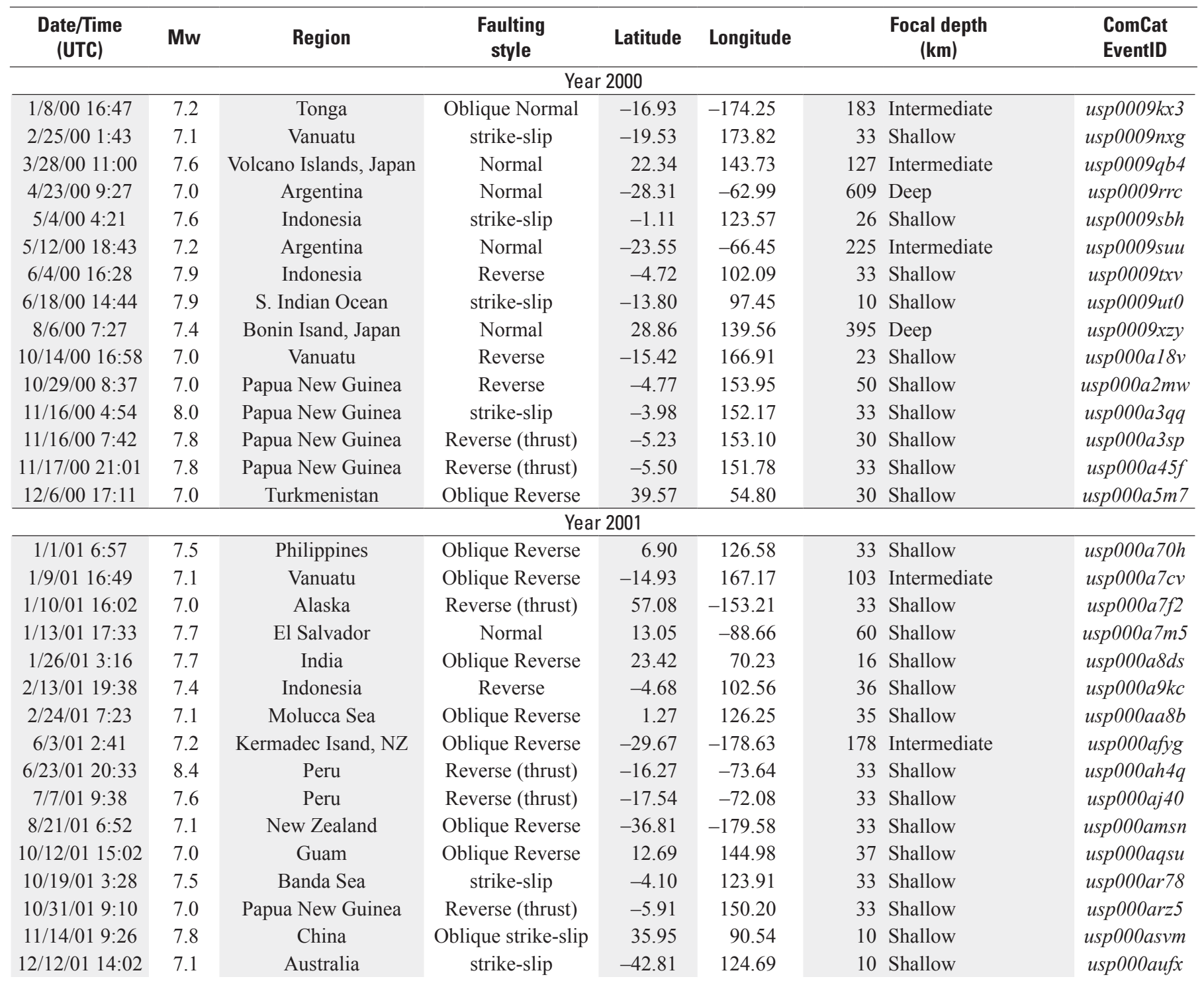


Table 1. Earthquakes of magnitude 7 or greater, 2000-2015.-Continued

[Date/Time (UTC) - Date and time of the onset of the earthquake, expressed in Coordinated Universal Time.

$\mathrm{Mw}$ - Moment magnitude of the earthquake that is used by the NEIC as the preferred measure of earthquake size. Moment magnitudes that are computed by different procedures sometimes differ by $0.1-0.2$ units of magnitude: accordingly, Mw listed for some earthquakes may differ slightly from Mw listed for the same earthquakes in other scientific reports. While tectonic summaries typically list magnitude with the notation "M", to denote a generic magnitude, the size of all earthquakes in this report have been calculated with moment tensor analyses and are accordingly moment magnitude estimates.

Region - Source region of the earthquake, described in very general geographic terms.

Faulting Style - Mode of faulting, whether predominantly strike-slip, normal, reverse, or containing major components of both strike-slip and reverse or normal faulting (respectively oblique/reverse and oblique/normal). The term "thrust-fault," used in some of the tectonic summaries, is commonly used to describe a shallowly dipping $\left(<30^{\circ}\right)$ reverse fault. In the table below, reverse faulting events occurring on the shallow megathrust interfaces of subduction zones are noted with an additional "thrust" label. Events thought to be located on subduction zone interfaces, but via more moderately dipping reverse faulting, are labeled with an additional “*”.

Focal depth - General description of the depth of the earthquake beneath the earth's surface:

Shallow - focal depth less than 70 kilometers $(\mathrm{km})$.

Intermediate - focal depth between $70 \mathrm{~km}$ and $300 \mathrm{~km}$.

Deep - focal depth greater than $300 \mathrm{~km}$.

ComCat EventID -Identification number that directly links to the event specific page in ComCat, when used as "EVENTID" in the following address: http:// earthquake.usgs.gov/earthquakes/eventpage/EVENTID. Italicized IDs correspond to events whose tectonic summaries were created as part of this report.]

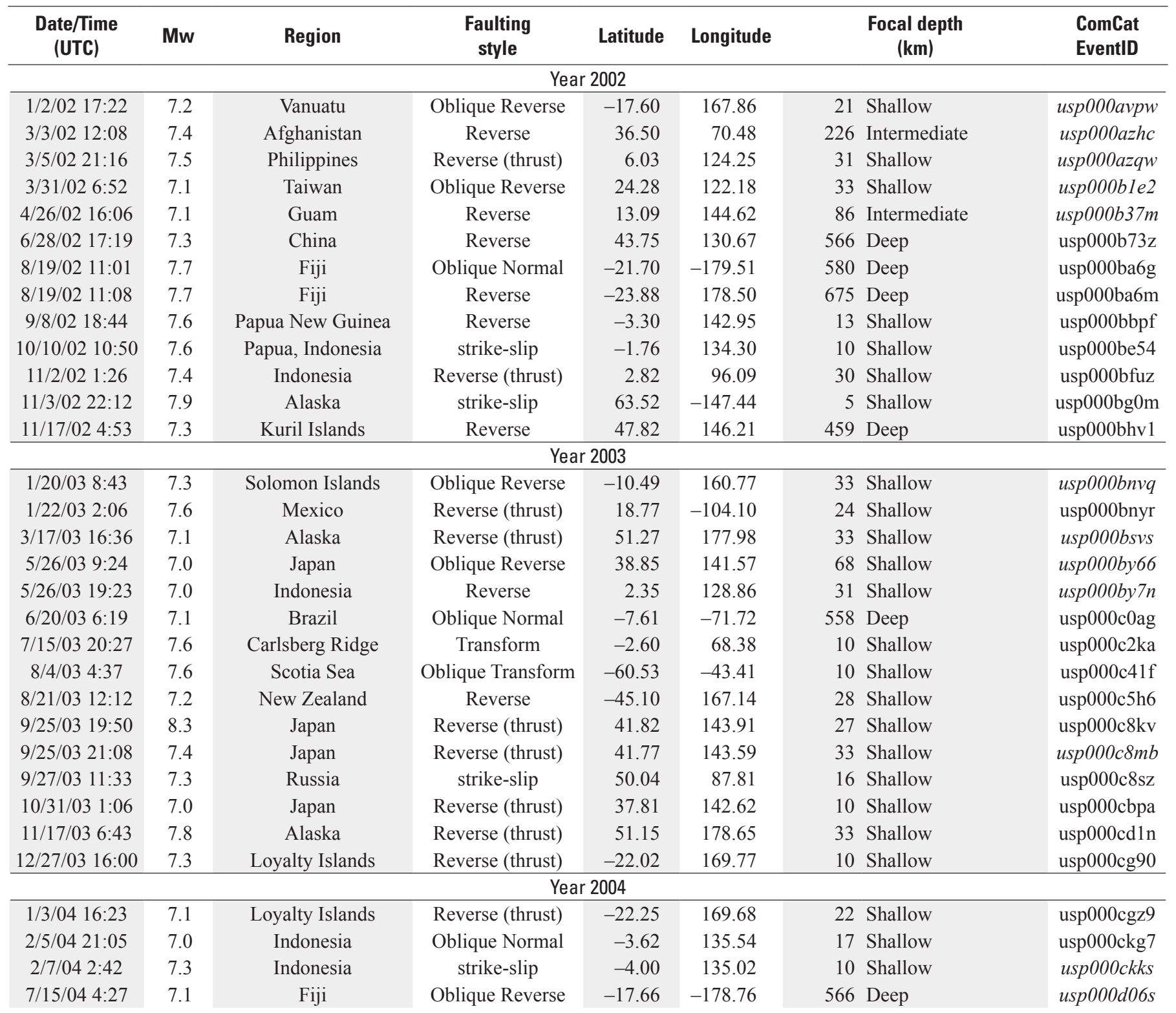


Table 1. Earthquakes of magnitude 7 or greater, 2000-2015.-Continued

[Date/Time (UTC) - Date and time of the onset of the earthquake, expressed in Coordinated Universal Time.

$\mathrm{Mw}$ - Moment magnitude of the earthquake that is used by the NEIC as the preferred measure of earthquake size. Moment magnitudes that are computed by different procedures sometimes differ by 0.1-0.2 units of magnitude: accordingly, Mw listed for some earthquakes may differ slightly from Mw listed for the same earthquakes in other scientific reports. While tectonic summaries typically list magnitude with the notation "M", to denote a generic magnitude, the size of all earthquakes in this report have been calculated with moment tensor analyses and are accordingly moment magnitude estimates.

Region - Source region of the earthquake, described in very general geographic terms.

Faulting Style - Mode of faulting, whether predominantly strike-slip, normal, reverse, or containing major components of both strike-slip and reverse or normal faulting (respectively oblique/reverse and oblique/normal). The term "thrust-fault," used in some of the tectonic summaries, is commonly used to describe a shallowly dipping $\left(<30^{\circ}\right)$ reverse fault. In the table below, reverse faulting events occurring on the shallow megathrust interfaces of subduction zones are noted with an additional "thrust" label. Events thought to be located on subduction zone interfaces, but via more moderately dipping reverse faulting, are labeled with an additional “*”.

Focal depth - General description of the depth of the earthquake beneath the earth's surface:

Shallow - focal depth less than 70 kilometers $(\mathrm{km})$.

Intermediate - focal depth between $70 \mathrm{~km}$ and $300 \mathrm{~km}$.

Deep - focal depth greater than $300 \mathrm{~km}$.

ComCat EventID -Identification number that directly links to the event specific page in ComCat, when used as "EVENTID" in the following address: http:// earthquake.usgs.gov/earthquakes/eventpage/EVENTID. Italicized IDs correspond to events whose tectonic summaries were created as part of this report.]

\begin{tabular}{|c|c|c|c|c|c|c|c|c|}
\hline $\begin{array}{l}\text { Date/Time } \\
\text { (UTC) }\end{array}$ & Mw & Region & $\begin{array}{l}\text { Faulting } \\
\text { style }\end{array}$ & Latitude & Longitude & & $\begin{array}{l}\text { Focal depth } \\
(\mathbf{k m})\end{array}$ & $\begin{array}{l}\text { ComCat } \\
\text { EventID }\end{array}$ \\
\hline $7 / 25 / 0414: 35$ & 7.3 & Indonesia & Oblique Normal & -2.43 & 103.98 & 582 & Deep & usp000d0v4 \\
\hline 9/5/04 10:07 & 7.2 & Japan & Reverse & 33.07 & 136.62 & 14 & Shallow & usp000d3ka \\
\hline 10/9/04 21:26 & 7.0 & Nicaragua & Reverse (thrust) & 11.42 & -86.67 & 35 & Shallow & usp000d63h \\
\hline 11/11/04 21:26 & 7.5 & Indonesia & Reverse (thrust) & -8.15 & 124.87 & 10 & Shallow & usp000d85g \\
\hline $11 / 26 / 042: 25$ & 7.1 & Papua, Indonesia & Oblique strike-slip & -3.61 & 135.40 & 10 & Shallow & usp000d975 \\
\hline 11/28/04 18:32 & 7.0 & Japan & Reverse (thrust) & 43.01 & 145.12 & 39 & Shallow & usp000d9h1 \\
\hline $12 / 23 / 0414: 59$ & 8.1 & Macquarie Island & strike-slip & -49.31 & 161.35 & 10 & Shallow & usp000db93 \\
\hline $12 / 26 / 040: 58$ & 9.1 & Indonesia & Reverse (thrust) & 3.30 & 95.98 & 30 & Shallow & usp000dbed \\
\hline $12 / 26 / 044: 21$ & 7.2 & Nicobar Islands & Reverse (thrust) & 6.91 & 92.96 & 39 & Shallow & usp000dbg6 \\
\hline $6 / 13 / 05$ 22:44 & 7.8 & Chile & Normal & -19.99 & -69.20 & 116 & Intermediate & usp000dsw1 \\
\hline $6 / 15 / 052: 50$ & 7.2 & California & strike-slip & 41.29 & -125.95 & 16 & Shallow & usp000dt25 \\
\hline $7 / 24 / 05$ 15:42 & 7.2 & Nicobar Islands & strike-slip & 7.92 & 92.19 & 16 & Shallow & usp000dvtc \\
\hline $8 / 16 / 052: 46$ & 7.2 & Japan & Reverse (thrust) & 38.28 & 142.04 & 36 & Shallow & usp000dxe2 \\
\hline 9/9/05 7:26 & 7.6 & Papua New Guinea & Reverse & -4.54 & 153.47 & 90 & Intermediate & usp000dz $2 \mathrm{j}$ \\
\hline 9/26/05 1:55 & 7.5 & Peru & Normal & -5.68 & -76.40 & 115 & Intermediate & usp000e09h \\
\hline $10 / 8 / 053: 50$ & 7.6 & Pakistan & Reverse & 34.54 & 73.59 & 26 & Shallow & usp000e12e \\
\hline $11 / 14 / 0521: 38$ & 7.0 & Japan & Normal & 38.11 & 144.90 & 11 & Shallow & usp000e462 \\
\hline \multicolumn{9}{|c|}{ Year 2006} \\
\hline $1 / 2 / 066: 10$ & 7.4 & S. Sandwich Islands & Transform & -60.96 & -21.61 & 13 & Shallow & usp000e7dd \\
\hline $8 / 20 / 063: 41$ & 7.0 & Scotia Sea & Transform & -61.03 & -34.37 & 13 & Shallow & usp000erc2 \\
\hline
\end{tabular}


Table 1. Earthquakes of magnitude 7 or greater, 2000-2015.-Continued

[Date/Time (UTC) - Date and time of the onset of the earthquake, expressed in Coordinated Universal Time.

$\mathrm{Mw}$ - Moment magnitude of the earthquake that is used by the NEIC as the preferred measure of earthquake size. Moment magnitudes that are computed by different procedures sometimes differ by $0.1-0.2$ units of magnitude: accordingly, Mw listed for some earthquakes may differ slightly from Mw listed for the same earthquakes in other scientific reports. While tectonic summaries typically list magnitude with the notation "M", to denote a generic magnitude, the size of all earthquakes in this report have been calculated with moment tensor analyses and are accordingly moment magnitude estimates.

Region - Source region of the earthquake, described in very general geographic terms.

Faulting Style - Mode of faulting, whether predominantly strike-slip, normal, reverse, or containing major components of both strike-slip and reverse or normal faulting (respectively oblique/reverse and oblique/normal). The term "thrust-fault," used in some of the tectonic summaries, is commonly used to describe a shallowly dipping $\left(<30^{\circ}\right)$ reverse fault. In the table below, reverse faulting events occurring on the shallow megathrust interfaces of subduction zones are noted with an additional "thrust" label. Events thought to be located on subduction zone interfaces, but via more moderately dipping reverse faulting, are labeled with an additional "*”.

Focal depth - General description of the depth of the earthquake beneath the earth's surface:

Shallow - focal depth less than 70 kilometers $(\mathrm{km})$.

Intermediate - focal depth between $70 \mathrm{~km}$ and $300 \mathrm{~km}$.

Deep - focal depth greater than $300 \mathrm{~km}$.

ComCat EventID -Identification number that directly links to the event specific page in ComCat, when used as "EVENTID" in the following address: http:// earthquake.usgs.gov/earthquakes/eventpage/EVENTID. Italicized IDs correspond to events whose tectonic summaries were created as part of this report.]




Table 1. Earthquakes of magnitude 7 or greater, 2000-2015.-Continued

[Date/Time (UTC) - Date and time of the onset of the earthquake, expressed in Coordinated Universal Time.

$\mathrm{Mw}$ - Moment magnitude of the earthquake that is used by the NEIC as the preferred measure of earthquake size. Moment magnitudes that are computed by different procedures sometimes differ by 0.1-0.2 units of magnitude: accordingly, Mw listed for some earthquakes may differ slightly from Mw listed for the same earthquakes in other scientific reports. While tectonic summaries typically list magnitude with the notation "M", to denote a generic magnitude, the size of all earthquakes in this report have been calculated with moment tensor analyses and are accordingly moment magnitude estimates.

Region - Source region of the earthquake, described in very general geographic terms.

Faulting Style - Mode of faulting, whether predominantly strike-slip, normal, reverse, or containing major components of both strike-slip and reverse or normal faulting (respectively oblique/reverse and oblique/normal). The term "thrust-fault," used in some of the tectonic summaries, is commonly used to describe a shallowly dipping $\left(<30^{\circ}\right)$ reverse fault. In the table below, reverse faulting events occurring on the shallow megathrust interfaces of subduction zones are noted with an additional "thrust" label. Events thought to be located on subduction zone interfaces, but via more moderately dipping reverse faulting, are labeled with an additional "*”.

Focal depth - General description of the depth of the earthquake beneath the earth's surface:

Shallow - focal depth less than 70 kilometers $(\mathrm{km})$.

Intermediate - focal depth between $70 \mathrm{~km}$ and $300 \mathrm{~km}$.

Deep - focal depth greater than $300 \mathrm{~km}$.

ComCat EventID -Identification number that directly links to the event specific page in ComCat, when used as "EVENTID" in the following address: http:// earthquake.usgs.gov/earthquakes/eventpage/EVENTID. Italicized IDs correspond to events whose tectonic summaries were created as part of this report.]

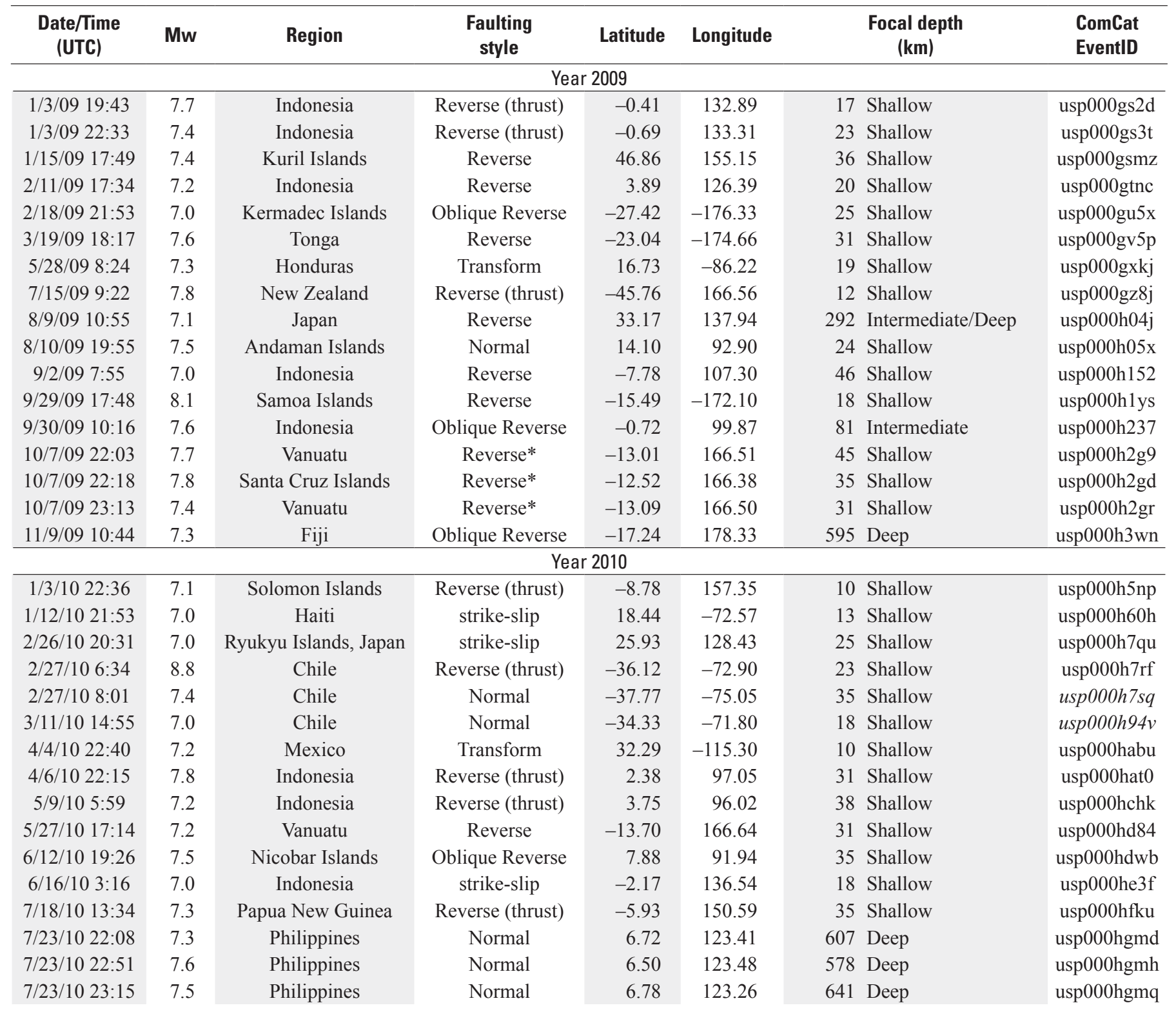


Table 1. Earthquakes of magnitude 7 or greater, 2000-2015.-Continued

[Date/Time (UTC) - Date and time of the onset of the earthquake, expressed in Coordinated Universal Time.

$\mathrm{Mw}$ - Moment magnitude of the earthquake that is used by the NEIC as the preferred measure of earthquake size. Moment magnitudes that are computed by different procedures sometimes differ by $0.1-0.2$ units of magnitude: accordingly, Mw listed for some earthquakes may differ slightly from Mw listed for the same earthquakes in other scientific reports. While tectonic summaries typically list magnitude with the notation "M", to denote a generic magnitude, the size of all earthquakes in this report have been calculated with moment tensor analyses and are accordingly moment magnitude estimates.

Region - Source region of the earthquake, described in very general geographic terms.

Faulting Style - Mode of faulting, whether predominantly strike-slip, normal, reverse, or containing major components of both strike-slip and reverse or normal faulting (respectively oblique/reverse and oblique/normal). The term "thrust-fault," used in some of the tectonic summaries, is commonly used to describe a shallowly dipping $\left(<30^{\circ}\right)$ reverse fault. In the table below, reverse faulting events occurring on the shallow megathrust interfaces of subduction zones are noted with an additional "thrust" label. Events thought to be located on subduction zone interfaces, but via more moderately dipping reverse faulting, are labeled with an additional “*”.

Focal depth - General description of the depth of the earthquake beneath the earth's surface:

Shallow - focal depth less than 70 kilometers $(\mathrm{km})$.

Intermediate - focal depth between $70 \mathrm{~km}$ and $300 \mathrm{~km}$.

Deep - focal depth greater than $300 \mathrm{~km}$.

ComCat EventID -Identification number that directly links to the event specific page in ComCat, when used as "EVENTID" in the following address: http:// earthquake.usgs.gov/earthquakes/eventpage/EVENTID. Italicized IDs correspond to events whose tectonic summaries were created as part of this report.]




Table 1. Earthquakes of magnitude 7 or greater, 2000-2015.-Continued

[Date/Time (UTC) - Date and time of the onset of the earthquake, expressed in Coordinated Universal Time.

$\mathrm{Mw}$ - Moment magnitude of the earthquake that is used by the NEIC as the preferred measure of earthquake size. Moment magnitudes that are computed by different procedures sometimes differ by 0.1-0.2 units of magnitude: accordingly, Mw listed for some earthquakes may differ slightly from Mw listed for the same earthquakes in other scientific reports. While tectonic summaries typically list magnitude with the notation "M", to denote a generic magnitude, the size of all earthquakes in this report have been calculated with moment tensor analyses and are accordingly moment magnitude estimates.

Region - Source region of the earthquake, described in very general geographic terms.

Faulting Style - Mode of faulting, whether predominantly strike-slip, normal, reverse, or containing major components of both strike-slip and reverse or normal faulting (respectively oblique/reverse and oblique/normal). The term "thrust-fault," used in some of the tectonic summaries, is commonly used to describe a shallowly dipping $\left(<30^{\circ}\right)$ reverse fault. In the table below, reverse faulting events occurring on the shallow megathrust interfaces of subduction zones are noted with an additional "thrust" label. Events thought to be located on subduction zone interfaces, but via more moderately dipping reverse faulting, are labeled with an additional “*”.

Focal depth - General description of the depth of the earthquake beneath the earth's surface:

Shallow - focal depth less than 70 kilometers $(\mathrm{km})$.

Intermediate - focal depth between $70 \mathrm{~km}$ and $300 \mathrm{~km}$.

Deep - focal depth greater than $300 \mathrm{~km}$.

ComCat EventID -Identification number that directly links to the event specific page in ComCat, when used as "EVENTID" in the following address: http:// earthquake.usgs.gov/earthquakes/eventpage/EVENTID. Italicized IDs correspond to events whose tectonic summaries were created as part of this report.]

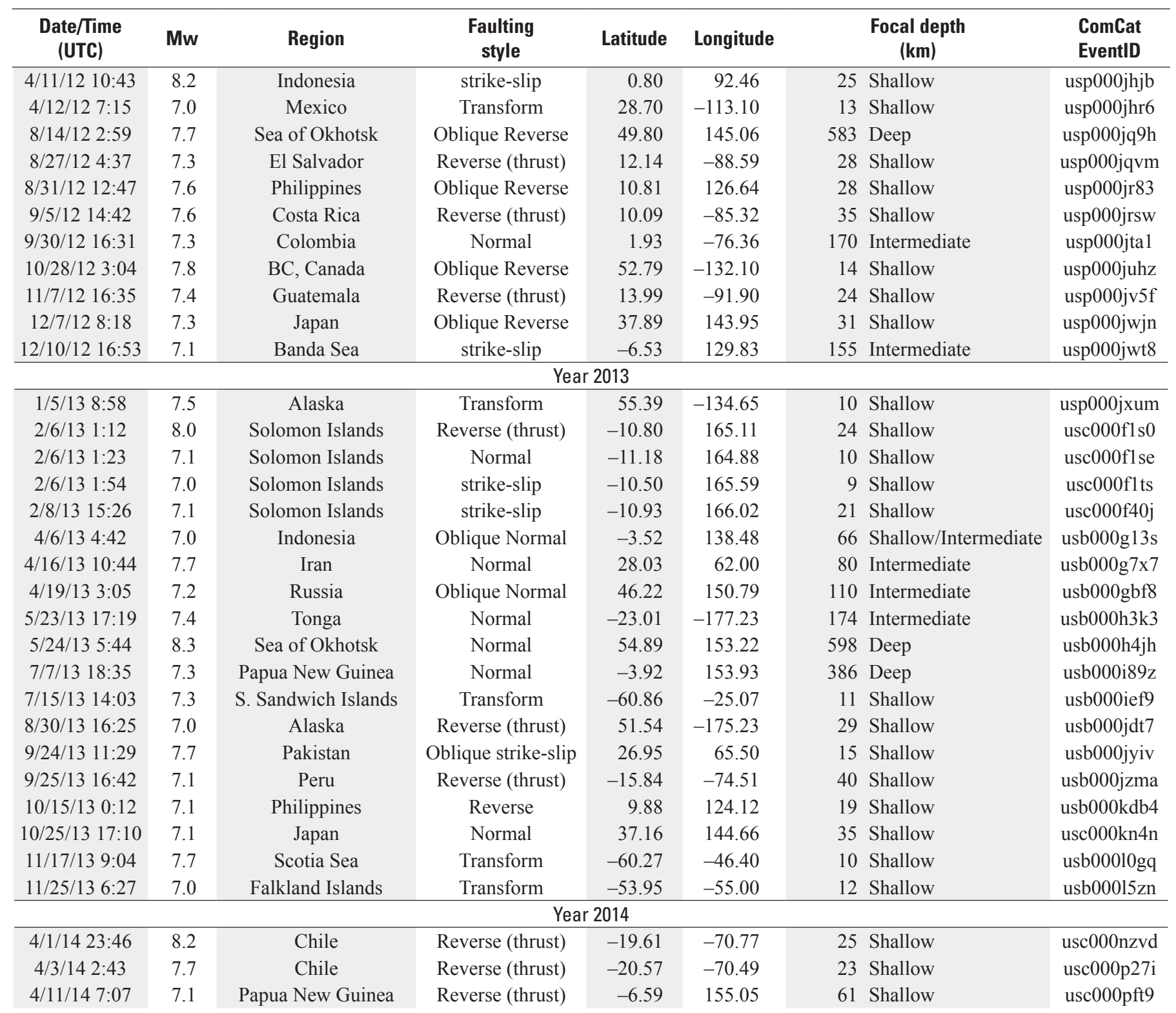


Table 1. Earthquakes of magnitude 7 or greater, 2000-2015.-Continued

[Date/Time (UTC) - Date and time of the onset of the earthquake, expressed in Coordinated Universal Time.

$\mathrm{Mw}$ - Moment magnitude of the earthquake that is used by the NEIC as the preferred measure of earthquake size. Moment magnitudes that are computed by different procedures sometimes differ by $0.1-0.2$ units of magnitude: accordingly, Mw listed for some earthquakes may differ slightly from Mw listed for the same earthquakes in other scientific reports. While tectonic summaries typically list magnitude with the notation "M", to denote a generic magnitude, the size of all earthquakes in this report have been calculated with moment tensor analyses and are accordingly moment magnitude estimates.

Region - Source region of the earthquake, described in very general geographic terms.

Faulting Style - Mode of faulting, whether predominantly strike-slip, normal, reverse, or containing major components of both strike-slip and reverse or normal faulting (respectively oblique/reverse and oblique/normal). The term "thrust-fault," used in some of the tectonic summaries, is commonly used to describe a shallowly dipping $\left(<30^{\circ}\right)$ reverse fault. In the table below, reverse faulting events occurring on the shallow megathrust interfaces of subduction zones are noted with an additional "thrust" label. Events thought to be located on subduction zone interfaces, but via more moderately dipping reverse faulting, are labeled with an additional “*”.

Focal depth - General description of the depth of the earthquake beneath the earth's surface:

Shallow - focal depth less than 70 kilometers $(\mathrm{km})$.

Intermediate - focal depth between $70 \mathrm{~km}$ and $300 \mathrm{~km}$.

Deep - focal depth greater than $300 \mathrm{~km}$.

ComCat EventID -Identification number that directly links to the event specific page in ComCat, when used as "EVENTID" in the following address: http:/ earthquake.usgs.gov/earthquakes/eventpage/EVENTID. Italicized IDs correspond to events whose tectonic summaries were created as part of this report.]

\begin{tabular}{|c|c|c|c|c|c|c|c|c|}
\hline $\begin{array}{l}\text { Date/Time } \\
\text { (UTC) }\end{array}$ & Mw & Region & $\begin{array}{c}\text { Faulting } \\
\text { style }\end{array}$ & Latitude & Longitude & & $\begin{array}{c}\text { Focal depth } \\
(\mathbf{k m})\end{array}$ & $\begin{array}{l}\text { ComCat } \\
\text { EventID }\end{array}$ \\
\hline $4 / 12 / 1420: 14$ & 7.6 & Solomon Islands & Transform & -11.27 & 162.15 & 23 & Shallow & usc000phx5 \\
\hline $4 / 13 / 1412: 36$ & 7.4 & Solomon Islands & Reverse & -11.46 & 162.05 & 39 & Shallow & usc000piqj \\
\hline $4 / 18 / 1414: 27$ & 7.2 & Mexico & Reverse (thrust) & 17.40 & -100.97 & 24 & Shallow & usb000pq41 \\
\hline 4/19/14 13:28 & 7.5 & Papua New Guinea & Reverse (thrust) & -6.75 & 155.02 & 44 & Shallow & usb000pr89 \\
\hline $6 / 23 / 1420: 53$ & 7.9 & Alaska & Oblique Normal & 51.85 & 178.74 & 109 & Intermediate & usc000rki5 \\
\hline $11 / 1 / 1418: 57$ & 7.1 & Fiji & Reverse & -19.69 & -177.76 & 434 & Deep & usc000stdc \\
\hline $11 / 15 / 142: 31$ & 7.1 & Indonesia & Reverse & 1.89 & 126.52 & 45 & Shallow & usc $000 \operatorname{sxh} 8$ \\
\hline \multicolumn{9}{|c|}{ Year 2015} \\
\hline $2 / 13 / 1518: 59$ & 7.1 & N Mid-Atlantic Ridge & Transform & 52.65 & -31.90 & 17 & Shallow & usb000tp5q \\
\hline $2 / 27 / 1513: 45$ & 7.0 & Indonesia & Oblique strike-slip & -7.30 & 122.53 & 552 & Deep & usc000ttkd \\
\hline $5 / 7 / 157: 10$ & 7.1 & Papua New Guinea & Normal & -7.22 & 154.56 & 20 & Shallow & us20002das \\
\hline $5 / 12 / 157: 05$ & 7.3 & Nepal & Reverse (thrust) & 27.81 & 86.07 & 15 & Shallow & us20002ej1 \\
\hline $5 / 30 / 1511: 23$ & 7.8 & Japan & Oblique Normal & 27.84 & 140.49 & 664 & Deep & us20002ki3 \\
\hline $6 / 17 / 1512: 51$ & 7.0 & S Mid-Atlantic Ridge & Transform & -35.36 & -17.16 & 10 & Shallow & us20002qn7 \\
\hline $7 / 18 / 152: 27$ & 7.0 & Solomon Islands & Normal & -10.40 & 165.14 & 11 & Shallow & us20002yaw \\
\hline $7 / 27 / 1521: 41$ & 7.0 & Indonesia & Reverse & -2.63 & 138.53 & 48 & Shallow & us200030kn \\
\hline $9 / 16 / 1522: 54$ & 8.3 & Chile & Reverse (thrust) & -31.57 & -71.67 & 22 & Shallow & us $20003 \mathrm{k} 7 \mathrm{a}$ \\
\hline 9/16/15 23:18 & 7.0 & Chile & Reverse (thrust) & -31.56 & -71.43 & 28 & Shallow & us $20003 \mathrm{k} 7 \mathrm{w}$ \\
\hline 10/20/15 21:52 & 7.1 & Vanuatu & Oblique Reverse & -14.86 & 167.30 & 135 & Intermediate & us $10003 q 0 q$ \\
\hline 10/26/15 9:09 & 7.5 & Afghanistan & Reverse & 36.52 & 70.37 & 231 & Intermediate & us10003re5 \\
\hline $11 / 24 / 1522: 45$ & 7.6 & Peru-Brazil Border & Normal & -10.54 & -70.94 & 606 & Deep & us $100040 \mathrm{ww}$ \\
\hline
\end{tabular}




\section{Event-Specific Tectonic Summaries}

Tectonic summaries for each event listed in table 1 follow, grouped consecutively by year. The existence of an earthquake summary poster is also noted with the text "Electronic Poster Available," if such a poster was prepared for that earthquake. These posters contain similar information to the tectonic summary, but also contain maps that show the epicentral area, plate tectonic environment, earthquake history, and generalized seismic hazard of the region. Each poster is linked from the specific Web page for the earthquake, which can be found at http://earthquake.usgs.gov/earthquakes/eventpage/EVENTID, where "EVENTID" should be replaced by the ComCat EventID listed in table 1 and in the header for each summary.

\section{0: 15 Events}

01/08/2000 16:47:20 UTC

\section{$16.925^{\circ} \mathrm{S}, 174.248^{\circ} \mathrm{W}$}

\section{7.2 - Tonga}

\section{Depth 183.4 km}

The January 8, 2000, M 7.2 Tonga earthquake occurred as the result of oblique normal faulting at intermediate depth within the subducted Pacific plate, approximately $180 \mathrm{~km}$ beneath the Pacific Ocean north of Tonga. Focal mechanism solutions for the earthquake indicate that rupture occurred on either a near-vertical normal fault or on a very shallowly dipping oblique normal fault within the interior of the subducted Pacific slab. Slip on a fault of either orientation would accommodate the down-dip extension of the Pacific slab that is implied by the normal-component of the faulting solution. At the location of the earthquake, the Pacific plate moves westward with respect to the interior of the Australia plate at a velocity of about 82 millimeters per year (mm/yr).

The broad-scale tectonics of the January 8, 2000, M 7.2 earthquake region are dominated by the relative convergence of the Pacific and Australia plates. The Pacific plate subducts westward beneath the Australia plate at the Tonga Trench, about $250 \mathrm{~km}$ to the east of the January $8^{\text {th }}$ earthquake. The eastern edge of the Australia plate may itself be viewed as a collection of microplates whose relative motions help to accommodate the overall Pacific-Australia convergence and associated back-arc spreading.

Earthquakes like this event, with focal depths between 70 and $300 \mathrm{~km}$, are commonly termed "intermediate-depth" earthquakes. Intermediate-depth earthquakes represent deformation within subducted slabs rather than at the shallow plate interface between subducting and overriding tectonic plates. They typically cause less damage on the ground surface above their foci than is the case with similar-magnitude shallow-focus earthquakes, but large intermediate-depth earthquakes may be felt at great distance from their epicenters. "Deep-focus" earthquakes, those with focal depths greater than $300 \mathrm{~km}$, also occur in the subducted Pacific plate beneath the Lau Ridge and South Fiji Basin to the west. Earthquakes have been reliably located to depths of about $650 \mathrm{~km}$ in this region.

The Australia-Pacific plate boundary is one of the most active in the world. Earthquakes occur on the thrust fault boundary between the Australia and Pacific plates (at shallow depths, above about $50 \mathrm{~km}$ ), within the subducting Pacific plate (beneath depths of about $70 \mathrm{~km}$ ), and within and on the boundaries of the small microplates that together compose the eastern edge of the Australia plate. Nine other earthquakes above M 7 occurred within $400 \mathrm{~km}$ of the January $8^{\text {th }}$ event over the preceding 40 years. The largest was a M 7.8 event in December 1975, approximately $200 \mathrm{~km}$ to the northeast of the January $8^{\text {th }}$ event, and likely on the shallow plate boundary interface between the two plates. None are known to have caused fatalities, likely because of their remote location far from population centers that might be vulnerable to earthquake shaking.

\section{2/25/2000 01:43:58 UTC usp0009nxg \\ $19.528^{\circ} \mathrm{S}, 173.818^{\circ} \mathrm{E}$}

\section{7.1 - Vanuatu region \\ Depth 33.0 km}

The February 25, 2000, M 7.1 earthquake in the Vanuatu region occurred as the result of strike-slip faulting at shallow depths within the interior of the Pacific plate in the North Fiji Basin, several hundred kilometers north of the regional plate boundary between the Pacific and Australia plates (the New Hebrides Trench). Focal mechanism solutions for the earthquake indicate that rupture occurred on either a right-lateral, northwest-southeast-striking fault, or along a left-lateral, northeast-southwest-striking fault. At the location of the earthquake, the Australia plate moves to the east-northeast with respect to the Pacific plate at a velocity of about $80 \mathrm{~mm} / \mathrm{yr}$. The edges of the Pacific and Australia plates in the Vanuatu-Tonga-Kermadec region are often subdivided into a collection of microplates that together accommodate the relative motions between the broader Australia 
and Pacific plates. These include the New Hebrides and Conway Reef microplates in the region of the February $25^{\text {th }}$ earthquake, close to the Central Spreading Ridge (oriented north-south) separating these two tectonic blocks.

The North Fiji Basin region often experiences earthquake activity, with nine events of M 6.5 or greater (M 6.5+) within $400 \mathrm{~km}$ of the February $25^{\text {th }}$ earthquake over the preceding 40 years. These include a M 7.6 earthquake in March 1990 and a M 7.0 earthquake in July 1981, both to the south of the February $25^{\text {th }}$ earthquake and likely on or close to the Pacific-Australia plate boundary. Neither is known to have caused fatalities or damage.

\section{3/28/2000 11:00:22 UTC usp0009qb4 $22.338^{\circ} \mathrm{N}, 143.730^{\circ} \mathrm{E}$ \\ M 7.6 - Volcano Islands, Japan region \\ Depth 126.5 km}

The March 28, 2000, M 7.6 earthquake in the Volcano Islands, Japan region, occurred as the result of normal faulting at intermediate depth within the subducted Pacific plate, approximately $127 \mathrm{~km}$ beneath the Philippine Sea southeast of Japan. Focal mechanism solutions for the earthquake indicate that rupture occurred on either a near-vertical normal fault or on a very shallowly dipping oblique normal fault within the interior of the subducted Pacific slab. Of these two possible fault orientations, finite-fault modeling of globally recorded seismic data is more consistent with slip on the steep, southeast-striking fault. At the location of this earthquake, the Pacific plate moves westward with respect to the Philippine Sea plate at a velocity of about $31 \mathrm{~mm} / \mathrm{yr}$.

Earthquakes like this event, with focal depths between 70 and $300 \mathrm{~km}$, are commonly termed "intermediate-depth" earthquakes. Intermediate-depth earthquakes represent deformation within subducted slabs rather than at the shallow plate interface between subducting and overriding tectonic plates. They typically cause less damage on the ground surface above their foci than is the case with similar-magnitude shallow-focus earthquakes, but large intermediate-depth earthquakes may be felt at great distance from their epicenters. "Deep-focus" earthquakes, those with focal depths greater than $300 \mathrm{~km}$, also occur in the subducted Pacific plate beneath the Mariana Island Arc. Earthquakes have been reliably located to depths of about $630 \mathrm{~km}$ beneath the Mariana Island Arc.

Historically, this area has hosted several other large earthquakes. Within $400 \mathrm{~km}$ of the March $28^{\text {th }}$ event there have been seven earthquakes from M 6.5 to M 6.9 over the preceding 40 years. All of these earthquakes likely occurred either on or close to the Pacific-Philippine Sea plate subduction zone interface. None are known to have any associated fatalities or damage.

\section{4/23/2000 09:27:23 UTC usp0009rrc $28.307^{\circ} \mathrm{S}, 62.990^{\circ} \mathrm{W}$ \\ M 7.0 - Santiago Del Estero, Argentina Depth 608.5 km}

The April 23, 2000, M 7.0 earthquake near Santiago Del Estero, Argentina, occurred as the result of deep normal faulting within the subducted oceanic Nazca plate, more than $600 \mathrm{~km}$ beneath South America in northern Argentina. Focal mechanism solutions for the earthquake indicate that rupture occurred on either a near-vertical normal fault or on a very shallowly dipping oblique normal fault within the interior of the subducted Nazca slab. Slip on a fault of either orientation would accommodate the down-dip extension of the Nazca slab that is implied by the normal-component of the faulting solution. At the location of the earthquake, the Nazca plate moves eastward with respect to the South America plate, subducting at the Peru-Chile Trench west of the April $23^{\text {rd }}$ earthquake at a velocity of about $71 \mathrm{~mm} / \mathrm{yr}$.

Earthquakes that have focal depths greater than $300 \mathrm{~km}$ are commonly termed "deep-focus" earthquakes. Deep-focus earthquakes cause less damage on the ground surface above their foci than similar-magnitude shallow-focus earthquakes, but large deep-focus earthquakes may be felt at great distance from their epicenters. The largest recorded deep-focus earthquake prior to this April 2000 earthquake was a M 8.2 event that occurred at a depth of $630 \mathrm{~km}$ within the subducted Nazca plate beneath South America near the northern Bolivian border in 1994. A larger event has since occurred-namely the M 8.3 earthquake that occurred at a depth of $600 \mathrm{~km}$ within the subducted Pacific plate beneath the Sea of Okhotsk offshore of northeastern Russia in 2013. The M 8.3 Sea of Okhotsk earthquake was felt all over Asia, as far away as Moscow, and across the Pacific Ocean along the western seaboard of the United States (though at distant locations, individuals reporting having felt the event were likely very favorably situated for the perception of small ground motions). The M 8.2 Bolivian deep-focus earthquake in 1994 had similarly been reported by individuals in North America at great distance from the epicenter.

Over the past century, 66 earthquakes with M 7 or larger have occurred at depths greater than $300 \mathrm{~km}$ globally; 3 of these were located in the same region as the April 23, 2000, event. The largest nearby event at these depths was a M 7.3 earthquake in June 1991, a widely felt event less than $150 \mathrm{~km}$ to the northwest and $50 \mathrm{~km}$ shallower than the April $23^{\text {rd }}$ event, with no reported casualties. 
05/04/2000 04:21:16 UTC

\section{usp0009sbh}

\section{$1.105^{\circ} \mathrm{S}, 123.573^{\circ} \mathrm{E}$}

\section{7.6 - Sulawesi, Indonesia \\ Depth 26.0 km}

The May 4, 2000, M 7.6 earthquake near Sulawesi, Indonesia, occurred as a result of strike-slip faulting at shallow depths within the interior of the Molucca Sea microplate, part of the broader Sunda tectonic plate. Focal mechanism solutions for the earthquake indicate that rupture occurred on either a left-lateral northwest-southeast-striking fault, or along a right-lateral northeast-southwest-striking fault. Of these two possible fault orientations, finite-fault modeling of globally recorded seismic data is more consistent with slip on the southwest-striking (right-lateral) fault. Eastern Indonesia is characterized by complex tectonics in which motions of numerous small microplates are accommodating large-scale convergence among the Australia, Sunda, Pacific, and Philippine Sea plates. At the location of the May $4^{\text {th }}$ earthquake, the Sunda plate moves south with respect to Molucca Sea plate at a velocity of about $30 \mathrm{~mm} / \mathrm{yr}$.

While commonly plotted as points on maps, earthquakes of this size are more appropriately described as slip over a larger fault area. Strike-slip events of the size of the May 4, 2000, earthquake are typically about 140x20 km (length x width); modeling of this earthquake implies dimensions of about 100x20 km, predominantly up-dip and northeast of the hypocenter.

Shallow earthquakes of this size can often have a deadly impact on nearby communities. Historically, this region has hosted several large earthquakes, with eight events of M 7.0+ within $400 \mathrm{~km}$ of the May $4^{\text {th }}$ earthquake over the preceding 40 years. Several of these larger events caused extensive building damage, injuries, and fatalities.

\section{5/12/2000 18:43:18 UTC usp0009suu}

\section{$23.548^{\circ} \mathrm{S}, 66.452^{\circ} \mathrm{W}$}

\section{7.2 - Jujuy, Argentina Depth 225.0 km}

The May 12, 2000, M 7.2 earthquake near Jujuy, Argentina occurred as the result of normal faulting at intermediate depth within the subducted Nazca plate, approximately $225 \mathrm{~km}$ beneath South America in northern Argentina. Focal mechanism solutions for the earthquake indicate that rupture occurred on either a near-vertical normal fault or on a very shallowly dipping oblique normal fault within the interior of the subducted Nazca slab. Slip on a fault of either orientation would accommodate the down-dip extension of the Nazca slab that is implied by the normal-component of the faulting solution. At the location of the earthquake, the Nazca plate moves eastward with respect to the South America plate, subducting at the Peru-Chile Trench west of the May $12^{\text {th }}$ earthquake at a velocity of about $71 \mathrm{~mm} / \mathrm{yr}$.

Earthquakes like this event, with focal depths between 70 and $300 \mathrm{~km}$, are commonly termed "intermediate-depth" earthquakes. Intermediate-depth earthquakes represent deformation within subducted slabs rather than at the shallow plate interface between subducting and overriding tectonic plates. They typically cause less damage on the ground surface above their foci than is the case with similar-magnitude shallow-focus earthquakes, but large intermediate-depth earthquakes may be felt at great distance from their epicenters. "Deep-focus" earthquakes, those with focal depths greater than $300 \mathrm{~km}$, also occur in the subducted Nazca plate beneath central Argentina, such as the M 7.0 earthquake that occurred to the southeast of the May $12^{\text {th }}$ event earlier this year at a depth of more than $600 \mathrm{~km}$. Earthquakes have been reliably located to depths greater than $600 \mathrm{~km}$ in this region. Over the preceding 13 years there have been three other M 6.5 or larger earthquakes within $200 \mathrm{~km}$ of the May $12^{\text {th }}$ event, all with depths close to $200 \mathrm{~km}$.

\section{6/04/2000 16:28:26 UTC usp0009txv}

\section{$4.721^{\circ} \mathrm{S}, 102.087^{\circ} \mathrm{E}$}

\section{7.9 - Southern Sumatra, Indonesia \\ Depth 33.0 km}

The June 4, 2000, M 7.9 earthquake off southern Sumatra, one of the many islands in the large Indonesian Island Arc system, occurred as the result of complex, shallow, oblique-reverse faulting near the subduction zone plate boundary between the Australia and Sunda plates. Focal mechanism solutions for the earthquake indicate that rupture occurred on either a steeply dipping, south-southeast-striking reverse fault, or on a moderately dipping, east-striking reverse fault. Both nodal planes are oriented obliquely to the direction of subduction along this arc. Of these two possible fault orientations, finite-fault modeling of globally recorded seismic data is more consistent with slip on the southeast-striking fault. The location, depth, and focal mechanism solutions of the earthquake suggest this is likely an intraslab event, associated with the local subduction zone, but occurring 
within the downgoing slab rather than on the overlying plate boundary interface. At the location of the earthquake, the Australia plate moves northward beneath the Sunda plate at a velocity of about $60 \mathrm{~mm} / \mathrm{yr}$. The Australia plate is seismically active to a depth of about $650 \mathrm{~km}$ beneath Sumatra and Java.

While commonly plotted as points on maps, earthquakes of this size are more appropriately described as slip over a larger fault area. Reverse-faulting events of the size of the June 4, 2000, earthquake are typically about $145 \times 40 \mathrm{~km}$ (length $\mathrm{x}$ width); modeling of this earthquake implies similar dimensions, predominantly surrounding the hypocenter and to the northeast.

\section{6/18/2000 14:44:13 UTC usp0009ut0}

\section{$13.802^{\circ} \mathrm{S}, 97.453^{\circ} \mathrm{E}$}

\section{7.9 - South Indian Ocean}

\section{Depth 10.0 km}

The June 18, 2000, M 7.9 earthquake in the South Indian Ocean occurred as a result of shallow strike-slip faulting within the oceanic crust of the Australia plate, several hundred kilometers southwest of the Sunda-Java Trench and the Australia-Sunda plate boundary. Focal mechanism solutions for the earthquake indicate that rupture occurred on either a left-lateral nearly northsouth-striking fault or a right-lateral nearly east-west-striking fault. Of these two possible fault orientations, finite-fault modeling of globally recorded seismic data is more consistent with slip on the north-south-striking (left-lateral) fault. At the location of the earthquake, the Australia plate is moving to the northeast relative to the Sunda plate at a velocity of approximately $60 \mathrm{~mm} / \mathrm{yr}$.

While commonly plotted as points on maps, earthquakes of this size are more appropriately described as slip over a larger fault area. Strike-slip events of the size of the June 18, 2000, earthquake are typically about 210x25 km (length x width); modeling of this earthquake implies dimensions of about 190x10 km, predominantly up-dip of and bilateral from the hypocenter.

Other than the M 5.4 aftershock that was triggered by this earthquake, about 20 minutes after the initial event, only one other earthquake has occurred within $400 \mathrm{~km}$ of the June $18^{\text {th }}$ event greater than M 5 over the preceding 40 years—a M 5.4 earthquake in September 1989. The remote location of all of these earthquakes makes them minimally disruptive.

\section{8/06/2000 07:27:12 UTC Usp0009xzy}

$28.856^{\circ} \mathrm{N}, 139.556^{\circ} \mathrm{E}$

\section{7.4 - Bonin Islands, Japan region Depth 394.8 km}

The August 6, 2000, M 7.4 earthquake in the Bonin Islands, Japan region occurred as the result of deep normal faulting within the subducted Pacific plate, approximately $390 \mathrm{~km}$ beneath the Philippine Sea south of Japan. Focal mechanism solutions for the earthquake indicate that rupture occurred on either a steeply dipping normal fault or on a shallowly dipping oblique normal fault within the interior of the subducted Pacific slab. Slip on a fault of either orientation would accommodate the down-dip extension of the Pacific slab that is implied by the normal-component of the faulting solution. At the location of the earthquake, the Pacific plate moves westward with respect to the Philippine Sea plate at a velocity of about $40 \mathrm{~mm} / \mathrm{yr}$ and subducts at the Izu Trench, about $300 \mathrm{~km}$ to the east of the August $6^{\text {th }}$ earthquake. The subducted Pacific plate is seismically active to a depth of about $560 \mathrm{~km}$.

Earthquakes that have focal depths greater than $300 \mathrm{~km}$ such as this are commonly termed "deep-focus" earthquakes. Deepfocus earthquakes cause less damage on the ground surface above their foci than similar-magnitude shallow-focus earthquakes, but large deep-focus earthquakes may be felt at great distance from their epicenters. The largest recorded deep-focus earthquake prior to this August 2000 earthquake was a M 8.2 event that occurred at a depth of $630 \mathrm{~km}$ within the subducted Nazca plate beneath South America near the northern Bolivian border in 1994. A larger event has since occurred-namely the M 8.3 earthquake that occurred at a depth of $600 \mathrm{~km}$ within the subducted Pacific plate beneath the Sea of Okhotsk offshore of northeastern Russia in 2013. The M 8.3 Sea of Okhotsk earthquake was felt all over Asia, as far away as Moscow, and across the Pacific Ocean along the western seaboard of the United States (though at distant locations, individuals reporting having felt the event were likely very favorably situated for the perception of small ground motions). The M 8.2 Bolivian deep-focus earthquake in 1994 had similarly been reported by individuals in North America at great distance from the epicenter.

Over the preceding century, 67 earthquakes with a magnitude of M 7+ have occurred at depths greater than $300 \mathrm{~km}$ globally; 12 of these were located in the same region as the August 6,2000, event. The largest nearby event at these depths was a M 7.3 earthquake in October 1968, approximately $200 \mathrm{~km}$ to the south and $110 \mathrm{~km}$ deeper than the August $6^{\text {th }}$ event, with no recorded damage or casualties. 


\section{0/14/2000 16:58:44 UTC usp000a18v \\ $15.421^{\circ} \mathrm{S}, 166.910^{\circ} \mathrm{E}$}

M 7.0 - Vanuatu

\section{Depth 23.0 km}

The October 14, 2000, M 7.0 Vanuatu earthquake occurred as the result of shallow reverse faulting on or near the convergent boundary between the Australia and Pacific plates. Focal mechanism solutions for the earthquake indicate that rupture occurred on a moderately dipping reverse fault striking to the northwest or to the southeast. The October $14^{\text {th }}$ earthquake's location, depth, and focal mechanism solutions are consistent with the earthquake resulting from reverse faulting associated with northeastward-directed subduction along this plate boundary. At the location of the earthquake, the Australia plate moves to the east-northeast with respect to the Pacific plate at a velocity of about $84 \mathrm{~mm} / \mathrm{yr}$.

The Vanuatu region experiences a high level of earthquake activity at depths up to $350 \mathrm{~km}$ and has hosted 15 events of M 7 or larger within $200 \mathrm{~km}$ of the October $14^{\text {th }}$ earthquake over the preceding 40 years. Recent large earthquakes nearby include a M 7.5 earthquake in November 1999 and a M 7.2 earthquake in July 1994.

10/29/2000 08:37:08 UTC

usp000a2mw

\section{$4.766^{\circ} \mathrm{S}, 153.945^{\circ} \mathrm{E}$}

\section{7.0 - New Ireland region, Papua New Guinea \\ Depth $\mathbf{5 0 . 0}$ km}

The October 29, 2000, M 7.0 earthquake in the New Ireland region of Papua New Guinea occurred as the result of shallow reverse faulting within the subducted lithosphere of the Australia plate. Focal mechanism solutions for the earthquake indicate that rupture occurred on either a steeply dipping northwest-striking reverse fault or a shallow southeast-striking fault. Slip on a fault of either orientation is consistent with the intraplate compressional tectonics implied by the faulting mechanism and earthquake depth. In this region, the Australia plate moves to the east-northeast with respect to the Pacific plate at a velocity of about $105 \mathrm{~mm} / \mathrm{yr}$. At the location of the earthquake, some researchers consider the edges of the Australia and Pacific plates to be divided into several microplates that together take up the overall convergence between Australia and the Pacific, including the Solomon Sea and South Bismark microplates local to this event. In this context, the Solomon Sea microplate moves slightly faster and more northeasterly with respect to the Pacific plate than does the Australia plate due to sea-floor spreading in the Woodlark Basin several hundred kilometers to the southeast of the October $29^{\text {th }}$ earthquake, facilitating the classic subduction evident beneath New Britain and New Ireland.

The New Ireland region of Papua New Guinea commonly hosts shallow events associated with plate boundary deformation and intermediate-depth events related to internal deformation of subducted slabs. Though shallower than typical intermediatedepth events ( $55 \mathrm{~km}$ versus $70-300 \mathrm{~km}$, respectively), this event likely represents intraplate faulting within the subducted Australia plate, which is seismically active to depths of more than $500 \mathrm{~km}$. Within $400 \mathrm{~km}$ of the October $29^{\text {th }} \mathrm{M} 7.0$ event, 26 other events of at least M 7 have occurred over the preceding 40 years. The focal depths of these events range from $16 \mathrm{~km}$ to nearly $410 \mathrm{~km}$. The largest event in the region was a M 7.9 earthquake in August 1975, approximately $200 \mathrm{~km}$ southeast of the October $29^{\text {th }}$ event, with a comparable focal depth.

11/16/2000 04:54:56 UTC

\section{usp000a3qq}

\section{$3.980^{\circ} \mathrm{S}, 152.169^{\circ} \mathrm{E}$}

\section{8.0 - New Ireland region, Papua New Guinea \\ Depth 33.0 km}

The November 16, 2000, M 8.0 earthquake in the New Ireland region of Papua New Guinea occurred as the result of shallow strike-slip faulting within the interior of the Pacific plate. Focal mechanism solutions for the earthquake indicate that rupture occurred on either a right-lateral northeast-southwest or a left-lateral southeast-northwest-striking fault. Of these two possible fault orientations, finite-fault modeling of globally recorded seismic data is more consistent with slip on the southeast-striking (left-lateral) fault. In this region, the Australia plate moves to the east-northeast with respect to the Pacific plate at a velocity of about $105 \mathrm{~mm} / \mathrm{yr}$. At the location of the earthquake, some researchers consider the edges of the Australia and Pacific plates to be divided into several microplates that take up the overall convergence between Australia and the Pacific, including the Solomon Sea, South Bismark, and Manus microplates local to this event. In this context, the November $16^{\text {th }}$ event occurred along the boundary between the South Bismark and Manus microplates. 
While commonly plotted as points on maps, earthquakes of this size are more appropriately described as slip over a larger fault area. Strike-slip events of the size of the November 16, 2000, M 8.0 earthquake are typically about $245 \times 25 \mathrm{~km}$ (length $\mathrm{x}$ width); modeling of this earthquake implies dimensions of about $150 \times 30 \mathrm{~km}$, predominantly down-dip of the hypocenter.

Shallow earthquakes predominantly represent deformation along plate boundaries and associated structures, rather than within subducted slabs where intermediate-depth and deep earthquakes (70-300 and 300+ km, respectively) occur. This region hosts shallow and intermediate-depth events, and the Australia plate in this region is known to be seismically active to depths of more than $500 \mathrm{~km}$. Within $400 \mathrm{~km}$ of the November $16^{\text {th }}$ M 8.0 earthquake, there have been 21 other events of at least M 7 over the preceding 40 years. Two of these events were M 8 or larger. Large-magnitude aftershocks, including the M 7.8 earthquake that occurred only 3 hours later and approximately $100 \mathrm{~km}$ to the southeast of the November $16^{\text {th }}$ event, were also associated with this earthquake.

\section{1/16/2000 07:42:16 UTC usp000a3sp $5.233^{\circ} \mathrm{S}, 153.102^{\circ} \mathrm{E}$ \\ M 7.8 - New Ireland region, Papua New Guinea Depth $30.0 \mathrm{~km}$}

The November 16, 2000, M 7.8 earthquake in the New Ireland region of Papua New Guinea occurred as the result of shallow thrust faulting on or near the plate boundary interface between the subducting Australia and overriding Pacific plates and can also be considered an aftershock of the M 8.0 earthquake that occurred only 3 hours previously and about $100 \mathrm{~km}$ to the northwest. In this region, the Australia plate moves to the east-northeast with respect to the Pacific plate at a velocity of about $105 \mathrm{~mm} / \mathrm{yr}$. At the location of the earthquake, some researchers consider the edges of the Australia and Pacific plates to be divided into several microplates that take up the overall convergence between Australia and the Pacific, including the Solomon Sea and South Bismark microplates local to this event. In this context, the November $16^{\text {th }}$ event occurred along the boundary between the Solomon Sea and South Bismark microplates. The Solomon Sea microplate moves slightly faster and more northeasterly with respect to the Pacific plate (and South Bismark microplate) than does the Australia plate due to sea-floor spreading in the Woodlark Basin several hundred kilometers to the southeast of the November $16^{\text {th }}$ earthquake, facilitating the classic subduction evident beneath New Britain and New Ireland. Focal mechanism solutions and finite-fault modeling of globally recorded seismic data for the November $16^{\text {th }} \mathrm{M} 7.8$ event are consistent with its occurrence on the shallow subduction interface in this region.

While commonly plotted as points on maps, earthquakes of this size are more appropriately described as slip over a larger fault area. Thrust-faulting events of the size of the November 16, 2000, M 7.8 earthquake are typically about 120x50 km (length $\mathrm{x}$ width); modeling of this earthquake implies dimensions of about $80 \times 60 \mathrm{~km}$, predominantly surrounding the hypocenter.

Shallow earthquakes represent deformation along plate boundaries and associated structures, rather than within subducted slabs where intermediate-depth earthquakes (70-300 km) nucleate. However, this area of Papua New Guinea commonly experienes both shallow and intermediate-depth events, and the Australia plate in this region is known to be seismically active to depths of more than $500 \mathrm{~km}$. Within $400 \mathrm{~km}$ of the November $16^{\text {th }} \mathrm{M} 7.8$ earthquake, 30 other events of at least M 7 have occurred over the preceding 40 years. Three of these events were M 8 or larger, with one being the damaging M 8.0 earthquake that occurred only 3 hours prior to this 07:42 UTC event.

\section{1/17/2000 21:01:56 UTC usp000a45f $5.496^{\circ} \mathrm{S}, 151.781^{\circ} \mathrm{E}$ \\ M 7.8 - New Britain region, Papua New Guinea Depth 33.0 km}

The November 17, 2000, M 7.8 earthquake in the New Ireland region of Papua New Guinea occurred as the result of shallow thrust faulting on or near the plate boundary interface between the subducting Australia and overriding Pacific plates and can also be considered an aftershock of the M 8.0 earthquake that occurred about 30 hours previously and $170 \mathrm{~km}$ to the northeast. In this region, the Australia plate moves to the east-northeast with respect to the Pacific plate at a velocity of about $105 \mathrm{~mm} / \mathrm{yr}$. At the location of the earthquake, some researchers consider the edges of the Australia and Pacific plates to be divided into several microplates that take up the overall convergence between Australia and the Pacific, including the Solomon Sea and South Bismark microplates local to this event. In this context, the November $17^{\text {th }}$ event occurred along the boundary between the Solomon Sea and South Bismark microplates. The Solomon Sea microplate moves slightly faster and more northeasterly with respect to the Pacific plate (and South Bismark microplate) than does the Australia plate due to sea-floor spreading in the Woodlark Basin several hundred kilometers to the southeast of the November $17^{\text {th }}$ earthquake, facilitating the classic subduction evident beneath New Britain and New Ireland. Focal mechanism solutions and finite-fault modeling of globally 
recorded seismic data for the November $17^{\text {th }} \mathrm{M} 7.8$ event are consistent with its occurrence on the shallow subduction interface in this region.

While commonly plotted as points on maps, earthquakes of this size are more appropriately described as slip over a larger fault area. Thrust-faulting events of the size of the November 17, 2000, earthquake are typically about 120x50 km (length $\mathrm{x}$ width); modeling of this earthquake implies dimensions of about $100 \times 80 \mathrm{~km}$, predominantly up-dip of the hypocenter.

Shallow earthquakes represent deformation along plate boundaries and associated structures rather than within the subducted slabs where intermediate-depth earthquakes $(70-300 \mathrm{~km})$ nucleate. However, this area of Papua New Guinea commonly sees both types of events, and the Australia plate in this region is known to be seismically active to depths of more than $500 \mathrm{~km}$. Within $400 \mathrm{~km}$ of the November $17^{\text {th }}$ M 7.8 earthquake, there have been 28 other events of at least $\mathrm{M} 7$ over the preceding 40 years. Three of these events were M 8 or larger, one being the damaging M 8.0 earthquake that occurred the previous day roughly $170 \mathrm{~km}$ to the northeast.

\section{2/06/2000 17:11:06 UTC}

$39.566^{\circ} \mathrm{N}, 54.799^{\circ} \mathrm{E}$

\section{7.0 - Turkmenistan \\ Depth 30.0 km}

The December 6, 2000, M 7.0 earthquake in Turkmenistan occurred as the result of shallow, oblique reverse faulting within the Eurasia plate, almost 1,000 km northeast of the regional plate boundary between the Arabia and Eurasia plates that is responsible for the faulting and uplift of the local mountain ranges, such as the Zagros and Caucasus Mountains. The focal mechanism solutions for the earthquake indicate that rupture occurred on a moderately dipping reverse fault oriented northwest-southeast or east-west. Slip on a fault of either orientation would accommodate the broad regional compression between Arabia and Eurasia. At the location of the earthquake, the Arabia plate moves northward relative to the Eurasia plate at a velocity of about $31 \mathrm{~mm} / \mathrm{yr}$.

Large earthquakes in Turkmenistan are infrequent, but can be devastating. Within $400 \mathrm{~km}$ of the December $6^{\text {th }}$ event, six other M 6+ events occurred over the preceding 40 years. The style of faulting for these events strongly differs, but all were shallow in depth. The most recent event was a M 6.5 earthquake in February 1997 near the Turkmenistan-Iran border, more than $200 \mathrm{~km}$ southeast of the December $6^{\text {th }}$ event. Despite being a smaller magnitude event than the December $6^{\text {th }}$ earthquake, this strike-slip event was very shallow, produced more intense shaking, and occurred in a more densely populated region, resulting in more than 100 fatalities and $\$ 30$ million in damage. In 1948, a M 7.3 earthquake $350 \mathrm{~km}$ to the southeast of the December 2000 event caused significant destruction in the capital city of Ashgabat and resulted in between 10,000 and 110,000 casualties. (Soviet-regime media did not report on the extent of damage and casualties resulting from natural disasters.)

\section{1: 16 Events}

\section{1/01/2001 06:57:04 UTC usp000a70h $6.898^{\circ} \mathrm{N}, 126.579^{\circ} \mathrm{E}$ \\ M 7.5 - Mindanao, Philippines \\ Depth 33.0 km}

The January 1, 2001, M 7.5 earthquake off the southeastern coast of Mindanao, Philippines, occurred as the result of shallow oblique reverse faulting approximately $60 \mathrm{~km}$ to the west of the Philippine Trench. Focal mechanism solutions for the earthquake indicate that rupture occurred on a moderately dipping reverse fault striking either to the south-southeast or to the northeast. At the location of the earthquake, the Philippine Sea plate subducts west-northwest with respect to the Sunda plate at a velocity of approximately $105 \mathrm{~mm} / \mathrm{yr}$. Northeastern Indonesia and southern Philippines are characterized by complex tectonics in which motions of numerous small microplates accommodate the large-scale convergence among the Australia, Sunda, Pacific, and Philippine Sea plates. The location, depth, and focal mechanism solutions for this event are consistent with the local Phillipine Sea:Sunda subduction zone complex, indicating slip either on the plate interface itself (the southeast-striking focal plane), or more likely within the subducting Philippine Sea plate (consistent with either fault plane of the focal mechanism solution).

Historically, this is an area of frequent earthquakes. Five earthquakes of at least M 7 have occurred within $100 \mathrm{~km}$ of the January $1^{\text {st }}$ event over the preceding 40 years. The largest of these events was a M 8.0 earthquake in December 1972, roughly $90 \mathrm{~km}$ to the south of the January $1^{\text {st }}$ earthquake. A M 5.7 earthquake in June 1990, roughly $80 \mathrm{~km}$ to the southwest of the January $1^{\text {st }}$ earthquake, resulted in 4 fatalities and 15 injuries, indicating the region is vulnerable to shaking from even moderatesized earthquakes. 
01/09/2001 16:49:28 UTC

\section{$14.928^{\circ} \mathrm{S}, 167.170^{\circ} \mathrm{E}$}

\section{7.1 - Vanuatu}

\section{Depth 103.0 km}

The January 9, 2001, M 7.1 Vanuatu earthquake occurred as the result of oblique reverse faulting at intermediate depth within the subducting Australia plate, approximately $100 \mathrm{~km}$ beneath the island of Vanuatu in the Pacific Ocean. The focal mechanism solutions for the earthquake indicate that oblique rupture occurred on either a steep north-south reverse fault or a near-vertical east-west reverse fault. Slip on a fault of either orientation is consistent with the intraplate compressional tectonics implied by the faulting mechanism and earthquake depth. At the location of the earthquake, the Australia plate moves to the east-northeast with respect to the Pacific plate at a velocity of about $117 \mathrm{~mm} / \mathrm{yr}$, subducting at the New Hebrides Trench west of the January $9^{\text {th }}$ earthquake. The western edge of the Pacific plate can be subdivided into smaller microplates, such as the New Hebrides microplate in the region of this event.

Earthquakes with focal depths between 70 and $300 \mathrm{~km}$ are commonly termed "intermediate-depth" events. Intermediatedepth earthquakes represent deformation within subducted slabs rather than at the shallow plate interface between subducting and overriding tectonic plates. They typically cause less damage on the ground surface above their foci than is the case with similarmagnitude shallow-focus earthquakes, but large intermediate-depth earthquakes may be felt at great distance from their epicenters. "Deep-focus" earthquakes, those with focal depths greater than $300 \mathrm{~km}$, also occur beneath the North Fiji Basin, but are thought to be associated with a detached fragment of subducted Australia plate, rather than with active subduction from the New Hebrides Trench, which reaches depths of close to $300 \mathrm{~km}$. Earthquakes have been reliably located to depths of about $650 \mathrm{~km}$ in this region. The Vanuatu region experiences a very high level of earthquake activity, with more than a dozen events of M 7 or larger recorded since the early decades of the $20^{\text {th }}$ century within $400 \mathrm{~km}$ of the January $9^{\text {th }}$ event. Recent large earthquakes include a M 7.5 earthquake in November 1999 that occurred approximately $200 \mathrm{~km}$ to the southeast of the January $9^{\text {th }}$ event.

01/10/2001 16:02:44 UTC

usp000a7f2

\section{$57.078^{\circ} \mathrm{N}, 153.211^{\circ} \mathrm{W}$}

\section{7.0 - Kodiak Island region, Alaska Depth 33.0 km}

The January 10, 2001, M 7.0 earthquake in the Kodiak Island region of Alaska occurred as the result of thrust faulting on or near the subduction zone interface between the Pacific and North America plates. At the location of the earthquake, the Pacific plate moves to the northwest with respect to the North America plate at a velocity of about $60 \mathrm{~mm} / \mathrm{yr}$. The depth and mechanism of this earthquake are consistent with it occurring along the megathrust interface between these two plates.

Two other M 7.0 earthquakes have occurred around the coast of Kodiak Island over the preceding 40 years, in December 1999 and September 1965, demonstrating the ongoing seismic activity of the Aleutians. Neither event is known to have any associated fatalities or damage.

\section{1/13/2001 17:33:32 UTC usp000a7m5 $13.049^{\circ} \mathrm{N}, 88.660^{\circ} \mathrm{W}$ \\ M 7.7 - offshore El Salvador \\ Depth 60.0 km}

The January 13, 2001, M 7.7 earthquake offshore of El Salvador occurred as the result of shallow normal faulting within the Caribbean plate. Focal mechanism solutions for the earthquake indicate that rupture occurred on either a moderately dipping northwest-striking normal fault or a shallower southeast-striking normal fault. Of these two possible fault orientations, finitefault modeling of globally recorded seismic data is more consistent with slip on the northwest-striking fault. At the location of the earthquake, the Cocos plate moves north-northeast with respect to the Caribbean plate at a velocity of approximately $72 \mathrm{~mm} / \mathrm{yr}$, subducting beneath Central America at the Middle America Trench southwest of the January $13^{\text {th }}$ earthquake.

While commonly plotted as points on maps, earthquakes of this size are more appropriately described as slip over a larger fault area. Normal-faulting events of the size of the January 13, 2001, earthquake are typically about 95x35 km (length $\mathrm{x}$ width); modeling of this earthquake implies dimensions of about $50 \times 50 \mathrm{~km}$, predominantly up-dip of the hypocenter.

The plate boundary region in Central America within $250 \mathrm{~km}$ of the January $13^{\text {th }}$ event has experienced more than 26 earthquakes of M 6+ over the preceding 40 years, and of those 9 had magnitudes of M 6.5+. The largest of these was a M 7.7 earthquake in September 1992, approximately $190 \mathrm{~km}$ to the southeast of the January $13^{\text {th }}$ earthquake. The 1992 earthquake has been 
labeled a tsunami earthquake, characterized by the unusually large tsunami it caused in relation to the size of the earthquake. The large, damaging tsunami struck the coastline of Central America, particularly in Nicaragua and Costa Rica, and resulted in more than 100 fatalities. The January 13, 2001, earthquake offshore of El Salvador resulted in more than eight times as many fatalities, many of which were caused by large landslides in multiple El Salvador cities.

\section{1/26/2001 03:16:40 UTC Usp000a8ds \\ $23.419^{\circ} \mathrm{N}, 70.232^{\circ} \mathrm{E}$}

\section{7.7 - Gujarat, India \\ Depth 16.0 km}

The January 26, 2001, M 7.7 earthquake near Gujarat, India, occurred as the result of shallow oblique reverse faulting within the continental crust of the India plate, near the India-Eurasia plate boundary where there is both transform and convergent motion. Focal mechanism solutions for the earthquake indicate that oblique rupture occurred on either an east-northeast-, or a west-northwest-striking, moderately dipping reverse fault. Of these two possible fault orientations, finite-fault modeling of globally recorded seismic data is more consistent with slip on the east-northeast-striking fault. At the location of this earthquake, the India plate moves northward with respect to the Eurasia plate at a velocity of about $39 \mathrm{~mm} / \mathrm{yr}$.

While commonly plotted as points on maps, earthquakes of this size are more appropriately described as slip over a larger fault area. Reverse-faulting events of the size of the January 26, 2001, earthquake are typically about 110x35 km (length $\mathrm{x}$ width); modeling of this earthquake implies dimensions of about $90 \times 30 \mathrm{~km}$, predominantly up-dip of and bilaterally from the hypocenter.

Many M 5 aftershocks followed this large earthquake, with four occurring within 4 hours of the mainshock. In the 40 years preceding the January $26^{\text {th }}$ event, there had been no earthquakes larger than M 5.5 in the area. The January $26^{\text {th }}$ earthquake is the most damaging event in the region to date, with at least 20,000 fatalities, 166,836 injuries, and nearly a million buildings destroyed or damaged.

\section{2/13/2001 19:28:30 UTC usp000a9kc}

\section{$4.680^{\circ} \mathrm{S}, 102.562^{\circ} \mathrm{E}$}

\section{7.4 - southern Sumatra, Indonesia \\ Depth 36.0 km}

The February 13, 2001, M 7.4 earthquake just off the southwest coast of the island of Sumatra, one of many islands in the large Indonesian Island Arc system, occurred as the result of shallow reverse faulting. The focal mechanism solutions indicate that rupture occurred on either a steeply dipping reverse fault, or a shallowly dipping thrust fault. At the location of the earthquake, the Australia plate subducts northward beneath the Sunda plate at a velocity of about $62 \mathrm{~mm} / \mathrm{yr}$. The boundary is marked by the 3,400-km-long Sunda-Java Trench, about $200 \mathrm{~km}$ southeast of the February $13^{\text {th }}$ earthquake. While the focal mechanism solution of this earthquake is consistent with Australia:Sunda subduction, its location and depth indicate that it occurred 15-30 km above the subduction zone interface, in the overriding Sunda plate, perhaps in association with some of the steep accretionary structures mapped in the region. The Australia plate is seismically active to a depth of about $650 \mathrm{~km}$ beneath Sumatra and Java.

Because of the earthquake's depth and proximity to shore it was felt along the coast, but caused little damage. This was not the case for the M 7.9 earthquake in June 2000 that happened less than $60 \mathrm{~km}$ west of the February $13^{\text {th }}$ event with similar depth and reverse faulting orientation, which resulted in at least 103 fatalities in the coastal town area of Bengkulu.

\section{2/24/2001 07:23:48 UTC usp000aa8b \\ $1.271^{\circ} \mathrm{N}, 126.249^{\circ} \mathrm{E}$}

\section{7.1 - Molucca Sea}

\section{Depth 35.0 km}

The February 24, 2001, M 7.1 Molucca Sea earthquake occurred as the result of shallow oblique reverse faulting within the complex active tectonic zone of eastern Indonesia. The focal mechanism solutions indicate that rupture occurred on either a northeast- or southwest-striking, moderately dipping reverse fault. Slip on a fault of either orientation is consistent with the compressional tectonics implied by the faulting mechanism and earthquake depth. At this location, the Sunda and Philippine Sea plates are converging in an east-west direction at a rate of approximately $109 \mathrm{~mm} / \mathrm{yr}$. In the broader region surrounding this event, the north-south convergence between the Australia and Sunda plates, and the east-west convergence between Sunda and the Pacific and Philippine Sea plates, together drive the motion of small microplates that are situated among them. Of these local 
microplates, the Febrary $24^{\text {th }}$ earthquake occurred near the boundary between the northern edge of the Birds Head microplate and the larger Sunda plate, just east of the Molucca Sea microplate.

Frequent volcanic eruptions and earthquakes testify to the active and complex tectonic processes in this region. The distribution of small ocean basins, continental fragments, remnants of ancient magmatic arcs and numerous subduction complexes that make up the Indonesian region point to an equally active and complex tectonic history. There have been five other M 7+ earthquakes within $200 \mathrm{~km}$ of the February $24^{\text {th }}$ event over the preceding 40 years. The largest was a M 7.6 earthquake in August 1986, approximately $30 \mathrm{~km}$ to the north. The most damaging event within the vicinity was a M 6.9 earthquake in January 1994, roughly $175 \mathrm{~km}$ to the east, which resulted in at least 7 fatalities and 40 injuries.

06/03/2001 02:41:57 UTC $29.666^{\circ} \mathrm{S}, 178.633^{\circ} \mathrm{W}$

\section{7.2 - Kermadec Islands, New Zealand Depth 178.1 km}

The June 3, 2001, M 7.2 Kermadec Islands earthquake occurred in the Tonga-Kermadec subduction zone northeast of New Zealand as the result of oblique reverse faulting at intermediate depth, approximately $180 \mathrm{~km}$ beneath the South Pacific Ocean and South Fiji Basin. Focal mechanism solutions for the event indicate that rupture occurred on either a northeast- or southweststriking, moderately dipping reverse fault. Slip on a fault of either orientation would accommodate the down-dip compression of the Pacific slab that is implied by the reverse component of the faulting solution. At the location of the earthquake, the Pacific plate moves westward relative to the Australia plate at a velocity of about $120 \mathrm{~mm} / \mathrm{yr}$, beginning its descent into the mantle at the Kermadec Trench, to the east of the June $3^{\text {rd }}$ earthquake. This subduction zone extends north-northeast from the North Island of New Zealand for more than 2,500 km through Tonga to within $100 \mathrm{~km}$ of Samoa. The eastern edge of the Australia plate may itself be viewed as a collection of microplates whose relative motions help to accommodate the overall Pacific-Australia convergence and associated back-arc spreading. The location and focal mechanism solutions of the earthquake are consistent with it occurring as oblique thrust faulting within the interior of the subducting Pacific plate, rather than on the shallow interface between the Pacific and the overriding Australia plates.

Earthquakes like this event, with focal depths between 70 and $300 \mathrm{~km}$, are commonly termed "intermediate-depth" earthquakes. Intermediate-depth earthquakes represent deformation within subducted slabs rather than at the shallow plate interface between subducting and overriding tectonic plates. They typically cause less damage on the ground surface above their foci than is the case with similar-magnitude shallow-focus earthquakes, but large intermediate-depth earthquakes may be felt at great distance from their epicenters. "Deep-focus" earthquakes, those with focal depths greater than $300 \mathrm{~km}$, also occur in the subducted Pacific plate beneath the Lau Ridge and South Fiji Basin, to the northwest of the June $3^{\text {rd }}$ event. Earthquakes have been reliably located to depths of about $650 \mathrm{~km}$ in this region.

The interaction between the Pacific and Australia plates in this region creates one of the most active tectonic environments in the world, with a high level of associated earthquake activity. Since 1971, a 400-km-long section of the Tonga-Kermadec subduction zone that includes the epicenter of the June 3rd earthquake has produced 120 earthquakes of M 6 or larger; the largest to date was a M 8.0 earthquake in January 1976. None are known to have caused any associated fatalities or damage.

\section{6/23/2001 20:33:14 UTC usp000ah4q $16.265^{\circ} \mathrm{S}, 73.641^{\circ} \mathrm{W}$ \\ M 8.4 - near the coast of southern Peru Depth $33.0 \mathrm{~km}$}

The June 23, 2001, M 8.4 earthquake near the coast of southern Peru occurred as the result of thrust faulting on the plate boundary interface between the Nazca and South America plates. At the location of the earthquake, the Nazca plate moves towards the east-northeast with respect to South America at a velocity of about $78 \mathrm{~mm} / \mathrm{yr}$, and begins its descent into the mantle at the Peru-Chile Trench, to the southwest of the June $23^{\text {rd }}$ earthquake. This great-sized earthquake resulted in many casualties, the majority of which were associated with the subsequent tsunami and landsliding.

Subduction zones such as the South America Arc are geologically complex and generate numerous earthquakes from a variety of tectonic processes that in turn cause deformation of the western edge of South America. Crustal deformation and subsequent mountain building in the overriding South America plate generate shallow earthquakes. Slip along the dipping interface between the two plates generates frequent, and often large, interplate thrust earthquakes between depths of approximately 10 and $60 \mathrm{~km}$. Since 1900, numerous M 8+ earthquakes have occurred on the interface between the Nazca and South America plates, including the $1960 \mathrm{M} 9.5$ earthquake in southern Chile, the largest instrumentally recorded earthquake in the world, and the 2010 M 8.8 earthquake immediately to the north of the 1960 quake. Earthquakes can also be generated to depths greater than 
$600 \mathrm{~km}$ from internal deformation of the subducting Nazca plate, and the slab down-dip of the June $23^{\text {rd }}$ event hosted the largest deep earthquake on record to date - a M 8.2 event that was $630 \mathrm{~km}$ deep near the Peru-Bolivia border in 1994.

While commonly plotted as points on maps, earthquakes of this size are more appropriately described as slip over a larger fault area. Thrust-faulting events of the size of the June 23, 2001, earthquake are typically about 260x100 km (length x width); modeling of this earthquake implies dimensions of about 150-200x150 km, predominantly southeast of the hypocenter.

Southwestern Peru has a history of very large earthquakes. In November 1996, a M 7.7 earthquake ruptured part of the plate boundary to the northwest of the June $23^{\text {rd }}$ event. This plate boundary segment is also thought to have ruptured in an earthquake of about M 8.8 in 1868 . The 1868 event was destructive in the same towns that were heavily damaged in the June $23^{\text {rd }}$ earthquake, and produced a tsunami that resulted in thousands of fatalities along the South America coast and also caused damage in Hawaii and alarm in Japan. The June 23, 2001, earthquake was a complex event with an initial onset of one or more moderate to large subevents followed by at least one larger complex event about 40 seconds later.

\section{7/07/2001 09:38:43 UTC usp000aj40 \\ $17.543^{\circ} \mathrm{S}, 72.077^{\circ} \mathrm{W}$}

\section{$M 7.6$ - near the coast of southern Peru Depth $33.0 \mathrm{~km}$}

The July 7, 2001, M 7.6 earthquake near the coast of southern Peru occurred as the result of shallow thrust faulting on the plate boundary between the Nazca and South America plates. At the location of the earthquake, the Nazca plate moves towards the east-northeast with respect to South America at a velocity of about $78 \mathrm{~mm} / \mathrm{yr}$ and begins its descent into the mantle at the Peru-Chile Trench, to the southwest of the July $7^{\text {th }}$ earthquake. This large earthquake can be considered part of the aftershock sequence of the June 23, 2001, M 8.4 earthquake, whose epicenter was located approximately $200 \mathrm{~km}$ to the northwest of the July $7^{\text {th }}$ event.

Subduction zones such as the South America Arc are geologically complex and generate numerous earthquakes from a variety of tectonic processes that in turn cause deformation of the western edge of South America. Crustal deformation and subsequent mountain building in the overriding South America plate generate shallow earthquakes. Slip along the dipping interface between the two plates generates frequent, and often large, interplate thrust earthquakes between depths of approximately 10 and $60 \mathrm{~km}$. Since 1900, numerous M 8+ earthquakes have occurred on the interface between the Nazca and South America plates, including the 1960 M 9.5 earthquake in southern Chile, the largest instrumentally recorded earthquake in the world, and the 2010 M 8.8 earthquake immediately to the north of the 1960 quake. Earthquakes can also be generated to depths greater than $600 \mathrm{~km}$ from internal deformation of the subducting Nazca plate, and the slab down-dip of the June $23^{\text {rd }}$ event hosted the largest deep earthquake on record to date - a M 8.2 event $630 \mathrm{~km}$ deep near the Peru-Bolivia border in 1994.

Modeling of the slip history of the July $7^{\text {th }}$ earthquake indicates that it broke a small section of the plate boundary approximately $60 \mathrm{~km}$ long and about $60 \mathrm{~km}$ wide at the southeast end of the larger June $23^{\text {rd }}$ rupture. Between the dates of the two major events, almost 60 other aftershocks of M 5 or larger occurred in this region.

\section{8/21/2001 06:52:06 UTC usp000amsn}

\section{$36.813^{\circ} \mathrm{S}, 179.575^{\circ} \mathrm{W}$}

\section{7.1 - east of the North Island of New Zealand Depth $33.0 \mathrm{~km}$}

The August 21, 2001, M 7.1 earthquake east of the North Island of New Zealand occurred as the result of shallow oblique reverse faulting near the boundary between the Australia and Pacific plates. Focal mechanism solutions indicate that rupture occurred on a moderately dipping fault, striking either to the northwest or southeast. At the location of the earthquake, the Pacific plate subducts to the west beneath the Australia plate at the Kermadec Trench at a velocity of about $44 \mathrm{~mm} / \mathrm{yr}$. The hypocenter of the earthquake places the event directly beneath the Kermadec Trench, within the lower subducting (Pacific) plate. Slip on a fault aligned with either nodal plane of the focal mechanism solution is consistent with this intraplate setting.

The Australia-Pacific plate boundary region east of the North Island has a history of large earthquakes both along the plate boundary proper as well as west of the plate boundary internal to the Australia plate, especially within the Kermadec Islands about $600 \mathrm{~km}$ to the north. The August $21^{\text {st }}$ earthquake is the largest event in the region since the M 7.6 strike-slip earthquake less than $100 \mathrm{~km}$ to the north in May 1981. However, seven earthquakes of M 6.5+ have occurred within $400 \mathrm{~km}$ of the August $21^{\text {st }}$ event in the preceding 40 years, all in this northeastern area off the North Island of New Zealand. The two most recent events occurred as the result of normal faulting to the southwest of the August $21^{\text {st }}$ event-a M 7.1 earthquake in February 1995 and a M 6.5 aftershock 5 days later. The most damaging event within this distance range was a M 5.4 earthquake in July 2004 on the mainland of the North Island, which resulted in at least one fatality and two injuries. 
10/12/2001 15:02:16 UTC

\section{$12.686^{\circ} \mathrm{N}, 144.980^{\circ} \mathrm{E}$}

\section{7.0 - Guam region}

\section{Depth 37.0 km}

The October 12, 2001, M 7.0 earthquake near Guam occurred as the result of shallow oblique reverse faulting within the inclined seismic zone that marks the position of the subducted Pacific plate at depth beneath the overriding Philippine Sea plate. Focal mechanism solutions indicate that rupture occurred on either a steeply dipping reverse fault or a shallowly dipping thrust fault. Both are oriented obliquely to the direction of subduction. At the location of the earthquake, the Pacific plate subducts to the west relative to the Philippine Sea plate at a velocity of about $18 \mathrm{~mm} / \mathrm{yr}$, beginning its descent into the mantle at the Mariana Trench, south of the October $12^{\text {th }}$ earthquake. The location, depth, and focal mechanism solutions of this event are consistent with intraplate deformation internal to the subducted Pacific slab rather than with the overlying plate boundary interface between the Pacific and Philippine Sea plates. Slip on a fault aligned with either nodal plane of the focal mechanism solution is consistent with this intraplate setting.

The Mariana Islands and Guam region have experienced several large earthquakes in the past, with six other earthquakes of M 6.5+ within $400 \mathrm{~km}$ of the October $12^{\text {th }}$ event over the preceding 40 years. The largest was a M 7.8 event less than $50 \mathrm{~km}$ to the northwest of the October 12 event that caused extensive damage and injury on Guam. None of these events are known to have any associated fatalities.

\section{0/19/2001 03:28:44 UTC}

\section{usp000ar78}

\subsection{2 ${ }^{\circ} \mathrm{S}, 123.907^{\circ} \mathrm{E}$}

\section{7.5 - Banda Sea}

\section{Depth 33.0 km}

The October 19, 2001, M 7.5 Banda Sea earthquake occurred as the result of shallow strike-slip faulting in the tectonically complex region of eastern Indonesia. Focal mechanism solutions indicate that rupture occurred on either a left-lateral east-weststriking fault or on a right-lateral north-south-trending fault. At the location of the earthquake, the Australia plate moves northward relative to the Sunda plate at a velocity of about $75 \mathrm{~mm} / \mathrm{yr}$, driving the motion of small microplates in eastern Indonesia that together accommodate the overall convergence between these two plates and the Philippine Sea and Pacific plates farther to the north and east. This earthquake occurred close to the boundary between two of these smaller microplates (oriented northsouth), called the Banda Sea and Molucca Sea microplates.

This large, strike-slip faulting event is one of many historical large earthquakes in this tectonically complex region. Within $400 \mathrm{~km}$ of the October $19^{\text {th }}$ event, there have been five other earthquakes of M 7.0+ over the preceding 40 years. The two largest were a deep-focus M 7.9 earthquake in June 1996 and a M 8.2 earthquake in January 1965. Despite having greater magnitudes, these events are not known to have caused fatalities, while shallow earthquakes in November 1998 (M 7.7) and May 2000 (M 7.6), both roughly $240 \mathrm{~km}$ to the north of the October 19 event, resulted in at least 30 fatalities each.

\section{0/31/2001 09:10:20 UTC usp000arz5 $5.912^{\circ} \mathrm{S}, 150.195^{\circ} \mathrm{E}$ \\ M 7.0 - New Britain region Papua New Guinea Depth 33.0 km}

The October 31, 2001, M 7.0 earthquake in the New Britain region of Papua New Guinea occurred as the result of shallow thrust faulting on or near the plate boundary between the Australia and Pacific plates. In this region, the Australia plate moves to the east-northeast with respect to the Pacific plate at a velocity of about $105 \mathrm{~mm} / \mathrm{yr}$. At the location of the earthquake, some researchers consider the edges of the Australia and Pacific plates to be divided into several microplates that together take up the overall convergence between the Australia and Pacific playtes, including the Solomon Sea and South Bismark microplates local to this event. In this context, the October $31^{\text {st }}$ event occurred along the boundary between the Solomon Sea and South Bismarck microplates. The Solomon Sea microplate moves slightly faster and more northeasterly with respect to the Pacific plate (and South Bismark microplate) than does the Australia plate due to sea-floor spreading in the Woodlark Basin to the east-southeast of the October $31^{\text {st }}$ earthquake, facilitating the classic subduction evident beneath New Britain and New Ireland. The October $31^{\text {st }}$ earthquake's location, depth, and focal mechanism solutions are consistent with the earthquake resulting from thrust faulting along the shallow subduction thrust plate boundary, which is seismically active to depths of about $600 \mathrm{~km}$ beneath the island. 
The New Britain region experiences a high level of earthquake activity, with 22 events of M 7 or larger within $400 \mathrm{~km}$ of the October $31^{\text {st }}$ event since 1961. One of these events, a M 7.2 earthquake in May 1985, roughly $100 \mathrm{~km}$ to the east of the October $31^{\text {st }}$ earthquake, resulted in at least one fatality. The region also has a history of large earthquakes occurring close together in time. In November 2000, three earthquakes of M 7.8+ occurred over a 2-day period approximately 50-300 km to the northeast of the October $31^{\text {st }}$ earthquake. The largest of these earthquakes, a M 8.0 event, resulted in at least one fatality and two injuries.

\section{1/14/2001 09:26:10 UTC usp000asvm}

\section{$35.946^{\circ} \mathrm{N}, 90.541^{\circ} \mathrm{E}$}

\section{7.8 - southern Qinghai, China \\ Depth 10.0 km}

The November 14, 2001, M 7.8 earthquake in southern Qinghai province of China occurred as the result of shallow strike-slip faulting in the crust of the Tibetan Plateau, northeast of the Himalaya Mountain Range. Focal mechanism solutions, finite-fault modeling of globally recorded seismic data, and geological field observations all indicate that rupture occurred on a left-lateral east-west-striking fault known as the Kunlun fault, which extends roughly east-west for about 1,600 km in north Tibet. This earthquake occurred several hundred kilometers north of the convergent India:Eurasia plate boundary, where the India plate is moving northward with respect to Eurasia at a rate of approximately $46 \mathrm{~mm} / \mathrm{yr}$. This convergence drives the uplift of the Himalaya Mountains and the Tibetan Plateau, which is an extremely broad region of thickened and uplifted crust sitting above $4.5-5 \mathrm{~km}$, at a rate of approximately $10 \mathrm{~mm} / \mathrm{yr}$.

The uplifted Tibetan Plateau is spreading to the east and, as a result, is an area of east-west extension and eastward crustal motion within a larger region of generally north-south convergence. The Kunlun earthquake, as this event has been named, likely reflects the interplay among these major tectonic forces, dominated in this location by the eastward motion of Tibet, with respect to Eurasia farther north. Farther to the north, the large intra-continental Altyn Tagh fault system also helps to accommodate this motion.

While commonly plotted as points on maps, earthquakes of this size are more appropriately described as slip over a larger fault area. Strike-slip events of the size of the November 14, 2001, earthquake are typically about $185 \times 20 \mathrm{~km}$ (length $\mathrm{x}$ width); modeling of this earthquake implies dimensions of about $300 \times 30 \mathrm{~km}$, directed from the hypocenter eastward.

In November 1997, a M 7.5 strike-slip faulting earthquake occurred along another segment of the same active fault system about $300 \mathrm{~km}$ to the southwest of the November 2001 event. It was the only other local earthquake of M 7+ in the past 40 years; however, eight earthquakes above M 6 have occurred within $400 \mathrm{~km}$ of the November 2001 event. The only historical earthquake that has caused damage in the vicinity of the November $14^{\text {th }}$ event was a shallow M 6.0 earthquake in January 1977, $200 \mathrm{~km}$ to the north, which resulted in at least two fatalities and four injuries.

12/12/2001 14:02:35 UTC

\section{usp000aufx}

\section{$42.813^{\circ} \mathrm{S}, 124.688^{\circ} \mathrm{E}$}

\section{7.1 - south of Australia}

\section{Depth 10.0 km}

The December 12, 2001, M 7.1 earthquake just south of Australia occurred as the result of shallow strike-slip faulting in the oceanic crust of the Australia plate, several hundred kilometers to the north of the Southeast Indian Ridge spreading center. Focal mechanism solutions indicate that rupture occurred on either a right-lateral east-west oriented fault or on a left-lateral north-south-striking fault, and likely involved some complexity in faulting and rupture. At the location of the earthquake, the Australia plate is moving to the north away from the Antarctic plate at a velocity of about $70 \mathrm{~mm} / \mathrm{yr}$. The location and focal mechanism solutions of the earthquake are consistent with it occurring as shallow strike-slip along one of the many north-south fracture zones separating divergent segments of the main Southeast Indian Ridge.

Due to relatively simple local tectonics and mid-ocean ridge setting, this location is not a site of extensive largemagnitude seismicity. Since 1961, there has been only one other earthquake greater than M 6 in a 400-km area surrounding the December $12^{\text {th }}$ event. A smaller M 5.2 aftershock followed the December $12^{\text {th }}$ M 7.1 earthquake nearly 4 hours later. 


\section{2: 13 Events}

01/02/2002 17:22:48 UTC $17.600^{\circ} \mathrm{S}, 167.856^{\circ} \mathrm{E}$

\section{7.2 - Vanuatu}

\section{Depth 21.0 km}

\section{Electronic Poster Available}

The January 2, 2002, M 7.2 Vanuatu earthquake occurred as the result of shallow oblique reverse faulting on or near the convergent boundary between the Australia plate and the New Hebrides microplate (a segment of the much larger Pacific plate). Focal mechanism solutions indicate that rupture occurred on either a steeply dipping reverse fault or a shallowly dipping thrust fault striking northwest-southeast. At the location of the earthquake, the Australia plate moves to the east-northeast relative to the Pacific plate at a velocity of about $84 \mathrm{~mm} / \mathrm{yr}$, subducting at the New Hebrides Trench to the west of the January $2^{\text {nd }}$ event. The earthquake's location and depth are consistent with the earthquake having occurred close to the interplate thrust that defines the Australia-Pacific plate boundary at depth, though the obliquity of the focal mechanism solution to the subduction direction indicates that the event likely occurred on an intraplate fault within the Australia slab. Slip on a fault aligned with either nodal plane of the focal mechanism solution is consistent with this intraplate setting. The subducting Australia plate is seismically active to depths of about $300 \mathrm{~km}$ beneath the islands.

The Vanuatu region experiences a very high level of earthquake activity, with half a dozen events of M 7 or larger within $200 \mathrm{~km}$ of the January $2^{\text {nd }}$ earthquake during the preceding 40 years. Recent large earthquakes near the January $2^{\text {nd }}$ event include a M 7.5 earthquake in November 1999 and a M 7.2 earthquake in July 1994.

\section{3/03/2002 12:08:19 UTC usp000azhc \\ $36.502^{\circ} \mathrm{N}, 70.482^{\circ} \mathrm{E}$}

\section{7.4 - Hindu Kush region, Afghanistan Depth 225.6 km}

\section{Electronic Poster Available}

The March 3, 2002, M 7.4 earthquake near the Hindu Kush region of Afghanistan occurred as the result of reverse faulting at intermediate depth, approximately $225 \mathrm{~km}$ below the Hindu Kush Range in northeastern Afghanistan. Focal mechanism solutions indicate that rupture occurred on either a steeply dipping reverse fault or a shallowly dipping thrust fault. Slip on a fault of either orientation is consistent with the intraplate compressional tectonics implied by the faulting mechanism and earthquake depth. At the location of the earthquake, the India subcontinent moves northward and collides with Eurasia at a velocity of about $37 \mathrm{~mm} / \mathrm{yr}$.

Earthquakes like this event, with focal depths between 70 and $300 \mathrm{~km}$, are commonly termed "intermediate-depth" earthquakes. Intermediate-depth earthquakes represent deformation within subducted lithosphere rather than at the shallow plate interface between subducting and overriding tectonic plates. They typically cause less damage on the ground surface above their foci than is the case with similar-magnitude shallow-focus earthquakes, but large intermediate-depth earthquakes may be felt at great distance from their epicenters. "Deep-focus" earthquakes, those with focal depths greater than $300 \mathrm{~km}$, also occur beneath the northeastern part of Afghanistan. Earthquakes have been reliably located to depths of just over $300 \mathrm{~km}$ in this region.

Active faults and their resultant earthquakes in northern Pakistan and adjacent parts of India and Afghanistan are the direct result of the convergence between the India and Eurasia plates. This collision is causing uplift that produces the highest mountain peaks in the world including the Himalayan, the Karakoram, the Pamir and the Hindu Kush Ranges.

Four other M 7+ earthquakes have occurred within $60 \mathrm{~km}$ of this March $3^{\text {rd }}$ event over the preceding 40 years. The most recent was a M 7.0 earthquake in August 1993 approximately $40 \mathrm{~km}$ to the east-southeast of the March $3^{\text {rd }}$ event, with a similar depth and thrust fault orientation. 
03/05/2002 21:16:09 UTC

usp000azqw

\section{$6.033^{\circ} \mathrm{N}, 124.249^{\circ} \mathrm{E}$}

\section{7.5 - Mindanao, Philippines}

\section{Depth 31.0 km}

\section{Electronic Poster Available}

The March 5, 2002, M 7.5 earthquake south of Mindanao, Philippines, occurred as the result of shallow oblique reverse faulting within the Sunda plate. Focal mechanism solutions indicate that rupture occurred on either a moderately dipping, southeast-striking fault, or on a thrust fault dipping shallowly towards the northeast. Of these two possible fault orientations, finite-fault modeling of globally recorded seismic data is more consistent with slip on the northwest-striking thrust fault. At the location of the earthquake, the Philippine Sea plate moves west-northwest with respect to the Sunda plate at a velocity of approximately $100 \mathrm{~mm} / \mathrm{yr}$. Locally, lithosphere of the Celebes Sea Basin is subducting to the east-northeast beneath the Philippines at the Cotabato Trench, and the March $5^{\text {th }}$ earthquake is likely associated with thrust faulting along that microplate boundary fault.

Northeastern Indonesia and southern Philippines are characterized by complex tectonics in which motions of numerous small microplates accommodate the large-scale convergence among the Philippine Sea, Sunda, Pacific, and Australia plates. The tectonic setting of the Philippines is unusual in that it is characterized by opposite-facing subduction systems on its east and west sides. North of the Cotabato system that likely generated this March 5 earthquake, Sunda lithosphere is also subducting at the Sulu Trench in the south, at the Negros Trench in central Philippines, and at the Manila Trench in the north.

While commonly plotted as points on maps, earthquakes of this size are more appropriately described as slip over a larger fault area. Reverse-faulting events of the size of the March 5, 2002, earthquake are typically about $85 \times 30 \mathrm{~km}$ (length $\mathrm{x}$ width); modeling of this earthquake implies similar dimensions, predominantly surrounding the hypocenter.

The most recent large earthquake of at least M 7 that occurred in the 200-km vicinity of the March 5, 2002, event was a M 7.5 event in November 1984, approximately $140 \mathrm{~km}$ to the southeast. Additionally, a M 7.9 earthquake occurred less than $50 \mathrm{~km}$ to the northwest of the March $5^{\text {th }}$ event in August 1976. The 1976 earthquake and its associated tsunami caused upwards of 7,000 fatalities and 10,000 injuries and widespread damage along local coastlines, making the event one of the most devastating earthquakes in the history of the Philippines.

03/31/2002 06:52:50 UTC

\section{usp000b1e2}

\section{$24.279^{\circ} \mathrm{N}, 122.179^{\circ} \mathrm{E}$}

\section{7.1 - Taiwan region}

Depth 32.8 km

\section{Electronic Poster Available}

The March 31, 2002, M 7.1 earthquake off the northeastern coast of Taiwan occurred as the result of shallow reverse faulting in a zone of transition along the boundary between the Eurasia plate and the Philippine Sea plate, at the most southwestern end of the Ryukyu subduction zone, and where subduction-dominated tectonics to the northeast progressively evolve towards more collision-dominated convergence in Taiwan. Focal mechanism solutions for the earthquake indicate that rupture occurred on an east-west-striking, moderately dipping, reverse fault. At the location of the earthquake, the Philippine Sea plate is moving northwest with respect to the Eurasia plate at a velocity of about $78 \mathrm{~mm} / \mathrm{yr}$.

In Taiwan, the type of lithosphere local to the plate boundary determines how the two major plates interact; oceanic lithosphere in the south causes the denser Eurasia plate to subduct beneath the Philippine Sea plate, while the buoyant continental lithosphere in the north resists subduction and a significant fraction of plate convergence is accommodated by intense compressional deformation of the Earth's crust. To the east of Taiwan, seismicity is predominantly associated with the northward subduction of the Philippine Sea plate beneath Eurasia; the location, depth, and focal mechanism solutions for the March $31^{\text {st }}$ earthquake are consistent with its occurrence on this subduction thrust interface.

This tectonically complex region has historically produced many other large earthquakes of M 7+. Over the preceding 40 years, the $200-\mathrm{km}$ area surrounding the March $31^{\text {st }}$ earthquake has experienced nine such events. The most recent was also the largest - a M 7.7 earthquake in September 1999 (the Chi-Chi earthquake) that resulted in at least 2,297 fatalities, caused damage estimated at $\$ 14$ billion, and occurred on land $150 \mathrm{~km}$ southwest of the March $31^{\text {st }}$ event. 
04/26/2002 16:06:07 UTC

\section{$13.088^{\circ} \mathrm{N}, 144.619^{\circ} \mathrm{E}$}

\section{7.1 - Guam region}

Depth 85.7 km

\section{Electronic Poster Available}

The April 26, 2002, M 7.1 earthquake near Guam occurred as the result of reverse faulting at intermediate depth, approximately $85 \mathrm{~km}$ beneath the Pacific Ocean less than $50 \mathrm{~km}$ off the southern coast of Guam. Focal mechanism solutions indicate that rupture occurred on either a near-vertical reverse fault or a very shallowly dipping oblique thrust fault. At the location of the earthquake, the Pacific plate subducts to the northwest beneath the Philippine Sea plate at a velocity of about $18 \mathrm{~mm} / \mathrm{yr}$, beginning its descent into the mantle at the Mariana Trench to the south of the April $26^{\text {th }}$ earthquake. The depth, location, and focal mechanism solutions of this earthquake suggest reverse faulting associated with internal deformation of the subducted Pacific slab, rather than occurring on the shallower thrust interface between the two plates. Slip on a fault aligned with either nodal plane of the focal mechanism solution is consistent with this intraplate setting.

Earthquakes like this event, with focal depths between 70 and $300 \mathrm{~km}$, are commonly termed "intermediate-depth" earthquakes. Intermediate-depth earthquakes represent deformation within subducted slabs rather than at the shallow plate interface between subducting and overriding tectonic plates. They typically cause less damage on the ground surface above their foci than is the case with similar-magnitude shallow-focus earthquakes, but large intermediate-depth earthquakes may be felt at great distance from their epicenters. "Deep-focus" earthquakes, those with focal depths greater than $300 \mathrm{~km}$, also occur in the subducted Pacific plate beneath the Mariana Island Arc. Earthquakes have been reliably located to depths of about $630 \mathrm{~km}$ beneath the Mariana Island Arc.

In the past decade, this location has been the site of two other M 7+ events. The larger of the two was a M 7.8 earthquake in August 1993 about $20 \mathrm{~km}$ to the southeast of the April 26 $6^{\text {th }}$ event, which caused injury and extensive damage on the island of Guam.

06/28/2002 17:19:30 UTC usp000b73z

\section{$43.752^{\circ} \mathrm{N}, 130.666^{\circ} \mathrm{E}$}

\section{7.3 - Jilin-Heilongjiang border region, China Depth 566.0 km}

\section{Electronic Poster Available}

The June 28, 2002, M 7.3 earthquake near the Jilin-Heilongjiang border region of China occurred as the result of deep reverse faulting within the subducted Pacific plate, approximately $565 \mathrm{~km}$ beneath northeastern China and 1,300 km west of the Japan Trench, where the oceanic Pacific plate begins its descent into the mantle. Focal mechanism solutions indicate that rupture occurred on either a steeply dipping reverse fault or a very shallowly dipping thrust fault. Slip on a fault of either orientation would accommodate the down-dip compression of the Pacific slab that is implied by the normal-component of the faulting solution. At the location of the earthquake, the Pacific plate subducts at a rate of about $90 \mathrm{~mm} / \mathrm{yr}$.

The locations of intermediate-depth and deep earthquakes form features known as Wadati-Benioff zones that image their associated tectonic plate's descent into the mantle. The June $28^{\text {th }}$ earthquake occurred near the base of its particularly long and straight Wadati-Benioff zone that is well-imaged in the accompanying cross-section (see earthquake summary poster). Since 1972, this segment of the subducted Pacific plate has produced 11 earthquakes with focal depths between 400 and $600 \mathrm{~km}$ and with magnitudes of $6+$.

Earthquakes that have focal depths greater than $300 \mathrm{~km}$ are commonly termed "deep-focus" earthquakes. Deep-focus earthquakes cause less damage on the ground surface above their foci than similar-magnitude shallow-focus earthquakes, but large deep-focus earthquakes may be felt at great distance from their epicenters. The largest recorded deep-focus earthquake prior to this June 2002 earthquake was a M 8.2 event that occurred at a depth of $630 \mathrm{~km}$ within the subducted Nazca plate beneath South America near the northern Bolivian border in 1994. A larger event has since occurred-namely the M 8.3 earthquake that occurred at a depth of $600 \mathrm{~km}$ within the subducted Pacific plate beneath the Sea of Okhotsk offshore of northeastern Russia in 2013. The M 8.3 Sea of Okhotsk earthquake was felt all over Asia, as far away as Moscow, and across the Pacific Ocean along the western seaboard of the United States (though at distant locations, individuals reporting having felt the event were likely very favorably situated for the perception of small ground motions). The M 8.2 Bolivian deep-focus earthquake in 1994 had similarly been reported by individuals in North America at great distance from the epicenter. 
Over the past century, 68 earthquakes with a magnitude of M 7+ have occurred at depths greater than $300 \mathrm{~km}$ globally; two of these were located in the same region as the June 28, 2002 event. The closest was a M 7.1 earthquake in April 1999, roughly $30 \mathrm{~km}$ to the southwest and at the same depth.

08/19/2002 11:01:01 UTC

\section{$21.696^{\circ} \mathrm{S}, 179.513^{\circ} \mathrm{W}$}

\section{7.7 - Fiji region}

\section{Depth 580.0 km}

\section{Electronic Poster Available}

The August 19, 2002, M 7.7 (11:01:01 UTC) earthquake in the region of Fiji occurred as the result of deep, oblique normal faulting approximately $580 \mathrm{~km}$ beneath the South Pacific Ocean in the Tonga-Fiji subduction zone. Focal mechanism solutions indicate that rupture occurred on either a steeply dipping normal fault or shallowly dipping normal fault. Slip on a fault of either orientation would accommodate the down-dip extension of the Pacific slab that is implied by the normal-component of the faulting solution. At the location of the earthquake, the Pacific plate moves west relative to the Australia plate, subducting at the Tonga Trench to the east of the August $19^{\text {th }}$ earthquake at a velocity of about $75 \mathrm{~mm} / \mathrm{yr}$. The August 19, 11:01 UTC earthquake was the first of two M 7.7 events that occurred within 7 minutes and $315 \mathrm{~km}$ of one another; both are located within an area of deep-focus activity near the bottom of the subducted Pacific plate.

The pair of August 19 earthquakes was interesting in that the events occurred very close to one another in space and time, had large magnitudes (both M 7.7) and were at great depths $(580 \mathrm{~km}$ and $675 \mathrm{~km}$, respectively). Very large earthquakes are common in this area of the Pacific (35 other events greater than M 7.5 have been recorded since 1900), and deep-focus earthquakes are plentiful. What is unusual about this pair of earthquakes is the near coincidence in both time and space at the extreme lower depth limit of global earthquakes.

Earthquakes occur in this complex seismic zone because of the interaction of two tectonic plates, the Australia plate and the Pacific plate. Both plates are composed of relatively cold and rigid lithosphere (thin oceanic crust and uppermost mantle), moving towards one another at a rate of between 50 and $90 \mathrm{~mm} / \mathrm{yr}$. At the zone of contact, the cold Pacific plate subducts under the overlying Australia plate lithosphere and sinks into the hotter upper mantle. Where the rigid plates are in contact, a deep trench or trough forms - the Tonga Trench - and numerous shallow-focus earthquakes occur (occasionally large), typically demonstrating the thrust-type mechanism expected in this zone of strong horizontal compression and brittle deformation. As the subducting plate continues to greater depths, earthquakes indicate strain relief within the relatively cold slab. The inclined pattern of earthquake foci from shallow (typically 0 to $70 \mathrm{~km}$ ) to intermediate (70 to $300 \mathrm{~km}$ ) and deep depths (greater than $300 \mathrm{~km}$ ) is called the Wadati-Benioff zone. Volcanoes are frequently found above the 100-km depth contour of the Wadati-Benioff zone.

08/19/2002 11:08:24 UTC

\section{usp000ba6m}

\section{$23.884^{\circ} \mathrm{S}, 178.495^{\circ} \mathrm{E}$}

\section{7.7 - south of the Fiji Islands}

\section{Depth 675.4 km}

\section{Electronic Poster Available}

The August 19, 2002, M 7.7 (11:08:24 UTC) earthquake south of the Fiji Islands occurred as the result of deep reverse faulting approximately $675 \mathrm{~km}$ beneath the South Pacific Ocean in the Tonga-Fiji subduction zone. Focal mechanism solutions indicate that rupture occurred on either a steeply dipping reverse fault or a very shallowly dipping thrust fault. Slip on a fault of either orientation would accommodate the down-dip compression of the Pacific slab that is implied by the reverse component of the faulting solution. At the location of the earthquake, the Pacific plate moves west relative to the Australia plate, subducting at the Tonga Trench to the east of the August $19^{\text {th }}$ earthquake at a velocity of about $75 \mathrm{~mm} / \mathrm{yr}$. This second August $19^{\text {th }}$ earthquake (11:08 UTC) is located at the extreme depth limit of the Wadati-Benioff zone at this location. Its depth is well constrained by an excellent and large set of observations of "depth phases," which are characteristic seismic waves reflected off the underside of Earth's surface. Thus, the depth of the second event is clearly one of the deepest in the entire catalog of historical and recent seismic activity.

The pair of August $19^{\text {th }}$ earthquakes was interesting in that the events occurred very close to one another in space and time, had large magnitudes (both M 7.7) and were at great depths $(580 \mathrm{~km}$ and $675 \mathrm{~km}$, respectively). Very large earthquakes are commonplace in this area of the Pacific (35 other events greater than M 7.5 have been recorded since 1900) and deep-focus earthquakes are plentiful. What is unusual about this pair of earthquakes is the near coincidence in both time and space at the extreme lower depth limit of global earthquakes. 
Earthquakes occur here in this complex seismic zone because of the interaction of two tectonic plates, the Australia plate and the Pacific plate. Both plates are composed of relatively cold and rigid lithosphere (thin oceanic crust and uppermost mantle), moving towards one another at a rate of between 50 and $90 \mathrm{~mm} / \mathrm{yr}$. At the zone of contact, the cold Pacific plate subducts under the overlying Australia plate lithosphere and sinks into the hotter upper mantle. Where the rigid plates are in contact, a deep trench or trough forms - the Tonga Trench — and numerous shallow-focus earthquakes occur (occasionally large), typically demonstrating the thrust-type mechanism expected in this zone of strong horizontal compression and brittle deformation. As the subducting plate continues to greater depths, earthquakes indicate strain relief within the relatively cold slab. The inclined pattern of earthquake foci from shallow (typically 0 to $70 \mathrm{~km}$ ) to intermediate (70 to $300 \mathrm{~km}$ ) and deep depths (greater than $300 \mathrm{~km}$ ) is called the Wadati-Benioff zone. Volcanoes are frequently found above the $100 \mathrm{~km}$ depth of the Wadati-Benioff zone.

09/08/2002 18:44:23 UTC

usp000bbpf

$3.302^{\circ} \mathrm{S}, 142.945^{\circ} \mathrm{E}$

\section{7.6 - near the north coast of New Guinea, Papua New Guinea Depth $13.0 \mathrm{~km}$}

\section{Electronic Poster Available}

The September 8, 2002, M 7.6 earthquake near the north coast of New Guinea, Papua New Guinea, occurred as the result of shallow reverse faulting in the subduction zone near the eastern end of the New Guinea Trench. Focal mechanism solutions indicate that rupture occurred on either a steep, northwest-striking reverse fault or on a moderately dipping, southeast-striking reverse fault. Of these two possible fault orientations, finite-fault modeling of globally recorded seismic data is more consistent with slip on the southeast-striking fault. At the location of the earthquake, the Pacific plate is moving west-southwest relative to the Australia plate at a velocity of about $100 \mathrm{~mm} / \mathrm{yr}$. The earthquake reflects the complex interaction between these two major plates and the smaller Bismarck, Caroline, and Woodlark microplates. The Bismarck plate itself is divided into two smaller pieces (the North and South Bismarck plates), interrupting the New Guinea Trench that follows the northern coast of Papua New Guinea. The depth, location, and focal mechanism solutions for this earthquake demonstrate how the complex motions of these numerous small microplates accommodate the large-scale convergence between the Pacific and Australia plates.

While commonly plotted as points on maps, earthquakes of this size are more appropriately described as slip over a larger fault area. Reverse-faulting events of the size of the September 8, 2002, earthquake are typically about 90x45 km (length $\mathrm{x}$ width); modeling of this earthquake implies dimensions of about $70 \times 35 \mathrm{~km}$, predominantly up-dip and east of the hypocenter.

This region has recently suffered several damaging earthquakes. The most significant was on July 17, 1998, when a M 7.0 earthquake generated a tsunami that resulted in at least 2,183 fatalities and injured thousands.

10/10/2002 10:50:20 UTC

usp000be54

\section{$1.757^{\circ} \mathrm{S}, 134.297^{\circ} \mathrm{E}$}

\section{7.6 - near the north coast of Papua, Indonesia Depth 10.0 km \\ Electronic Poster Available}

The October 10, 2002, M 7.6 earthquake near the north coast of Papua, Indonesia, occurred as the result of shallow strikeslip faulting within the Birds Head microplate, one of the many small microplates in the region that help to accommodate the relative motions between the major Philippine Sea, Pacific, Australia, and Sunda plates. Focal mechanism solutions indicate that rupture occurred on either a left-lateral, northeast-striking fault or a right-lateral, northwest-striking fault. Of these two possible fault orientations, finite-fault modeling of globally recorded seismic data is more consistent with slip on the northeast-striking (left-lateral) fault. At the location of the earthquake, the Pacific plate moves westward at a velocity of about $13 \mathrm{~mm} / \mathrm{yr}$ relative to the Philippine plate and southwestward at a velocity of $113 \mathrm{~mm} / \mathrm{yr}$ with respect to Australia.

While commonly plotted as points on maps, earthquakes of this size are more appropriately described as slip over a larger fault area. Strike-slip events of the size of the October 10, 2002 earthquake are typically about 140x20 km (length x width); modeling of this earthquake implies dimensions of about $120 \times 15 \mathrm{~km}$, predominantly up-dip of and bilaterally around the hypocenter.

In the past few decades, several earthquakes in this area have caused notable casualties. On September 12, 1979, a M 7.9 earthquake that struck about $190 \mathrm{~km}$ to the east resulted in 15 fatalities. Damage estimates for this quake ranged from $\$ 5$ million to $\$ 25$ million. Another quake with a magnitude of 6.3 occurred $330 \mathrm{~km}$ to the southeast on September 9, 1985, and killed at least 10 people. Most recently, a M 6.3 earthquake $190 \mathrm{~km}$ to the east on November 20, 1994, injured 28 people. 
11/02/2002 01:26:10 UTC

usp000bfuz

\section{$2.824^{\circ} \mathrm{N}, 96.085^{\circ} \mathrm{E}$}

\section{7.4 - Simeulue, Indonesia}

\section{Depth 30.0 km}

\section{Electronic Poster Available}

The November 2, 2002, M 7.4 near Simeulue, Indonesia, occurred as the result of shallow thrust faulting on the boundary between the subducting Australia plate and the overriding Sunda plate. In the region of the epicenter, the Australia plate is moving at a velocity of about $55 \mathrm{~mm} / \mathrm{yr}$ in a northerly direction relative to the Eurasia plate, with motion oblique to the northwest trend of the plate boundary.

Earthquakes such as the November $2^{\text {nd }}$ event accommodate the component of plate motion that is perpendicular to the trend of the plate boundary. The component of plate motion that is parallel to the trend of the plate boundary is mostly accommodated by strike-slip faulting in the interior of the island of Sumatra. The largest thrust fault earthquakes in the Sumatran subduction zone in the last two centuries were that of 1833, which had a magnitude of 8.8-9.2, and that of 1861, which had a magnitude of 8.3-8.5.

\section{1/03/2002 22:12:41 UTC usp000bg0m}

\section{$63.517^{\circ} \mathrm{N}, 147.444^{\circ} \mathrm{W}$}

\section{7.9 - Central Alaska}

\section{Depth 4.9 km}

\section{Electronic Poster Available}

The November 3, 2002, M 7.9 central Alaska earthquake occurred as the result of shallow strike-slip faulting within the Alaska Range mountains of the North America plate, several hundred kilometers northwest from the Alaska-Aleutian Trench that marks the bathymetric expression of the Pacific:North America plate boundary. Focal mechanism solutions, finite-fault modeling of globally distributed seismic data, and geological field mapping all indicate that rupture occurred on a right-lateral northwest-striking fault. At the location of the earthquake, the Pacific plate moves north-northwestward at a velocity of about $55 \mathrm{~mm} / \mathrm{yr}$ relative to North America.

This November 2002 earthquake was one of the largest ever recorded on U.S. soil, and occurred on the Denali-Totschunda fault system, which is one of the longest strike-slip fault systems in the world and rivals in length California's famed San Andreas strike-slip fault system that spawned the destructive M 7.8 San Francisco earthquake in 1906.

Most of the seismic activity in Alaska results from interaction of the northwestward-moving Pacific plate with the corner of the North America plate that includes Alaska. Along the southeastern panhandle of Alaska, this motion is accommodated by right-lateral strike-slip faulting, but from Yakutat Bay westward along the southern coast of Alaska and the Aleutian Islands, the Pacific plate is colliding with Alaska. West of Kayak Island, this collision results in subduction of the Pacific plate beneath continental Alaska and the Aleutian Islands. This under-thrusting motion was the cause of the M 9.2 Alaska earthquake of 1964. Between Kayak Island and Yakutat Bay, the Pacific plate is mostly coupled to southern Alaska. This coupling has resulted in the rapid, geologically recent building of the coastal St. Elias Mountains and produces northwest-southeast-oriented compressive stress that extends inland through the Alaskan crust to Fairbanks and seaward into the Gulf of Alaska. This compressive stress drives the right-lateral slip witnessed on the Denali-Totschunda fault system.

The Denali fault is a prominent topographic scar on the Alaskan landscape. Prior to the recent earthquake, the fault scarp between Denali National Park on the west and the Richardson Highway on the east appeared degraded, indicating that the last major earthquake was a few hundred years ago. In the epicentral area of the recent quake, USGS geologist George Plafker observed that the last major earthquake had 6-8 m of right-lateral offset. Slip rate on the Denali fault since the last glaciation $(10,000$ years before present) has averaged about $10 \mathrm{~mm} / \mathrm{yr}$. Accordingly, a 6-m displacement would require 600 years of strain accumulation.

This is the largest earthquake on the Denali fault since at least 1912, when a M 7.2 earthquake occurred in the general vicinity of the fault, more than $80 \mathrm{~km}$ to the east of the November $3^{\text {rd }}$ epicenter. Because no seismographs were operating in Alaska at that time and surface faulting in the remote Alaska Range was not reported, the location of the 1912 event is not well-constrained. Fault rupture initiated about $25 \mathrm{~km}$ east of the M 6.7 October $23^{\text {rd }}$ foreshock and continued eastward and southeastward for about $300 \mathrm{~km}$, crossing the Richardson and Glenn (Tok Cutoff) highways. Near Mentasta Lake the rupture branched from the Denali fault and continued for about $75 \mathrm{~km}$ along the Totschunda fault. This branching from the Denali to the Totschunda was expected based on earlier geologic fault investigations and is reflected in the USGS seismic hazard map of Alaska. The seismic radiation pattern determined by Harvard University seismologists is consistent with the observed rightlateral slip. Preliminary measurements of fault displacements in the field by geologists range from under a meter in some locations in the west to nearly $9 \mathrm{~m}$ near Mentasta Lake. 
11/17/2002 04:53:53 UTC

\section{$47.824^{\circ} \mathrm{N}, 146.209^{\circ} \mathrm{E}$}

M 7.3 - northwest of the Kuril Islands

\section{Depth 459.1 km}

\section{Electronic Poster Available}

The November 17, 2002, M 7.3 earthquake northwest of the Kuril Islands occurred as the result of deep reverse faulting approximately $459 \mathrm{~km}$ beneath the Sea of Okhotsk. Focal mechanism solutions indicate that rupture occurred on either a near-vertical reverse fault or a very shallowly dipping thrust fault. Slip on a fault of either orientation would accommodate the down-dip compression of the Pacific slab that is implied by the reverse component of the faulting solution. At the location of the earthquake, the Pacific plate subducts to the west beneath the North America plate at a velocity of about $80 \mathrm{~mm} / \mathrm{yr}$, beginning its descent into the mantle at the Kuril-Kamchatka Trench, several hundred kilometers southeast of the November $17^{\text {th }}$ event. This convergence results in the volcanic Kuril Island Arc parallel to the plate boundary trench.

Subduction zones produce numerous earthquakes from multiple sources. Shallow earthquakes occur within the crust of the overriding plate between the trench and the volcanic arc at the interface between the plates. Deeper earthquakes occur mostly within the subducting plate. Given this earthquake's faulting mechanism and depth, it likely resulted from internal deformation of the Pacific plate as it descends into the mantle.

Earthquakes that have focal depths greater than $300 \mathrm{~km}$ are commonly termed "deep-focus" earthquakes. Deep-focus earthquakes cause less damage on the ground surface above their foci than similar-magnitude shallow-focus earthquakes, but large deep-focus earthquakes may be felt at great distance from their epicenters. The largest recorded deep-focus earthquake prior to this November 2002 earthquake was a M 8.2 event that occurred at a depth of $630 \mathrm{~km}$ within the subducted Nazca plate beneath South America near the northern Bolivian border in 1994. A larger event has since occurred-namely the M 8.3 earthquake that occurred at a depth of $600 \mathrm{~km}$ within the subducted Pacific plate beneath the Sea of Okhotsk offshore of northeastern Russia in 2013. The M 8.3 Sea of Okhotsk earthquake was felt all over Asia, as far away as Moscow, and across the Pacific Ocean along the western seaboard of the United States (though at distant locations, individuals reporting having felt the event were likely very favorably situated for the perception of small ground motions). The M 8.2 Bolivian deep-focus earthquake in 1994 had similarly been reported by individuals in North America at great distance from the epicenter.

Over the past century, 69 earthquakes with a magnitude of M 7+ have occurred at depths greater than 300 km globally; 4 of these were located in the same region as the November 17, 2002, event. The largest was a M 7.3 earthquake in August 1970 , several hundred kilometers to the northeast and $188 \mathrm{~km}$ deeper than the November $17^{\text {th }}$ event.

Within this tectonically diverse region, several other large earthquakes have occurred within the last 40 years. Five other earthquakes of at least M 7 have occurred within $400 \mathrm{~km}$ of the November $17^{\text {th }}$ event. The events range in focal depth from shallow to deep as well as in focal mechanism solution, which is further evidence for the multiple faulting styles typical of subduction zones.

\section{3: 15 Events}

\section{1/20/2003 08:43:06 UTC usp000bnvq $10.491^{\circ} \mathrm{S}, 160.770^{\circ} \mathrm{E}$ \\ M 7.3 - Solomon Islands \\ Depth 33.0 km}

The January 20, 2003, M 7.3 Solomon Islands earthquake occurred as the result of shallow oblique reverse faulting near the convergent plate boundary between the Australia and Pacific plates. Focal mechanism solutions indicate that rupture occurred on either a northwest or north-south-striking, moderately dipping reverse fault. At the location of the earthquake, the Australia plate subducts beneath the Pacific plate towards the northeast at a velocity of about $96 \mathrm{~mm} / \mathrm{yr}$. The location, depth, and focal mechanism solutions of the January $20^{\text {th }}$ earthquake are consistent with its relation to under-thrusting of the Australia plate beneath the Pacific plate (in other words, the northwest-striking plane of the focal mechanism solution).

The Solomon Islands Arc as a whole experiences a very high level of earthquake activity, and many events of M 7 or larger have been recorded since the early decades of the $20^{\text {th }}$ century. The largest and most recent event in relation to the January $20^{\text {th }}$ earthquake was a M 7.6 quake less than $20 \mathrm{~km}$ to the northeast in August 1988, with a similar focal mechanism solution and depth. 


\section{1/22/2003 02:06:34 UTC usp000bnyr $18.770^{\circ} \mathrm{N}, 104.104^{\circ} \mathrm{W}$}

\section{7.6 - offshore Colima, Mexico}

\section{Depth 24.0 km}

\section{Electronic Poster Available}

The January 22, 2003, M 7.6 earthquake offshore of Colima, Mexico, occurred as the result of shallow thrust faulting near the junction of three tectonic plates: the North America plate to the northwest, the Rivera plate to the northeast, and the Cocos plate to the south. Both the Rivera plate and the Cocos plate are being consumed beneath the North America plate in a northeast direction. At the location of the earthquake, the slower moving Rivera plate is moving northeast at about $20 \mathrm{~mm} / \mathrm{yr}$ relative to the North America plate, and the faster moving Cocos plate is moving in a similar direction at a velocity of about $45 \mathrm{~mm} / \mathrm{yr}$. Focal mechanism solutions and finite-fault modeling of globally distributed seismic data are consistent with the earthquake occurring on the shallowly dipping plate boundary interface.

While commonly plotted as points on maps, earthquakes of this size are more appropriately described as slip over a larger fault area. Thrust-faulting events of the size of the January 22, 2003, earthquake are typically about 90x45 km (length x width); modeling of this earthquake implies dimensions of about $60 \times 50 \mathrm{~km}$, predominantly surrounding the hypocenter.

Historically, several significant earthquakes have occurred near the January $22^{\text {nd }}$ event. In 1932 , a M 8.4 thrust earthquake occurred about $100 \mathrm{~km}$ to the northwest. More recently, on October 9, 1995, a M 8.0 earthquake took place about $20 \mathrm{~km}$ to the northwest. This event resulted in at least 49 fatalities and left 1,000 people homeless. The most deadly earthquake in the region occurred about $170 \mathrm{~km}$ to the southeast of the January 22 earthquake on September 19, 1985; a M 8.0 earthquake resulted in at least 9,500 fatalities, injured about 30,000, and left 100,000 people homeless.

\section{3/17/2003 16:36:17 UTC usp000bsvs $51.272^{\circ} \mathrm{N}, 177.978^{\circ} \mathrm{E}$}

\section{7.1 - Rat Islands, Aleutian Islands, Alaska Depth 33.0 km}

The March 17, 2003, M 7.1 earthquake near the Rat Islands, in the Aleutian Islands of southwestern Alaska, occurred as a result of shallow oblique thrust faulting on or near the subduction zone interface between the Pacific and North America plates. At the location of this earthquake, the Pacific plate is moving north-northwestward with respect to the North America plate at a velocity of approximately $75 \mathrm{~mm} / \mathrm{yr}$, which begins its descent into the mantle at the Aleutian Trench to the south of the March $17^{\text {th }}$ earthquake. Based on the location, depth, and focal mechanism solutions of the event, this earthquake is likely associated with rupture of the megathrust interface between these two plates.

Within a $400-\mathrm{km}$ area surrounding the March $17^{\text {th }}$ earthquake, the plate boundary has hosted 10 earthquakes of $\mathrm{M} 7+$ over the preceding 40 years. One of the largest and most recent local events occurred in 1965, a M 8.7 earthquake that nucleated along the same Pacific-North America megathrust plate boundary approximately $50 \mathrm{~km}$ to the east of the March $17^{\text {th }}$ event.

\section{5/26/2003 09:24:00 UTC usp000by66 $38.860^{\circ} \mathrm{N}, 141.500^{\circ} \mathrm{E}$ \\ M 7.0 - near the east coast of Honshu, Japan Depth $\mathbf{6 8 . 0}$ km}

The May 26, 2003, M 7.0 earthquake near the east coast of Honshu, Japan, occurred as the result of oblique reverse faulting close to the coast of Japan, at a depth of approximately $60-70 \mathrm{~km}$. Focal mechanism solutions indicate that rupture occurred as the result of either a near-vertical, westward-dipping reverse fault, or a shallow, eastward-dipping thrust fault. At the location of the earthquake, the Pacific plate moves westward relative to the North America plate at a velocity of about $83 \mathrm{~mm} / \mathrm{yr}$, subducting beneath Japan at the Japan Trench to the east of the May $26^{\text {th }}$ earthquake. Note that some authors divide this region into several microplates that together define the relative motions between among the larger Pacific, North America and Eurasia plates; these include the Okhotsk and Amur microplates that are part of North America and Eurasia, respectively. Given the depth and focal mechanism solutions of this earthquake, the event likely represents rupture of a fault within the subducting Pacific slab, rather than on the overlying plate boundary interface between the Pacific and North America plates. Slip on a fault aligned with either nodal plane of the focal mechanism solution is consistent with this intraplate setting.

The plate boundary region surrounding the May 26, 2003, earthquake hosts moderate to large earthquakes fairly regularly; 11 events of M 6.5+ have occurred within $200 \mathrm{~km}$ of this earthquake over the preceding 40 years. These events include a M 7.7 
earthquake on June 12, 1978, approximately $95 \mathrm{~km}$ to the southeast of the May $26^{\text {th }}$ event that resulted in at least 22 fatalities and 421 injured.

\section{5/26/2003 19:23:27 UTC usp000by7n $2.354^{\circ} \mathrm{N}, 128.855^{\circ} \mathrm{E}$}

\section{7.0 - Halmahera, Indonesia Depth 31.0 km}

The May 26, 2003, M 7.0 earthquake near Halmahera, Indonesia, occurred as the result of shallow reverse faulting within the complex tectonic zone of eastern Indonesia. Focal mechanism solutions indicate that rupture occurred on either a northnorthwest or south-striking, moderately dipping reverse fault. In this region, the overall convergence among the Australia, Sunda, Philippine Sea, and Pacific plates is taken up by the smaller-scale relative motions of local microplates, specifically the Birds Head microplate in the context of this event. At the location of the earthquake, the Australia plate is moving northward with respect to Sunda at a velocity of about $76 \mathrm{~mm} / \mathrm{yr}$; the Philippine Sea plate moves westward with respect to Sunda at a velocity of approximately $107 \mathrm{~mm} / \mathrm{yr}$. Locally, the May $26^{\text {th }}$ earthquake reflects the convergence of the Philippine Sea plate with Sunda, and likely occurred within the inclined seismic zone that defines this plate boundary beneath Halmahera (in other words, the southward-striking plane of the focal mechanism solution).

Frequent volcanic eruptions and earthquakes are evidence of the active and complex tectonic processes in this region. The distribution of small ocean basins, continental fragments, remnants of ancient magmatic arcs and numerous subduction complexes that make up the Indonesian region point to an equally active and complex tectonic history. Over the preceding 40 years, the $300 \mathrm{~km}$ surrounding the May 26, 2003, earthquake has hosted six earthquakes of at least M 7. The largest was also the closest—a M 7.7 earthquake on September 8, 1966, less than $50 \mathrm{~km}$ to the west.

\section{6/20/2003 06:19:38 UTC usp000c0ag}

\section{$7.606^{\circ} \mathrm{S}, 71.722^{\circ} \mathrm{W}$}

\section{7.1 - Amazonas, Brazil \\ Depth 558.1 km}

\section{Electronic Poster Available}

The June 20, 2003, M 7.1 near Amazonas, Brazil, occurred as the result of deep oblique normal faulting approximately $558 \mathrm{~km}$ beneath western Brazil, several hundred kilometers east of the Peru-Chile Trench within the subducted oceanic lithosphere of the Nazca plate. Focal mechanism solutions indicate that rupture occurred on either a north or south-southeast-striking, moderately dipping normal fault. Slip on a fault of either orientation would accommodate the down-dip extension of the Nazca slab that is implied by the normal-component of the faulting solution. At the location of the earthquake, the Nazca plate subducts to the east under the South America plate at a velocity of about $68 \mathrm{~mm} / \mathrm{yr}$.

As it descends into the mantle from the Peru-Chile Trench off of the west coast of Peru to beneath eastern Peru, the Nazca plate is seismically active to depths of about $170 \mathrm{~km}$. Between depths of 170 and $530 \mathrm{~km}$, where the Nazca plate subducts beneath eastern Peru and western Brazil, very few earthquakes are produced. Beneath western Brazil in the region of the June $20^{\text {th }}$ earthquake, the subducted Nazca plate is again seismically active between depths of 530 and $650 \mathrm{~km}$. The deep part of the Nazca plate, in which the June $20^{\text {th }}$ earthquake occurred, took 10 million years or more to descend from the point at which it initially thrust under the South America plate.

Earthquakes that have focal depths greater than $300 \mathrm{~km}$ are commonly termed "deep-focus" earthquakes. Deep-focus earthquakes cause less damage on the ground surface above their foci than similar-magnitude shallow-focus earthquakes, but large deep-focus earthquakes may be felt at great distance from their epicenters. The largest recorded deep-focus earthquake prior to this June 2003 earthquake was a M 8.2 event that occurred at a depth of $630 \mathrm{~km}$ within the subducted Nazca plate beneath South America near the northern Bolivian border in 1994. A larger event has since occurred-namely the M 8.3 earthquake that occurred at a depth of $600 \mathrm{~km}$ within the subducted Pacific plate beneath the Sea of Okhotsk offshore of northeastern Russia in 2013. The M 8.3 Sea of Okhotsk earthquake was felt all over Asia, as far away as Moscow, and across the Pacific Ocean along the western seaboard of the United States (though at distant locations, individuals reporting having felt the event were likely very favorably situated for the perception of small ground motions). The M 8.2 Bolivian deep-focus earthquake in 1994 had similarly been reported by individuals in North America at great distance from the epicenter.

Over the past century, 70 earthquakes with magnitudes of 7+ have occurred at depths greater than $300 \mathrm{~km}$ globally; 12 of these were located in the same region as the June 20,2003, event. The largest nearby event at these depths was the aforementioned M 8.2 Bolivian earthquake, the largest global deep-focus event to date. 
07/15/2003 20:27:50 UTC

usp000c2ka

\section{$2.598^{\circ} \mathrm{S}, 68.382^{\circ} \mathrm{E}$}

\section{7.6 - Carlsberg Ridge}

\section{Depth 10.0 km}

\section{Electronic Poster Available}

The July 15, 2003, M 7.6 earthquake on the Carlsberg Ridge occurred as the result of shallow transform faulting within a mid-ocean ridge system, located in the Arabia Sea between India and Northern Africa. The ridge marks the boundary between the India and Nubia (Africa) plates. Focal mechanism solutions indicate that rupture occurred on either a left-lateral northweststriking fault or a right-lateral northeast-striking fault; the latter is consistent with the orientation of the local plate boundary. Of the two possible fault orientations, finite-fault modeling of globally recorded seismic data is also more consistent with slip on the northeast-striking (right-lateral) fault. At the location of the earthquake, the India plate is moving to the northeast away from the Nubia plate at a rate of $33 \mathrm{~mm} / \mathrm{yr}$.

The Carlsberg Ridge is a slow-spreading ridge with rough topography and a depth that ranges from 1,700 to 4,400 m. Midocean ridges are divergent plate boundaries, where two tectonic plates move apart from each other. New oceanic crust is formed as magma rises up between the two diverging plates. Active spreading ridges are offset by transform faults, where plates slide horizontally past each other neither destroying nor forming crust. This gives the plate boundary a zigzag pattern. Ocean ridges represent the longest linear uplifted features of the Earth's surface and are marked by a belt of shallow earthquakes. Earthquakes can be caused by the release of tensional stress in the uplifted ridge or by the horizontal movement of plates along the transform faults.

While commonly plotted as points on maps, earthquakes of this size are more appropriately described as slip over a larger fault area. Strike-slip events of the size of the July 15, 2003, earthquake are typically about 140x20 km (length x width); modeling of this earthquake implies dimensions of about 100x $20 \mathrm{~km}$, well to the northeast of the hypocenter.

Few large earthquakes occur along mid-ocean ridges. Only three events greater than M 6 have occurred within $400 \mathrm{~km}$ of the July $15^{\text {th }}$ event over the preceding 40 years; all were shallow M 6.0 earthquakes. Due to the remote location of these far from population centers that might be vulnerable to earthquake shaking, none have recorded damage or casualties.

\section{8/04/2003 04:37:20 UTC usp000c41f $60.532^{\circ} \mathrm{S}, 43.411^{\circ} \mathrm{W}$}

\section{7.6 - Scotia Sea}

\section{Depth 10.0 km}

The August 4, 2003, M 7.6 Scotia Sea earthquake in the southern Atlantic Ocean, to the east of the South Orkney Islands, occurred as the result of shallow, oblique transform faulting between the Scotia Sea and Antarctica plates. Focal mechanism solutions indicate that rupture occurred on either a right-lateral south-southwest-striking fault or a left-lateral east-striking fault. Of these two possible fault orientations, finite-fault modeling of globally recorded seismic data is more consistent with slip on the east-striking (left-lateral) fault. At the location of the earthquake, plate motion is also left-lateral; the Antarctica plate moves eastward with respect to the Scotia plate at a velocity about $6 \mathrm{~mm} / \mathrm{yr}$.

While commonly plotted as points on maps, earthquakes of this size are more appropriately described as slip over a larger fault area. Strike-slip events of the size of the August 4, 2003, earthquake are typically about 140x20 km (length x width); modeling of this earthquake implies dimensions of about $100 \times 20 \mathrm{~km}$, mostly to the east of the hypocenter.

Though the region surrounding the Scotia Sea frequently experiences earthquakes, the majority occur around the subduction zone adjacent to the South Sandwich Islands, to the east of the August $4^{\text {th }}$ earthquake. Only four earthquakes greater than M 6 have occurred in the 400-km vicinity of this earthquake over the past 40 years. Due to the remote location of these far from population centers that might be vulnerable to earthquake shaking, none have recorded damage or casualties.

\section{8/21/2003 12:12:49 UTC Usp000c5h6}

\section{$45.104^{\circ} \mathrm{S}, 167.144^{\circ} \mathrm{E}$}

\section{7.2 - South Island of New Zealand}

\section{Depth 28.0 km}

\section{Electronic Poster Available}

The August 21, 2003, M 7.2 earthquake in the southwest corner of the South Island of New Zealand occurred as the result of shallow reverse faulting on or near the convergent Australia-Pacific plate boundary. Focal mechanism solutions indicate that 
rupture occurred on either a steeply dipping reverse fault or a shallowly southeastward-dipping thrust fault. Of these two possible fault orientations, finite-fault modeling of globally recorded seismic data is more consistent with slip on the steeply dipping reverse fault. At the location of the earthquake, the Australia plate moves to the northeast at a velocity of about $35-45 \mathrm{~mm} / \mathrm{yr}$ relative to the Pacific plate. In central South Island, this plate motion results in predominantly strike-slip movement along the Alpine fault. In southwestern South Island, relative plate motion is accommodated by oblique subduction of the Australia plate along the Puysegur Trench and deformation of the overriding Pacific plate inland of the trench. The Southern Alps of New Zealand result from this oblique plate convergence.

The August $21^{\text {st }}$ earthquake is located at the southwesternmost end of the Southern Alps mountain chain, just inland of the Australia-Pacific plate boundary. This southern tip of the South Island is a region known as Fiordland. The preliminary location, depth, and estimate of fault orientation are consistent with the earthquake having resulted from slip on the thrust interface between the Pacific and Australia plates. The deformed and subducted Australia plate beneath Fiordland and below the thrust interface is also highly active, and several surface strands of the Alpine fault are observed in the vicinity of the earthquake epicenter in the overriding Pacific plate above the thrust interface.

Over the past two decades, several large earthquakes have occurred in Fiordland. A M 7.0 event on August 10, 1993, caused power outages in the Te Anau area and was felt throughout South Island and as far away as Sydney, Australia. A M 6.4 earthquake struck on May 31, 1989, and was felt strongly in the southwestern part of South Island and a M 6.7 quake struck on June 3, 1988. However, neither of these latter two events resulted in damage or casualties.

\section{9/25/2003 19:50:06 UTC usp000c8kv}

\section{$41.815^{\circ} \mathrm{N}, 143.910^{\circ} \mathrm{E}$}

\section{8.3 - Hokkaido, Japan region Depth 27.0 km}

\section{Electronic Poster Available}

The September 25, 2003, M 8.3 earthquake near Hokkaido, Japan, occurred as the result of shallow thrust faulting on or near the plate interface between the overriding North America plate (which extends into the northeast corner of the Eurasian landmass) and the subducting Pacific plate. At the location of this earthquake, the Pacific plate is moving west-northwest at a velocity of about $82 \mathrm{~mm} / \mathrm{yr}$ relative to the North America plate, subducting beneath Japan and Eurasia at the Japan and KurilKamchatka Trenches to the east of the September $25^{\text {th }}$ earthquake.

In addition to experiencing great-sized thrust earthquakes that originate on the interface between these plates, eastern Hokkaido also experiences large earthquakes that originate from the interior of the subducted Pacific plate. The earthquakes of March 4, 1952 (30 km north of the 2003 earthquake), and May 16, 1968 (110 km southwest) were interface-thrust earthquakes, whereas the earthquake of January 15, 1993 (170 km north) occurred within the interior of the subducted Pacific plate. The September 25, 2003, earthquake appears to have involved rupture of the same section of the plate interface that ruptured in 1952.

While commonly plotted as points on maps, earthquakes of this size are more appropriately described as slip over a larger fault area. Thrust-faulting events of the size of the July 15, 2003, earthquake are typically about 230x80 km (length $\mathrm{x}$ width); modeling of this earthquake implies dimensions of about 100x120 km, mostly down-dip of the hypocenter.

The last great-sized earthquake (M 8+) in the world was a M 8.4 event that occurred on June 23, 2001, near the coast of Peru. That earthquake resulted in at least 75 fatalities, including 26 killed by the associated tsunami.

\section{9/25/2003 21:08:00 UTC usp000c8mb $41.774^{\circ} \mathrm{N}, 143.593^{\circ} \mathrm{E}$}

\section{7.4 - Hokkaido, Japan region Depth 33.0 km}

The September 25, 2003, M 7.4 earthquake near Hokkaido, Japan, occurred as the result of shallow thrust faulting on or near the plate interface between the overriding North America plate (which extends into the northeast corner of the Eurasian landmass) and the subducting Pacific plate. It is an aftershock of the M 8.3 earthquake that occurred just over an hour prior and less than $50 \mathrm{~km}$ to the west. At the location of the M 7.4 earthquake, the Pacific plate is moving west-northwest at a velocity of about $82 \mathrm{~mm} / \mathrm{yr}$ relative to the North America plate, subducting beneath Japan and Eurasia at the Japan and Kuril-Kamchatka Trenches to the east of the September $25^{\text {th }}$ earthquake.

In addition to experiencing great thrust earthquakes that originate on the interface between the plates, eastern Hokkaido experiences great earthquakes that originate from the interior of the subducted Pacific plate. The earthquakes of March 4, 1952, and May 16, 1968, were interface-thrust earthquakes, whereas the M 7.6 earthquake of January 15, 1993 occurred within the interior 
of the subducted Pacific plate. The 1993 event resulted in at least 2 fatalities and more than 900 injured. The September $25^{\text {th }}$ earthquake appears to have involved rupture of the same section of the plate interface that ruptured in 1952.

\section{9/27/2003 11:33:25 UTC usp000c8sz $50.038^{\circ} \mathrm{N}, 8^{87.813^{\circ} \mathrm{E}}$}

\section{7.3 - southwestern Siberia, Russia Depth 16.0 km}

\section{Electronic Poster Available}

The September 27, 2003, M 7.3 earthquake in southwestern Siberia, Russia, occurred as the result of shallow strike-slip faulting within the Altay Mountains of the Eurasia plate. Focal mechanism solutions indicate that rupture occurred on either a left-lateral southwest-striking fault or a right-lateral southeast-striking fault. Finite-fault modeling of satellite data and geological field mapping both indicate that rupture occurred on a right-lateral northwest-striking fault that was unrecognized prior to the earthquake.

This earthquake resulted from stresses originating with the collision of the India plate against the Eurasia plate. The collision of the two major plates has generated the Himalaya Mountains, far to the south of the epicenter of this earthquake, and produces deformation of the Earth's crust over a broad region of central and eastern Asia. In the epicentral region of southern Russia, northwestern China, eastern Kazakhstan, and western Mongolia, earthquakes of past decades have been caused by strike-slip faulting (as with this earthquake) and reverse faulting.

The September $27^{\text {th }}$ event is the largest in this region since an earthquake on December 20, 1761, that is thought to have had a magnitude of about 7.7 .

\section{0/31/2003 01:06:28 UTC usp000cbpa}

\section{$37.812^{\circ} \mathrm{N}, 142.619^{\circ} \mathrm{E}$}

\section{7.0 - off the east coast of Honshu, Japan \\ Depth 10.0 km}

\section{Electronic Poster Available}

The October 31, 2003, M 7.0 earthquake off the east coast of Honshu, Japan, occurred as the result of shallow thrust faulting on or near the plate interface between the overriding North America plate (which extends into the northeast corner of the Eurasian landmass) and the subducting Pacific plate. At the location of the earthquake, the Pacific plate moves westward relative to the North America plate at a velocity of about $83 \mathrm{~mm} / \mathrm{yr}$, subducting beneath the North America plate at the Japan Trench east of the October $31^{\text {st }}$ earthquake. Note that some authors divide this region into several microplates that together define the relative motions between the larger Pacific, North America, and Eurasia plates; these include the Okhotsk and Amur microplates that are part of North America and Eurasia, respectively. The location, depth and focal mechanism solutions of this earthquake imply that it occurred as the result of thrust faulting on the plate interface between the Pacific and North America plates.

In addition to experiencing great thrust earthquakes that originate on the interface between the plates, western Honshu experiences great earthquakes that originate from the interior of subducted Pacific plate. Extremely deadly and destructive earthquakes have struck this part of Honshu repeatedly over the past 400 years; in the past century, the earthquakes of June 1964, June 1978, and January 1995 are notable for having caused costly property damages.

\section{1/17/2003 06:43:06 UTC usp000cd1n}

\section{$51.146^{\circ} \mathrm{N}, 178.650^{\circ} \mathrm{E}$}

\section{7.8 - Rat Islands, Aleutian Islands, Alaska \\ Depth 33.0 km}

\section{Electronic Poster Available}

The November 17, 2003, M 7.8 Rat Islands earthquake occurred as the result of shallow thrust faulting on or near the plate interface between the overriding North America plate and the subducting Pacific plate, along the subduction zone defining the Aleutian Arc of Alaska. The Pacific plate subducts northwest relative to the North America plate at the Aleutian Trench south of the November $17^{\text {th }}$ earthquake, at a velocity of about $66 \mathrm{~mm} / \mathrm{yr}$ in the arc's eastern region where convergence is nearly perpendicular to the plate boundary and up to $86 \mathrm{~mm} / \mathrm{yr}$ near its western extent. However, because of the boundary's curvature, as one travels westward along the arc, the subduction becomes more and more oblique to the boundary until the relative plate motion 
becomes almost parallel to the boundary at its western edge. The Aleutian Arc extends about 3,000 km from the Gulf of Alaska to Kamchatka.

While commonly plotted as points on maps, earthquakes of this size are more appropriately described as slip over a larger fault area. Thrust-faulting events of the size of the November 17, 2003, earthquake are typically about 120x50 km (length $\mathrm{x}$ width); modeling of this earthquake implies dimensions of about 120x100 km, mostly to the west and up-dip of the hypocenter.

Subduction zones such as the Aleutian Arc are geologically complex and produce numerous earthquakes from multiple sources. Deformation of the overriding North America plate generates shallow crustal earthquakes, whereas slip at the interface of the plates generates interplate earthquakes that extend from near the base of the trench to depths of 40 to $60 \mathrm{~km}$. At greater depths, Aleutian Arc earthquakes occur within the subducting Pacific plate and can reach depths of $300 \mathrm{~km}$.

The depth and thrust mechanism of the November $17^{\text {th }}$ event are consistent with those of an interplate earthquake. The Aleutian subduction zone has produced four great interplate earthquakes in the last century: the 1938 M 8.2 earthquake that occurred off the Alaska Peninsula, the 1957 M 8.6 Andreanof earthquake, the 1964 M 9.2 Gulf of Alaska earthquake that caused \$311 million in property damage and 125 fatalities, and the 1965 M 8.7 Rat Island earthquake.

\section{2/27/2003 16:00:59 UTC usp000cg90 \\ $22.015^{\circ} \mathrm{S}, 169.766^{\circ} \mathrm{E}$}

\section{7.3 - southeast of the Loyalty Islands Depth 10.0 km}

\section{Electronic Poster Available}

The December 27, 2003, M 7.3 earthquake was part of an extended sequence of about 270 earthquakes that commenced in December 2003 in the Loyalty Islands, located in the southeastern corner of the French territory of New Caledonia. The sequence included three large earthquakes: a M 6.8 foreshock on December 26, this M 7.3 mainshock on December 27, and a M 7.1 earthquake, which was part of an aftershock series that essentially terminated on January 13, 2004.

This earthquake sequence occurred within the broader zone of intense regional seismicity of the New Hebrides (Vanuatu) Island Arc. The arc gently curves to the south-southeast from the Santa Cruz Islands, across the island nation of Vanuatu, and terminates where the seismic zone curves sharply to the east near the Loyalty Islands (see Seismicity of the New Hebrides Arc map in the related Earthquake Summary Poster). The arc's islands, many of which are volcanic, lie parallel to the New Hebrides Trench southwest of the December $27^{\text {th }}$ earthquake. Bands of shallow $(0-70 \mathrm{~km})$ and intermediate-depth $(70-300 \mathrm{~km})$ earthquakes are also parallel to the axes of the trench and island chain. A band of shallow seismicity clearly defines the extent of the outer ridge of the New Hebrides Trench. The foreshocks were located principally in this outer ridge band, but the aftershocks were located principally under the inner arc.

The shallow seismicity defines the zone of convergence of the Australia plate with the New Hebrides microplate (a segment of the much larger Pacific plate) and the intermediate seismicity defines the extent of the down-going slab of Australia plate. The rate of convergence of the Australia plate is estimated to be about $75 \mathrm{~mm} / \mathrm{yr}$, and the plate motion is east-northeast relative to the New Hebrides microplate. Focal mechanism solutions of the foreshock sequence were typical of normal faulting in a tensional horizontal stress regime, but mechanisms of the December $27^{\text {th }}$ mainshock and the many aftershocks were characteristic of shallow thrust faulting and northeastward-oriented subduction.

The region surrounding the Loyalty Islands and Vanuatu frequently hosts large earthquakes. Within $400 \mathrm{~km}$ of the December $27^{\text {th }}$ event, 11 other earthquakes of $\mathrm{M} 7$ or larger have occurred over the preceding 40 years. The largest of these events was a M 7.7 earthquake in May 1995 about $130 \mathrm{~km}$ to the south of the December $27^{\text {th }}$ earthquake. This large event had no associated casualties but did generate a local tsunami that was recorded along the coast of New South Wales, Australia. 


\section{4: 16 Events}

\section{1/03/2004 16:23:21 UTC usp000cgz9 \\ $22.253^{\circ} \mathrm{S}, 169.683^{\circ} \mathrm{E}$}

\section{7.1 - southeast of the Loyalty Islands}

\section{Depth 22.0 km}

\section{Electronic Poster Available}

The January 3, 2004, M 7.1 event was part of an extended sequence of about 270 earthquakes that commenced in December 2003 in the Loyalty Islands, located in the southeastern corner of the French territory of New Caledonia. The sequence included three large earthquakes: a M 6.8 foreshock on December 26, a M 7.3 mainshock on December 27, and this M 7.1 earthquake, which was part of an aftershock series that essentially terminated on January 13, 2004.

This earthquake sequence occurred within the broader zone of intense regional seismicity of the New Hebrides Island Arc. The arc gently curves to the south-southeast from the Santa Cruz Islands, across the island nation of Vanuatu, and terminates where the seismic zone curves sharply to the east near the Loyalty Islands (see Seismicity of the New Hebrides Arc map in the related Earthquake Summary Poster). The arc's islands, many of which are volcanic, lie parallel to the New Hebrides Trench immediately northeast of the location of the January $3^{\text {rd }}$ earthquake. Bands of shallow $(0-70 \mathrm{~km})$ and intermediate-depth $(70-300 \mathrm{~km})$ earthquakes are also parallel to the axes of the trench and island chain. A band of shallow seismicity clearly defines the extent of the outer ridge of the New Hebrides Trench. The foreshocks of this earthquake were located principally in this outer ridge band, but the aftershocks were located principally under the inner arc.

The shallow seismicity defines the zone of convergence of the Australia plate with the New Hebrides microplate (a segment of the much larger Pacific plate) and the intermediate seismicity defines the extent of the down-going slab of the Australia plate. The rate of convergence of the Australia plate is estimated to be about $75 \mathrm{~mm} / \mathrm{yr}$ and the plate motion is east-northeast relative to the New Hebrides microplate. Focal mechanism solutions of the foreshock sequence were typical of normal faulting in a tensional horizontal stress regime, but mechanisms of the mainshock and the many aftershocks, such as this event, were characteristic of shallow thrust faulting and northeastward-oriented subduction.

The region surrounding the Loyalty Islands and Vanuatu frequently hosts large earthquakes. Within $400 \mathrm{~km}$ of the January $3^{\text {rd }}$ event, there have been 12 other earthquakes of M 7+ over the preceding 40 years. The largest of these events was a M 7.7 earthquake in May 1995 about $100 \mathrm{~km}$ to the south of the January $3^{\text {rd }}$ earthquake. This large event had no associated casualties but did generate a local tsunami that was recorded along the coast of New South Wales, Australia.

02/05/2004 21:05:02 UTC

\section{usp000ckg7}

\section{$3.615^{\circ} \mathrm{S}, 135.538^{\circ} \mathrm{E}$}

\section{7.0 - Papua, Indonesia \\ Depth 16.6 km}

\section{Electronic Poster Available}

The February 5, 2004, M 7.0 Papua, Indonesiaearthquake occurred as a result of shallow, oblique normal faulting on or near the transform faulting plate boundary separating the Australia and Sunda plates. Focal mechanism solutions indicate that rupture occurred on either a near-vertical right-lateral strike-slip fault trending southeast-northwest, or on a shallower left-lateral fault striking towards the northeast, parallel to the regional plate boundary. The earthquake lies near the boundary between the Birds Head and Maoke microplates, an east-northeast trending boundary that accommodates approximately $80 \mathrm{~mm} / \mathrm{yr}$ of leftlateral motion. Eastern Indonesia is broadly characterized by complex tectonics in which motions of numerous small microplates are accommodating large-scale convergence among the Australia, Pacific, Philippine Sea, and Sunda plates. The interactions among these microplates produce all possible styles of faulting.

Eastern Indonesia has experienced many strong earthquakes. Since 1979, the region within $300 \mathrm{~km}$ of the mainshock of the February $5^{\text {th }}$ earthquake has experienced three other earthquakes with magnitudes greater than 7 , the largest of which was a M 7.9 event in September 1979, roughly $200 \mathrm{~km}$ to the north-northeast. 
02/07/2004 02:42:35 UTC

\section{$4.003^{\circ} \mathrm{S}, 135.023^{\circ} \mathrm{E}$}

\section{7.3 - Papua, Indonesia \\ Depth 10.0 km}

The February 7, 2004, 7.3 Papua, Indonesia earthquake occurred as a result of shallow strike-slip faulting on or near the plate boundary separating the Australia and Sunda plates. Focal mechanism solutions indicate that rupture occurred on either a left-lateral east-west oriented fault or a right-lateral fault trending north-south. The earthquake lies near the boundary between the Birds Head and the Maoke microplates, an east-northeast trending boundary that accommodates approximately $80 \mathrm{~mm} / \mathrm{yr}$ of left-lateral motion. While slightly oblique to this orientation, the east-west plane of the focal mechanism solution is more consistent with motion along this plate boundary. Eastern Indonesia is broadly characterized by complex tectonics in which motions of numerous small microplates are accommodating large-scale convergence among the Australia, Pacific, Philippine Sea, and Sunda plates. The interactions among these microplates produce all possible styles of faulting.

Eastern Indonesia has experienced many strong earthquakes. Since 1979, the region within $300 \mathrm{~km}$ of the mainshock of the February $7^{\text {th }}$ earthquake has experienced four other earthquakes with magnitudes greater than 7, the largest of which was a M 7.9 event in September 1979. The earthquake closest to the February $7^{\text {th }}$ event was the damaging M 7.0 event 2 days earlier, approximately $60 \mathrm{~km}$ to the northeast, which resulted in almost 40 casualties and significant damage to housing and local infrastructure.

\section{7/15/2004 04:27:14 UTC}

\section{usp000d06s}

\section{$17.656^{\circ} \mathrm{S}, 178.760^{\circ} \mathrm{W}$}

\section{7.1 - Fiji region \\ Depth 565.5 km}

The July 15, 2004, M 7.1 earthquake near Fiji occurred as the result of deep, oblique reverse faulting approximately $565 \mathrm{~km}$ beneath the South Pacific Ocean several hundred kilometers to the west of the Tonga Trench. Focal mechanism solutions indicate that rupture occurred on a moderately dipping reverse fault striking to the north-northwest or the southeast. Slip on a fault of either orientation would accommodate the down-dip compression of the Pacific slab that is implied by the reverse component of the faulting solution. At the location of this earthquake, the Pacific plate moves approximately due west relative to the Australia plate at a velocity of about $81 \mathrm{~mm} / \mathrm{yr}$. The eastern edge of the Australia plate may be viewed as a collection of microplates whose relative motions help to accommodate the overall Pacific-Australia convergence and associated back-arc spreading. The location, depth, and focal mechanism solutions of the July $15^{\text {th }}$ event indicate that the earthquake is related to faulting within the subducted Pacific slab. The geometry of the Pacific plate at depth is known to be quite complex and may involve interactions between the Pacific plate proper and one or more relict slab fragments. The stresses generating the July $15^{\text {th }}$ earthquake likely result from the slow deformation within the interior of one of these slabs, near the base of the mantle transition zone.

Earthquakes that have focal depths greater than $300 \mathrm{~km}$ are commonly termed "deep-focus" earthquakes. Deep-focus earthquakes cause less damage on the ground surface above their foci than similar-magnitude shallow-focus earthquakes, but large deep-focus earthquakes may be felt at great distance from their epicenters. The largest recorded deep-focus earthquake prior to this July 2004 earthquake was a M 8.2 event that occurred at a depth of $630 \mathrm{~km}$ within the subducted Nazca plate beneath South America near the northern Bolivian border in 1994. A larger event has since occurred-namely the M 8.3 earthquake that occurred at a depth of $600 \mathrm{~km}$ within the subducted Pacific plate beneath the Sea of Okhotsk offshore of northeastern Russia in 2013. The M 8.3 Sea of Okhotsk earthquake was felt all over Asia, as far away as Moscow, and across the Pacific Ocean along the western seaboard of the United States (though at distant locations, individuals reporting having felt the event were likely very favorably situated for the perception of small ground motions). The M 8.2 Bolivian deep-focus earthquake in 1994 had similarly been reported by individuals in North America at great distance from the epicenter.

Over the past century, 71 earthquakes with a magnitude of M 7+ have occurred at depths greater than $300 \mathrm{~km}$ globally; 22 of these were located in the same region as July $15^{\text {th }}$ event. The largest nearby event at these depths was a M 7.8 earthquake in January 1919, $200 \mathrm{~km}$ to the north and $80 \mathrm{~km}$ shallower than the July 15, 2004, event. 
07/25/2004 14:35:19 UTC

usp000d0v4

\section{$2.455^{\circ} \mathrm{S}, 103.977^{\circ} \mathrm{E}$}

\section{7.3 - Southern Sumatra, Indonesia}

\section{Depth 582.1 km}

\section{Electronic Poster Available}

The July 25, 2004, M 7.3 earthquake in southern Sumatra, Indonesia, occurred as the result of deep, oblique normal faulting approximately $580 \mathrm{~km}$ beneath the island of Sumatra, several hundred kilometers to the northeast of the Sunda-Java Trench. Focal mechanism solutions indicate that rupture occurred on a moderately dipping oblique normal fault striking either to the north-northwest or to the east-southeast. Slip on a fault of either orientation would accommodate the down-dip extension of the Australia slab that is implied by the normal-component of the faulting solution. At the location of the earthquake, the Australia plate subducts towards the north-northeast beneath the Sunda plate at a velocity of about $62 \mathrm{~mm} / \mathrm{yr}$. The location, depth, and focal mechanism solutions of the July 15 event indicate that the earthquake is related to faulting within the subducted Australia slab, rather than on the much shallower plate boundary. The subducted Indo-Australia plate is seismically active to a depth of about $650 \mathrm{~km}$ beneath Sumatra and Java.

Earthquakes that have focal depths greater than $300 \mathrm{~km}$ are commonly termed "deep-focus" earthquakes. Deep-focus earthquakes cause less damage on the ground surface above their foci than similar-magnitude shallow-focus earthquakes, but large deep-focus earthquakes may be felt at great distance from their epicenters. The largest recorded deep-focus earthquake prior to this July 2004 earthquake was a M 8.2 event that occurred at a depth of $630 \mathrm{~km}$ within the subducted Nazca plate beneath South America near the northern Bolivian border in 1994. A larger event has since occurred-namely the M 8.3 earthquake that occurred at a depth of $600 \mathrm{~km}$ within the subducted Pacific plate beneath the Sea of Okhotsk offshore of northeastern Russia in 2013. The M 8.3 Sea of Okhotsk earthquake was felt all over Asia, as far away as Moscow, and across the Pacific Ocean along the western seaboard of the United States (though at distant locations, individuals reporting having felt the event were likely very favorably situated for the perception of small ground motions). The M 8.2 Bolivian deep-focus earthquake in 1994 had similarly been reported by individuals in North America at great distance from the epicenter.

Over the past century, 72 earthquakes with a magnitude of M 7+ have occurred at depths greater than $300 \mathrm{~km}$ globally; 7 of these were located in the same region as the July 15, 2004, event, the closest being a M 7.0 earthquake in December 1963, more than $400 \mathrm{~km}$ to the southeast and $80 \mathrm{~km}$ deeper than the July $15^{\text {th }}$ event, with no recorded damage or casualties.

09/05/2004 10:07:07 UTC

\section{$33.070^{\circ} \mathrm{N}, 136.618^{\circ} \mathrm{E}$}

\section{7.2 - Near the south coast of Honshu, Japan Depth 14.0 km}

The September 5, 2004, M 7.2 earthquake southeast of Osaka, Japan, occurred as the result of shallow reverse faulting on or near the plate boundary between the Philippine Sea and Eurasia plates, where the Philippine Sea plate subducts northwestward beneath southern Japan at the Nankai Trough. Focal mechanism solutions indicate that rupture occurred on either an eastor west-striking, moderately dipping reverse fault. At the location of the earthquake, the Philippine Sea plate moves towards the northwest relative to the Eurasia plate at a velocity of about $52 \mathrm{~mm} / \mathrm{yr}$. Note that some authors divide this region into several microplates that together define the relative motions among the larger Pacific, North America and Eurasia plates; these include the Yangtze and Amur microplates local to this earthquake, both part of the eastern edge of Eurasia. Given the obliquity of the focal mechanism solution to the trend of the local subduction zone and the depth of the event relative to the interplate thrust boundary, the event likely represents intraplate faulting within the subducting Philippine Sea plate, rather than thrusting on the overlying plate boundary. Slip on a fault aligned with either nodal plane of the focal mechanism solution is consistent with this intraplate setting.

The plate boundary region surrounding the September 5, 2004, earthquake has hosted large and damaging earthquakes in the past. The epicenter of the September $5^{\text {th }}$ earthquake is just northeast of the 1946 Nankai earthquake, a M 8.3 event that caused 1,300 fatalities and severe damage in southern Japan, as well as an extensive tsunami. Similar megathrust earthquakes are thought to recur on this section of the Nankai subduction zone every $90-150$ years. 
09/05/2004 14:57:18 UTC

usp000d3mb

$33.216^{\circ} \mathrm{N}, 137.061^{\circ} \mathrm{E}$

\section{7.4 - Near the south coast of Honshu, Japan Depth 10.0 km}

The September 05, 2004, M 7.4 earthquake southeast of Osaka, Japan, occurred as the result of shallow, oblique reverse faulting on or near the plate boundary between the Philippine Sea and Eurasia plates, where the Philippine Sea plate subducts northwestward beneath southern Japan at the Nankai Trough. This M 7.4 event occurred less than 5 hours after a nearby M 7.2 earthquake with the same faulting mechanism. Focal mechanism solutions indicate that rupture occurred on either an east- or west-striking, moderately dipping reverse fault. At the location of the earthquake, the Philippine Sea plate moves towards the northwest relative to the Eurasia plate at a velocity of about $52 \mathrm{~mm} / \mathrm{yr}$. Note that some authors divide this region into several microplates that together define the relative motions among the larger Pacific, North America and Eurasia plates; these include the Yangtze and Amur microplates local to this earthquake, both part of the eastern edge of Eurasia. Given the obliquity of both nodal planes in the focal mechanism solution to the trend of the local subduction zone and the depth of the event relative to the interplate thrust, the event likely represents intraplate faulting within the subducting Philippine Sea plate, rather than thrusting on the overlying plate boundary. Slip on a fault aligned with either nodal plane of the focal mechanism solution is consistent with this intraplate setting.

The plate boundary region surrounding the September 5, 2004 earthquake has hosted large and damaging earthquakes in the past. This M 7.4 (14:57 UTC) event was preceded by a M 7.2 earthquake that occurred 45 km west just 5 hours earlier. The epicenters of both September $5^{\text {th }}$ earthquakes are also just northeast of the 1946 Nankai earthquake, a M 8.3 event that caused 1,300 fatalities and severe damage in southern Japan, as well as an extensive tsunami. Similar megathrust earthquakes are thought to recur on this section of the Nankai subduction zone every 90-150 years.

\section{0/09/2004 21:26:53 UTC Usp000d63h}

\section{$11.422^{\circ} \mathrm{N}, 86.665^{\circ} \mathrm{W}$}

\section{7.0 - near the coast of Nicaragua}

\section{Depth 35.0 km}

\section{Electronic Poster Available}

The October 9, 2004, M 7.0 earthquake near the coast of Nicaragua occurred as the result of shallow thrust faulting just east of the Middle America Trench at the interface between the Cocos and Caribbean plates. The northwest-southeast-trending trench marks the boundary where the Cocos plate begins subducting beneath the overriding Caribbean plate at a rate of about $80 \mathrm{~mm} / \mathrm{yr}$.

In addition to interface thrust fault earthquakes, shallow strike-slip earthquakes occur within the deforming crust of the overriding Caribbean plate as well as within the subducting Cocos plate from shallow depths to depths of more than $200 \mathrm{~km}$. The world's largest earthquakes have been interface thrust fault earthquakes, including the 1960 M 9.5 Chilean earthquake and the 1964 M 9.2 Alaskan earthquake. Historically, however, the most damaging Nicaraguan earthquakes have been earthquakes occurring beneath population centers at shallow depths in the Caribbean plate. The 1972 M 6.2 Managua earthquake, for example, destroyed the center of the city and resulted in an estimated 6,000 fatalities.

This region of Central America hosts large earthquakes fairly regularly. Within $400 \mathrm{~km}$ of the October $9^{\text {th }}$ event, there were five other earthquakes of M 7+ over the preceding 40 years. One of the largest and closest of these events was a M 7.7 earthquake in September 1992 roughly $50 \mathrm{~km}$ to the northwest that resulted in hundreds of fatalities and widespread damage, mostly associated with a tsunami generated by that event.

\section{1/11/2004 21:26:41 UTC usp000d85g}

\section{$8^{8.172^{\circ}} \mathrm{S}, 124.856^{\circ} \mathrm{E}$}

\section{7.5 - Kepulauan Alor, Indonesia Depth 10.0 km}

\section{Electronic Poster Available}

The November 11, 2004, M 7.5 earthquake near Kepulauan Alor, Indonesia, occurred as the result of shallow thrust faulting on or near the convergent boundary between the Banda Sea microplate to the north and the Timor microplate to the south. Focal mechanism solutions indicate that rupture occurred on either a steep, near-vertical reverse fault or on a shallow, 
southward-dipping thrust fault. Of these two possible fault orientations, finite-fault modeling of globally recorded seismic data is more consistent with slip on the southward-dipping thrust fault. At the location of the earthquake, the Banda Sea microplate thrusts beneath the Timor microplate to the south at a velocity of about $30 \mathrm{~mm} / \mathrm{yr}$. The two microplates are sandwiched along with other microplates between the larger Sunda, Philippine Sea, Australia, and Pacific plates. The location, depth, and focal mechanism solutions of the November $11^{\text {th }}$ earthquake are consistent with it having occurred on the thrust interface between these two local microplates. A similar earthquake occurred only $20 \mathrm{~km}$ to the west in July 1991, a M 6.9 earthquake that resulted in 23 fatalities and 181 injuries.

While commonly plotted as points on maps, earthquakes of this size are more appropriately described as slip over a larger fault area. Thrust-faulting events of the size of the November 11, 2004, earthquake are typically about $80 \times 40 \mathrm{~km}$ (length $\mathrm{x}$ width); modeling of this earthquake implies dimensions of about 70x50 km, predominantly up-dip and east of the hypocenter.

\section{1/15/2004 09:06:56 UTC usp000d8gx}

\section{$4.679^{\circ} \mathrm{N}, 77.511^{\circ} \mathrm{W}$}

\section{7.2 - Near the west coast of Colombia Depth 15.0 km}

\section{Electronic Poster Available}

The November 15, 2004, M 7.2 earthquake near the west coast of Columbia occurred as the result of shallow thrust faulting at the northernmost end of the Peru-Chile Trench, on or near the plate boundary between the Nazca and South America plates. At the location of the earthquake, the Nazca plate subducts to the east relative to the South America plate at a velocity of about $59 \mathrm{~mm} / \mathrm{yr}$. The location, depth, and focal mechanism solutions of the earthquake are consistent with the event occurring on the thrust interface between the two plates. The M 7.2 earthquake of November 11, 1991, had a very similar location and focal mechanism solution to the November 15, 2004, event; the 1991 earthquake killed two people.

\section{1/22/2004 20:26:23 UTC usp000d8ze $46.694^{\circ} \mathrm{S}, 164.777^{\circ} \mathrm{E}$ \\ M 7.1 - Off the west coast of the South Island, N.Z. \\ Depth 10.0 km}

\section{Electronic Poster Available}

The November 22, 2004, M 7.1 earthquake off the southwest coast of the South Island of New Zealand occurred as the result of reverse faulting on or near the plate boundary interface between the Australia and Pacific plates in the Puysegur subduction zone. Focal mechanism solutions indicate that rupture occurred on either a reverse fault dipping moderately to the southeast, or on a steeper, northwest-dipping fault. At the location of the earthquake, the Australia plate moves northeast with respect to to the Pacific plate at a velocity of about $40 \mathrm{~mm} / \mathrm{yr}$. The main islands of New Zealand straddle the boundary between these two plates and are undergoing a gradual elongation and compression due to these plate motions. Along New Zealand, the plate boundary consists of a transform fault system connecting two subduction zones of opposing convergent directions that lie to the north and south of South Island. Both nodal planes of the focal mechanism solution are consistent with the compressive tectonics of this plate boundary region, though the location of the earthquake slightly west and south of the plate boundary implies that this earthquake was likely an intraplate event.

The November $22^{\text {nd }}$ earthquake occurred in the Fiordland and Puysegur region. This region includes the southwest corner of South Island (Fiordland) and extends offshore to the southwest and covers the Puysegur Trench. Oblique subduction of the Australia plate beneath the Pacific plate occurs along the Puysegur Trench. The subducted plate is moderately dipping in the southern part of the trench and farther to the north, a gradual change in strike of 17 degrees accompanies a steepening in dip of the slab to near-vertical below Fiordland. The exact age and mechanism of this young subduction zone are presently being debated in the scientific community.

Off the south coast of Fiordland, active subduction at the Puysegur Trench produces earthquakes in three areas: within the subducting Australia plate, in the overlying Pacific plate, and at the interface between the plates. The earthquake occurred to the west of the trench in the Australia plate. There are many fault systems in the region, and the particular fault responsible for this recent earthquake is unknown.

Although Fiordland is sparsely populated, some earthquakes in this region are felt by people throughout South Island, such as the M 7.2 thrust earthquake of August 21, 2003. People felt this event as far north as Wellington on North Island and Sydney, Australia. Most of the historical major earthquakes have occurred offshore. For example, on October 12, 1979, a M 7.3 thrust earthquake occurred beneath the Puysegur Trench. None of these events have recorded damage or casualties. 
11/26/2004 02:25:03 UTC

\section{$3.573^{\circ} \mathrm{S}, 135.346^{\circ} \mathrm{E}$}

\section{7.1 - Papua, Indonesia \\ Depth 10.0 km}

\section{Electronic Poster Available}

The November 26, 2004, M 7.1 earthquake near Papua, Indonesia, occurred as the result of shallow, oblique slip on or near the transform faulting plate boundary between the Australia and Sunda plates. Focal mechanism solutions indicate that rupture occurred on either a near-vertical, right-lateral east-west-oriented fault or on a left-lateral, moderately dipping north-striking fault. The earthquake lies near the east-northeast trending boundary between the Birds Head and the Maoke microplates, which accommodates approximately $80 \mathrm{~mm} / \mathrm{yr}$ of left-lateral motion. Surrounding Irian Jaya (the western half of New Guinea), four major tectonic plates (the Australia, Sunda, Philippine Sea, and Caroline plates) sandwich half a dozen proposed microplates. The interactions among these microplates produce all possible styles of faulting. In February 2003, three large earthquakes (M 7.0, M 7.3, and M 6.9) occurred over 3 days in the epicentral area of the November $26^{\text {th }}$ event. There were at least 37 fatalities and more than 600 injured as a result of that sequence.

\section{1/28/2004 18:32:14 UTC usp000d9h1}

\section{$42.995^{\circ} \mathrm{N}, 145.056^{\circ} \mathrm{E}$}

\section{7.0 - Hokkaido, Japan region}

\section{Depth 39.0 km}

\section{Electronic Poster Available}

The November 28, 2004, M 7.0 earthquake near the province of Hokkaido, Japan, occurred as the result of shallow, oblique thrust faulting on or near the plate boundary between the Pacific and North America plates near the bend in the Japan/KurilKamchatka Trench. At the location of the earthquake, the Pacific plate is subducting to the northwest beneath Japan at a velocity of about $80 \mathrm{~mm} / \mathrm{yr}$.

The depth, location, and focal mechanism solutions of this earthquake imply that it occurred as the result of thrust faulting on the plate interface between these two plates. The Pacific plate begins its descent into the mantle at the Kuril Trench, which lies about $160 \mathrm{~km}$ to the southeast of the earthquake. At first, the plate subducts at an extremely low angle, then when it reaches a depth of about $30 \mathrm{~km}$, the angle of subduction steepens to about 30 degrees. In addition to experiencing significant thrust earthquakes that originate on the interface between the plates, eastern Hokkaido experiences great earthquakes (M 8+) that originate from the interior of the subducted Pacific plate. The earthquakes of September 25, 2003, March 4, 1952, and May 16, 1968, were all interface-thrust earthquakes, whereas the earthquake of January 15, 1993, occurred within the interior of the subducted Pacific plate. The January 1993 earthquake was quite damaging, and resulted in at least 2 fatalities and almost 1,000 injured.

\section{2/23/2004 14:59:04 UTC usp000db93}

\section{$50.145^{\circ} \mathrm{S}, 160.365^{\circ} \mathrm{E}$}

\section{8.1 - North of Macquarie Island Depth 10.0 km}

The December 23, 2004, M 8.1 earthquake north of Macquarie Island occurred as the result of shallow strike-slip faulting within the Australia plate in the South Pacific Ocean, about $150 \mathrm{~km}$ to the west of the main Australia-Pacific plate boundary. Focal mechanism solutions indicate that rupture occurred on either a left-lateral south-southeast-striking fault or a right-lateral east-west-oriented fault. Of these two possible fault orientations, finite-fault modeling of globally recorded seismic data is more consistent with slip on the south-southeast-striking (left-lateral) fault. At the location of the earthquake, the Australia plate moves north-northeast (right-lateral transform faulting motion) relative to the Pacific plate at a velocity of about $37 \mathrm{~mm} / \mathrm{yr}$.

This is a region of rapid transitions in plate motion, from convergence at the Hjort Trench (south of the earthquake) to strike-slip motion along the Macquarie Ridge (east of the earthquake), to subduction again just north of the earthquake at the Puysegur Trench. This rapid transition is brought about by the close proximity of this section of the plate boundary to the Australia-Pacific pole of rotation, and is highlighted by earthquakes of both thrust and strike-slip orientation in the region surrounding the December 23, 2004, earthquake. Significant intraplate deformation is also evident within the Australia plate in the immediate vicinity of the December $23^{\text {rd }}$ earthquake, to the west of the Macquarie Ridge. 
While commonly plotted as points on maps, earthquakes of this size are more appropriately described as slip over a larger fault area. Strike-slip events of the size of the December 23, 2004, earthquake are typically about 280x25 km (length x width); modeling of this earthquake implies dimensions of about $140 \times 20 \mathrm{~km}$, predominantly up-dip and south of the hypocenter.

The Australia-Pacific plate boundary south of New Zealand experiences numerous strong earthquakes and has hosted great (M 8+) earthquakes in recent history. In 1989, a M 8.1 earthquake occurred on the Australia:Pacific plate boundary approximately $250 \mathrm{~km}$ south of the December $23^{\text {rd }}$ event.

12/26/2004 00:58:53 UTC

usp000dbed

\section{$3.316^{\circ} \mathrm{N}, 95.854^{\circ} \mathrm{E}$}

\section{9.1 - Off the west coast of northern Sumatra, Indonesia Depth 30.0 km \\ Electronic Poster Available}

The devastating M 9.1 earthquake off the west coast of northern Sumatra on December 26, 2004, occurred as the result of thrust faulting on the interface of the India plate and the Burma microplate. In a period of minutes, the faulting released elastic strains that had accumulated for centuries from ongoing subduction of the India plate beneath the overriding Burma microplate.

In a broad sense, the India and Australia plates move towards the north-northeast with respect to the interior of the Eurasia plate with velocities of about $60 \mathrm{~mm} / \mathrm{yr}$ in the region of the earthquake. This results in oblique convergence at the Sunda Trench, about $200 \mathrm{~km}$ to the southwest of the December $26^{\text {th }}$ earthquake. The oblique motion is partitioned into thrust faulting, which occurs on the interface between the India plate and the Burma microplate and involves slip directed at a large angle to the orientation of the trench, and strike-slip faulting, which occurs on the eastern boundary of the Burma microplate and involves slip directed approximately parallel to the trench. Details of the velocity of the Burma microplate remain to be determined and may, in fact, be clarified by further analysis of the December mainshock and its aftershocks.

Early models of the December $26^{\text {th }}$ mainshock fault displacement differ in many details, but are consistent in implying that fault rupture propagated to the northwest from the epicenter and that substantial fault rupture occurred hundreds of kilometers northwest of the epicenter. The data upon which the modeling is based do not permit confident resolution of the extent of rupture beyond about $500 \mathrm{~km}$ northwest of the mainshock epicenter. The width of the earthquake rupture, measured perpendicular to the Sunda Trench, was about $150 \mathrm{~km}$, and maximum displacement on the fault plane was upwards of $20 \mathrm{~m}$. The sea floor overlying the thrust fault was uplifted by several meters as a result of the earthquake, causing the ensuing tsunami that devastated shores around the Indian Ocean.

The zone of aftershocks of the December $26^{\text {th }}$ earthquake is more than $1,300 \mathrm{~km}$ long. Because aftershocks occur on and very near the fault planes of mainshocks, the length of the aftershock zone suggests that mainshock fault rupture may have extended north of the epicenter by an amount significantly larger than $500 \mathrm{~km}$. However, a great earthquake may also trigger earthquake activity on faults that are distinct from the mainshock fault plane and separated from it by tens or even hundreds of kilometers. Detailed modeling of this earthquake over the months and years following the event, using teleseismic data (that the models discussed here were based on) and data from regional global positioning system (GPS) stations, indicates that significant slip extended over a region up to about $1,500 \mathrm{~km}$ to the north of the epicenter, and that rupture lasted for more than 500 seconds.

This is the third largest earthquake in the world since 1900 and is the largest since the 1964 Prince William Sound, Alaska, earthquake. Since 1900, earthquakes similarly sized or larger than the December 26 th earthquake have been the M 9.01952 Kamchatka earthquake, the M 9.5 1960 Chile earthquake, and the M 9.2 1964 Prince William Sound, Alaska, earthquake. All of these earthquakes, like the December $26^{\text {th }}$ earthquake, were megathrust events, occurring where one tectonic plate subducts beneath another. All produced destructive tsunamis, although fatalities and damage from the December $26^{\text {th }}$ tsunami have far exceeded those caused by tsunamis associated with the earlier earthquakes and was documented nearly worldwide on tide gages.

12/26/2004 04:21:29 UTC

\section{usp000dbg6}

\section{$6.910^{\circ} \mathrm{N}, 92.958^{\circ} \mathrm{E}$}

\section{7.2 - Nicobar Islands, India region \\ Depth 39.2 km}

The December 26, 2004, M 7.2 earthquake near the Nicobar Islands region east of India (northwest of Sumatra) occurred as the result of shallow, oblique thrust faulting near the northern end of the Sunda-Java Trench, defining the boundary between the IndoAustralia and Sunda plates. The location, depth, focal mechanism solutions, and timing of the earthquake (occurring soon after and within the rupture area of the great December 26, 00:58 UTC, M 9.1 Banda-Aceh earthquake) indicate that rupture 
likely occurred on the subduction interface between the two plates. At the location of the event, the IndoAustralia plate moves to the north relative to the Sunda plate at a velocity of about $45-50 \mathrm{~mm} / \mathrm{yr}$.

Even though the Sumatra region frequently experiences moderate to large earthquakes, prior to December 26, 2004, the megathrust in this region had relatively few thrust-faulting earthquakes. In 2002, two events-M 7.4 and M 6.3 - occurred beneath Simeulue Island, just to the south of the subsequent M 9.1 earthquake epicenter. The larger of the two caused at least three fatalities and significant damage to structures on that island.

\section{5: 11 Events}

\section{2/05/2005 12:23:18 UTC usp000dfj2 $5.358^{\circ} \mathrm{N}, 123.209^{\circ} \mathrm{E}$ \\ M 7.1 - Celebes Sea \\ Depth 525.0 km}

The February 5, 2005, M 7.1 Celebes Sea earthquake occurred as a result of deep normal faulting, approximately $525 \mathrm{~km}$ beneath the ocean, $150 \mathrm{~km}$ offshore of the Philippine island of Mindanao. Focal mechanism solutions indicate that rupture occurred on a normal fault dipping either shallowly to the west or steeply to the east. The earthquake occurred within the inclined seismic zone defining the deep limit of the Molucca Sea microplate beneath the Celebes Sea Basin. Slip on a fault aligned with either nodal plane of the focal mechanism solution is consistent with this intraplate setting.

Northeastern Indonesia and southern Philippines are characterized by complex tectonics in which motions of numerous small plates accommodate the large-scale convergence between the Philippine Sea and Sunda plates. In the region of the February $5^{\text {th }}$ earthquake, the Philippine Sea plate moves west-northwest with respect to the Sunda plate at a velocity that various models would place in the 60-110-mm/yr range. Locally, arc-arc collision is occurring between the Sangihe microplate and the Philippine Sea plate, wedging between them the Molucca Sea microplate, which subducts beneath both (to the east and west) and forms an inverted-U-shaped seismic zone. At the location of the February $5^{\text {th }}$ earthquake, the top of the Molucca Sea microplate is at a depth of about $150 \mathrm{~km}$ beneath the Earth's surface. Seismicity within the Molucca Sea microplate is active to depths of approximately $260 \mathrm{~km}$ to the east and $650 \mathrm{~km}$ to the west. The tectonic setting of this region is unique in that it is the only global example of an active arc-arc collision consuming an oceanic basin via subduction in two directions.

Earthquakes that have focal depths greater than $300 \mathrm{~km}$ are commonly termed "deep-focus" earthquakes. Deep-focus earthquakes cause less damage on the ground surface above their foci than similar-magnitude shallow-focus earthquakes, but large deep-focus earthquakes may be felt at great distance from their epicenters. The largest recorded deep-focus earthquake prior to this February 2005 earthquake was a M 8.2 event that occurred at a depth of $630 \mathrm{~km}$ within the subducted Nazca plate beneath South America near the northern Bolivian border in 1994. A larger event has since occurred-namely the M 8.3 earthquake that occurred at a depth of $600 \mathrm{~km}$ within the subducted Pacific plate beneath the Sea of Okhotsk offshore of northeastern Russia in 2013. The M 8.3 Sea of Okhotsk earthquake was felt all over Asia, as far away as Moscow, and across the Pacific Ocean along the western seaboard of the United States (though at distant locations, individuals reporting having felt the event were likely very favorably situated for the perception of small ground motions). The M 8.2 Bolivian deep-focus earthquake in 1994 had similarly been reported by individuals in North America at great distance from the epicenter.

Over the past century, 73 earthquakes with a magnitude of M 7+ have occurred at depths greater than $300 \mathrm{~km}$ globally; two of these were located in the same region as the February 5, 2005, event. The largest was a M 7.7 earthquake in June 1972, more than $200 \mathrm{~km}$ to the southeast and almost $200 \mathrm{~km}$ shallower than the February $5^{\text {th }}$ event.

Historically, this area has hosted several large earthquakes, though most have been shallow. For example, a M 7.7 earthquake occurred on June 11, 1972, approximately $190 \mathrm{~km}$ southeast of the February $5^{\text {th }}$ earthquake. Another M 7.1 earthquake in 1999 occurred $150 \mathrm{~km}$ to the west, which was followed a year later by a M 7.5 earthquake in approximately the same place. More recently and just off the coast of the main island, a M 7.5 earthquake occurred $130 \mathrm{~km}$ northeast of the February $5^{\text {th }}$ earthquake on March 5, 2002. The 2002 earthquake resulted in at least 15 fatalities and caused damage to 800 buildings in southern and central Mindanao. 
03/02/2005 10:42:12 UTC

\section{$6.527^{\circ} \mathrm{S}, 129.933^{\circ} \mathrm{E}$}

\section{7.1 - Banda Sea}

\section{Depth 201.7 km}

\section{Electronic Poster Available}

The March 2, 2005, M 7.1 Banda Sea earthquake occurred as the result of oblique faulting at an intermediate depth, approximately $200 \mathrm{~km}$ beneath the ocean near the Weber Basin. Focal mechanism solutions indicate that rupture occurred on either a near-vertical fault or on a moderately dipping reverse fault. Slip on a fault aligned with either nodal plane is consistent with the intraplate setting of this event. At the location of the earthquake, the Australia plate moves to the north relative to the Sunda plate at a velocity of about $76 \mathrm{~mm} / \mathrm{yr}$. The relative motion between these two major tectonic plates drives the motion of several small microplates that together take up the overall convergence in the region. The March $2^{\text {nd }}$ earthquake occurred in the inclined seismic zone that dips northward from the Timor trough and that marks the position of the subducted Australia plate. Until recently in geologic time, the Australia plate subducted beneath the Timor plate at the Timor trough. Within geologically recent time, northward subduction of Australia beneath the Timor plate has largely ceased, and the northward motion of the Australia plate relative to the Sunda plate is now accommodated substantially by the southward subduction of the Banda Sea plate beneath the Timor plate on the northern boundary of the Timor plate. The subducted Australia plate nonetheless remains intensely seismic, probably because of high stresses that are generated by the distortion of the plate.

Earthquakes like this event, with focal depths between 70 and $300 \mathrm{~km}$, are commonly termed "intermediate-depth" earthquakes. Intermediate-depth earthquakes represent deformation within subducted slabs rather than at the shallow plate interface between subducting and overriding tectonic plates. They typically cause less damage on the ground surface above their foci than is the case with similar-magnitude shallow-focus earthquakes, but large intermediate-depth earthquakes may be felt at great distance from their epicenters. "Deep-focus" earthquakes, those with focal depths greater than $300 \mathrm{~km}$, also occur beneath the Banda Sea to the northwest of the March $2^{\text {nd }}$ event. Earthquakes have been reliably located to depths of about $500 \mathrm{~km}$ in this region.

The tectonically complex region surrounding the Banda Sea experiences large earthquakes fairly regularly. Seven other earthquakes with M 7+ have occurred within $400 \mathrm{~km}$ of the March $2^{\text {nd }}$ event over the preceding 40 years. The largest was a M 7.3 earthquake in December 1992 only $50 \mathrm{~km}$ to the east, with no associated damage or casualties.

\section{3/28/2005 16:09:36 UTC}

\section{usp000dk85}

\section{$2.074^{\circ} \mathrm{N}, 97.013^{\circ} \mathrm{E}$}

\section{8.6 - Northern Sumatra, Indonesia}

\section{Depth 30.0 km}

\section{Electronic Poster Available}

The March 28, 2005, M 8.6 northern Sumatra, Indonesia, earthquake occurred as the result of thrust faulting on the interface of the Australia plate and Sunda plate and was caused by the release of stresses that develop as the Australia plate subducts beneath the overriding Sunda plate. The Australia plate begins its descent into the mantle at the Sunda Trench, which lies to the southwest of the earthquake's epicenter. At this location, the trench is the surface expression of the plate interface between the Australia plate and the Sunda plate.

In the region of the earthquake, the Australia plate moves towards the northeast at a rate of about $50 \mathrm{~mm} / \mathrm{yr}$ relative to the Sunda plate. This results in oblique convergence at the Sunda Trench. The oblique motion is partitioned into thrust faulting, which occurs on the plate interface and which involves slip directed perpendicular to the trench, and strike-slip faulting, which occurs several hundred kilometers northeast of the trench and involves slip directed parallel to the trench. The March $28^{\text {th }}$ earthquake occurred as the result of northeast-oriented thrust faulting.

While commonly plotted as points on maps, earthquakes of this size are more appropriately described as slip over a larger fault area. Thrust-faulting events of the size of the March 28, 2005, earthquake are typically about 340x125 km (length x width); modeling of this earthquake implies dimensions of about 360x200 km, predominantly surrounding the hypocenter, and up-dip to the south.

The March $28^{\text {th }}$ earthquake was likely triggered by stress changes caused by the December 26, 2004 (M 9.1) earthquake. However, it occurred on a segment of the fault 100 miles (160 kilometers) to the southeast of the rupture zone of the M 9.1 Sumatra earthquake. At least 1,000 fatalities and a great deal of damage resulted from the shaking related to the March $28^{\text {th }}$ event; it also spawned a local tsunami, much smaller in size than the devastating tsunami that followed the M 9.1 December 2004 event.

The most recent M 8+ earthquake in the immediate region of this earthquake occurred in 1861 . The 1861 earthquake also generated a regionally destructive tsunami. Another earthquake of similar magnitude occurred farther south in 1833. 
06/13/2005 22:44:33 UTC $19.934^{\circ} \mathrm{S}, 69.028^{\circ} \mathrm{W}$

\section{7.8 - Tarapaca, Chile}

\section{Depth 115.6 km}

\section{Electronic Poster Available}

The June 13, 2005, M 7.8 earthquake near Tarapaca, Chile, occurred as the result of normal faulting at an intermediate depth, approximately $115 \mathrm{~km}$ beneath northern Chile, east of the Peru-Chile Trench where the Nazca plate begins subducting beneath South America. Focal mechanism solutions indicate that rupture occurred on either a steep, north-striking fault or on a shallow, south-striking fault. Of these two possible fault orientations, finite-fault modeling of globally recorded seismic data is more consistent with slip on the south-striking fault. At the location of the earthquake, the Nazca plate subducts beneath the South America plate at a velocity of about $78 \mathrm{~mm} / \mathrm{yr}$ in an east-northeast direction. This earthquake resulted from the release of stresses within the subducting Nazca slab, rather than on the shallower thrust interface between the two plates. The subduction process in this region generates numerous earthquakes and volcanism, and actively builds the Andes Mountains.

Subduction zones produce the biggest earthquakes on the planet. The largest earthquake of the past 100 years, the M 9.5 1960 Chilean earthquake, also occurred in the Peru-Chile subduction zone. The 1960 Chilean earthquake ruptured a 900-km long swath along the Chilean coast about 2,000 km to south of the June 13, 2005, earthquake. The devastating December 26, 2004, Sumatra-Andaman Island's earthquake and tsunami occurred in a subduction zone in the Indian Ocean. Those and others of the very largest subduction zone earthquakes were thrust faulting earthquakes on the interface between the subducting plate and the overriding plate, and much of their seismic energy was the result of faulting at depths of $50 \mathrm{~km}$ and less. The earthquake of June 13, 2005, by contrast, occurred within the subducted Nazca plate at a depth of about $115 \mathrm{~km}$.

Earthquakes like this event, with focal depths between 70 and $300 \mathrm{~km}$, are commonly termed "intermediate-depth" earthquakes. Intermediate-depth earthquakes represent deformation within subducted slabs rather than at the shallow plate interface between subducting and overriding tectonic plates. They typically cause less damage on the ground surface above their foci than is the case with similar-magnitude shallow-focus earthquakes, but large intermediate-depth earthquakes may be felt at great distance from their epicenters. "Deep-focus" earthquakes, those with focal depths greater than $300 \mathrm{~km}$, also occur in the subducted Nazca plate farther east from the Peru-Chile Trench, beneath western Brazil and central Argentina. Earthquakes have been reliably located to depths of about $650 \mathrm{~km}$ in this region.

06/15/2005 02:50:53 UTC

usp000dt25

\section{$41.284^{\circ} \mathrm{N}, 125.983^{\circ} \mathrm{W}$}

\section{7.2 - Off the coast of northern California Depth $16.0 \mathrm{~km}$ \\ Electronic Poster Available}

The June 15, 2005, M 7.2 earthquake off the coast of northern California occurred as the result of shallow strike-slip faulting within a deformed section of the southernmost oceanic crust of the Juan de Fuca plate, commonly called the Gorda plate, west of the Cascadia subduction zone. Focal mechanism solutions indicate that rupture occurred on either a left-lateral northeastsouthwest-striking fault or on a right-lateral southeast-northwest-striking fault. At the location of the earthquake, the Juan de Fuca plate moves to the northeast relative to the North America plate at a velocity of about $30 \mathrm{~mm} / \mathrm{yr}$.

Preliminary analysis of the quake indicates that it resulted from slip on a northeast-striking left-lateral strike-slip fault, a type of mechanism that has been documented for other earthquakes located in the interior of the Gorda plate. This earthquake did not produce a tsunami. Earthquakes with strike-slip mechanisms are less likely to produce tsunamis because they cause relatively little vertical ground displacement.

Earthquakes are common in the Gorda plate, which is subjected to north-south compression due to the northwest-moving Pacific plate that collides with the southern boundary of the Gorda plate along the east-west Mendocino fracture zone. This quake occurred approximately $110 \mathrm{~km}$ west of the epicenter of the November 8, 1980, M 7.2 earthquake. Three other quakes with a magnitude greater than 6 have occurred within an 80-km radius of the epicenter of this quake (August 16 and 17, 1991, and July 24, 1996). 


\section{7/24/2005 15:42:06 UTC usp000dvtc}

\section{$7.909^{\circ} \mathrm{N}, 92.139^{\circ} \mathrm{E}$}

\section{7.2 - Nicobar Islands region, India \\ Depth 16.0 km}

\section{Electronic Poster Available}

The July 24, 2005, M 7.2 earthquake in the Nicobar Islands region occurred as the result of shallow strike-slip faulting in the oceanic crust near the western boundary of the aftershock zone of the devastating Sumatra-Andaman Islands earthquake of December 26, 2004. The aftershock zone of the December $26^{\text {th }}$ earthquake continues to be active and forms a crescent-shaped region extending about 1,200 km north of Sumatra, Indonesia. Focal mechanism solutions for the July $24^{\text {th }}$ event indicate that rupture occurred on either a right-lateral southeast-striking fault or a left-lateral northeast-southwest-striking fault. The event likely occurred within the India plate, below its shallowly dipping subduction zone boundary with the overriding Burma plate, resulting from horizontal displacement of the ground across a nearly vertical fault plane. Slip on a fault aligned with either nodal plane of the focal mechanism solution is consistent with this intraplate setting. This is unlike the thrust fault motion that produced the devastating December $26^{\text {th }}$ earthquake and that occurred on the interface of the eastward-dipping subduction zone. The July $24^{\text {th }}$ event therefore occurred on a different fault than the fault that caused the great Sumatra-Andaman Islands earthquake: however, the two earthquakes are almost certainly related.

A great earthquake can trigger earthquake activity on faults that are distinct from the mainshock fault plane and separated from it by tens or even hundreds of kilometers. A M 7.2 earthquake is considered a major earthquake, but the size of this recent earthquake pales in comparison to the December $26^{\text {th }}$ earthquake. A 7.2 strike-slip earthquake typically ruptures a $15-\mathrm{km}$ by $80-\mathrm{km}$ patch along a fault, whereas the devastating December 26, 2004, earthquake ruptured a patch of fault about 1,200 km long and $200 \mathrm{~km}$ wide.

\section{8/16/2005 02:46:28 UTC usp000dxe2}

\section{$38.251^{\circ} \mathrm{N}, 142.059^{\circ} \mathrm{E}$}

\section{7.2 - Near the east coast of Honshu, Japan Depth 36.0 km}

\section{Electronic Poster Available}

The August 16, 2005, M 7.2 earthquake east of Sendai, Japan, occurred as the result of thrust faulting on or near the subduction zone plate boundary between the Pacific and North America plates. At the location of this earthquake, the Pacific plate moves approximately westward with respect to the North America plate at a velocity of about $83 \mathrm{~mm} / \mathrm{yr}$, and begins its westward descent beneath Japan at the Japan Trench. Note that some authors divide this region into several microplates that together define the relative motions between the larger Pacific, North America and Eurasia plates; these include the Okhotsk and Amur microplates that are part of North America and Eurasia, respectively.

The plate boundary region surrounding the November 14, 2005, earthquake hosts moderate to large earthquakes fairly regularly - 4 events of M 7 or larger have occurred within $400 \mathrm{~km}$ of this earthquake since 1978. These historic events include the M 7.7 earthquake of June 12, 1978, that resulted in at least 22 fatalities and 421 injuries.

09/09/2005 07:26:43 UTC

\section{usp000dz2j}

\section{$4.539^{\circ} \mathrm{S}, 153.445^{\circ} \mathrm{E}$}

\section{7.6 - New Ireland region, Papua New Guinea \\ Depth 90.0 km \\ Electronic Poster Available}

The September 9, 2005, M 7.6 earthquake in the New Ireland region of Papua New Guinea occurred as the result of reverse faulting at an intermediate depth, approximately $90 \mathrm{~km}$ beneath the Pacific Ocean within the subducted lithosphere of the Australia plate between the Solomon Sea Trench to the south and the West Melanesian Trench to the north. Focal mechanism solutions indicate that rupture occurred on either a steep reverse fault or a moderately dipping reverse fault. Finite-fault modeling of globally recorded seismic data for this earthquake is not able to distinguish between these two possibilities. In this region, the Australia plate moves to the east-northeast with respect to the Pacific plate at a velocity of about $100 \mathrm{~mm} / \mathrm{yr}$. At the location of the earthquake, some researchers consider the edges of the Australia and Pacific plates to be divided into several microplates that take up the overall convergence between the two plates, including the Solomon Sea and South Bismark microplates. In 
this context, the September $9^{\text {th }}$ event occurred within the subducted Solomon Sea microplate, deeper than the overlying thrust interface between this microplate and the overriding South Bismark microplate. The Solomon Sea microplate moves slightly faster and more northeasterly with respect to the Pacific plate (and South Bismark microplate) than does the Australia plate due to sea-floor spreading in the Woodlark Basin to the southeast of the September $9^{\text {th }}$ earthquake, facilitating the classic subduction evident beneath New Britain and New Ireland.

Earthquakes like this event, with focal depths between 70 and $300 \mathrm{~km}$, are commonly termed "intermediate-depth" earthquakes. Intermediate-depth earthquakes represent deformation within subducted slabs rather than at the shallow plate interface between subducting and overriding tectonic plates. They typically cause less damage on the ground surface above their foci than is the case with similar-magnitude shallow-focus earthquakes, but large intermediate-depth earthquakes may be felt at great distance from their epicenters. "Deep-focus" earthquakes, those with focal depths greater than $300 \mathrm{~km}$, also occur in the subducted Solomon Sea microplate to the north. Earthquakes have been reliably located to depths of about $500 \mathrm{~km}$ in this region.

The Papua New Guinea region frequently hosts large earthquakes. Over the preceding 40 years, 29 other earthquakes with M 7+ occurred within $400 \mathrm{~km}$ of the September $9^{\text {th }}$ event. One of the largest events was a M 8.0 earthquake in November 2000, about $100 \mathrm{~km}$ to the northwest, that resulted in at least 2 fatalities and left more than 5,000 people homeless.

\section{9/26/2005 01:55:37 UTC usp000e09h}

\section{$5.674^{\circ} \mathrm{S}, 76.409^{\circ} \mathrm{W}$}

\section{7.5 - Northern Peru Depth $115.0 \mathrm{~km}$}

\section{Electronic Poster Available}

The September 26, 2005, M 7.5 northern Peru earthquake occurred as the result of normal faulting at an intermediate depth, approximately $115 \mathrm{~km}$ beneath the surface within the subducted lithosphere of the Nazca plate. Focal mechanism solutions indicate that rupture occurred on either a north- or south-striking, moderately dipping normal fault. Of these two possible fault orientations, finite-fault modeling of globally recorded seismic data is more consistent with slip on the north-striking fault. At the location of the earthquake, the Nazca plate moves to the east relative to the South America plate at a velocity of about $70 \mathrm{~mm} / \mathrm{yr}$, subducting at the Peru-Chile Trench, to the west of the Peruvian coast and the September $26^{\text {th }}$ earthquake. The earthquakes of northern Peru and most of western South America are due to strains generated by this ongoing subduction; at these latitudes, the Nazca plate is seismically active to depths of about $650 \mathrm{~km}$. This earthquake occurred in a segment of the subducted plate that has produced frequent earthquakes with focal depths of 100 to $150 \mathrm{~km}$.

Large intermediate-depth earthquakes are reasonably common in this section of the Nazca slab, and four other M 7+ events have occurred within $300 \mathrm{~km}$ of the September $26^{\text {th }}$ earthquake over the past two decades. A M 7.2 earthquake in 1997, located at a similar depth but $150 \mathrm{~km}$ to the north of the September $26^{\text {th }}$ earthquake, caused only slight damage. Two smaller earthquakes in the early 1990s, a M 5.5 and M 6.9, less than $100 \mathrm{~km}$ to the southwest but much shallower, caused hundreds of injuries.

Earthquakes like this event, with focal depths between 70 and $300 \mathrm{~km}$, are commonly termed "intermediate-depth" earthquakes. Intermediate-depth earthquakes represent deformation within subducted slabs rather than at the shallow plate interface between subducting and overriding tectonic plates. They typically cause less damage on the ground surface above their foci than is the case with similar-magnitude shallow-focus earthquakes, but large intermediate-depth earthquakes may be felt at great distance from their epicenters.

\section{0/08/2005 03:50:40 UTC usp000e12e $34.493^{\circ} \mathrm{N}, 73.629^{\circ} \mathrm{E}$ \\ M 7.6 - Pakistan \\ Depth 26.0 km}

\section{Electronic Poster Available}

The October 8, 2005, M 7.6 Pakistan earthquake occurred as the result of shallow reverse faulting near the convergent boundary between the India and Eurasia plates. Focal mechanism solutions indicate that rupture occurred on either a steep southeast-striking reverse fault or a moderately dipping northwest-striking reverse fault. Of these two possible fault orientations, finite-fault modeling of globally recorded seismic data is more consistent with slip on the northwest-striking fault. At the location of the earthquake, the India subcontinent moves northward at a velocity of about $40 \mathrm{~mm} / \mathrm{yr}$, colliding with Eurasia. Earthquakes and active faults in northern Pakistan and adjacent parts of India and Afghanistan are the direct result of this collision. The boundary also produces the highest mountain peaks in the world, including the Himalayan, the Karakoram, the Pamir, and the Hindu Kush Ranges. As the India plate moves northward, it is being subducted or pushed beneath the Eurasia plate. 
Much of the compressional motion between these two colliding plates has been and continues to be accommodated by slip on a suite of major thrust faults that are at the Earth's surface in the foothills of the mountains and dip north-northeastward beneath the ranges. These include the Main Frontal Thrust, the Main Central Thrust, the Main Boundary Thrust, and the Main Mantle Thrust. These faults have a sinuous trace as they arc across the foothills in northern India and into northern Pakistan. In detail, the modern active faults are actually a system of faults composed of a number of individual fault traces. In the rugged mountainous terrain, it is difficult to identify and map all of the individual thrust faults, but the overall tectonic style of the modern deformation is clear in the area of the earthquake; north- and northeast-directed compression is producing thrust faulting. Near the city of Muzaffarabad, about $10 \mathrm{~km}$ southwest of the earthquake epicenter, active thrust faults that strike northwest-southeast have deformed and warped alluvial-fan surfaces of Pleistocene age into anticlinal ridges. The strike and dip direction of these thrust faults is compatible with the style of faulting indicated by the focal mechanism solutions from the nearby October 8, 2005, M 7.6 earthquake.

While commonly plotted as points on maps, earthquakes of this size are more appropriately described as slip over a larger fault area. Reverse-faulting events of the size of the October 8, 2005, earthquake are typically about 90x40 km (length $\mathrm{x}$ width); modeling of this earthquake implies dimensions of about $70 \times 35 \mathrm{~km}$, predominantly up-dip of the hypocenter.

Few large earthquakes have occurred in the immediate vicinity of the October $8^{\text {th }}$ event in recent history, though several have occurred just over $200 \mathrm{~km}$ to the northwest in northeastern Afghanistan, four with M 7 and greater over the preceding 40 years. The most recent event, one of the largest, was a M 7.4 earthquake in March 2002 that resulted in at least 150 fatalities, several injuries, and 400 houses being damaged or destroyed by a landslide that dammed and flooded the Surkundara Valley.

\section{1/14/2005 21:38:51 UTC usp000e462}

\section{$38.101^{\circ} \mathrm{N}, 144.925^{\circ} \mathrm{E}$}

\section{7.0 - Off the east coast of Honshu, Japan \\ Depth 11.0 km}

The November 14, 2005, M 7.0 earthquake east of Sendai, Japan, occurred as the result of shallow normal faulting within the oceanic lithosphere of the Pacific plate, approximately $90 \mathrm{~km}$ east of the Japan Trench that marks the location where the Pacific plate begins its subduction beneath Japan. Focal mechanism solutions indicate that rupture occurred on either a north- or south-striking, moderately dipping normal fault. Slip on a fault aligned with either nodal plane is consistent with this intraplate setting. At the location of the earthquake, the Pacific plate moves approximately westward with respect to the North America plate at a velocity of about $83 \mathrm{~mm} / \mathrm{yr}$. Note that some authors divide this plate boundary region into several microplates that together define the relative motions between the larger Pacific, North America and Eurasia plates; these include the Okhotsk and Amur microplates that are part of North America and Eurasia, respectively.

The plate boundary region surrounding the November 14, 2005 earthquake hosts moderate to large earthquakes fairly regularly - 10 events of M 7 or larger have occurred within $400 \mathrm{~km}$ of this earthquake since 1973 . These historic events include the M 7.2 earthquake that occurred $250 \mathrm{~km}$ east on the subduction zone plate boundary earlier in 2005, as well as the M 7.7 earthquake of June 12, 1978 (also likely a plate interface event) that resulted in at least 22 fatalities and 421 injuries.

\section{6: 11 Events}

\section{1/02/2006 06:10:49 UTC usp000e7dd $60.807^{\circ} \mathrm{S}, 21.474^{\circ} \mathrm{W}$}

\section{7.4 - East of the South Sandwich Islands \\ Depth 13.0 km}

The January 2, 2006, M 7.4 South Sandwich Islands earthquake occurred as the result of shallow transform faulting in the South Atlantic Ocean. Focal mechanism solutions indicate that rupture occurred on either an east-west, left-lateral or a northsouth, right-lateral strike-slip fault at shallow oceanic lithosphere depths $(13 \mathrm{~km})$. At the location of the earthquake, the South America plate translates eastward (left-lateral motion) with respect to the Antartica plate at a velocity of about $14 \mathrm{~mm} / \mathrm{yr}$. The earthquake occurred about $300 \mathrm{~km}$ east of a complex plate triple junction between the South America, Antarctica, and Scotia plates and close to the America-Antarctic Ridge that represents the South America:Antarctica boundary. Given the strike-slip nature and location of the event, the earthquake likely resulted from left-lateral (east-west oriented) relative motion between the South America and Antarctica plates. 
Several large earthquakes have occurred along this portion of the plate boundary, including events of M 7.2 in October 1983, close to the aforementioned triple junction, and M 7.0 in October 1973, $20 \mathrm{~km}$ north of the January 2, 2006, earthquake. Due to the remoteness of this location, none of these events are known to have caused any associated fatalities or damage.

\section{1/02/2006 22:13:40 UTC usp000e7fo $19.926^{\circ} \mathrm{S}, 178.178^{\circ} \mathrm{W}$ \\ M 7.2 - Fiji region \\ Depth 582.9 km}

The January 2, 2006, M 7.2 earthquake in the region of Fiji occurred as the result of deep normal faulting approximately $580 \mathrm{~km}$ beneath the South Pacific Ocean and roughly $400 \mathrm{~km}$ west of the Tonga Trench, which defines the location where Pacific plate lithosphere begins its westward subduction beneath Australia. Focal mechanism solutions indicate that rupture occurred on either a steep, northeast-striking fault, or on a shallow, west-northwest-striking fault. Slip on a fault of either orientation would accommodate the down-dip extension of the Pacific slab that is implied by the normal-component of the faulting solution. At the location of the earthquake, the Pacific plate moves westward relative to the Australia plate at a velocity of about $78 \mathrm{~mm} / \mathrm{yr}$. The eastern edge of the Australia plate may itself be viewed as a collection of microplates whose relative motions help to accommodate the overall Pacific-Australia convergence and associated back-arc spreading.

Earthquakes in this region mostly occur on the thrust fault boundary between the Australia and Pacific plates (at shallow depths), within the Pacific plate (at shallow-, intermediate-, and deep-focus depths), and within and on the boundaries of the small microplates that together comprise the eastern edge of the Australia plate. The location, depth, and mechanism of this earthquake indicate that it occurred within the interior of the subducted Pacific plate at depth. This subduction zone frequently hosts large-magnitude earthquakes, and is one of the most active regions on the planet seismically. Over the past 30 years, 12 events of M 7 or larger have occurred within $400 \mathrm{~km}$ of the January $2^{\text {nd }}$ earthquake, including the July 15, 2004, M 7.1 event, which occurred approximately $200 \mathrm{~km}$ north and also resulted in no fatalities.

Earthquakes that have focal depths greater than $300 \mathrm{~km}$ are commonly termed "deep-focus" earthquakes. Deep-focus earthquakes cause less damage on the ground surface above their foci than similar-magnitude shallow-focus earthquakes, but large deep-focus earthquakes may be felt at great distance from their epicenters. The largest recorded deep-focus earthquake prior to this January 2006 earthquake was a M 8.2 event that occurred at a depth of $630 \mathrm{~km}$ within the subducted Nazca plate beneath South America near the northern Bolivian border in 1994. A larger event has since occurred-namely the M 8.3 earthquake that occurred at a depth of $600 \mathrm{~km}$ within the subducted Pacific plate beneath the Sea of Okhotsk offshore of northeastern Russia in 2013. The M 8.3 Sea of Okhotsk earthquake was felt all over Asia, as far away as Moscow, and across the Pacific Ocean along the western seaboard of the United States (though at distant locations, individuals reporting having felt the event were likely very favorably situated for the perception of small ground motions). The M 8.2 Bolivian deep-focus earthquake in 1994 had similarly been reported by individuals in North America at great distance from the epicenter.

Over the past century, 74 earthquakes with a magnitude of M 7+ have occurred at depths greater than $300 \mathrm{~km}$ globally; 23 of these were located in the same region as January $2^{\text {nd }}$ event. The largest nearby event at these depths was a M 7.7 earthquake in August 2002, just $200 \mathrm{~km}$ to the southwest and nearly at the same depth as the January $2^{\text {nd }}$ event.

\section{1/27/2006 16:58:53 UTC usp000e8ys}

\section{$5.842^{\circ} \mathrm{S}, 128.093^{\circ} \mathrm{E}$}

\section{7.6 - Banda Sea}

Depth $397.0 \mathrm{~km}$

\section{Electronic Poster Available}

The January 27, 2006, M 7.6 Banda Sea earthquake occurred as the result of deep oblique normal faulting approximately $397 \mathrm{~km}$ beneath the Banda Sea, in the tectonically complex region of southeastern Indonesia. Here, the overall convergence between the Australia and Sunda plates is accommodated by the relative motions of numerous small microplates, including the Banda Sea and Timor microplates local to this event. Focal mechanism solutions for the earthquake indicate that rupture occurred on either a northeast or south-southeast-striking, moderately dipping normal fault. Slip on a fault of either orientation would accommodate the downdip extension of the Australia slab that is implied by the normal-component of the faulting solution. At the location of the event, the Australia plate moves northward relative to the Sunda plate at a velocity of about $70 \mathrm{~mm} / \mathrm{yr}$. The earthquake occurred in the inclined seismic zone that dips northward from the Timor trough and that marks the position of the subducted Australia plate at depth.

Until recently in geologic time, the Australia plate subducted beneath the Timor microplate at the Timor trough. Within geologically recent time, northward subduction of Australia beneath the Timor plate has largely ceased, and the northward motion 
of the Australia plate relative to the Sunda plate is now accommodated substantially by the southward subduction of the Banda Sea microplate beneath the Timor microplate on the northern boundary of the Timor microplate. The subducted Australia plate nonetheless remains intensely seismic, probably because of high stresses that are generated by the distortion of the slab at depth.

The tectonically complex region surrounding the Banda Sea experiences large earthquakes fairly regularly. Eight other M 7 or larger earthquakes have occurred within $400 \mathrm{~km}$ of the January $27^{\text {th }}$ event over the preceding 40 years. The largest was a M 7.3 earthquake in December 1992, nearly $200 \mathrm{~km}$ to the southeast, with no associated damage or casualties.

Earthquakes that have focal depths greater than $300 \mathrm{~km}$ are commonly termed "deep-focus" earthquakes. Deep-focus earthquakes cause less damage on the ground surface above their foci than similar-magnitude shallow-focus earthquakes, but large deep-focus earthquakes may be felt at great distance from their epicenters. The largest recorded deep-focus earthquake prior to this January 2006 earthquake was a M 8.2 event that occurred at a depth of $630 \mathrm{~km}$ within the subducted Nazca plate beneath South America near the northern Bolivian border in 1994. A larger event has since occurred-namely the M 8.3 earthquake that occurred at a depth of $600 \mathrm{~km}$ within the subducted Pacific plate beneath the Sea of Okhotsk offshore of northeastern Russia in 2013. The M 8.3 Sea of Okhotsk earthquake was felt all over Asia, as far away as Moscow, and across the Pacific Ocean along the western seaboard of the United States (though at distant locations, individuals reporting having felt the event were likely very favorably situated for the perception of small ground motions). The M 8.2 Bolivian deep-focus earthquake in 1994 had similarly been reported by individuals in North America at great distance from the epicenter.

Over the past century, 74 earthquakes with a magnitude of M 7+ have occurred at depths greater than $300 \mathrm{~km}$ globally; 7 of these were located in the same region as the January 27, 2006, event. The largest nearby event at these depths was a M 7.9 earthquake in June 1996, several hundred kilometers to the southwest and $210 \mathrm{~km}$ deeper than the January $27^{\text {th }}$ event. The June 1996 event resulted in only minor damage at Kupang, Indonesia.

02/22/2006 22:19:07 UTC usp000eamh

\section{$21.259^{\circ} \mathrm{S}, 33.480^{\circ} \mathrm{E}$}

\section{7.0 - Mozambique \\ Depth 11.0 km}

\section{Electronic Poster Available}

The February 22, 2006, M 7.0 Mozambique earthquake was the result of shallow normal faulting on or near the boundary between the Africa (Nubia) and Somalia plates, near the southern end of the East African Rift system. Focal mechanism solutions indicate that rupture occurred on either a northwest or south-striking, moderately dipping normal fault. Finite-fault modeling of satellite data and geological field mapping both indicate that rupture occurred on a south-striking, steeply westwarddipping normal fault. At the location of the earthquake, the Somalia plate moves to the east relative to the Africa (Nubia) plate at a velocity of about $6 \mathrm{~mm} / \mathrm{yr}$.

The East African Rift system is a diffuse zone of crustal extension that passes through eastern Africa from Djibouti and Eritrea in the north to Malawi and Mozambique in the south and which constitutes the boundary between the Somalia and Africa plates. The Victoria and Rovuma microplates also help to accommodate the dominantly divergent (extensional) tectonics of the rift system. The largest earthquake to occur in the rift since 1900 had a magnitude of about 7.3, and was located just east of Lake Tanganyika in Tanzania, more than 1,000 km north of the February 22, 2006, earthquake. Most earthquakes within the East African Rift system occur as the result of either normal or strike-slip faulting.

\section{4/20/2006 23:25:02 UTC usp000ef1h $61.075^{\circ} \mathrm{N}, 167.085^{\circ} \mathrm{E}$}

\section{7.6 - Koryakia, Russia \\ Depth $22.0 \mathrm{~km}$}

\section{Electronic Poster Available}

The April 20, 2006, M 7.6 earthquake near Koryakia, Russia, occurred as the result of shallow reverse faulting in northeastern Russia several hundred kilometers north of the intersection between the Aleutian and Kuril-Kamchatka Trenches. Focal mechanism solutions indicate that rupture occurred on either a northeast- or southwest-striking, moderately dipping reverse fault. Of these two possible fault orientations, finite-fault modeling of globally recorded seismic data is more consistent with slip on the southwest-striking fault. The Koryakia earthquake occurred in sparsely populated northeastern Russia, directly north-northeast of the Kamchatka Peninsula. The earthquake occurred in a complicated geological setting where the configuration and interaction of the tectonic plates between northeastern Asia and northwestern North America are poorly understood. Recent models of the tectonic plates in eastern Russia show that the earthquake occurred near the junction of two 
plates. These are (1) the Okhotsk plate, which includes the Sea of Okhotsk, the Kamchatka Peninsula, and northern Japan, and (2) the extreme northwestern margin of the North America plate. Some evidence indicates that a third plate, the Bering plate, may be present and may play a role in the regional tectonics, but this plate is poorly defined with uncertain boundaries.

Geologically, northeastern Russia in the vicinity of the Koryakia earthquake is composed of a sequence of volcanic island arcs that have been attached or accreted to the margin of a continent. In addition, about 65-160 million years ago, sedimentary basins formed in the region, and magma intruded the crust and erupted onto it as volcanoes. The boundaries between accreted island arcs are commonly large faults that, under suitable conditions, might be reactivated, resulting in earthquakes. Because many of these old faults formed during the accretion process, it is difficult to determine which, if any of them, ruptured to cause the Koryakia earthquake.

Current models of plate interactions in northeastern Russia indicate that the region is being squeezed in a southeastnorthwest direction, which causes shortening at a rate that might be only a few millimeters per year. This southeast-northwest direction of long-term shortening is consistent with the focal mechanism solution of the Koryakia earthquake, which shows that shortening produced thrust movement on faults that are oriented in a northeast-southwest direction.

While commonly plotted as points on maps, earthquakes of this size are more appropriately described as slip over a larger fault area. Reverse-faulting events of the size of the April 20, 2006, earthquake are typically about 90x45 km (length x width); modeling of this earthquake implies dimensions of about $120 \times 30 \mathrm{~km}$, predominantly up-dip to the north of the hypocenter.

This M 7.6 event was followed approximately 3 minutes later by a M 6.1 aftershock. The only other event of M $6+$ within $400 \mathrm{~km}$ of the April $20^{\text {th }}$ event over the preceding century was a M 6.6 earthquake in March 1991, just $6 \mathrm{~km}$ to the south.

\section{5/03/2006 15:26:40 UTC usp000eg5g $20.130^{\circ} \mathrm{S}, 174.164^{\circ} \mathrm{W}$ \\ M 8.0 - Tonga \\ Depth 55.0 km \\ Electronic Poster Available}

The May 3, 2006, M 8.0 Tonga earthquake occurred as the result of reverse faulting less than $100 \mathrm{~km}$ west of the Tonga Trench in the South Pacific Ocean. Focal mechanism solutions indicate that rupture occurred on either a steeply dipping reverse fault or on a shallowly dipping thrust fault. Of these two possible fault orientations, finite-fault modeling of globally recorded seismic data is more consistent with slip on the shallowly dipping thrust fault. At the location of the earthquake, the Pacific plate subducts westward beneath the Australia plate at velocity of about $77 \mathrm{~mm} / \mathrm{yr}$. The eastern edge of the Australia plate may itself be viewed as a collection of microplates whose relative motions help to accommodate the overall Pacific-Australia convergence and associated back-arc spreading.

The broad-scale Australia-Pacific plate boundary is one of the most active in the world. Earthquakes occur on the thrust fault boundary between the Australia and Pacific plates, within the Pacific plate, and within and on the boundaries of the small microplates that together comprise the eastern edge of the Australia plate. On the basis of currently available information (in particular, the depth of the event relative to the local subduction thrust interface), we infer that the earthquake of May 3, 2006, occurred within the subducted Pacific plate, rather than on the overlying plate boundary between the Pacific and Australia plates.

While commonly plotted as points on maps, earthquakes of this size are more appropriately described as slip over a larger fault area. Reverse-faulting events of the size of the May 3, 2006, earthquake are typically about $155 \mathrm{x} 65 \mathrm{~km}$ (length $\mathrm{x}$ width); modeling of this earthquake implies dimensions of about $100 \times 70 \mathrm{~km}$, predominantly surrounding the hypocenter, and to the northeast.

The subduction zone surrounding Tonga and Fiji hosts large earthquakes quite regularly. Over the preceding 40 years, nine other events of M 7 or larger have occurred within $400 \mathrm{~km}$ of the May $3^{\text {rd }}$ event. The largest was a M 7.8 earthquake in January 2000, about $200 \mathrm{~km}$ to the north that had no recorded damage or casualties.

\section{5/16/2006 10:39:23 UTC usp000eh87}

\section{$31.527^{\circ} \mathrm{S}, 179.303^{\circ} \mathrm{W}$}

\section{7.4 - Kermadec Islands region \\ Depth 152.0 km \\ Electronic Poster Available}

The May 16, 2006, M 7.4 earthquake in the Kermadec Islands region occurred as the result of reverse faulting at an intermediate depth, approximately $152 \mathrm{~km}$ beneath the South Pacific Ocean, less than $200 \mathrm{~km}$ west of the Kermadec Trench. Focal mechanism solutions indicate that rupture occurred on either a steeply dipping reverse fault or a shallowly dipping thrust 
fault. At the location of the earthquake, the Pacific plate subducts westward relative to the Australia plate at a velocity of about $55 \mathrm{~mm} / \mathrm{yr}$. The eastern edge of the Australia plate may itself be viewed as a collection of microplates whose relative motions help to accommodate the overall Pacific-Australia convergence and associated back-arc spreading.

Earthquakes like this event, with focal depths between 70 and $300 \mathrm{~km}$, are commonly termed "intermediate-depth" earthquakes. Intermediate-depth earthquakes represent deformation within subducted slabs rather than at the shallow plate interface between subducting and overriding tectonic plates. They typically cause less damage on the ground surface above their foci than is the case with similar-magnitude shallow-focus earthquakes, but large intermediate-depth earthquakes may be felt at great distance from their epicenters. "Deep-focus" earthquakes, those with focal depths greater than $300 \mathrm{~km}$, also occur in the subducted Pacific plate beneath the Lau Ridge and South Fiji Basin to the northwest. Earthquakes have been reliably located to depths of about $650 \mathrm{~km}$ in this region.

Earthquakes in this region occur on the subduction thrust boundary between the Australia and Pacific plates, within the subducting Pacific plate, and within and on the boundaries of the small microplates that together compose the eastern edge of the Australia plate. On the basis of currently available information, we infer that the earthquake of May 16, 2006, occurred within the subducted Pacific plate beneath the overriding eastern edge of the Australia plate. Slip on a fault aligned with either nodal plane of the focal mechanism solution is consistent with this intraplate setting.

The broad-scale Australia-Pacific plate boundary is one of the most active in the world. Within $400 \mathrm{~km}$ of the May $16^{\text {th }}$ event, 13 other earthquakes of M 7 or larger have occurred over the preceding century. The largest was a M 8.0 earthquake in January 1976, $375 \mathrm{~km}$ to the northeast, with no recorded damage or casualties.

\section{7/17/2006 08:19:26 UTC usp000ensm \\ $9.222^{\circ} \mathrm{S}, 107.320^{\circ} \mathrm{E}$}

\section{7.7 - South of Java, Indonesia \\ Depth 20.0 km \\ Electronic Poster Available}

The July 17, 2006, M 7.7 earthquake south of Java occurred as the result of shallow thrust faulting on or near the boundary between the Australia and Sunda plates, $50 \mathrm{~km}$ to the north of the Sunda-Java Trench that marks the sea-floor expression of this plate boundary. At the location of the earthquake, the Australia plate moves north-northwest relative to the Sunda plate, subducting at a velocity of about $59 \mathrm{~mm} / \mathrm{yr}$ to progressively greater depths beneath Java and north of Java. The earthquake occurred on the shallow part of the plate boundary.

The region of the plate boundary between the Australia and Sunda plates is seismically highly active. From preliminary results, it appears that the July $17^{\text {th }}$ earthquake is similar to the M 7.8 Java earthquake of June 2, 1994, which produced a tsunami that had a maximum run-up height of $13 \mathrm{~m}$ and resulted in more than 200 fatalities. That earthquake occurred south of Java about $600 \mathrm{~km}$ east-southeast of the July $17^{\text {th }}$ earthquake, also as a result of thrust faulting on the shallow plate boundary. Events like these, which produce disproportionately large tsunamis given their moment magnitude, have been termed "tsunami earthquakes." On August 20, 1977, a M 8.3 normal-fault earthquake occurred within the Australia plate about 1,200 km eastsoutheast of the July $17^{\text {th }}$ earthquake, producing a tsunami that had a maximum run-up height of $15 \mathrm{~m}$ and resulted in nearly 200 fatalities. The M 6.3 Yogyakarta earthquake on May 26, 2006, a shallow rupture in the overriding Sunda plate near the Java coastline, $350 \mathrm{~km}$ northeast of the July 17, 2006, event, devastated the local population, causing more than 5,000 fatalities, nearly 40,000 injuries, and major damage.

\section{8/20/2006 03:41:48 UTC usp000erc2 $61.006^{\circ} \mathrm{S}, 34.391^{\circ} \mathrm{W}$}

\section{7.0 - Scotia Sea \\ Depth 13.0 km}

\section{Electronic Poster Available}

The August 20, 2006, M 7.0 Scotia Sea earthquake occurred as the result of shallow transform faulting on or near the plate boundary between the Antarctica and Scotia plates in the southern Atlantic Ocean. Focal mechanism solutions indicate that rupture occurred on either an east-west left-lateral fault or a right-lateral north-striking fault - the former plane aligns with the local plate boundary system. At the location of the earthquake, the Antarctica plate moves approximately eastward (left-lateral) relative to the Scotia plate at a velocity of about $7 \mathrm{~mm} / \mathrm{yr}$. The boundary between these two plates is predominantly strike-slip. There does not appear to be any north-south compression of the small Scotia plate as it twists between the larger Antarctica and South America plates. However, pure strike-slip earthquakes do not represent all the motion between the Scotia and Antarctic 
plates. Partitioning occurs on one or both of the Scotia Sea boundaries and modeled motions are consistent with the existence of a rigid Scotia plate.

Beyond the eastern end of the Scotia plate, the Sandwich microplate is moving rapidly eastward, at rates from 65 to $90 \mathrm{~mm} / \mathrm{yr}$. This forms an eastern flank of the spreading system behind the South Sandwich Arc. There are no land-based observations within the Scotia Sea or Sandwich plates to measure plate motion; all reported plate motions are derived from remote earthquake recordings. Six earthquakes of M 6 or larger have occurred within $400 \mathrm{~km}$ of the August $20^{\text {th }}$ event over the preceding 40 years. However, due to the remote location of these events far from population centers that might be vulnerable to earthquake shaking, none have associated damage or casualties.

11/15/2006 11:14:13 UTC Usp000exfn

\section{$46.607^{\circ} \mathrm{N}, 153.230^{\circ} \mathrm{E}$}

\section{8.3 - Kuril Islands}

\section{Depth 10.0 km}

\section{Electronic Poster Available}

The November 15, 2006, M 8.3 Kuril Islands earthquake occurred as the result of thrust faulting on the boundary between the Pacific plate and the Okhotsk microplate (part of the broader North America plate). At the location of the earthquake, the Pacific plate moves northwest relative to the Okhotsk microplate at a velocity of about $90 \mathrm{~mm} / \mathrm{yr}$. The Pacific plate subducts beneath the Okhotsk microplate at the Kuril Trench and becomes progressively deeper to the northwest, remaining seismically active to a depth of $680 \mathrm{~km}$. The November $15^{\text {th }}$ mainshock occurred at shallow depth within about $80 \mathrm{~km}$ of the trench axis.

While commonly plotted as points on maps, earthquakes of this size are more appropriately described as slip over a larger fault area. Thrust-faulting events of the size of the November 15, 2006, earthquake are typically about 230x90 km (length x width); modeling of this earthquake implies dimensions of about $260 \times 80 \mathrm{~km}$, predominantly up-dip and to the northeast of the hypocenter.

The November $15^{\text {th }}$ earthquake is the largest earthquake to have occurred in the central Kuril Islands since the early $20^{\text {th }}$ century. A central Kuril Islands earthquake in 1915 is estimated to have had a magnitude of about 8. The central Kuril Islands commonly experiences one or more events of $\mathrm{M} 6+$ in a decade. To the southwest, the southern Kuril Islands chain experienced a M 8.5 earthquake in 1963. To the northeast, a M 9 earthquake occurred offshore of Kamchatka in 1952. No damage or casualties have been recoreded in association with these earthquakes.

\section{2/26/2006 12:26:21 UTC usp000f114}

\section{$21.825^{\circ} \mathrm{N}, 120.538^{\circ} \mathrm{E}$}

\section{7.1 - Taiwan region Depth $10.0 \mathrm{~km}$}

\section{Electronic Poster Available}

The December 26, 2006, M 7.1 Taiwan region earthquake occurred in a zone of tectonic transition along the north-south boundary between the Eurasia plate and the Philippine Sea plate, off the south coast of Taiwan. Focal mechanism solutions indicate that rupture occurred as normal faulting on either steeply dipping fault or on a shallowly dipping fault. At the location of the earthquake, the Eurasia plate moves east-southeast with respect to the Philippine Sea plate at a velocity of about $80 \mathrm{~mm} / \mathrm{yr}$. Along the plate boundary south of Taiwan, the Eurasia plate is oceanic lithosphere, and convergence is mostly accommodated by the subduction of the Eurasia plate beneath the Philippine Sea plate. The subducted Eurasia plate is seismically active to depths of about $200 \mathrm{~km}$ offshore of southeastern Taiwan, to the east-southeast of the December $26^{\text {th }}$ earthquake. North along the plate boundary from southwestern Taiwan to northern Taiwan, by contrast, the Eurasia plate is buoyant continental lithosphere that resists subduction, and a significant fraction of plate convergence is accommodated by intense compressional deformation of the Earth's crust rather than by subduction of one plate beneath the other. A predominantly strike-slip faulting earthquake of M 6.9 (12:34 UTC) occurred only 8 minutes after this M 7.1 event (12:26 UTC).

The normal-faulting focal mechanism solution of the 12:26 UTC event suggests that it occurred as the result of intraplate stresses within the subducting Eurasia plate. Normal-faulting focal mechanism solutions are commonly observed in the shallow parts of subducting plates; the causative stresses are generated by the bending of the subducting plates. A normal-fault focal mechanism solution is not consistent with the earthquake resulting from the result of shallow compressional deformation between two converging plates which each consist of buoyant lithosphere. Slip on a fault aligned with either nodal plane of the focal mechanism solution is consistent with this intraplate setting. 
Presently available evidence does not permit a confident statement on the whether the earthquake at 12:34 UTC occurred as the result of shallow deformation caused by convergence between two plates consisting of buoyant lithosphere or instead occurred as the result of deeper deformation within a subducted and deformed Eurasia plate. The style of faulting preliminarily inferred for the event at 12:34 UTC - right-lateral strike-slip faulting on a northeast-striking fault or left-lateral faulting on a north-northwest-striking fault - would be consistent with the style of faulting that has been observed at the surface in southwestern Taiwan and that helps accommodate the mutual convergence of buoyant Eurasia lithosphere and Philippine Sea lithosphere. It is possible, however, that this style of faulting could also occur as the result of intraplate stresses within the subducting Eurasia plate, beneath its boundary with the Philippine Sea plate.

The region surrounding Taiwan hosts frequent large earthquakes, with 10 earthquakes of magnitude 7+ within $400 \mathrm{~km}$ of the December $26^{\text {th }}$ event over the preceding 40 years. The largest of these events was a M 7.7 earthquake in September 1999, roughly $200 \mathrm{~km}$ to the north, in the middle of the island of Taiwan (the Chi-Chi earthquake). That event resulted in at least 2,297 fatalities and 8,700 injuries, and left over half a million people homeless. Damage from large-scale subsidence and resulting landslides contributed to an estimated cost of $\$ 14$ billion.

\section{7: 18 Events}

\section{1/13/2007 04:23:21 UTC usp000ł2ab}

\section{$46.272^{\circ} \mathrm{N}, 154.455^{\circ} \mathrm{E}$}

\section{8.1 - East of the Kuril Islands}

\section{Depth 10.0 km}

\section{Electronic Poster Available}

The January 13, 2007, M 8.1 Kuril Islands earthquake occurred as the result of shallow normal faulting within the lithosphere of the Pacific plate. The epicenter of this event lies just east of the Kuril Trench, which marks the sea-floor expression of the plate boundary between the Pacific plate and the Okhotsk microplate (which is in turn part of the broader North America plate). Focal mechanism solutions indicate that rupture occurred on either an east-striking or southwest-striking, moderately dipping normal fault. Of these two possible fault orientations, finite-fault modeling of globally recorded seismic data is more consistent with slip on the southwest-striking fault. At the location of the earthquake, the Pacific plate moves northwest relative to the Okhotsk plate at a velocity of about $90 \mathrm{~mm} / \mathrm{yr}$, subducting at the Kuril Trench and becoming progressively deeper to the northwest, remaining seismically active to a depth of $680 \mathrm{~km}$.

While commonly plotted as points on maps, earthquakes of this size are more appropriately described as slip over a larger fault area. Normal-faulting events of the size of the January 13, 2007, earthquake are typically about 150x50 km (length x width); modeling of this earthquake implies similar dimensions, predominantly surrounding and down-dip of the hypocenter.

The location of the January $13^{\text {th }}$ earthquake lies approximately $95 \mathrm{~km}$ east-southeast of a M 8.3 earthquake that occurred on November 15, 2006. Immediately following that 2006 event, aftershocks began occurring in the epicentral region of this subsequent January 13, 2007, earthquake, leading up to this rupture 2 months later. The November $15^{\text {th }}$ earthquake is the largest event to have occurred in the central Kuril Islands since the early $20^{\text {th }}$ century. The central Kuril Islands commonly experience one or more events of M 6+ in a decade. A central Kuril Islands earthquake in 1915 is estimated to have had a magnitude of about 8. To the southwest, the southern Kuril Islands chain experienced a M 8.5 earthquake in 1963. To the northeast, a M 9 earthquake occurred offshore of Kamchatka in 1952. No damage or casualties have been recorded in association with these earthquakes.

\section{1/21/2007 11:27:45 UTC usp000ł34b}

\section{$1.222^{\circ} \mathrm{N}, 126.395^{\circ} \mathrm{E}$}

\section{7.5 - Molucca Sea}

\section{Depth 22.0 km}

\section{Electronic Poster Available}

The January 21, 2007, M 7.5 Molucca Sea earthquake occurred as the result of shallow reverse faulting on or near the boundary between the Sunda plate and the Birds Head microplate, one of the many small microplates in the region of eastern Indonesia that together accommodate the relative convergence between the Australia, Sunda, Philippine Sea, and Pacific plates. Focal mechanism solutions indicate that rupture occurred on either a steeply dipping reverse fault or a shallowly dipping thrust fault. Of these two possible fault orientations, finite-fault modeling of globally recorded seismic data is more consistent with slip 
on the shallowly dipping fault. At this location, the Sunda and Philippine Sea plates are converging in an east-west direction at a rate of approximately $109 \mathrm{~mm} / \mathrm{yr}$.

While commonly plotted as points on maps, earthquakes of this size are more appropriately described as slip over a larger fault area. Reverse-faulting events of the size of the May 3, 2006, earthquake are typically about 80x40 km (length x width); modeling of this earthquake implies dimensions of about $150 \times 40 \mathrm{~km}$, predominantly surrounding the hypocenter and to the northeast.

Frequent volcanic eruptions and earthquakes testify to the active tectonic processes that are currently in progress in response to the continued movement of the Australia, Sunda, and Pacific plates. The distribution of small ocean basins, continental fragments, remnants of ancient magmatic arcs, and numerous subduction complexes that make up the Indonesian region indicate that its history was equally tectonically active. Eleven earthquakes of M 7+ have occurred within $400 \mathrm{~km}$ of the January $21^{\text {st }}$ event over the preceding 40 years. The largest of these earthquakes was a M 7.8 event in April 1990, roughly $350 \mathrm{~km}$ to the west, that resulted in at least 3 fatalities and 25 injuries.

\section{3/25/2007 00:40:01 UTC usp000f7b4 \\ $20.666^{\circ} \mathrm{S}, 169.426^{\circ} \mathrm{E}$ \\ M 7.1 - Vanuatu \\ Depth $34.0 \mathrm{~km}$}

The March 25, 2007, M 7.1 Vanuatu earthquake occurred as the result of shallow reverse faulting less than $100 \mathrm{~km}$ to the east of the South New Hebrides Trench, on or near the subduction zone plate boundary between the Australia and Pacific plates. At the location of the earthquake, the Australia plate subducts to the east-northeast with respect to the New Hebrides microplate (a segment of the much larger Pacific plate) at a velocity of about $79 \mathrm{~mm} / \mathrm{yr}$. The March $25^{\text {th }}$ earthquake's location, depth, and focal mechanism solutions are consistent with the earthquake resulting from northeastward-dipping thrust faulting associated with subduction along this plate boundary.

The Vanuatu region experiences a very high level of earthquake activity, and more than two dozen events of M 7 or larger have occurred within $300 \mathrm{~km}$ of the March 25, 2007, event since the beginning of the $20^{\text {th }}$ century. Recent large earthquakes close to the March $25^{\text {th }}$ event include a M 7.3 earthquake in December 2003, approximately $150 \mathrm{~km}$ to the south. In February 1990, a M 7.0 event had an almost identical location to this 2007 earthquake. Like the March $25^{\text {th }}$ event, no damage or casualties were reported. The subducting Australia plate is seismically active to depths of about $350 \mathrm{~km}$ in this region.

\section{4/01/2007 20:39:58 UTC usp000f83m}

\section{$8.481^{\circ} \mathrm{S}, 156.978^{\circ} \mathrm{E}$}

\section{8.1 - Solomon Islands}

\section{Depth 24.0 km}

\section{Electronic Poster Available}

The April 1, 2007, M 8.1 Solomon Islands earthquake occurred as the result of shallow thrust faulting along the boundary of the Pacific plate with the Australia, Woodlark, and Solomon Sea microplates. At the location of the earthquake, the latter three plates converge to the east-northeast or northeast against the Pacific plate with velocities of $90-105 \mathrm{~mm} / \mathrm{yr}$. Along much of the plate boundary between the Pacific plate and the Australia/Woodlark/Solomon Sea microplates, relative plate motion is accomplished principally by subduction of the Australia/Woodlark/Solomon Sea microplates beneath the Pacific plate. The April $1^{\text {st }}$ earthquake's location and focal mechanism solutions are consistent with the earthquake resulting from part of this broader northeast-directed subduction process.

While commonly plotted as points on maps, earthquakes of this size are more appropriately described as slip over a larger fault area. Thrust-faulting events of the size of the April 1, 2007, earthquake are typically about $175 \times 70 \mathrm{~km}$ (length x width); modeling of this earthquake implies dimensions of about 200x $80 \mathrm{~km}$, predominantly in the shallow trench region around the hypocenter and to the northwest.

The Solomon Islands Arc as a whole experiences a very high level of earthquake activity, and many events of M 7 or larger have been recorded since the early decades of the $20^{\text {th }}$ century. The April $1^{\text {st }}$ earthquake, however, nucleated in a $250-\mathrm{km}-l o n g$ segment of the arc that had produced no events of M 7 or larger since the early $20^{\text {th }}$ century. 
08/01/2007 17:08:51 UTC

\section{$15.736^{\circ} \mathrm{S}, 167.745^{\circ} \mathrm{E}$}

\section{7.2 - Vanuatu}

\section{Depth 120.0 km}

\section{Electronic Poster Available}

The August 1, 2007, M 7.2 Vanuatu earthquake occurred as the result of reverse faulting at an intermediate depth, approximately $120 \mathrm{~km}$ beneath the Pacific Ocean and to the east of the New Hebrides Trench, within the lithosphere of the subducting Australia plate. Focal mechanism solutions indicate that rupture occurred on either a steep south-striking reverse fault or a shallowly dipping north-striking thrust fault. Slip on a fault of either orientation is consistent with the intraplate compressional tectonics implied by the faulting mechanism and earthquake depth. At the location of the earthquake, the Australia plate moves east-northeast relative to the Pacific plate, subducting beneath the New Hebrides Arc and North Fiji Basin at a velocity of about $100 \mathrm{~mm} / \mathrm{yr}$. The lithosphere of the New Hebrides Arc and North Fiji Basin consists of zones of deformation and small tectonic microplates that accommodate the convergence of the much larger Australia and Pacific plates. The subducted Australia plate is seismically active to a depth of about $300 \mathrm{~km}$ in the region of the August 1, 2007, earthquake.

Earthquakes such as this one, with focal depths between 70 and $300 \mathrm{~km}$, are commonly termed "intermediate-depth" earthquakes. Intermediate-depth earthquakes represent deformation within subducted slabs rather than at the shallow plate interface between subducting and overriding tectonic plates. They typically cause less damage on the ground surface above their foci than is the case with similar-magnitude shallow-focus earthquakes, but large intermediate-depth earthquakes may be felt at great distance from their epicenters.

The Vanuatu region experiences a very high level of earthquake activity, and 22 earthquakes of M 7+ have occurred within $400 \mathrm{~km}$ of the August $1^{\text {st }}$ event over the preceding 40 years. The largest was a M 7.7 earthquake in April 1997, near the Santa Cruz Islands to the north, with no recorded casualties and minimal damage.

08/08/2007 17:05:04 UTC usp000fj6k

\section{$5.968^{\circ} \mathrm{S}, 107.655^{\circ} \mathrm{E}$}

\section{7.5 - Java, Indonesia}

\section{Depth 280.0 km}

\section{Electronic Poster Available}

The August 8, 2007, M 7.5 Java earthquake occurred as the result of oblique reverse faulting at an intermediate depth, approximately $280 \mathrm{~km}$ beneath the north coast of Java within the lithosphere of the Australia plate subducting beneath the Sunda plate. Focal mechanism solutions indicate that rupture occurred on either a steeply dipping east-striking reverse fault or a shallowly dipping, northwest-striking thrust fault. Of these two possible fault orientations, finite-fault modeling of globally recorded seismic data is more consistent with slip on the steep, east-striking fault. At the location of the earthquake, the Australia plate moves to the north with respect to the Sunda plate at a velocity of about $58 \mathrm{~mm} / \mathrm{yr}$. The Australia plate is thrust beneath the Sunda plate at the Sunda-Java Trench, south of the island of Java and the August $8^{\text {th }}$ earthquake, and is subducted to progressively greater depths with distance north of the trench. The subducted lithosphere beneath and north of Java is seismically active to a depth of about $650 \mathrm{~km}$.

Earthquakes such as this one, with focal depths between 70 and $300 \mathrm{~km}$, are commonly termed "intermediate-depth" earthquakes. Intermediate-depth earthquakes represent deformation within subducted slabs rather than at the shallow plate interface between subducting and overriding tectonic plates. They typically cause less damage on the ground surface above their foci than is the case with similar-magnitude shallow-focus earthquakes, but large intermediate-depth earthquakes may be felt at great distance from their epicenters.

The most recent large earthquake local to this event was a M 7.7 earthquake in July 2006, very close to the Sunda-Java Trench. That event resulted in several hundred fatalities and widespread damage. 


\section{$13.354^{\circ} \mathrm{S}, 76.509^{\circ} \mathrm{W}$}

\section{8.0 - Near the coast of central Peru}

\section{Depth 39.0 km}

\section{Electronic Poster Available}

The August 15, 2007, M 8.0 earthquake near the coast of central Peru occurred as the result of shallow thrust faulting about $100 \mathrm{~km}$ east of the Peru-Chile Trench and on the subduction zone interface between the Nazca and South America plates. At the location of the earthquake, the two plates converge at a velocity of about $77 \mathrm{~mm} / \mathrm{yr}$, with the South American plate moving up and seaward over the Nazca plate. The earthquake location, depth, and focal mechanism solutions indicate that the source of the earthquake was likely along the interface between the two plates.

While commonly plotted as points on maps, earthquakes of this size are more appropriately described as slip over a larger fault area. Thrust-faulting events of the size of the August 15, 2007, earthquake are typically about 150x65 km (length x width); modeling of this earthquake implies dimensions of about 120x140 km, predominantly up-dip of the hypocenter.

Coastal Peru has a history of very large earthquakes. The August $15^{\text {th }}$ event originated just south of the source region of the M 8.1 earthquake of October 1974 and just north of the source regions of major earthquakes that occurred in August 1942 (M 7.7) and November 1996 (M 7.7). The largest coastal Peru earthquake of the last two centuries was the M 9 earthquake of 1868 , which was centered about $700 \mathrm{~km}$ southeast of the August $15^{\text {th }}$ earthquake. The 1868 event produced a tsunami that resulted in several thousand fatalities along the South America coast and also caused damage in Hawaii.

\section{9/02/2007 01:05:18 UTC usp000fm6b}

$11.510^{\circ} \mathrm{S}, 165.814^{\circ} \mathrm{E}$

\section{7.2 - Santa Cruz Islands \\ Depth 35.0 km}

\section{Electronic Poster Available}

The September 2, 2007, M 7.2 Santa Cruz Islands earthquake occurred as the result of shallow thrust faulting less than $30 \mathrm{~km}$ east of the North New Hebrides Trench along the boundary between the Pacific plate and Australia plates. At the location of the earthquake, the Australia plate subducts to the east-northeast relative to the Pacific plate at a velocity of about $91 \mathrm{~mm} / \mathrm{yr}$. The September $2^{\text {nd }}$ earthquake's location and focal mechanism solutions are consistent with the earthquake resulting from eastward-dipping thrust faulting on the plate interface.

The Santa Cruz Islands region experiences a very high level of earthquake activity, and there have been 18 earthquakes of magnitude 7 and greater within $400 \mathrm{~km}$ of the September $2^{\text {nd }}$ event over the preceding 40 years. One of the largest events was a M 7.7 in April 1997 about $100 \mathrm{~km}$ to the south that resulted in minimal damage from a local tsunami. The subducting Australia plate is seismically active to depths of about $250 \mathrm{~km}$ beneath the islands.

09/12/2007 11:10:26 UTC

\section{usp000fmz4}

\section{$4.520^{\circ} \mathrm{S}, 101.374^{\circ} \mathrm{E}$}

\section{8.5 - Southern Sumatra, Indonesia}

\section{Depth 34.0 km}

\section{Electronic Poster Available}

The September 12, 2007, M 8.5 southern Sumatra earthquake occurred as the result of shallow thrust faulting on the boundary between the Australia and Sunda plates. At the location of the earthquake, the Australia plate moves northeast with respect to the Sunda plate at a velocity of about $60 \mathrm{~mm} / \mathrm{yr}$. The direction of relative plate motion is oblique to the orientation of the plate boundary offshore of the west coast of Sumatra. The component of plate motion perpendicular to the boundary is accommodated by thrust faulting on the offshore plate boundary. Much of the component of plate motion parallel to the plate boundary is accommodated by strike-slip faulting on the Sumatra fault, which is inland on Sumatra proper.

While commonly plotted as points on maps, earthquakes of this size are more appropriately described as slip over a larger fault area. Thrust-faulting events of the size of the September 12, 2007, M 8.5 earthquake are typically about 300x110 km (length $\mathrm{x}$ width); modeling of this earthquake implies dimensions of about 250x170 km, predominantly surrounding the hypocenter, and to the northwest. 
The M 8.5 earthquake of September 12, 2007, is the fourth earthquake with a magnitude greater than 7.9 to occur over the preceding decade on or near the plate boundaries offshore of western Sumatra. The earthquake occurred just north of the source region of the M 7.9 earthquake on June 4, 2000. The September 12, 2007, magnitude 7.9 earthquake (23:49 UTC) occurred about $225 \mathrm{~km}$ northwest of the magnitude 8.5 earthquake (11:10 UTC) at the northern end of the aftershock zone. These two earthquakes and their aftershocks overlay the southern portion of the estimated 1833 rupture zone, which extends from approximately Enggano Island to the northern portion of Siberut Island. The great-sized M 9.1 earthquake of December 26, 2004, which produced the devastating Indian Ocean tsunami of that date, ruptured much of the boundary separating the India plate (the northern portion of the Indo-Australia plate) and the Burma plate (which can be considered a microplate of the larger Sunda plate). Immediately to the south of the 2004 earthquake, the M 8.6 Nias Island earthquake of March 28, 2005, ruptured a segment of the plate boundary separating the Australia and Sunda plates. Since the December 26, 2004, earthquake, much of the Java-Sunda Trench between the northern Andaman Islands and Enggano Island, a distance of more than 2,000 km, has ruptured in a series of large subduction zone earthquakes.

\section{9/12/2007 23:49:03 UTC Usp000fn2b}

\section{$2.506^{\circ} \mathrm{S}, 100.906^{\circ} \mathrm{E}$}

\section{7.9 - Kepulauan Mentawai region, Indonesia \\ Depth $35.0 \mathrm{~km}$}

The September 12, 2007, M 7.9 earthquake of the Kepulauan Mentawai region of Indonesia occurred as the result of shallow thrust faulting on the boundary between the Australia and Sunda plates. At the location of the earthquake, the Australia plate moves northeast relative to the Sunda plate at a velocity of about $60 \mathrm{~mm} / \mathrm{yr}$. The direction of relative plate motion is oblique to the orientation of the plate boundary offshore of the west coast of Sumatra. The component of plate motion perpendicular to the boundary is accommodated by thrust faulting on the offshore plate boundary. Much of the component of plate motion parallel to the plate boundary is accommodated by strike-slip faulting on the Sumatra fault, which is inland of Sumatra proper.

While commonly plotted as points on maps, earthquakes of this size are more appropriately described as slip over a larger fault area. Thrust-faulting events of the size of the September 12, 2007, M 7.9 earthquake are typically about $135 \times 60 \mathrm{~km}$ (length $\mathrm{x}$ width); modeling of this earthquake implies slip occurred on two patches, each about 50x40 km or smaller in size, but separated by about $120 \mathrm{~km}$ along strike. The first surrounds the hypocenter, and the second is at a similar depth to the northwest.

The September 12, 2007, M 7.9 event occurred about $225 \mathrm{~km}$ northwest of the M 8.5 earthquake that occurred almost 13 hours previously, and at the northern end of the aftershock zone of the larger shock. These two earthquakes and their aftershocks overlay the southern portion of the estimated 1833 rupture zone, which extends from approximately Enggano Island to the northern portion of Siberut Island. The great-sized M 9.1 earthquake of December 26, 2004, which produced the devastating Indian Ocean tsunami of that date, ruptured much of the boundary separating the India plate (the northern portion of the IndoAustralia plate) and the Burma plate (which can be considered a microplate of the larger Sunda plate). Immediately to the south of the 2004 earthquake, the M 8.6 Nias Island earthquake of March 28, 2005, ruptured a segment of the plate boundary separating the Australia and Sunda plates. Since the December 26, 2004, earthquake, much of the Java-Sunda Trench between the northern Andaman Islands and Enggano Island, a distance of more than 2,000 km, has ruptured in a series of large subduction zone earthquakes.

\section{9/13/2007 03:35:28 UTC usp000fn3d}

\section{$2.130^{\circ} \mathrm{S}, 99.627^{\circ} \mathrm{E}$}

\section{7.0 - Kepulauan Mentawai region, Indonesia Depth 22.0 km}

The September 13, 2007, M 7.0 earthquake in the Kepulauan Mentawai region of Indonesia occurred as the result of shallow thrust faulting on or near the boundary between the Australia and Sunda plates, and was an aftershock of the M 8.5 and M 7.9 earthquakes that occurred the previous day. At the location of the earthquake, the Australia plate moves northeast with respect to the Sunda plate at a velocity of about $60 \mathrm{~mm} / \mathrm{yr}$. The direction of relative plate motion is oblique to the orientation of the plate boundary offshore of the west coast of Sumatra. The component of plate motion perpendicular to the boundary is accommodated by thrust faulting on the offshore plate boundary. Much of the component of plate motion parallel to the plate boundary is accommodated by strike-slip faulting on the Sumatra fault, which is inland of Sumatra proper.

The M 8.5 earthquake of September 12, 2007 is the fourth earthquake with a magnitude greater than 7.9 to occur in the past decade on or near the plate boundaries offshore of western Sumatra. This earthquake occurred just north of the source region of the M 7.9 earthquake on June 4, 2000. The September 13, 2007, M 7.0 earthquake occurred about $320 \mathrm{~km}$ northwest of the M 8.5 earthquake and $160 \mathrm{~km}$ west of the M 7.9 earthquake, at the northern end of the aftershock zone. This aftershock 
sequence overlays the southern portion of the estimated 1833 rupture zone, which extends from approximately Enggano Island to the northern portion of Siberut Island. The great-sized M 9.1 earthquake of December 26, 2004, which produced the devastating Indian Ocean tsunami of that date, ruptured much of the boundary separating the India plate and the Burma plate. Immediately to the south of the 2004 earthquake, the M 8.6 Nias Island earthquake of March 28, 2005, ruptured a segment of the plate boundary separating the Australia and Sunda plates. Since the December 26, 2004, earthquake, much of the Sunda Trench between the northern Andaman Islands and Enggano Island, a distance of more than 2,000 km, has ruptured in a series of large subduction zone earthquakes.

\section{9/28/2007 13:38:57 UTC usp000fpca}

\section{$21.980^{\circ} \mathrm{N}, 142.685^{\circ} \mathrm{E}$}

\section{7.5 - Volcano Islands, Japan region Depth 260.0 km \\ Electronic Poster Available}

The September 28, 2007, M 7.5 Mariana Islands earthquake south of Japan occurred as the result of oblique reverse faulting at intermediate depth approximately $260 \mathrm{~km}$ beneath the North Pacific Ocean and about $300 \mathrm{~km}$ west of the Mariana Trench, marking where the Pacific plate begins its subduction beneath the Philippine Sea plate. Focal mechanism solutions indicate that oblique rupture occurred on either a northwest- or east-northeast-striking, moderately dipping reverse fault. Of these two possible fault orientations, finite-fault modeling of globally recorded seismic data is more consistent with slip on the east-northeast-striking fault. At the location of the earthquake, the Pacific plate moves to the west with respect to the Philippine Sea plate at a velocity of about $40 \mathrm{~mm} / \mathrm{yr}$. The earthquake represents the release of stress resulting from the distortion of the Pacific plate at depth.

Earthquakes like this event, with focal depths between 70 and $300 \mathrm{~km}$, are commonly termed "intermediate-depth" earthquakes. Intermediate-depth earthquakes represent deformation within subducted slabs rather than at the shallow plate interface between subducting and overriding tectonic plates. They typically cause less damage on the ground surface above their foci than is the case with similar-magnitude shallow-focus earthquakes, but large intermediate-depth earthquakes may be felt at great distance from their epicenters. "Deep-focus" earthquakes, with focal depths greater than $300 \mathrm{~km}$, also occur in the subducted Pacific plate beneath the Mariana Island Arc. Earthquakes have been reliably located to depths of about $630 \mathrm{~km}$ beneath the Mariana Island Arc.

Though the Volcano Islands region near Japan is frequented by earthquakes, only one other of M 7+ has occurred within $400 \mathrm{~km}$ of the September $28^{\text {th }}$ earthquake in the preceding 40 years. A M 7.6 event occurred in March 2000, about $100 \mathrm{~km}$ to the east of the September 28, 2007, earthquake, but no recorded damage or casualties were reported.

\section{9/30/2007 05:23:34 UTC usp000fpgq}

\section{$49.418^{\circ} \mathrm{S}, 163.954^{\circ} \mathrm{E}$}

\section{7.4 - Auckland Islands, New Zealand region \\ Depth 10.0 km \\ Electronic Poster Available}

The September 30, 2007, M 7.4 Auckland Islands earthquake occurred as the result of shallow thrust faulting on the boundary between the Australia and Pacific plates just south of New Zealand. The earthquake is located at the southeast end of the small Puysegur subduction zone where a segment of the Australia plate subducts to the north-northeast beneath the South Island of New Zealand (Pacific plate) at a velocity of about $32 \mathrm{~mm} / \mathrm{yr}$. The location of this event is immediately north of the transition from dominantly strike-slip plate motions along the Macquarie Ridge to the south, to the subduction-related thrusting to the north. This plate boundary transition is well delineated by numerous earthquakes of both thrust and strike-slip orientation. This is the largest earthquake in the region since a M 7.6 strike-slip event less than $100 \mathrm{~km}$ to the north in May 1981.

The Australia-Pacific plate boundary region west of the Auckland Islands has a history of large earthquakes both along the plate boundary proper and also west of the plate boundary internal to the Australia plate. The September $30^{\text {th }}$ event is approximately $200 \mathrm{~km}$ east of the M 8.1 earthquake of December 2004, which occurred within the oceanic lithosphere of the Australia plate, and about $450 \mathrm{~km}$ northeast of the M 8.0 earthquake of May 1989, which occurred along the Macquarie Ridge plate boundary itself. 


\section{0/31/2007 03:30:15 UTC usp000frnh}

\section{$18.854^{\circ} \mathrm{N}, 145.315^{\circ} \mathrm{E}$}

\section{7.2 - Pagan region, Northern Mariana Islands \\ Depth 207.0 km}

\section{Electronic Poster Available}

The October 31, 2007, M 7.2 Pagan region earthquake occurred as the result of oblique reverse faulting at an intermediate depth, approximately $207 \mathrm{~km}$ beneath the Northern Mariana Islands of the North Pacific Ocean and $200 \mathrm{~km}$ west of the Mariana Trench, which marks where the Pacific plate begins its subduction beneath the overriding Philippine Sea plate. Focal mechanism solutions indicate that oblique rupture occurred on either a northwest-striking reverse fault or a north-northeast-striking fault. Slip on a fault of either orientation is consistent with the intraplate compressional tectonics implied by the faulting mechanism and earthquake depth. At the location of the earthquake, the Pacific plate moves to the west relative to the Philippine Sea plate at a velocity of about $40 \mathrm{~mm} / \mathrm{yr}$ and relative to the Mariana plate at a velocity of about $60 \mathrm{~mm} / \mathrm{yr}$. The earthquake represents the release of stress resulting from the distortion of the Pacific plate at depth.

Although the broad-scale tectonics of the epicentral region are dominated by the subduction of the Pacific plate beneath the Philippine Sea plate, the two plates do not strictly have a mutual boundary at the location of the earthquake. Instead, they are separated by a spreading ridge (the Mariana Trough) and the small Mariana microplate. The Pacific plate moves to the west with respect to the Mariana plate at a velocity of about $60 \mathrm{~mm} / \mathrm{yr}$.

Earthquakes like this event, with focal depths between 70 and $300 \mathrm{~km}$, are commonly termed "intermediate-depth" earthquakes. Intermediate-depth earthquakes represent deformation within subducted slabs rather than at the shallow plate interface between subducting and overriding tectonic plates. They typically cause less damage on the ground surface above their foci than is the case with similar-magnitude shallow-focus earthquakes, but large intermediate-depth earthquakes may be felt at great distance from their epicenters. "Deep-focus" earthquakes, those with focal depths greater than $300 \mathrm{~km}$, also occur in the subducted Pacific plate beneath the Mariana Island Arc. Earthquakes have been reliably located to depths of about $630 \mathrm{~km}$ beneath the Mariana Island Arc.

The Mariana Island Arc hosts frequent earthquakes, but only one other event greater than M 7 has occurred within $400 \mathrm{~km}$ of the October $31^{\text {st }}$ earthquake in the preceding 40 years - a M 7.1 event in August 1995, less than $20 \mathrm{~km}$ to the west with no reported causalities or damage.

\section{1/14/2007 15:40:50 UTC usp000fshy}

\section{$22.204^{\circ} \mathrm{S}, 69.869^{\circ} \mathrm{W}$}

\section{7.7 - Antofagasta, Chile \\ Depth $40.0 \mathrm{~km}$}

\section{Electronic Poster Available}

The November 14, 2007, M 7.7 earthquake near Antofagasta, Chile, occurred as the result of shallow thrust faulting in northern Chile about $100 \mathrm{~km}$ east of the Peru-Chile Trench, where the oceanic Nazca plate begins its subduction beneath the South America plate. At the location of the earthquake, the Nazca plate moves to the east-northeast relative to the South America plate at a velocity of about $79 \mathrm{~mm} / \mathrm{yr}$. The location, depth, and focal mechanism solutions of the earthquake indicate that this event likely resulted from subduction-related thrusting on the interface between these two plates.

While commonly plotted as points on maps, earthquakes of this size are more appropriately described as slip over a larger fault area. Thrust-faulting events of the size of the November 14, 2007, earthquake are typically about $100 \times 50 \mathrm{~km}$ (length $\mathrm{x}$ width); modeling of this earthquake implies dimensions of about $120 \times 80 \mathrm{~km}$, predominantly surrounding and to the south of the hypocenter.

This earthquake occurred at the southern end of the rupture area of the great-sized M 8.8 earthquake of 1877, which produced a destructive tsunami and whose source region has since the late 1970 s been recognized as a potentially dangerous seismic gap. In July 1995, a M 8.0 earthquake occurred approximately $200 \mathrm{~km}$ farther south of the November $14^{\text {th }}$ event and caused at least 3 fatalities, injuried to 58 people, and widespread damage from landslides, tsunami impact, and building collapse. 
11/29/2007 19:00:20 UTC

usp000ftj1

$14.943^{\circ} \mathrm{N}, 61.244^{\circ} \mathrm{W}$

\section{7.4 - Martinique region, Windward Islands \\ Depth 156.0 km}

\section{Electronic Poster Available}

The November 29, 2007, M 7.4 Martinique earthquake occurred as the result of oblique normal faulting at an intermediate depth, approximately $156 \mathrm{~km}$ beneath the Lesser Antilles Island Arc of the eastern Caribbean Sea. Focal mechanism solutions indicate that oblique rupture occurred on either a near-vertical north-south normal fault or shallowly dipping east-striking normal fault. At the location of the earthquake, the South America plate subducts to the west-northwest beneath the Caribbean plate at a velocity of about $20 \mathrm{~mm} / \mathrm{yr}$. The earthquake occurred within the subducted South America plate in response to stresses generated by the plate's slow distortion at depth, rather than on the thrust fault that constitutes the interface the between the Caribbean and South America plates. Slip on a fault aligned with either nodal plane of the focal mechanism solution would accommodate the down-dip extension of the South America slab that is implied by the normal-component of the faulting solution.

Earthquakes like this event, with focal depths between 70 and $300 \mathrm{~km}$, are commonly termed "intermediate-depth" earthquakes. Intermediate-depth earthquakes represent deformation within subducted slabs rather than at the shallow plate interface between subducting and overriding tectonic plates. They typically cause less damage on the ground surface above their foci than is the case with similar-magnitude shallow-focus earthquakes, but large intermediate-depth earthquakes may be felt at great distance from their epicenters. The subducted South America plate is seismically active to depths of almost $200 \mathrm{~km}$ beneath the Lesser Antilles Island Arc near Martinique.

The November $29^{\text {th }}$ event was the first earthquake of M 7 or larger to have occurred within its $400 \mathrm{~km}$ vicinity since the M 7.5 event in October 1974, about $250 \mathrm{~km}$ to the north. No fatalities were reported from that earthquake, though several people were injured and some building damage was documented.

\section{2/09/2007 07:28:20 UTC usp000fu3q}

\section{$25.872^{\circ} \mathrm{S}, 177.517^{\circ} \mathrm{W}$}

\section{7.8 - South of the Fiji Islands Depth $152.5 \mathrm{~km}$}

\section{Electronic Poster Available}

The December 9, 2007, M 7.8 earthquake occurred in the Tonga Kermadec subduction zone as the result of oblique reverse faulting at an intermediate depth, approximately $152 \mathrm{~km}$ beneath the South Pacific Ocean and $200 \mathrm{~km}$ west of the Tonga and Kermadec Trenches. Focal mechanism solutions indicate that rupture occurred on either a steeply dipping reverse fault or a shallowly dipping thrust fault. Of these two possible fault orientations, finite-fault modeling of globally recorded seismic data is more consistent with slip on the shallowly dipping thrust fault. The Tonga Kermadec subduction zone is situated from the North Island of New Zealand to the north-northeast and is about 2,500 km long. At a broad scale, tectonics of the subduction zone reflect the motion of the Pacific plate westward with respect to the interior of the Australia plate at a velocity of about $77 \mathrm{~mm} / \mathrm{yr}$. The Pacific plate subducts beneath the Australia plate at the Tonga and Kermadec Trenches and dips to the west. In detail, the eastern edge of the broad Australia plate may itself be viewed as a collection of small plates or microplates that move with respect to each other and with respect to the Pacific plate and the Australia plate interior.

The interaction between the Pacific and Australia plates creates one of the most active tectonic environments in the world, with a high level of associated earthquake activity. Earthquakes occur on the thrust fault interface between the Pacific and Australia plates, within the overriding Australia plate, and within the subducting Pacific plate. The December $9^{\text {th }}$ earthquake occurred at a depth of about $150 \mathrm{~km}$ within the Pacific plate and reflects stresses generated by the deformation of the Pacific plate as it is subducted.

Earthquakes like this event, with focal depths between 70 and $300 \mathrm{~km}$, are commonly termed "intermediate-depth" earthquakes. Intermediate-depth earthquakes represent deformation within subducted slabs rather than at the shallow plate interface between subducting and overriding tectonic plates. They typically cause less damage on the ground surface above their foci than is the case with similar-magnitude shallow-focus earthquakes, but large intermediate-depth earthquakes may be felt at great distance from their epicenters. "Deep-focus" earthquakes, those with focal depths greater than $300 \mathrm{~km}$, also occur in the subducted Pacific plate in the Tonga Kermadec subduction zone. Earthquakes have been reliably located to depths of nearly $700 \mathrm{~km}$ within the subduction zone.

Fiji and the surrounding region are among the most seismically active areas on the planet, and frequently host large earthquakes. Eleven earthquakes of magnitude 7 and greater have occurred within $400 \mathrm{~km}$ of the December $9^{\text {th }}$ event over the 
preceding 40 years. The largest of these events was a M 8.0 earthquake in January 1976, which was roughly $200 \mathrm{~km}$ to the south and had no reported casualties or damage.

\section{2/19/2007 09:30:27 UTC usp000fuse $51.495^{\circ} \mathrm{N}, 179.473^{\circ} \mathrm{W}$}

\section{7.2 - Andreanof Islands, Aleutian Islands, Alaska Depth 34.0 km}

\section{Electronic Poster Available}

The December 19, 2007, M 7.2 Aleutian Island earthquake occurred as the result of shallow thrust faulting on the boundary between the North America plate and the Pacific plate. At the location of the earthquake, the Pacific plate moves to the northwest relative to the North America plate at a velocity of about $72 \mathrm{~mm} / \mathrm{yr}$, subducting at the Aleutian Trench. The location, depth, and focal mechanism solutions indicate that the earthquake likely occurred from thrust faulting on the interface between the plates.

The earthquake of December 19, 2007, ruptured a segment of the Pacific/North America plate boundary that is spatially situated between the segments of the plate boundary that ruptured in the great Aleutian Island earthquakes of March 9, 1957 (M 8.6) and February 4, 1965 (M 8.7). Great earthquakes also occurred in the central Aleutian Arc on May 7, 1986 (M 8, about $300 \mathrm{~km}$ from the site of the 2007 earthquake) and June 10, 1996 (M 7.9, about $150 \mathrm{~km}$ from the site of the 2007 earthquake).

\section{8: 12 Events}

02/20/2008 08:08:30 UTC

\section{usp000fzau}

\section{$2.778^{\circ} \mathrm{N}, 95.978^{\circ} \mathrm{E}$}

\section{7.4 - Simeulue, Indonesia}

\section{Depth $26.0 \mathrm{~km}$}

\section{Electronic Poster Available}

The February 20, 2008, M 7.4 earthquake near Simeulue, Indonesia, occurred as the result of shallow thrust faulting on the boundary between the Australia and Sunda plates. At the location of this earthquake, the Australia plate moves north-northeast with respect to the Sunda plate at a velocity of about $55 \mathrm{~mm} / \mathrm{yr}$. The direction of relative plate motion is oblique to the orientation of the plate boundary offshore of the west coast of Sumatra. The component of plate motion perpendicular to the boundary is accommodated by thrust faulting such as this on the offshore plate boundary, with the Australia plate subducting beneath the Sunda plate. Much of the component of plate motion parallel to the plate boundary is accommodated by strike-slip faulting on the Sumatra fault, which is inland of Sumatra.

This earthquake occurred at the south end of the rupture zone of the great-sized M 9.1 earthquake of December 26, 2004, and at the north end of the rupture zone of the M 8.6 Nias Island earthquake of March 28, 2005, where the 2004 and 2005 rupture zones nearly abut. The earthquake of December 26, 2004, produced the devastating Indian Ocean tsunami of that date. Since 2000, much of the Sunda Trench between the northern Andaman Islands and Enggano Island, a distance of more than $2,000 \mathrm{~km}$, has ruptured in a series of large subduction zone earthquakes.

02/25/2008 08:36:33 UTC usp000fzx4

\section{$2.352^{\circ} \mathrm{S}, 100.018^{\circ} \mathrm{E}$}

\section{7.2 - Kepulauan Mentawai region, Indonesia}

\section{Depth 25.0 km}

\section{Electronic Poster Available}

The February 25, 2008, M 7.2 earthquake near Kepulauan Mentawai, Indonesia, occurred as the result of shallow thrust faulting on the boundary between the Australia and Sunda plates. At the location of this earthquake, the Australia plate moves north-northeast relative to the Sunda plate at a velocity of about $60 \mathrm{~mm} / \mathrm{yr}$. The direction of relative plate motion is oblique to the orientation of the plate boundary offshore of the west coast of Sumatra. The component of plate motion perpendicular to the boundary is accommodated by thrust faulting such as this on the offshore plate boundary, with the Australia plate subducting beneath the Sunda plate. Much of the component of plate motion parallel to the plate boundary is accommodated by strike-slip faulting on the Sumatra fault, which is inland of Sumatra. 
This earthquake continues an episode of unusually high earthquake activity that has impacted Sumatra and vicinity in recent years. Previous earthquakes in the series of events include the massive Sumatra-Andaman Islands earthquake of December 26, 2004 (M 9.1), the Nias earthquake of March 28, 2005 (M 8.6), and the southern Sumatra earthquakes of September 12, 2007 (M 8.4 and 7.9). The earthquake of February 25, 2008, occurred within the broad section of the Sumatra subduction zone that was spanned by aftershocks of the southern Sumatra earthquakes of September 12, 2007.

\section{3/20/2008 22:32:57 UTC usp000g1w2}

\section{$35.445^{\circ} \mathrm{N}, 81.392^{\circ} \mathrm{E}$}

\section{7.2 - Xinjiang-Xizang border region, China Depth $10.0 \mathrm{~km}$}

\section{Electronic Poster Available}

The March 20, 2008, M 7.2 earthquake in the Xinjiang-Xizang border region occurred as the result of shallow normal faulting in the tectonically complex region of the northern Tibetan Plateau. Focal mechanism solutions for the earthquake indicate that rupture occurred on a normal fault dipping moderately to the east or west. Finite-fault modeling of satellite data indicates that rupture occurred on a fault dipping moderately to the southeast. This earthquake occurred several hundred kilometers north of the convergent India-Eurasia plate boundary, where the India plate is moving northward with respect to Eurasia at a rate of approximately $46 \mathrm{~mm} / \mathrm{yr}$. This convergence drives the uplift of the Himalaya Mountains, at a velocity of about $10 \mathrm{~mm} / \mathrm{yr}$, and the Tibetan Plateau, which is an extremely broad region of thickened and uplifted crust sitting above $4.5-5.0 \mathrm{~km}$.

The uplifted Tibetan Plateau is spreading to the east and, as a result, is an area of east-west extension and eastward crustal motion within a larger region of generally north-south convergence. The Xinjiang-Xizang earthquake likely reflects the interplay amongst these major tectonic forces, dominated in this location by east-west extension. The eastward motion of Tibet, with respect to Eurasia farther north, is accommodated in part by the large intracontinental Altyn Tagh and Kunlun strike-slip fault systems. The March 20, 2008, event is one of the largest known historical earthquakes to have occurred in the northern Tibetan Plateau west of the Kunlun fault system. Local historic events of similar size include the earthquake of November 1996, a M 6.9 earthquake that occurred approximately $300 \mathrm{~km}$ to the west and had no recorded fatalities or injuries.

\section{4/09/2008 12:46:12 UTC usp000g3eq}

\section{$20.089^{\circ} \mathrm{S}, 168.852^{\circ} \mathrm{E}$}

\section{7.3 - Loyalty Islands \\ Depth 33.0 km}

\section{Electronic Poster Available}

The April 9, 2008, M 7.3 Loyalty Islands earthquake occurred as the result of shallow thrust faulting on the boundary between the Australia plate and the New Hebrides plate, a microplate that is considered part of the larger Pacific plate. In the epicentral region of the earthquake, the Australia plate moves east-northeast relative to the New Hebrides plate at a velocity of about $110 \mathrm{~mm} / \mathrm{yr}$. The Australia plate subducts beneath the New Hebrides plate and is seismically active to a depth of about $300 \mathrm{~km}$ northeast of the epicenter of the April $9^{\text {th }}$ earthquake.

The New Hebrides Arc region of the Australia/New Hebrides plate boundary experiences numerous strong earthquakes. In the past quarter century, the thousand-kilometer section of the arc centered on the epicenter of the April $9^{\text {th }}$ earthquake has produced more than 20 earthquakes of M 7+, the largest having M 7.7.

\section{4/12/2008 00:30:12 UTC usp000g3q9 $55.681^{\circ} \mathrm{S}, 158.527^{\circ} \mathrm{E}$}

\section{7.1 - Macquarie Island region \\ Depth 16.0 km}

\section{Electronic Poster Available}

The April 12, 2008, M 7.1 earthquake south of the Macquarie Island indicates reverse faulting on the plate boundary between the Australia and Pacific plates in the southwest Pacific Ocean. The earthquake is located in a region of rapid transition in plate motion from convergence at the Hjort Trench (just south of the earthquake) to strike-slip motion along the Macquarie Ridge (north of the earthquake), brought about by the close proximity of this section of the plate boundary to the AustraliaPacific pole of rotation. This plate boundary transition is delineated by earthquakes of both reverse and strike-slip orientation in 
the vicinity of the April 12, 2008 earthquake. In the epicentral region of this event, the Australian plate moves north-northeast with respect to the Pacific plate at a rate of approximately $27 \mathrm{~mm} / \mathrm{yr}$.

The Australia-Pacific plate boundary south of New Zealand experiences numerous strong earthquakes and has hosted greatsized (M 8+) earthquakes in recent history. In May 1989, a M 8.1 earthquake occurred on the plate boundary approximately $380 \mathrm{~km}$ north of the April 12 ${ }^{\text {th }}$ event, and most recently, a M 8.1 event occurred in December 2004 within the Australia plate west of the plate boundary another $250 \mathrm{~km}$ farther north. The April $12^{\text {th }}$ event is the largest known earthquake on the section of the plate boundary south of the 1989 event since a nearby M 8.3 earthquake in 1924.

\section{5/12/2008 06:28:01 UTC usp000g650}

\section{$30.986^{\circ} \mathrm{N}, 103.364^{\circ} \mathrm{E}$}

\section{7.9 - Eastern Sichuan, China \\ Depth $19.0 \mathrm{~km}$ \\ Electronic Poster Available}

The May 12, 2008, M 7.9 Sichuan earthquake occurred as the result of shallow oblique reverse faulting on the northwestern margin of the Sichuan Basin. Focal mechanism solutions indicate that rupture occurred on either a steeply dipping reverse fault or a shallowly dipping thrust fault. The epicenter, focal-mechanism, and finite-fault modeling of globally recorded seismic data for this earthquake are consistent with it resulting from the result of movement on the Longmenshan fault or a tectonically related structure, striking towards the southwest and dipping shallowly beneath the range front. The earthquake reflects tectonic stresses resulting from the convergence of crustal material slowly moving from the high Tibetan Plateau to the west, against strong crust underlying the Sichuan Basin and southeastern China.

On a continental scale, the seismicity of central and eastern Asia is a result of northward convergence of the India plate against the Eurasia plate at a velocity of about $50 \mathrm{~mm} / \mathrm{yr}$. The convergence of the two plates is broadly accommodated by the uplift of the Asian highlands and by the motion of crustal material to the east away from the uplifted Tibetan Plateau.

While commonly plotted as points on maps, earthquakes of this size are more appropriately described as slip over a larger fault area. Reverse-faulting events of the size of the May 12, 2008, earthquake are typically about $145 \times 40 \mathrm{~km}$ (length $\mathrm{x}$ width), while strike-slip events of this magnitude are typically about $210 \times 25 \mathrm{~km}$ in size. Modeling of this earthquake implies dimensions of about $250 \times 30 \mathrm{~km}$, involving complex faulting surrounding the hypocenter and further slip propagating to the northeast.

The northwestern margin of the Sichuan Basin has previously experienced destructive earthquakes. The M 7.5 earthquake of August 25, 1933, resulted in more than 9,300 fatalities.

\section{6/30/2008 06:17:43 UTC usp000gazv}

\section{$58.169^{\circ} \mathrm{S}, 22.014^{\circ} \mathrm{W}$}

\section{7.0 - South Sandwich Islands Region Depth 8.0 km}

The June 30, 2008, M 7.0 South Sandwich Islands earthquake occurred as the result of shallow strike-slip faulting within the oceanic crust of the South America plate, east of the South Sandwich Trench. Focal mechanism solutions indicate that rupture occurred on either a right-lateral southeast-northwest-striking fault or a left-lateral southwest-northeast-striking fault. Slip on a fault aligned with either nodal plane of the focal mechanism solution is consistent with this intraplate setting. At the location of the earthquake, the South America plate moves to the southeast with respect to the Scotia plate at a velocity of about $8 \mathrm{~mm} / \mathrm{yr}$, subducting to the west beneath the South Sandwich Islands at the South Sandwich Trench, just under $100 \mathrm{~km}$ to the west of this earthquake. Several hundred kilometers to the south of this event, the South America plate also slides past the Antarctica plate with left-lateral motion along the South Sandwich fracture zone at a velocity of about $15 \mathrm{~mm} / \mathrm{yr}$.

Several large earthquakes have occurred in this region of the South America plate, including events of M 7.2 in December 1991 approximately $310 \mathrm{~km}$ northwest and M 7.1approximately $160 \mathrm{~km}$ southeast in August 1977. Due to the remote location of these events far from population centers that might be vulnerable to earthquake shaking, none have recorded casualties or damage. 
07/05/2008 02:12:04 UTC $53.888^{\circ} \mathrm{N}, 152.869^{\circ} \mathrm{E}$

\section{7.7 - Sea of Okhotsk}

Depth $632.8 \mathrm{~km}$

\section{Electronic Poster Available}

The July 5, 2008, M 7.8 Sea of Okhotsk earthquake occurred as the result of deep oblique normal faulting, approximately $630 \mathrm{~km}$ deep off the west coast of the Kamchatka Peninsula, in an inclined seismic zone that dips to the west-northwest beneath Kamchatka and the Kuril Islands. Focal mechanism solutions indicate that rupture occurred on either a north-northeast- or southeast-striking normal fault. In the region of Kamchatka, the Pacific plate moves to the west-northwest with respect to the Okhotsk plate at a velocity of about $80 \mathrm{~mm} / \mathrm{yr}$. The Pacific plate thrusts under the Okhotsk plate at the Kuril-Kamchatka Trench and is subducted into the mantle. The earthquake occurred within the Pacific plate, in response to stresses generated by the plate's slow distortion, rather than on the thrust fault that constitutes the interface the between the Okhotsk and Pacific plates and which is seismically active near the Earth's surface. The Pacific plate is active to depths of about $650 \mathrm{~km}$ in the region of the earthquake. Slip on a fault aligned with either nodal plane of the focal mechanism solution would accommodate the down-dip extension of the Pacific slab that is implied by the normal component of the faulting solution.

Earthquakes that have focal depths greater than $300 \mathrm{~km}$ are commonly termed "deep-focus" earthquakes. Deep-focus earthquakes cause less damage on the ground surface above their foci than similar-magnitude shallow-focus earthquakes, but large deep-focus earthquakes may be felt at great distance from their epicenters. The largest recorded deep-focus earthquake prior to this July 2008 earthquake was a M 8.2 event that occurred at a depth of $630 \mathrm{~km}$ within the subducted Nazca plate beneath South America near the northern Bolivian border in 1994. A larger event has since occurred-namely the M 8.3 earthquake that occurred at a depth of $600 \mathrm{~km}$ within the subducted Pacific plate beneath the Sea of Okhotsk offshore of northeastern Russia in 2013. The M 8.3 Sea of Okhotsk earthquake was felt all over Asia, as far away as Moscow, and across the Pacific Ocean along the western seaboard of the United States (though at distant locations, individuals reporting having felt the event were likely very favorably situated for the perception of small ground motions). The M 8.2 Bolivian deep-focus earthquake in 1994 had similarly been reported by individuals in North America at great distance from the epicenter.

Over the past century, 75 earthquakes with a magnitude of M 7+ have occurred at depths greater than $300 \mathrm{~km}$ globally; 5 of these were located in the same region as the July 5, 2008, event, and the closest was a M 7.3 earthquake in August 1970, less than $200 \mathrm{~km}$ to the southwest and about $15 \mathrm{~km}$ deeper than the July $5^{\text {th }}$ event.

\section{7/19/2008 02:39:28 UTC usp000gcjg}

\section{$37.552^{\circ} \mathrm{N}, 142.206^{\circ} \mathrm{E}$}

\section{7.0 - Off the east coast of Honshu, Japan \\ Depth 22.0 km}

The July 19, 2008, M 7.0 earthquake near the east coast of Honshu, Japan, occurred as the result of shallow thrust faulting on or near the subduction zone interface plate boundary between the Pacific and North America plates. At the location of this earthquake, the Pacific plate moves approximately westward relative to the North America plate at a velocity of $70 \mathrm{~mm} / \mathrm{yr}$, subducting beneath Japan at the Japan Trench and dipping to the west beneath Eurasia. Note that some authors divide this region into several microplates that together define the relative motions among the larger Pacific, North America, and Eurasia plates; these include the Okhotsk and Amur microplates local to this earthquake that are part of North America and Eurasia, respectively.

The subduction zone offshore of Honshu has hosted nine events of M 7+ since 1973. The largest of these was a M 7.8 earthquake approximately $350 \mathrm{~km}$ to the north of the July $19^{\text {th }}$ event, in December 1994, which caused 3 fatalities and almost 700 injuries. In June, 1978, a M 7.7 earthquake $75 \mathrm{~km}$ to the northwest caused 22 fatalities and more than 400 injuries.

\section{9/29/2008 15:19:31 UTC usp000ghyg}

\section{$29.749^{\circ} \mathrm{S}, 177.678^{\circ} \mathrm{W}$}

\section{7.0 - Kermadec Islands, New Zealand Depth 36.0 km}

\section{Electronic Poster Available}

The September 29, 2008, M 7.0 Kermadec Islands earthquake occurred as the result of shallow reverse faulting within the Tonga-Kermadec subduction zone, which extends north-northeast from the North Island of New Zealand for more than 
2,500 km through Tonga to within $100 \mathrm{~km}$ of Samoa. Focal mechanism solutions indicate that rupture occurred on either a north-northeast- or a south-southwest-striking, moderately dipping reverse fault. At the location of the earthquake, the Pacific plate moves westward relative to the Australia plate at a velocity of about $60 \mathrm{~mm} / \mathrm{yr}$, subducting to the west beneath the Australia plate at the Tonga and Kermadec Trenches. The eastern edge of the Australia plate may itself be viewed as a collection of microplates whose relative motions help to accommodate the overall Pacific-Australia convergence and associated back-arc spreading. The location and focal mechanism solutions of the earthquake are consistent with it occurring as westward-dipping reverse faulting on the interface between the subducting Pacific plate and the overriding Australia plate (in detail, the overriding Kermadec microplate).

The interaction between the Pacific and Australia plates creates one of the most active tectonic environments in the world, with a high level of associated earthquake activity. Since 1976, a 200-km-long section of the Tonga-Kermadec subduction zone, which includes the epicenter of the September $29^{\text {th }}$ earthquake, has produced more than 50 earthquakes of M 6 or larger. The largest event was a M 8 earthquake in January 1976, more than $100 \mathrm{~km}$ to the north, with no associated casualties or damage.

\section{1/16/2008 17:02:32 UTC usp000gnur $1.290^{\circ} \mathrm{N}, 122.100^{\circ} \mathrm{E}$}

\section{7.4 - Minahasa, Sulawesi, Indonesia \\ Depth 30.0 km \\ Electronic Poster Available}

The November 16, 2008, M 7.4 Sulawesi, Indonesia earthquake occurred as a result of shallow thrust faulting on a plate boundary that is marked by the North Sulawesi Trench, separating the Celebes Sea Basin and the Minahasa Peninsula. Eastern Indonesia is characterized by complex tectonics in which motions of numerous small microplates are accommodating large-scale convergence among the Australia, Sunda, Pacific, and Philippine Sea plates. At the location of the earthquake, the Celebes Sea Basin (commonly considered part of the Sunda plate) moves south with respect to the Minahasa Peninsula (part of the Molucca Sea microplate) at a velocity of about $30 \mathrm{~mm} / \mathrm{yr}$, and moves in the same direction with respect to the broader Australia plate to the south at a rate of approximately $73 \mathrm{~mm} / \mathrm{yr}$. The lithosphere of the Celebes Sea Basin is thrust beneath that of the Minahasa Peninsula and is seismically active to a depth of about $250 \mathrm{~km}$.

The earthquake occurred approximately $25 \mathrm{~km}$ off the northern coast of the Minahasa Peninsula of the island of Sulawesi in an area that has hosted large earthquakes in the past. For example, a damaging M 7.6 earthquake occurred on April 18, 1990, approximately $85 \mathrm{~km}$ east of the November $16^{\text {th }}$ earthquake. The M 7.6 earthquake in 1990 was followed a year later by a M 7.5 earthquake in approximately the same place. More recently, a M 7.0 event occurred within $45 \mathrm{~km}$ of the November $16^{\text {th }}$ earthquake on November 25, 1997. The 1997 earthquake caused damage to at least 90 buildings in the Gorontalo area of northern Sulawesi.

11/24/2008 09:02:58 UTC

\section{$54.194^{\circ} \mathrm{N}, 154.315^{\circ} \mathrm{E}$}

\section{7.3 - Sea of Okhotsk Depth 492.3 km}

\section{Electronic Poster Available}

The November 24, 2008, M 7.3 Sea of Okhotsk earthquake occurred as the result of deep normal faulting, approximately $490 \mathrm{~km}$ beneath the Sea of Okhotsk off the west coast of the Kamchatka Peninsula, in an inclined seismic zone that dips to the west-northwest beneath Kamchatka and the Kuril Islands. Focal mechanism solutions indicate that rupture occurred on either a near-vertical northeast-striking normal fault or a shallowly dipping west-striking normal fault. In the region of Kamchatka, the Pacific plate moves to the west-northwest with respect to the Okhotsk plate at a velocity of about $80 \mathrm{~mm} / \mathrm{yr}$. The Pacific plate thrusts under the Okhotsk plate at the Kuril-Kamchatka Trench and is subducted into the mantle. The earthquake occurred within the Pacific plate, in response to stresses generated by the plate's slow distortion, rather than on the thrust fault that constitutes the interface the between the Okhotsk and Pacific plates and which is seismically active near the Earth's surface. Slip on a fault aligned with either nodal plane of the focal mechanism solution would accommodate the down-dip extension of the Pacific slab that is implied by the normal-component of the faulting solution. The Pacific plate is active to depths of about $650 \mathrm{~km}$ in the region of the earthquake. The M 7.7 Sea of Okhotsk earthquake on July 5, 2008, occurred about $100 \mathrm{~km}$ to the west-southwest and more than $100 \mathrm{~km}$ deeper than the event on November 24.

Earthquakes that have focal depths greater than $300 \mathrm{~km}$ are commonly termed "deep-focus" earthquakes. Deep-focus earthquakes cause less damage on the ground surface above their foci than similar-magnitude shallow-focus earthquakes, but large 
deep-focus earthquakes may be felt at great distance from their epicenters. The largest recorded deep-focus earthquake prior to this November 2008 earthquake was a M 8.2 event that occurred at a depth of $630 \mathrm{~km}$ within the subducted Nazca plate beneath South America near the northern Bolivian border in 1994. A larger event has since occurred-namely the M 8.3 earthquake that occurred at a depth of $600 \mathrm{~km}$ within the subducted Pacific plate beneath the Sea of Okhotsk offshore of northeastern Russia in 2013. The M 8.3 Sea of Okhotsk earthquake was felt all over Asia, as far away as Moscow, and across the Pacific Ocean along the western seaboard of the United States (though at distant locations, individuals reporting having felt the event were likely very favorably situated for the perception of small ground motions). The M 8.2 Bolivian deep-focus earthquake in 1994 had similarly been reported by individuals in North America at great distance from the epicenter.

Over the past century, 76 earthquakes with a magnitude of M 7+ have occurred at depths greater than $300 \mathrm{~km}$ globally; 6 of these were located in the same region as the November 24, 2008, event. The larger event of the two that occurred in 2008 was the M 7.7 earthquake on July 5.

\section{9: 17 Events}

\section{1/03/2009 19:43:50 UTC usp000gs2d $0.408^{\circ} \mathrm{S}, 132.886^{\circ} \mathrm{E}$}

\section{7.7 - Near the north coast of Papua, Indonesia Depth 17.0 km}

\section{Electronic Poster Available}

The M 7.7 (19:43 UTC) and M 7.4 (22:33 UTC) Papua, Indonesia earthquakes of January 3, 2009, 19:43 UTC and 22:33 UTC, respectively, occurred as a result of thrust faulting on a plate boundary along the northwest coast of the island of New Guinea. Eastern Indonesia is characterized by complex tectonics in which motions of numerous small plates are accommodating large-scale convergence among the Australia, Sunda, Pacific, and Philippine Sea plates. In broad-scale plate tectonic models that do not subdivide continent-sized plates into smaller plates, the locations of the January $3^{\text {rd }}$ earthquakes would be on the boundary of the Pacific and Australia plates. The Pacific plate (located north and northeast of the epicenter) is moving southwest with respect to the Australia plate (located south of the epicenter) at a velocity of about $112 \mathrm{~mm} / \mathrm{yr}$ at the epicenter of the earthquake, and the focal mechanism solutions of these earthquakes are broadly consistent with Pacific plate lithosphere being subducted beneath Australia plate lithosphere. The subduction zone along the northwest coast of New Guinea is characterized by an offshore oceanic trench, the New Guinea Trench, but teleseismically recorded earthquake hypocenters do not show a welldeveloped inclined seismic zone (a Wadati-Benioff zone) dipping south-southwest from the trench.

While commonly plotted as points on maps, earthquakes of this size are more appropriately described as slip over a larger fault area. Thrust-faulting events of the size of the January 3, 2009, M 7.7 earthquake are typically about 100x50 km (length x width); modeling of this earthquake implies similar dimensions, predominantly up-dip and to the west of the hypocenter.

The earthquake of January 3, 2009, 19:43 UTC, occurred about $470 \mathrm{~km}$ west of the M 8.2 earthquake of February 17, 1996. The 1996 earthquake produced a tsunami that was destructive on the island of Biak. At least 108 people were killed by the earthquake and associated tsunami.

The M 7.4 earthquake of January 3, 2009, 22:33 UTC, had the same focal mechanism solution as the M 7.7 event of the same date, 19:43 UTC, and was located about $70 \mathrm{~km}$ east of the earlier shock. The M 7.4 earthquake was almost certainly triggered by the earlier event. Seismologists sometimes refer to a pair of similarly sized shocks that occur at nearly the same time and location as an earthquake "doublet."

\section{1/03/2009 22:33:40 UTC usp000gs3t}

\section{$0.707^{\circ} \mathrm{S}, 133.361^{\circ} \mathrm{E}$}

\section{7.4 - Near the north coast of Papua, Indonesia Depth 23.0 km}

\section{Electronic Poster Available}

The M 7.7 (19:43 UTC) and M 7.4 (22:33 UTC) Papua, Indonesia earthquakes of January 3, 2009, occurred as a result of thrust faulting on a plate-boundary along the northwest coast of the island of New Guinea. Eastern Indonesia is characterized by complex tectonics in which motions of numerous small plates are accommodating large-scale convergence among the Australia, Sunda, Pacific, and Philippine Sea plates. In broad-scale plate tectonic models that do not subdivide continent-sized plates into 
smaller plates, the locations of January $3^{\text {rd }}$ earthquakes would be on the boundary of the Pacific and Australia plates. The Pacific plate (located north and northeast of the epicenter) is moving southwest with respect to the Australia plate (located south of the epicenter) at a velocity of about $112 \mathrm{~mm} / \mathrm{yr}$ at the epicenter of the earthquake, and the focal mechanism solutions of these earthquakes are broadly consistent with Pacific plate lithosphere being subducted beneath Australia plate lithosphere. The subduction zone along the northwest coast of New Guinea is characterized by an offshore oceanic trench, the New Guinea Trench, but teleseismically recorded earthquake hypocenters do not show a well-developed inclined seismic zone (a Wadati-Benioff zone) dipping south-southwest from the trench.

The M 7.7 earthquake of January 3, 2009, 19:43 UTC, occurred about $470 \mathrm{~km}$ west of the M 8.2 earthquake of February 17, 1996. The 1996 earthquake produced a tsunami that was destructive on the island of Biak. At least 108 people were killed by the earthquake and associated tsunami.

The M 7.4 earthquake of January 3, 2009, 22:33 UTC, had the same focal mechanism solution as the M 7.7 event of the same date, 19:43 UTC, and was located about $70 \mathrm{~km}$ east of the earlier shock. The M 7.4 earthquake was almost certainly triggered by the earlier earthquake. Seismologists sometimes refer to a pair of similarly sized shocks that occur at nearly the same time and location as an earthquake "doublet."

\section{1/15/2009 17:49:39 UTC usp000gsmz $46.862^{\circ} \mathrm{N}, 155.156^{\circ} \mathrm{E}$}

\section{7.4 - East of the Kuril Islands}

\section{Depth 36.0 km}

\section{Electronic Poster Available}

The January 15, 2009, M 7.4 earthquake east of the Kuril Islands occurred as a result of shallow reverse faulting within the Pacific plate near the outer rise region about $30 \mathrm{~km}$ to the east of where the Pacific plate subducts beneath the Okhotsk microplate. The Okhotsk microplate is itself part of the larger North America plate. Focal mechanism solutions indicate that rupture occurred on either a north-northeast- or southwest-striking, moderately dipping reverse fault. Slip on a fault aligned with either nodal plane of the focal mechanism solution is consistent with this intraplate setting. In this region, the Pacific plate moves northwest with respect to the Okhotsk plate at a velocity of about $90 \mathrm{~mm} / \mathrm{yr}$.

Large and great earthquakes are common in this region. The location of this event is approximately $90 \mathrm{~km}$ to the northeast of the M 8.1 outer rise earthquake of January 13,2007, which occurred as a result of normal faulting near the Pacific plate outer rise. On November 15, 2006, a M 8.3 subduction-related thrust earthquake occurred approximately $160 \mathrm{~km}$ to the southwest.

\section{2/11/2009 17:34:50 UTC usp000gtnc $3.902^{\circ} \mathrm{N}, 126.400^{\circ} \mathrm{E}$}

\section{7.2 - Kepulauan Talaud, Indonesia \\ Depth 20.0 km \\ Electronic Poster Available}

The February 11, 2009, M 7.2 earthquake near Kepulauan Talaud, Indonesia, occurred as the result of shallow reverse faulting on or near the plate boundary system separating the Philippine Sea and Celebes Sea basins. Focal mechanism solutions indicate that rupture occurred on a reverse fault dipping moderately to the east or west. Northeastern Indonesia is characterized by complex tectonics in which motions of numerous small plates are accommodating large-scale convergence among the Australia, Sunda, Pacific, and Philippine Sea plates. In the region of this earthquake, the Philippine Sea plate moves west-northwest with respect to the Sunda plate at a velocity of about $62 \mathrm{~mm} / \mathrm{yr}$. Locally, arc-arc collision is occurring between the Sangihe and Halmahera microplates, wedging between them the Molucca Sea microplate, which subducts beneath both (to the east and west) and forms an inverted-U-shaped seismic zone. The location and depth of the earthquake and the westward dipping plane of the focal mechanism solution are consistent with slip on the interface of the west flank of this subduction zone. Seismicity within the Molucca Sea plate is active to depths of approximately $260 \mathrm{~km}$ to the east and $400 \mathrm{~km}$ to the west. The tectonic setting of this region is unique in that it is the only global example of an active arc-arc collision consuming an oceanic basin via subduction in two directions.

The earthquake occurred approximately $30 \mathrm{~km}$ off the western coast of Pulau Salebabu (Indonesia) in an area that has hosted large earthquakes in the past. Within $400 \mathrm{~km}$ of the February $11^{\text {th }}$ earthquake, 18 earthquakes of $\mathrm{M} 7$ or larger have occurred over the preceding 40 years. The largest of these was a M 8.0 event in December 1972, about $200 \mathrm{~km}$ to the north of the February 11, 2009, earthquake. 
02/18/2009 21:53:45 UTC

usp000gu5x

$27.464^{\circ} \mathrm{S}, 176.324^{\circ} \mathrm{W}$

\section{7.0 - Kermadec Islands region \\ Depth 25.0 km}

The February 18, 2009, M 7.0 earthquake in the Tonga-Kermadec subduction zone occurred as the result of shallow strikeslip faulting near the Tonga-Kermadec Trench. Focal mechanism solutions indicate that rupture occurred on either a near-vertical north-striking left-lateral fault or on a moderately dipping, west-striking right-lateral fault. At the location of the earthquake, the Pacific plate moves to the west with respect to the Australia plate at a velocity of about $60 \mathrm{~mm} / \mathrm{yr}$, and begins its subduction at the Tonga-Kermadec Trench. This subduction zone extends north-northeast from the North Island of New Zealand for more than 2,500 km through Tonga to within $100 \mathrm{~km}$ of Samoa. The eastern edge of the Australia plate may itself be viewed as a collection of microplates whose relative motions help to accommodate the overall Pacific-Australia convergence and associated back-arc spreading. The location, depth, and focal mechanism solutions of the earthquake are consistent with it occurring within the subducting Pacific plate, rather than on the overlying thrust interface between the two plates. Slip on a fault aligned with either nodal plane of the focal mechanism solution is consistent with this intraplate setting.

The interaction between the Pacific and Australia plates creates one of the most active tectonic environments in the world, with a high level of associated earthquake activity. Over the preceding 40 years, the surrounding $400 \mathrm{~km}$ of the Tonga-Kermadec subduction zone that includes the epicenter of the February $18^{\text {th }}$ earthquake has produced 15 earthquakes of M 7 or larger. The largest event was a M 8.0 earthquake in January 1976, roughly $150 \mathrm{~km}$ to the southwest, with no recorded casualties or damage.

\section{3/19/2009 18:17:40 UTC usp000gv5p \\ $23.050^{\circ} \mathrm{S}, 174.668^{\circ} \mathrm{W}$}

\section{7.6 - Tonga region}

\section{Depth 31.0 km}

\section{Electronic Poster Available}

The March 19, 2009, M 7.6 Tonga region earthquake occurred as the result of shallow reverse faulting on or near the subduction zone interface between the Pacific and Australia plates to the southeast of Tonga. Focal mechanism solutions indicate that rupture occurred on either a south-southwest- or a north-northeast-striking, moderately dipping reverse fault. Of these two possible fault orientations, finite-fault modeling of globally recorded seismic data is more consistent with slip on the southsouthwest-striking fault. At the location of the earthquake, the Pacific plate moves west with respect to the Australia plate at a velocity of about $77 \mathrm{~mm} / \mathrm{yr}$, beginning its descent into the mantle at the Tonga Trench, just east of this earthquake.

The broad-scale tectonics of the earthquake region are dominated by the relative convergence of the Pacific and Australia plates. The eastern edge of the Australia plate may itself be viewed as a collection of small microplates whose relative motions help to accommodate the overall Pacific-Australia convergence and associated back-arc spreading. In terms of numbers of earthquakes, the broad-scale Australia-Pacific plate boundary is one of the most active in the world. Earthquakes occur on the thrust fault boundary between the Australia and Pacific plates, within the Pacific plate, and within and on the boundaries of the small microplates that together compose the eastern edge of the overall Australia plate. On the basis of currently available information, including the earthquake depth and the relative steepness of focal mechanism solution nodal plane dips, we infer that the earthquake of March 19, 2009, occurred within the subducting Pacific plate, rather than on its overlying thrust interface with the Australia plate.

While commonly plotted as points on maps, earthquakes of this size are more appropriately described as slip over a larger fault area. Reverse-faulting events of the size of the March 19, 2009, earthquake are typically about 90x40 km (length x width); modeling of this earthquake implies dimensions of about $70 \times 40 \mathrm{~km}$, predominantly down-dip of the hypocenter.

Over the preceding 50 years, a dozen earthquakes with M 7 or higher have occurred within $400 \mathrm{~km}$ of the March $19^{\text {th }}$ event. The largest and most recent earthquake was the M 8.0 event of May 2006, which occurred about $300 \mathrm{~km}$ to the north and resulted in one injury, some minimal damage, and a tsunami that was recorded as far away as La Push, Washington. That 2006 earthquake was also likely an intraplate event. 
05/28/2009 08:24:46 UTC usp000gxkj

\section{$16.733^{\circ} \mathrm{N}, 86.220^{\circ} \mathrm{W}$}

\section{7.3 - Offshore Honduras}

\section{Depth 19.0 km}

\section{Electronic Poster Available}

The May 28, 2009, M 7.3 Honduras earthquake occurred as the result of left-lateral strike-slip faulting on the Swan Islands transform fault, a segment of the boundary between the North America and Caribbean plates. In this region, the plate boundary accommodates about $20 \mathrm{~mm} / \mathrm{yr}$ of left-lateral slip.

Previous strong earthquakes along the North America-Caribbean plate boundary include the destructive Guatemala earthquake of February 4, 1976, M 7.5, which resulted in more than 23,000 fatalities. The 1976 earthquake occurred on the Motagua fault, a segment of the plate boundary that lies in southern Guatemala, several hundred kilometers southwest of the plate boundary that ruptured in the May 28, 2009, event.

\section{7/15/2009 09:22:29 UTC usp000gz8j}

\section{$45.750^{\circ} \mathrm{S}, 166.577^{\circ} \mathrm{E}$}

\section{7.8 - Off the west coast of the South Island, New Zealand}

\section{Depth 12.0 km}

\section{Electronic Poster Available}

The July 15, 2009, M 7.8 earthquake off the west coast of the South Island of New Zealand occurred as the result of shallow thrust faulting on or near the boundary between the Australia and Pacific plates. At the location of the earthquake, the Australia plate moves to the northeast at a velocity of about $35-45 \mathrm{~mm} / \mathrm{yr}$ relative to the Pacific plate. The North and South Islands of New Zealand straddle the boundary between the Australia and Pacific plates. In southwestern South Island, this motion is accommodated by oblique convergence at the Puysegur Trench, where the Australia plate subducts beneath the Pacific plate. Farther north along South Island's west coast, relative motion is accommodated via oblique strike-slip movement along the Alpine fault, driving the uplift of the Southern Alps.

This earthquake occurred near the southern tip of South Island in a region known as Fiordland, in a complex area of transition in plate boundary structure from Puysegur subduction to Alpine fault strike-slip motion. The preliminary location, depth, and estimate of fault orientation of this event are consistent with the earthquake having resulted from slip on the subduction thrust interface between the Pacific and Australia plates.

While commonly plotted as points on maps, earthquakes of this size are more appropriately described as slip over a larger fault area. Thrust-faulting events of the size of the July 15, 2009, earthquake are typically about 120x50 km (length x width); modeling of this earthquake implies dimensions of about $80 \times 40 \mathrm{~km}$, predominantly to the south of and up-dip from the hypocenter.

The deformed Australia plate beneath Fiordland is highly active both along its interface with the Pacific plate and internal to the subducted Australia plate. Over the past two decades, several large earthquakes have occurred in Fiordland, predominantly in a cluster to the northeast of the July $15^{\text {th }}$ earthquake. Though the faulting mechanisms of those events are similar to that of the July $15^{\text {th }}$ earthquake, their slip vectors are rotated clockwise with respect to plate motions, and thus may not represent exactly the same style of faulting.

The most recent of these previous large events occurred in August 2003 when a M 7.2 earthquake approximately $100 \mathrm{~km}$ to the northwest caused minor damage in Otago and Southland and numerous landslides across the Fiordland region. A M 7.0 event on August 10, 1993, caused power outages in the Te Anau area and was felt throughout South Island and as far away as Sydney, Australia. A M 6.4 earthquake struck on May 31, 1989, and was felt strongly in the southwestern part of South Island. A M 6.7 quake struck on June 3, 1988.

\section{8/09/2009 10:55:55 UTC usp000h04j}

\section{$33.122^{\circ} \mathrm{N}, 138.026^{\circ} \mathrm{E}$}

\section{7.1 - Near the south coast of Honshu, Japan \\ Depth 292.0 km}

\section{Electronic Poster Available}

The August 9, 2009, M 7.1 earthquake off the south coast of Honshu, Japan, occurred as the result of deep oblique-reverse faulting, approximately $300 \mathrm{~km}$ beneath the Pacific Ocean off the southern coast of Japan, within the Izu-Bonin subduction 
system. Focal mechanism solutions indicate that rupture occurred on either a near-vertical reverse fault or a shallowly dipping thrust fault. Slip on a fault of either orientation would accommodate the down-dip compression of the Pacific slab that is implied by the reverse component of the faulting solution. At the location of the earthquake, the Pacific plate moves westward relative to the Philippine Sea plate at a velocity of about $50 \mathrm{~mm} / \mathrm{yr}$, subducting at the Izu-Bonin Trench several hundred kilometers to the east of this earthquake. The Izu-Bonin subduction zone as a whole extends 1,200 km from southern Honshu to the Mariana Islands and constitutes part of the boundary between the Pacific plate and the Philippine Sea plate. The August 9, 2009, earthquake occurred at depth within the westward-dipping Pacific plate, well beneath the overriding Philippine Sea plate.

Subduction of the Pacific plate along the northern and western margins of the Pacific Ocean generates a large amount of seismicity. Earthquakes typically occur as thrust faulting on interfaces that separate the subducting Pacific plate from the overriding plates, as well as within the subducting or overriding plates as the result of stresses associated with intraplate deformation. The August 9, 2009, earthquake was an intraplate event. Earthquakes have been accurately located to depths of $450 \mathrm{~km}$ in the section of the Izu-Bonin subduction zone within which the August $9^{\text {th }}$ earthquake occurred.

Earthquakes that have focal depths greater than $300 \mathrm{~km}$ are commonly termed "deep-focus" earthquakes. Deep-focus earthquakes cause less damage on the ground surface above their foci than similar-magnitude shallow-focus earthquakes, but large deep-focus earthquakes may be felt at great distance from their epicenters. The largest recorded deep-focus earthquake prior to this August 2009 earthquake was a M 8.2 event that occurred at a depth of $630 \mathrm{~km}$ within the subducted Nazca plate beneath South America near the northern Bolivian border in 1994. A larger event has since occurred-namely the M 8.3 earthquake that occurred at a depth of $600 \mathrm{~km}$ within the subducted Pacific plate beneath the Sea of Okhotsk offshore of northeastern Russia in 2013. The M 8.3 Sea of Okhotsk earthquake was felt all over Asia, as far away as Moscow, and across the Pacific Ocean along the western seaboard of the United States (though at distant locations, individuals reporting having felt the event were likely very favorably situated for the perception of small ground motions). The M 8.2 Bolivian deep-focus earthquake in 1994 had similarly been reported by individuals in North America at great distance from the epicenter.

Over the past century, 77 earthquakes with a magnitude of M 7+ have occurred at depths greater than $300 \mathrm{~km}$ globally; 12 of these were located in the same region as the August 9, 2009, event. The largest nearby event at these depths was a M 7.3 earthquake in October 1968, several hundred kilometers to the southeast and $200 \mathrm{~km}$ deeper than the August $9^{\text {th }}$ event, which did not result in any recorded damage.

\section{8/10/2009 19:55:38 UTC usp000h05x $14.013^{\circ} \mathrm{N}, 92.923^{\circ} \mathrm{E}$}

\section{7.5 - Andaman Islands, India region Depth 24.0 km}

\section{Electronic Poster Available}

The August 10, 2009, M 7.5 earthquake near the Andaman Islands occurred as the result of shallow normal faulting in the boundary region of the India and Burma plates, near the north end of the rupture zone associated with the great-sized SumatraAndaman earthquake of December 26, 2004. At the location of the earthquake, the India plate moves to north-northeast relative to the Burma plate (part of the larger Sunda plate) at a velocity of about $50 \mathrm{~mm} / \mathrm{yr}$. Focal mechanism solutions indicate that rupture occurred on either a northeast or southwest-striking, moderately dipping normal fault. Finite-fault modeling of globally recorded seismic data for this earthquake is not able to distinguish between these two possibilities. This style of faulting is consistent with the earthquake occurring as a result of stresses generated by bending of the India plate as it subducts beneath the Burma plate. The August $10^{\text {th }}$ earthquake was therefore an intraplate earthquake, in contrast to the great-sized 2004 earthquake, which was an interplate thrust fault earthquake on the interface between the India and the Burma plates.

While commonly plotted as points on maps, earthquakes of this size are more appropriately described as slip over a larger fault area. Normal-faulting events of the size of the August 10,2009 earthquake are typically about $75 \times 30 \mathrm{~km}$ (length $\mathrm{x}$ width); modeling of this earthquake implies dimensions of about $120 \times 40 \mathrm{~km}$, predominantly surrounding and up-dip from the hypocenter.

Although the style of faulting that caused the August 10, 2009 earthquake differs from the style of faulting that caused the great-sized 2004 earthquake, it is possible that changes in the regional tectonic strain-field caused by the 2004 earthquake made conditions more favorable for the occurrence of the 2009 earthquake than would otherwise have been the case. In the days immediately following the 2004 earthquake, a large number of normal-faulting earthquakes occurred in the subducted India plate of the Andaman Islands region. The largest Andaman Islands intraplate normal-fault earthquake in the immediate aftermath of the 2004 earthquake was more than an order of magnitude smaller than the August 10, 2009, earthquake. 
09/02/2009 07:55:01 UTC

usp000h152

\section{$7.809^{\circ} \mathrm{S}, 107.259^{\circ} \mathrm{E}$}

\section{7.0 - Java, Indonesia}

\section{Depth 46.0 km}

\section{Electronic Poster Available}

The September 2, 2009, M 7.0 Java earthquake occurred at a depth of about $50 \mathrm{~km}$ as the result of reverse faulting near the boundary between the Australia and Sunda plates. Focal mechanism solutions indicate that rupture occurred on either a northnortheast- or south-striking, moderately dipping reverse fault. At the location of the earthquake, the Australia plate moves northnortheastward with respect to the Sunda plate at a velocity of about $59 \mathrm{~mm} / \mathrm{yr}$. Although the September $2^{\text {nd }}$ event's hypocenter would place it near the subduction interface between the Australia and Sunda plates, the orientation of the causative fault that is inferred from the seismic-wave radiation pattern is inconsistent with the earthquake occurring as interplate faulting on that interface. Instead, the earthquake likely occurred as the result of faulting within the subducting Australia plate. Slip on a fault aligned with either nodal plane of the focal mechanism solution is consistent with this intraplate setting.

The region of the plate boundary between the Australia plate and Sunda plate is highly seismically active, with past strong earthquakes having occurred within each of the Australia and Sunda plates as well as on the plate interface. The M 7.8 earthquake of June 2, 1994, and the M 7.7 earthquake of July 17, 2006, both of which occurred south of Java and both of which produced destructive tsunamis, occurred as the result of thrust faulting on the shallow plate interface near the Sunda-Java Trench. The devastating Yogyakarta earthquake of May 26, 2006, M 6.3, occurred at shallow depth within the overriding Sunda plate. The M 7.5 Java earthquake of August 28, 2007, occurred at a depth of about $290 \mathrm{~km}$ within the subducted Australia plate.

\section{9/29/2009 17:48:10 UTC usp000h1ys}

\section{$15.509^{\circ} \mathrm{S}, 172.034^{\circ} \mathrm{W}$}

\section{8.1 - Samoa Islands region Depth $18.0 \mathrm{~km}$}

\section{Electronic Poster Available}

The September 29, 2009, M 8.1 Samoa Islands earthquake occurred as the result of shallow normal faulting near the northern end of the Tonga-Kermadec subduction zone, and to the east of the Tonga-Kermadec Trench. Focal mechanism solutions indicate that rupture occurred on either a southeast or northwest-striking normal fault. Of these two possible fault orientations, finite-fault modeling of globally recorded seismic data is more consistent with slip on the northeast-striking fault. At the location of the earthquake, the Pacific plate moves westward relative to the Australia plate at a velocity of about $86 \mathrm{~mm} / \mathrm{yr}$, subducting at the Tonga Trench, a 3,000-km-long segment of this plate boundary that trends north-northeast. Farther north of the earthquake's source region, the plate boundary trends northwest and then west. The eastern edge of the Australia plate may itself be viewed as a collection of small microplates whose relative motions help to accommodate the overall Pacific-Australia convergence and associated back-arc spreading.

On the basis of currently available location and focal mechanism solutions, we infer that the September $29^{\text {th }}$ earthquake occurred as a normal-fault rupture on or near the outer rise of the subducting Pacific plate.

While commonly plotted as points on maps, earthquakes of this size are more appropriately described as slip over a larger fault area. Normal-faulting events of the size of the September 29, 2009, earthquake are typically about $120 x 40 \mathrm{~km}$ (length $\mathrm{x}$ width); modeling of this earthquake implies dimensions of about 100x30 km, predominantly up-dip from the hypocenter. Studies since this event have also identified a complex source process for the earthquake, including at least one additional thrust-faulting sub-event of a similar size to the normal-faulting source. The second source is located to the southwest of that first source within the Tonga-Kermadec subduction zone.

The broad-scale Australia-Pacific plate boundary is one of the most active earthquake regions in the world. Earthquakes occur on the thrust fault boundary between the Australia and Pacific plates, within the Pacific plate on both sides of the trench, and within and on the boundaries of the small microplates that compose the eastern edge of the overall Australia plate. Over the preceding 50 years, there have been nine other earthquakes of M 7+ within $400 \mathrm{~km}$ of the September $29^{\text {th }}$ event. The largest of these events was also the closest, a M 7.8 earthquake in December 1975, about $100 \mathrm{~km}$ to the southwest, on the opposite side of the plate boundary that had no associated casualties or damage recorded. 


\section{Electronic Poster Available}

The September 30, 2009, M 7.6 earthquake of southern Sumatra occurred as a result of oblique reverse faulting at an intermediate depth, approximately $80 \mathrm{~km}$ beneath the Indian Ocean off the western coast of Sumatra, and near the subduction interface plate boundary between the Australia and Sunda plates. Focal mechanism solutions indicate that oblique rupture occurred on either a northeast- or south-striking, moderately dipping reverse fault. Finite-fault modeling of globally recorded seismic data for this earthquake is not able to distinguish between these two possibilities. At the location of this earthquake, the Australia plate moves north-northeast relative to the Sunda plate at a velocity of about $60 \mathrm{~mm} / \mathrm{yr}$.

On the basis of the currently available fault mechanism information and earthquake depth of $80 \mathrm{~km}$, it is likely that this earthquake occurred within the subducting Australia plate rather than on the plate interface itself. The recent earthquake was deeper than typical subduction thrust earthquakes that generally occur at depths less than $50 \mathrm{~km}$.

The subduction zone surrounding the immediate region of this event has not witnessed a megathrust earthquake in the recent past, the last great-sized rupture being an earthquake of M 8.5 in 1797. Approximately $350 \mathrm{~km}$ to the south, a $250-\mathrm{km}-$ long section of the plate boundary slipped during a M 8.4 earthquake in September 2007, while approximately $300 \mathrm{~km}$ to the north, a 350-km-long section slipped during the M 8.6 earthquake of March 2005. Both of these events resulted in numerous fatalities and damage to surrounding areas. In early 2008 , the plate boundary up-dip of the September $30^{\text {th }}$ earthquake was active in a sequence of M 5-6 earthquakes. It is not clear how the September $30^{\text {th }}$ earthquake is related to the sequence of megathrust subduction zone events on the shallower section of the plate boundary.

Earthquakes like this event, with focal depths between 70 and $300 \mathrm{~km}$, are commonly termed "intermediate-depth" earthquakes. Intermediate-depth earthquakes represent deformation within subducted slabs rather than at the shallow plate interface between subducting and overriding tectonic plates. They typically cause less damage on the ground surface above their foci than is the case with similar-magnitude shallow-focus earthquakes, but large intermediate-depth earthquakes may be felt at great distance from their epicenters. "Deep-focus" earthquakes, those with focal depths greater than $300 \mathrm{~km}$, also occur in the subducted Australia plate beneath Sumatra and the Java Sea to the east. Earthquakes have been reliably located to depths of about 650 km within the subduction zone.

\section{0/07/2009 22:03:14 UTC}

\section{usp000h2g9}

\section{$13.052^{\circ} \mathrm{S}, 166.187^{\circ} \mathrm{E}$}

\section{7.7 - Vanuatu}

\section{Depth 45.0 km}

\section{Electronic Poster Available}

The Vanuatu region earthquakes of October 7, 2009: M 7.7, Vanuatu, 22:03:14; M 7.8 Santa Cruz Islands, 22:18:51 UTC; and M 7.4, Vanuatu, 23:13:48; all occurred as a result of shallow reverse faulting on or near the plate boundary interface between the Australia and Pacific plates. In the region of these earthquakes, the Australia plate moves to the east-northeast with respect to the Pacific plate at a velocity of about $91 \mathrm{~mm} / \mathrm{yr}$. The Australia plate thrusts under the Pacific plate at the New Hebrides Trench and dips to the east-northeast. The locations, depths, and focal mechanism solutions for the October $7^{\text {th }}$ events are all consistent with them resulting from reverse faulting associated with subduction along the Australia-Pacific plate boundary.

While commonly plotted as points on maps, earthquakes of this size are more appropriately described as slip over a larger fault area. Reverse-faulting events of the size of the October 7, 2009, M 7.7 earthquake are typically about 100x50 km (length x width); modeling of this earthquake implies dimensions of about 70x50 km, predominantly to the north of the hypocenter.

The earthquake of October 7, 2009 (22:03 UTC), occurred about $60 \mathrm{~km}$ south of, and 15 minutes prior to, a slightly larger event of the same date (22:18 UTC). A third, smaller event occurred at 23:13 UTC, $15 \mathrm{~km}$ to the southeast of the first event. All three events are likely related; while the first two similarly sized events may be considered an earthquake doublet, preliminary analysis suggests that the 23:13 UTC earthquake is likely a large aftershock of the previous events.

The Vanuatu region experiences a very high level of earthquake activity, with more than a dozen events of M 7+ having been recorded since the early decades of the $20^{\text {th }}$ century. Recent large earthquakes near the October $7^{\text {th }}$ events include a M 7.2 earthquake in 2007 and a M 7.3 earthquake in 1999. The subducting Australia plate is seismically active to depths of about $350 \mathrm{~km}$ beneath the islands. 
10/07/2009 22:18:56 UTC

\section{$12.554^{\circ} \mathrm{S}, 166.320^{\circ} \mathrm{E}$}

\section{7.8 - Santa Cruz Islands}

\section{Depth 35.0 km}

\section{Electronic Poster Available}

The Vanuatu region earthquakes of October 7, 2009: M 7.7, Vanuatu, 22:03:14; M 7.8 Santa Cruz Islands, 22:18:51 UTC; and M 7.4, Vanuatu, 23:13:48; all occurred as a result of shallow reverse faulting on or near the plate boundary interface between the Australia and Pacific plates. In the region of these earthquakes, the Australia plate moves to the east-northeast with respect to the Pacific plate at a velocity of about $91 \mathrm{~mm} / \mathrm{yr}$. The Australia plate thrusts under the Pacific plate at the New Hebrides Trench and dips to the east-northeast. The locations, depths, and focal mechanism solutions for the October $7^{\text {th }}$ events are all consistent with them resulting from reverse faulting associated with subduction along the Australia-Pacific plate boundary.

The earthquake of October 7, 2009 (22:18 UTC), occurred about $60 \mathrm{~km}$ north of, and 15 minutes after, a slightly smaller earthquake of the same date (22:03 UTC). A third, smaller event occurred at 23:13 UTC, $15 \mathrm{~km}$ to the southeast of the first event. All three events are likely related; while the first two similarly sized events may be considered an earthquake doublet, preliminary analysis suggests that the 23:13 UTC earthquake is likely a large aftershock of the previous events.

While commonly plotted as points on maps, earthquakes of this size are more appropriately described as slip over a larger fault area. Reverse-faulting events of the size of the October 7, 2009, M 7.8 earthquake are typically about 120x50 km (length x width); interference from the previous event in this sequence make modeling the M 7.8 event's source dimensions complicated; therefore, a slip model is not available at this time.

The Vanuatu region experiences a very high level of earthquake activity, with more than a dozen events of M 7+ having been recorded since the early decades of the $20^{\text {th }}$ century. Recent large earthquakes near the October $7^{\text {th }}$ events include a M 7.2 earthquake in 2007 and a M 7.3 earthquake in 1999. The subducting Australia plate is seismically active to depths of about $350 \mathrm{~km}$ beneath the islands.

\section{0/07/2009 23:13:48 UTC usp000h2gr \\ $13.145^{\circ} \mathrm{S}, 166.297^{\circ} \mathrm{E}$}

\section{7.4 - Vanuatu}

\section{Depth 31.1 km}

\section{Electronic Poster Available}

The Vanuatu region earthquakes of October 7, 2009: M 7.7, Vanuatu, 22:03:14; M 7.8 Santa Cruz Islands, 22:18:51 UTC; and M 7.4, Vanuatu, 23:13:48; all occurred as a result of shallow reverse faulting on or near the plate boundary interface between the Australia and Pacific plates. In the region of these earthquakes, the Australia plate moves to the east-northeast with respect to the Pacific plate at a velocity of about $91 \mathrm{~mm} / \mathrm{yr}$. The Australia plate thrusts under the Pacific plate at the New Hebrides Trench and dips to the east-northeast. The locations, depths, and focal mechanism solutions for the October $7^{\text {th }}$ events are all consistent with them resulting from reverse faulting associated with subduction along the Australia-Pacific plate boundary.

The earthquake of October 7, 2009 (23:13 UTC), occurred about $15 \mathrm{~km}$ southeast of, and 1 hour after, a larger earthquake of the same date (22:03 UTC). A second event of a similar size to the first occurred at 22:18 UTC, $60 \mathrm{~km}$ to the north of the first event. All three events are likely related; while the first two similarly sized events may be considered an earthquake doublet, preliminary analysis suggests that the 23:13 UTC earthquake is likely a large aftershock of the previous events.

The Vanuatu region experiences a very high level of earthquake activity, with more than a dozen events of M 7+ having been recorded since the early decades of the $20^{\text {th }}$ century. Recent large earthquakes near the October $7^{\text {th }}$ events include a M 7.2 earthquake in 2007 and a M 7.3 earthquake in 1999. The subducting Australia plate is seismically active to depths of about $350 \mathrm{~km}$ beneath the islands. 
11/09/2009 10:44:55 UTC

\section{$17.212^{\circ} \mathrm{S}, 178.413^{\circ} \mathrm{E}$}

\section{7.3 - Fiji}

\section{Depth 595.0 km}

\section{Electronic Poster Available}

The November 9, 2009, M 7.3 Fiji earthquake occurred as the result of deep, oblique reverse faulting, nearly $600 \mathrm{~km}$ beneath the north coast of Fiji, at the northern end of the inclined seismic zone that dips to the west beneath Tonga and Fiji. Focal mechanism solutions indicate that oblique rupture occurred on either a steep northeast-striking reverse fault or a moderately dipping, south-striking reverse fault. At the location of the earthquake, the Pacific plate moves westward with respect to the interior of the Australia plate at a velocity of about $86 \mathrm{~mm} / \mathrm{yr}$. The inclined seismic zone lies within the Pacific plate, which subducts westward beneath the Australia plate at the Tonga Trench. The earthquake occurred in response to stresses generated by the slow distortion of the Pacific plate, rather than on the shallow thrust fault that constitutes the interface between the two and which is seismically active near the Earth's surface. Slip on a fault aligned with either nodal plane of the focal mechanism solution is consistent with this intraplate setting.

Earthquakes that have focal depths greater than $300 \mathrm{~km}$ are commonly termed "deep-focus" earthquakes. Deep-focus earthquakes cause less damage on the ground surface above their foci than similar-magnitude shallow-focus earthquakes, but large deep-focus earthquakes may be felt at great distance from their epicenters. The largest recorded deep-focus earthquake prior to this November 2009 earthquake was a M 8.2 event that occurred at a depth of $630 \mathrm{~km}$ within the subducted Nazca plate beneath South America near the northern Bolivian border in 1994. A larger event has since occurred-namely the M 8.3 earthquake that occurred at a depth of $600 \mathrm{~km}$ within the subducted Pacific plate beneath the Sea of Okhotsk offshore of northeastern Russia in 2013. The M 8.3 Sea of Okhotsk earthquake was felt all over Asia, as far away as Moscow, and across the Pacific Ocean along the western seaboard of the United States (though at distant locations, individuals reporting having felt the event were likely very favorably situated for the perception of small ground motions). The M 8.2 Bolivian deep-focus earthquake in 1994 had similarly been reported by individuals in North America at great distance from the epicenter.

Over the past century, 78 earthquakes with a magnitude of M 7+ have occurred at depths greater than $300 \mathrm{~km}$ globally; 24 of these were located in the same region as the November 9, 2009, event. The largest nearby event at these depths was a M 7.7 earthquake in August 2002, about $400 \mathrm{~km}$ to the southeast and $10 \mathrm{~km}$ shallower than the November $9^{\text {th }}$ event with no resulting damage or casualties. Overall, the Pacific plate is active to depths of about $700 \mathrm{~km}$ in the region of the earthquake.

\section{0: 24 Events}

\section{1/03/2010 22:36:25 UTC Usp000h5np \\ $8.800^{\circ} \mathrm{S}, 157.370^{\circ} \mathrm{E}$ \\ M 7.1 - Solomon Islands \\ Depth $10.0 \mathrm{~km}$ \\ Electronic Poster Available}

The January 3, 2010, M 7.1 Solomon Islands earthquake occurred as the result of shallow thrust faulting at the boundary where the Australia plate subducts beneath the Pacific. Focal mechanism solutions indicate that rupture occurred on either a steeply dipping reverse fault or a shallowly dipping thrust fault. At the location of the earthquake, the Australia plate moves to the northeast relative to the Pacific plate at a velocity of about $95 \mathrm{~mm} / \mathrm{yr}$, subducting at the Solomon Trench. Relative motions of the many local, small microplates help to accommodate this broad Pacific-Australia convergence and its associated back-arc spreading. In this context, the January $3^{\text {rd }}$ earthquake is near the Woodlark and Solomon Sea microplates. The location, depth, and mechanism of the January $3^{\text {rd }}$ earthquake are consistent with its occurrence being part of this overall subduction process.

The Solomon Islands Arc as a whole experiences a very high level of earthquake activity, and many events of M 7 or larger have been recorded since the early decades of the $20^{\text {th }}$ century. The January $3^{\text {rd }}$ earthquake nucleated approximately $50 \mathrm{~km}$ to the southeast of a M 8.1 earthquake that occurred in April 2007, which with an associated tsunami caused at least 50 fatalities and destroyed several coastal villages on nearby islands. A M 6.5 foreshock occurred less than 1 hour before the January 3, 2010, M 7.1 event, in approximately the same location. 


\section{1/12/2010 21:53:10 UTC Usp000h60h \\ $18.443^{\circ} \mathrm{N}, 72.571^{\circ} \mathrm{W}$}

\section{7.0 - Haiti Region \\ Depth 13.0 km}

\section{Electronic Poster Available}

The January 12, 2010, M 7.0 Haiti earthquake occurred as the result of shallow strike-slip faulting in the boundary region separating the Caribbean plate and the North America plate. Focal mechanism solutions indicate that rupture occurred on either a right-lateral southeast-striking fault or on a left-lateral west-southwest-striking fault. Of these two possible fault orientations, finite-fault modeling of globally recorded seismic data is more consistent with slip on the west-southwest-striking (left-lateral) fault. At the location of the earthquake, the local plate boundary is dominated by left-lateral strike-slip motion and compression, and accommodates about $20 \mathrm{~mm}$ of slip per year, with the Caribbean plate moving eastward relative to the North America plate.

Haiti occupies the western part of the island of Hispaniola, one of the Greater Antilles Islands, situated between Puerto Rico and Cuba. At the location of the January $12^{\text {th }}$ earthquake, motion between the Caribbean and North America plates is partitioned between two major east-west-trending, strike-slip fault systems - the Septentrional fault system in northern Haiti and the Enriquillo-Plantain Garden fault system in southern Haiti.

The location and focal mechanism solutions of the earthquake are consistent with the event resulting from a combination of reverse and left-lateral strike-slip faulting on the Enriquillo-Plantain Garden fault system. The overall Enriquillo-Plantain Garden fault system accommodates about $7 \mathrm{~mm} / \mathrm{yr}$ of motion, nearly half the total oblique convergence between the Caribbean and North America plates. The January $12^{\text {th }}$ mainshock did not produce observable surface displacement on the geomorphologically well-expressed main strand of the Enriquillo-Plantain Garden fault system, but appears instead to have primarily involved rupture of a fault or faults distinct from the previously mapped principal strand, causing substantial uplift of the Léogâne delta.

The Enriquillo-Plantain Garden fault zone (EPGFZ) had not produced a major earthquake in recent decades. The EPGFZ is the likely source of historical large earthquakes in 1860, 1770, and 1751, though none of these has been confirmed in the field as associated with this fault.

The sequence of events possibly associated with the Enriquillo fault in 1751-1860 are as follows:

- October 18, 1751: a major earthquake caused heavy destruction in the Gulf of Azua (the eastern end of the Enriquillo fault); this earthquake also generated a tsunami. It is unclear if the rupture occurred on the Muertos thrust belt or on the eastern end of the Enriquillo fault.

- November 21, 1751: a major earthquake destroyed Port-au-Prince but was centered to the east of the city on the Plaine du Cul-de-Sac.

- June 3,1770: a major earthquake destroyed Port-au-Prince again and appeared to be centered west of the city. As a result of the 1751 and 1770 earthquakes and minor earthquakes that occurred between them, local authorities required building with wood and forbade building with masonry.

- April 8, 1860: a major earthquake occurred farther west of the 2010 earthquake and was accompanied by a tsunami.

\section{2/26/2010 20:31:26 UTC usp000h7qu}

\section{$25.902^{\circ} \mathrm{N}, 128.417^{\circ} \mathrm{E}$}

\section{7.0 - Ryukyu Islands, Japan}

\section{Depth $25.0 \mathrm{~km}$}

\section{Electronic Poster Available}

The February 26, 2010, M 7.9 Ryukyu Islands earthquake occurred as the result of shallow strike-slip faulting near the boundary that accommodates most of the relative motion between the Philippine Sea and Eurasia tectonic plates. Focal mechanism solutions indicate that rupture occurred on either a left-lateral east-striking fault or a right-lateral north-striking fault. In the region of the earthquake, the Philippine Sea plate moves west-northwest with respect to the Eurasia plate at a velocity of about $60 \mathrm{~mm} / \mathrm{yr}$. The Philippine Sea plate subducts beneath the Eurasia plate at the Ryukyu Trench and is seismically active to depths of about $250 \mathrm{~km}$. The initial estimates of the earthquake's epicenter, focal depth, and focal mechanism solutions imply that the shock occurred as an intraplate event, either within the subducting Philippine Sea plate or within the overlying Eurasia plate, rather than on the thrust fault plate interface that separates the two, but preliminarily data do not clearly discriminate between 
these two possibilities. Slip on a fault aligned with either nodal plane of the focal mechanism solution is consistent with intraplate rupture in either tectonic plate.

The largest, instrumentally recorded, shallow-focus earthquakes from the region of the central Ryukyu Trench have had magnitudes in the M 7.1-7.4 range. The two closest and most recent events of M 7+ relative to the February $26^{\text {th }}$ event are a M 7.7 earthquake in September 1998 east of Taiwan and a M 7.1 earthquake in October 1995 that was also within the Ryukyu Islands, about $200 \mathrm{~km}$ to the northeast. Both of these events were also shallow-focus earthquakes, but with dissimilar focal mechanism solutions to the February $26^{\text {th }}$ event.

\section{2/27/2010 06:34:11 UTC Usp000h7rf}

\section{$35.909^{\circ} \mathrm{S}, 72.733^{\circ} \mathrm{W}$}

\section{8.8 - Offshore Bio-Bio, Chile}

\section{Depth 22.9 km}

\section{Electronic Poster Available}

The February 27, 2010, M 8.8 Chilean (Maule) earthquake occurred as the result of shallow thrust faulting generated at the gently sloping plate boundary fault that conveys the Nazca plate eastward and downward beneath the South America plate. At the location of the earthquake, the two plates are converging at a rate of $71 \mathrm{~mm} / \mathrm{yr}$. The fault rupture, largely offshore, exceeded $100 \mathrm{~km}$ in width and extended nearly $500 \mathrm{~km}$ parallel to the coast. The rupture began approximately $25 \mathrm{~km}$ deep beneath the coast and spread westward, northward, and southward. As the rupture spread, the fault slip (up to $15 \mathrm{~m}$ in magnitude) generated earthquake shaking and warped the ocean floor, triggering a tsunami along the fault-rupture area.

The written history of very large plate boundary earthquakes between Valparaiso and Concepción probably begins with an event near Concepción in 1562. Another earthquake 8 years later set off a tsunami that led Spaniards to rebuild Concepción on higher ground. A 1730 earthquake, which was probably centered near Valparaiso generated a tsunami that caused flooding and damage in Japan, as did the great Concepción earthquake of 1751. Charles Darwin and Robert FitzRoy observed the next major Concepción earthquake in 1835. The northern part of the 2010 rupture overlaps with the probable source area of the 1906 Valpariso earthquake of M 8.2. The tsunami associated with the 1906 earthquake produced damage in Hawaii, with reported runup heights as great as $3.5 \mathrm{~m}$.

Other parts of Chile's coast have also produced notable earthquakes. South of Concepción, the source of the 2010 earthquake adjoins a fault rupture nearly $1,000 \mathrm{~km}$ long that produced the largest 20th-century earthquake worldwide, the giant earthquake of M 9.5 in 1960. An estimated 1,600 lives were lost because of the 1960 earthquake and tsunami in Chile, and the tsunami took another 200 lives in Japan, Hawaii, and the Philippines. At Valparaiso, a plate boundary earthquake of M 8.0 occurred in 1985. North of Valparaiso, a M 8.5 earthquake in 1922 generated a Pacific Ocean tsunami that reached heights of $9 \mathrm{~m}$ on the Chilean coast near Coquimbo and washed away boats in Hilo Harbor, Hawaii. Still farther north along the coast of Chile and Peru, great earthquakes with associated trans-Pacific tsunamis occurred in 1586, 1687, 1868, and 1877. Overall, along the Chilean coast, 13 earthquakes of M 7.0+ have occurred since 1973.

Since the beginning of the $20^{\text {th }}$ century, M 8.2 earthquakes have occurred in 1906, 1943 and 1960, and a M 8.0 earthquake occurred in 1985, all in the vicinity of the February 27, 2010, earthquake. The M 8.2 earthquake in 1960 was a foreshock that occurred the day before the great M 9.5 Chilean earthquake.

\section{2/27/2010 08:01:23 UTC usp000h7sq}

\section{$37.773^{\circ} \mathrm{S}, 75.048^{\circ} \mathrm{W}$}

\section{7.4 - Offshore Bio-Bio, Chile \\ Depth 35.0 km}

The February 27, 2010, M 7.4 Chilean earthquake occurred as the result of shallow normal faulting near the Peru-Chile Trench, which marks the location where the Nazca plate begins its eastward descent beneath South America. Focal mechanism solutions indicate that rupture occurred on either a roughly north- or south-striking, moderately dipping normal fault. At the location of the earthquake, the Nazca plate moves east relative to the South America plate at a velocity of about $70 \mathrm{~mm} / \mathrm{yr}$. The location and mechanism of this event indicate that it was generated by intraplate faulting within the oceanic lithosphere of the Nazca plate prior to entering the Peru-Chile subduction zone, rather than on the subduction zone interface farther to the east. Slip on a fault aligned with either nodal plane of the focal mechanism solution is consistent with this intraplate setting. The earthquake is an aftershock of the M 8.8 Maule earthquake that occurred only 2 hours previously. The epicenter of the Maule earthquake was located approximately $200 \mathrm{~km}$ to the northeast of this M 7.4 event, but broke a section of the plate boundary approximately $500 \mathrm{~km}$ in length, including the subduction zone directly adjacent to this 08:01 UTC earthquake. 
03/11/2010 14:55:27 UTC

usp000h94v

\section{$34.326^{\circ} \mathrm{S}, 71.799^{\circ} \mathrm{W}$}

\section{7.0 - Libertador General Bernando O’Higgins, Chile \\ Depth 18.0 km}

The March 11, 2010, M 7.0 Chilean earthquake occurred as the result of shallow normal faulting within the South America plate, above the subduction zone defined by the convergence between the Nazca and South America plates. Focal mechanism solutions indicate that rupture occurred on either a near-vertical normal fault or on a shallowly dipping normal fault. Of these two possible fault orientations, finite-fault modeling of globally recorded seismic data is more consistent with slip on the steep, southeast-striking fault. At the location of the earthquake, the Nazca plate moves east relative to the South America plate at a velocity of about $70 \mathrm{~mm} / \mathrm{yr}$, subducting at the Peru-Chile Trench to the west of the Chilean coast and sinking into the Earth's mantle beneath South America. This March 11 ${ }^{\text {th }}$ earthquake, and the M 6.9 event that occurred 16 minutes previously with similar faulting just to the northwest, is part of the aftershock sequence of the February 27, 2010, M 8.8 Maule earthquake. The epicenter of the Maule earthquake was located $200 \mathrm{~km}$ to the south of this M 7.0 earthquake, but broke a section of the plate boundary approximately $500 \mathrm{~km}$ in length, including the subduction zone directly beneath this March $11^{\text {th }}$ event.

\section{4/04/2010 22:40:43 UTC usp000habu}

\section{$32.259^{\circ} \mathrm{N}, 115.287^{\circ} \mathrm{W}$}

\section{7.2 - Baja California, Mexico \\ Depth 10.0 km}

\section{Electronic Poster Available}

The April 4, 2010, M 7.2 Baja California Sierra El Mayor earthquake occurred as the result of shallow strike-slip faulting in northern Baja California, approximately $65 \mathrm{~km}$ south of the Mexico-USA border along the principal plate boundary between the North America and Pacific plates. Focal mechanism solutions indicate that rupture occurred on either a left-lateral northeastsouthwest-striking fault or a right-lateral southeast-northwest-striking fault. At the location of the earthquake, the Pacific plate moves northwest relative to the North America plate at a velocity of about $46 \mathrm{~mm} / \mathrm{yr}$.

The principal plate boundary in northern Baja California consists of a series of northwest-trending strike-slip (transform) faults that are separated by pull-apart basins. The faults are distinct from, but parallel to, strands of the San Andreas Fault system. The April $4^{\text {th }}$ main-shock occurred along a strike-slip segment of the plate boundary that coincides with the southeastern part of the Laguna Salada fault system. This complex event may have begun with east-down motion along faults on the eastern edge of the Sierra El Mayor, then progressed to the northwest with oblique slip, that is, a combination of lateral shift to the right and also east-down motion. Overall, the location and focal mechanism solutions of the earthquake are consistent with the shock having occurred on this fault system. Field geologists from the Centro de Investigación Científica y de Educación Superior de Ensenada, Baja California (CICESE, written commun., 2010) observed surface rupture associated with the 2010 event at latitude $32.578621^{\circ}$, longitude $-115.725814^{\circ}$. Highway 2 was offset at this location by a total of about $1.2 \mathrm{~m}$ across a zone of fractures that offset the road towards the right, with the east side also dropping downward. Aftershocks appear to extend in both directions along this fault system from the epicenter of the April 4, 2010, event. The aftershock zone extends from near the northern tip of the Gulf of California to $10 \mathrm{~km}$ northwest of the Mexico-USA border.

Historically, this is an area with a high level of seismicity, though the April $4^{\text {th }}$ event is the largest earthquake to strike the area since 1892. The April $4^{\text {th }}$ earthquake was larger than the M 6.9 earthquake in 1940 or any of the early 20th-century events (for example, 1915 and 1934) in this region of northern Baja California. The 1892 earthquake occurred along the Laguna Salada fault system, but surface offsets associated with the 1892 event lie farther northwest than the April $4^{\text {th }}$ mainshock's epicenter. The 2010 event's aftershock zone extends to the northwest, overlapping with the portion of the fault system that is thought to have ruptured in 1892. The 1940 Imperial Valley earthquake approached M 7, though it occurred farther to the north and on the Imperial fault. Both the 1892 and 1940 earthquakes were associated with extensive surface faulting. An event of M 7.0 or 7.1 occurred in this region in 1915, and then a M 7.0 to 7.2 event in 1934 ruptured the Cerro Prieto fault with up to several meters of surface slip. 
04/06/2010 22:15:01 UTC

usp000hato

\section{$2.360^{\circ} \mathrm{N}, 97.132^{\circ} \mathrm{E}$}

\section{7.8 - Northern Sumatra, Indonesia}

\section{Depth 31.0 km}

\section{Electronic Poster Available}

The April 6, 2010, M 7.8 northern Sumatra earthquake occurred as the result of shallow thrust faulting on or near the subduction interface plate boundary between the Indo-Australia and Sunda plates. At the location of this earthquake, the Australia and India plates move north-northeast relative to the Sunda plate at a velocity of about $60-65 \mathrm{~mm} / \mathrm{yr}$. On the basis of the currently available faulting mechanism information and earthquake depth, this earthquake likely occurred along the subduction interface.

While commonly plotted as points on maps, earthquakes of this size are more appropriately described as slip over a larger fault area. Thrust-faulting events of the size of the April 6, 2010, earthquake are typically about 120x50 km (length x width); modeling of this earthquake implies dimensions of about $80 \times 60 \mathrm{~km}$, predominantly surrounding and up-dip of the hypocenter.

The subduction zone surrounding the immediate region of this event last slipped during the M 8.6 earthquake of March 2005, and the April $6^{\text {th }}$ event appears to have occurred within the rupture zone of that earthquake. The April $6^{\text {th }}$ earthquake is the latest in a sequence of large ruptures along the Sunda megathrust - two M 7.4 earthquakes beneath Simeulue $125 \mathrm{~km}$ to the north in 2002 and 2008; a M 9.1 earthquake ruptured to within $125 \mathrm{~km}$ north of this earthquake in 2004; a M 8.5 earthquake broke the plate boundary $375 \mathrm{~km}$ to the south in 2007; and a M 7.6 earthquake $260 \mathrm{~km}$ to the south near Padang in 2009.

\section{5/09/2010 05:59:41 UTC usp000hchk}

\section{$3.747^{\circ} \mathrm{N}, 96.013^{\circ} \mathrm{E}$}

\section{7.2 - Northern Sumatra, Indonesia Depth 38.0 km}

\section{Electronic Poster Available}

The May 9, 2010, M 7.2 northern Sumatra earthquake occurred as a result of shallow thrust faulting on or near the subduction interface plate boundary between the Indo-Australia and Sunda plates. At the location of this earthquake, the Australia and India plates move north-northeast relative to the Sunda plate at a velocity of about $60-65 \mathrm{~mm} / \mathrm{yr}$. On the basis of the currently available faulting mechanism information, earthquake depth, and finite-fault modeling of globally distributed seismic data, this earthquake likely occurred along the subduction interface.

The subduction zone surrounding the immediate region of this event slipped during the devastating M 9.1 earthquake of December 2004, and the May $9^{\text {th }}$ event appears to have occurred within the rupture zone of that earthquake. The May $9^{\text {th }}$ earthquake is the latest in a sequence of large ruptures along the Sunda megathrust megathrust — a M 7.8 earthquake in April of this year, approximately $200 \mathrm{~km}$ to the south of the May $9^{\text {th }}$ event; two M 7.4 earthquakes beneath Simeulue approximately $100 \mathrm{~km}$ to the south in 2002 and 2008; a M 8.6 earthquake $210 \mathrm{~km}$ to the south in 2005; a M 7.5 earthquake $650 \mathrm{~km}$ to the south near Padang in 2009; and two events, M 8.5 and M 7.9, approximately 1,000 km to the south in 2007.

05/27/2010 17:14:46 UTC

\section{$13.710^{\circ} \mathrm{S}, 166.507^{\circ} \mathrm{E}$}

\section{7.2 - Vanuatu}

\section{Depth 31.0 km}

\section{Electronic Poster Available}

The May 27, 2010, M 7.2 Vanuatu earthquake occurred as the result of shallow reverse faulting on or near the plate boundary between the Australia and Pacific plates in the Coral Sea region of the southwest Pacific. In the region of the earthquake, the Australia plate moves to the east-northeast relative to the Pacific plate at a velocity of about $91 \mathrm{~mm} / \mathrm{yr}$. The Australia plate thrusts under the Pacific plate at the New Hebrides Trench west of the May $27^{\text {th }}$ earthquake and dips to the northeast, remaining seismically active to depths of about $350 \mathrm{~km}$ beneath the islands. The May $27^{\text {th }}$ earthquake's location, depth, and focal mechanism solutions are consistent with the earthquake resulting from reverse faulting associated with subduction along the AustraliaPacific plate boundary.

This earthquake occurred between 70 and $130 \mathrm{~km}$ to the north of a sequence of large subduction thrust earthquakes in October 2009. On October 7, 2009, two earthquakes of M 7.7 and M 7.8 occurred 15 minutes apart. After these events, a M 7.4 
aftershock struck approximately 1 hour later, and two M 6.6 and M 6.8 aftershocks occurred on the following day. In general, the Vanuatu region experiences a very high level of earthquake activity, with almost 50 events of M 7 or larger recorded since 1973.

06/12/2010 19:26:50 UTC usp000hdwb

$7.848^{\circ} \mathrm{N}, 9^{1.919^{\circ} \mathrm{E}}$

\section{7.5 - Nicobar Islands, India region \\ Depth 35.0 km}

\section{Electronic Poster Available}

The June 12, 2010, M 7.5 Nicobar Islands earthquake occurred as a result of shallow, oblique reverse faulting near the oceanic trench defining the bathymetric expression of the plate boundary between the Indo-Australia and Sunda plates. Focal mechanism solutions indicate that rupture occurred on either a southwest- or east-southeast-striking, moderately dipping reverse fault. Of these two possible fault orientations, finite-fault modeling of globally recorded seismic data is more consistent with slip on the east-southeast-striking fault. At the location of this earthquake, the Australia and India plates move northward relative to the Sunda plate at a velocity of about $45-50 \mathrm{~mm} / \mathrm{yr}$. On the basis of the currently available faulting mechanism information, earthquake location and depth, this earthquake likely occurred within the subducting Indo-Australia oceanic plate, rather than on the interplate thrust boundary.

While commonly plotted as points on maps, earthquakes of this size are more appropriately described as slip over a larger fault area. Reverse-faulting events of the size of the June 12, 2010, earthquake are typically about $85 \times 30 \mathrm{~km}$ (length $\mathrm{x}$ width); modeling of this earthquake implies dimensions of about $60 \times 40 \mathrm{~km}$, predominantly surrounding the hypocenter and to the southeast.

The June $12^{\text {th }}$ earthquake was located adjacent to the 1300-km-long rupture area of the devastating M 9.1 earthquake of December 2004, approximately $650 \mathrm{~km}$ to the northwest of the hypocenter of that event, in a region of the Australia-India plate that has experienced a broad variety of faulting mechanisms in the past.

\section{6/16/2010 03:16:27 UTC usp000he3f}

\section{$2.171^{\circ} \mathrm{S}, 136.549^{\circ} \mathrm{E}$}

\section{7.0 - Near the north coast of Papua, Indonesia Depth 18.0 km}

\section{Electronic Poster Available}

The June 16, 2010, 03:16 UTC, M 7.0 earthquake near the north coast of Papua, Indonesia, occurred as a result of shallow strike-slip faulting. The causative fault has not yet been identified, though the radiation pattern of seismic waves generated by the earthquake is consistent with either left-lateral faulting on an east-northeast-striking fault or right-lateral faulting on a northnorthwest-striking fault.

Eastern Indonesia is characterized by complex tectonics in which motions of numerous small plates are accommodating large-scale convergence among the Australia, Sunda, Pacific, and Philippine Sea plates. The June $16^{\text {th }}$ earthquake lies near the boundary between what some workers term the Birds Head microplate and the Maoke microplate. This boundary has been modeled as accommodating approximately $80 \mathrm{~mm} / \mathrm{yr}$ of left-lateral motion along an east-northeast trend. The focal mechanism solution of this earthquake is consistent with it occurring within the proposed microplate boundary, either as left-lateral slip on a boundary-parallel fault or as right-lateral slip on a conjugate fault that is tectonically related to the microplate boundary. In light of large uncertainty in tectonic modeling of eastern Indonesia, however, any particular hypothesis for the causative fault of the earthquake must be regarded as tentative pending further study.

Eastern Indonesia experiences many strong earthquakes. Since 1979, the region within $300 \mathrm{~km}$ of the mainshock of June 16, 2010, has experienced eight other earthquakes with magnitudes larger than 7, the largest of which was a M 8.2 event in February 1996 about $100 \mathrm{~km}$ to the north of the June $16^{\text {th }}$ earthquake. The February 1996 event resulted in at least 166 fatalities and 423 injuries. 


\section{$5.939^{\circ} \mathrm{S}, 150.572^{\circ} \mathrm{E}$}

\section{7.3 - New Britain region, Papua New Guinea \\ Depth 35.0 km}

\section{Electronic Poster Available}

The July 18, 2010, M 7.3 earthquake of New Britain, Papua New Guinea, occurred as the result of shallow thrust faulting on or near the plate boundary between the Solomon Sea and South Bismarck plates, which are microplates involved in the accommodation of large-scale convergence between the Australia and Pacific plates in the Woodlark Basin region of the southwest Pacific. At the location of this earthquake, the Solomon Sea microplate moves approximately northward relative to the South Bismarck plate at a velocity of roughly $120 \mathrm{~mm} / \mathrm{yr}$, thrusting under the South Bismark plate at the New Britain Trench and dipping to the north-northwest. The location, depth, and focal mechanism solutions of the July 18, 2010, event are consistent with the earthquake resulting from thrust faulting associated with subduction along this plate boundary.

This earthquake occurred approximately $10 \mathrm{~km}$ to the north and 30 minutes after a M 6.9 earthquake. That smaller foreshock was deeper and occurred as a result of reverse faulting in a direction highly oblique to the plate convergence direction. It is thus likely that the earlier M 6.9 event occurred within the subducting Solomon Sea microplate, rather than on its thrust interface. The subducting Solomon Sea microplate is seismically active to depths of about $600 \mathrm{~km}$ beneath the island of New Britain.

In general, the New Britain region experiences a high level of earthquake activity, with 15 events of M 7 or larger within 3 degrees $(336 \mathrm{~km})$ of the July $18^{\text {th }}$ event since 1973 . The region also has a history of large earthquakes occurring close together in time; of those 15 events, 11 occurred within several days to months of another nearby large earthquake. In November 2000, three earthquakes of M 7.8+ occurred over a 2-day period approximately $300 \mathrm{~km}$ to the northeast of the July $18^{\text {th }}$ earthquake. The first event (M 8.0) resulted in at least two fatalities, left many people homeless, and caused widespread damage. The second two events resulted in additional minor damage.

\section{7/23/2010 22:08:11 UTC usp000hgmd $6.699^{\circ} \mathrm{N}, 123.475^{\circ} \mathrm{E}$ \\ M 7.3 - Moro Gulf, Mindanao, Philippines Depth $607.1 \mathrm{~km}$}

\section{Electronic Poster Available}

The July 23, 2010, (22:08:11 UTC) M 7.3 earthquake in the Moro Gulf, south of Mindanao, Philippines, occurred as the first of three M 7+ earthquakes within just over an hour (earthquakes of M 7.6 and M 7.5 followed at 22:51 UTC and 23:15 UTC, respectively). Each was the result of deep normal faulting within the inclined seismic zone defining the deep limit of the Molucca Sea microplate beneath the Celebes Sea Basin.

Northeastern Indonesia and southern Philippines are characterized by complex tectonics in which motions of numerous small plates accommodate the large-scale convergence between the Philippine Sea and Sunda plates. In the region of the July $23^{\text {rd }}$ earthquakes, the Philippine Sea plate moves west-northwest with respect to the Sunda plate at a velocity that various models would place in the $60-110-\mathrm{mm} / \mathrm{yr}$ range. Locally, arc-arc collision is occurring between the Sangihe microplate and the Philippine Sea plate, wedging between them the Molucca Sea microplate, which subducts beneath both (to the east and west) and forms an inverted-U-shaped seismic zone. At the location of the July $23^{\text {rd }}$ earthquakes, the top of the Molucca Sea microplate is at a depth of about $150 \mathrm{~km}$ beneath the Earth's surface. Seismicity within the Molucca Sea microplate is active to depths of approximately $260 \mathrm{~km}$ to the east and $650 \mathrm{~km}$ to the west. The tectonic setting of this region is unique in that it is the only global example of an active arc-arc collision consuming an oceanic basin via subduction in two directions.

The July $23^{\text {rd }}$ events occurred in response to stresses generated by the slow distortion of the Molucca Sea microplate at depth, rather than on one of the shallower interfaces with the overriding Sangihe and Philippine Sea plates. Slip on a fault aligned with either nodal plane of the focal mechanism solution is consistent with this intraplate setting.

Earthquakes that have focal depths greater than $300 \mathrm{~km}$ are commonly termed "deep-focus" earthquakes. Deep-focus earthquakes cause less damage on the ground surface above their foci than similar-magnitude shallow-focus earthquakes, but large deep-focus earthquakes may be felt at great distance from their epicenters. The largest recorded deep-focus earthquake prior to these July 2010 earthquakes was a M 8.2 event that occurred at a depth of $630 \mathrm{~km}$ within the subducted Nazca plate beneath South America near the northern Bolivian border in 1994. A larger event has since occurred - namely the M 8.3 earthquake that occurred at a depth of $600 \mathrm{~km}$ within the subducted Pacific plate beneath the Sea of Okhotsk offshore of northeastern Russia in 2013. The M 8.3 Sea of Okhotsk earthquake was felt all over Asia, as far away as Moscow, and across the Pacific Ocean along the western seaboard of the United States (though at distant locations, individuals reporting having felt the event were likely 
very favorably situated for the perception of small ground motions). The M 8.2 Bolivian deep-focus earthquake in 1994 had similarly been reported by individuals in North America at great distance from the epicenter.

Over the past century, 79 earthquakes with a magnitude of M 7+ have occurred at depths greater than $300 \mathrm{~km}$ globally; four of these were located in the same region as the July 23, 2010, events. The largest nearby event at these depths was a M 7.3 earthquake in March 1984, less than $200 \mathrm{~km}$ to the north and 10-60 km deeper than the July $23^{\text {rd }}$ events, with no associated damage or casualties.

\section{7/23/2010 22:51:11 UTC usp000hgmh}

\section{$6.470^{\circ} \mathrm{N}, 123.532^{\circ} \mathrm{E}$}

\section{7.6 - Moro Gulf, Mindanao, Philippines \\ Depth 578.0 km \\ Electronic Poster Available}

The July 23, 2010, (22:51:12 UTC) M 7.6 earthquake in the Moro Gulf, south of Mindanao, Philippines, occurred as the second of three M 7+ earthquakes within just over an hour (following an earthquake of M 7.3 at 22:08 UTC, and preceding a M 7.5 event at 23:15 UTC). Each was the result of deep normal faulting within the inclined seismic zone defining the deep limit of the Molucca Sea microplate beneath the Celebes Sea Basin.

Northeastern Indonesia and southern Philippines are characterized by complex tectonics in which motions of numerous small plates accommodate the large-scale convergence between the Philippine Sea and Sunda plates. In the region of the July $23^{\text {rd }}$ earthquakes, the Philippine Sea plate moves west-northwest with respect to the Sunda plate at a velocity that various models would place in the $60-110 \mathrm{~mm} / \mathrm{yr}$ range. Locally, arc-arc collision is occurring between the Sangihe microplate and the Philippine Sea plate, wedging between them the Molucca Sea microplate, which subducts beneath both (to the east and west) and forms an inverted-U-shaped seismic zone. At the location of the July $23^{\text {rd }}$ earthquakes, the top of the Molucca Sea microplate is at a depth of about $150 \mathrm{~km}$ beneath the Earth's surface. Seismicity within the Molucca Sea microplate is active to depths of approximately $260 \mathrm{~km}$ to the east and $650 \mathrm{~km}$ to the west. The tectonic setting of this region is unique in that it is the only global example of an active arc-arc collision consuming an oceanic basin via subduction in two directions.

The July $23^{\text {rd }}$ events occurred in response to stresses generated by the slow distortion of the Molucca Sea microplate at depth, rather than on one of the shallower interfaces with the overriding Sangihe and Philippine Sea plates. Slip on a fault aligned with either nodal plane of the focal mechanism solution is consistent with this intraplate setting.

Earthquakes that have focal depths greater than $300 \mathrm{~km}$ are commonly termed "deep-focus" earthquakes. Deep-focus earthquakes cause less damage on the ground surface above their foci than similar-magnitude shallow-focus earthquakes, but large deep-focus earthquakes may be felt at great distance from their epicenters. The largest recorded deep-focus earthquake prior to these July 2010 earthquakes was a M 8.2 event that occurred at a depth of $630 \mathrm{~km}$ within the subducted Nazca plate beneath South America near the northern Bolivian border in 1994. A larger event has since occurred-namely the M 8.3 earthquake that occurred at a depth of $600 \mathrm{~km}$ within the subducted Pacific plate beneath the Sea of Okhotsk offshore of northeastern Russia in 2013. The M 8.3 Sea of Okhotsk earthquake was felt all over Asia, as far away as Moscow, and across the Pacific Ocean along the western seaboard of the United States (though at distant locations, individuals reporting having felt the event were likely very favorably situated for the perception of small ground motions). The M 8.2 Bolivian deep-focus earthquake in 1994 had similarly been reported by individuals in North America at great distance from the epicenter.

Over the past century, 80 earthquakes with a magnitude of M 7+ have occurred at depths greater than $300 \mathrm{~km}$ globally; four of these were located in the same region as the July 23, 2010, events. The largest nearby event at these depths was a M 7.3 earthquake in March 1983, less than $200 \mathrm{~km}$ to the north and 10-60 km deeper than the July $23^{\text {rd }}$ events, with no associated damage or casualties.

\section{7/23/2010 23:15:10 UTC usp000hgmq $6.792^{\circ} \mathrm{N}, 123.282^{\circ} \mathrm{E}$ \\ M 7.5 - Moro Gulf, Mindanao, Philippines \\ Depth $640.6 \mathrm{~km}$ \\ Electronic Poster Available}

The July 23, 2010, (23:15:10 UTC) M 7.5 earthquake in the Moro Gulf, south of Mindanao, Philippines, occurred as the third of three M 7+ earthquakes within just over an hour on July $23^{\text {rd }}$ (following earthquakes of M 7.3 and M 7.6 at 22:08 UTC and 22:51 UTC, respectively). Each was the result of deep normal faulting within the inclined seismic zone defining the deep limit of the Molucca Sea microplate beneath the Celebes Sea Basin. 
Northeastern Indonesia and southern Philippines are characterized by complex tectonics in which motions of numerous small plates accommodate the large-scale convergence between the Philippine Sea and Sunda plates. In the region of the July $23^{\text {rd }}$ earthquakes, the Philippine Sea plate moves west-northwest with respect to the Sunda plate at a velocity that various models would place in the $60-110-\mathrm{mm} / \mathrm{yr}$ range. Locally, arc-arc collision is occurring between the Sangihe microplate and the Philippine Sea plate, wedging between them the Molucca Sea microplate, which subducts beneath both (to the east and west) and forms an inverted-U-shaped seismic zone. At the location of the July $23^{\text {rd }}$ earthquakes, the top of the Molucca Sea microplate is at a depth of about $150 \mathrm{~km}$ beneath the Earth's surface. Seismicity within the Molucca Sea microplate is active to depths of approximately $260 \mathrm{~km}$ to the east and $650 \mathrm{~km}$ to the west. The tectonic setting of this region is unique in that it is the only global example of an active arc-arc collision consuming an oceanic basin via subduction in two directions.

The July $23^{\text {rd }}$ events occurred in response to stresses generated by the slow distortion of the Molucca Sea microplate at depth, rather than on one of the shallower interfaces with the overriding Sangihe and Philippine Sea plates. Slip on a fault aligned with either nodal plane of the focal mechanism solution is consistent with this intraplate setting.

Earthquakes that have focal depths greater than $300 \mathrm{~km}$ are commonly termed "deep-focus" earthquakes. Deep-focus earthquakes cause less damage on the ground surface above their foci than similar-magnitude shallow-focus earthquakes, but large deep-focus earthquakes may be felt at great distance from their epicenters. The largest recorded deep-focus earthquake prior to these July 2010 earthquakes was a M 8.2 event that occurred at a depth of $630 \mathrm{~km}$ within the subducted Nazca plate beneath South America near the northern Bolivian border in 1994. A larger event has since occurred-namely the M 8.3 earthquake that occurred at a depth of $600 \mathrm{~km}$ within the subducted Pacific plate beneath the Sea of Okhotsk offshore of northeastern Russia in 2013. The M 8.3 Sea of Okhotsk earthquake was felt all over Asia, as far away as Moscow, and across the Pacific Ocean along the western seaboard of the United States (though at distant locations, individuals reporting having felt the event were likely very favorably situated for the perception of small ground motions). The M 8.2 Bolivian deep-focus earthquake in 1994 had similarly been reported by individuals in North America at great distance from the epicenter.

Over the past century, 81 earthquakes with a magnitude of M 7+ have occurred at depths greater than $300 \mathrm{~km}$ globally; four of these were located in the same region as the July 23, 2010, events. The largest nearby event at these depths was a M 7.3 earthquake in March 1983, less than $200 \mathrm{~km}$ to the north and 10-60 km deeper than the July $23^{\text {rd }}$ events, with no associated casualties or damage.

\section{8/04/2010 22:01:43 UTC usp000hhhx $5.768^{\circ} \mathrm{S}, 150.776^{\circ} \mathrm{E}$ \\ M 7.0 - New Britain region, Papua New Guinea Depth 44.0 km}

The August 4, 2010, M 7.0 earthquake of New Britain, Papua New Guinea, occurred as a result of shallow thrust faulting on or near the plate boundary between the Solomon Sea and South Bismarck microplates that are involved in the accommodation of large-scale convergence between the Australia and Pacific plates in the Woodlark Basin region of the southwest Pacific. At the location of this earthquake, the Solomon Sea microplate moves approximately north relative to the South Bismarck plate at a velocity of roughly $120 \mathrm{~mm} / \mathrm{yr}$, thrusting under the South Bismark plate at the New Britain Trench and dipping to the north-northwest. The location, depth, and focal mechanism solutions of the event are consistent with the earthquake resulting from thrust faulting associated with subduction along this plate boundary. The subducting Solomon Sea microplate is seismically active to depths of about $600 \mathrm{~km}$ beneath the island.

The New Britain region experiences a high level of earthquake activity, with 16 events of M 7 or larger within 3 degrees $(336 \mathrm{~km})$ of this event since 1973. The region also has a history of large earthquakes occurring close together in time; of those 16 events, 12 occurred within several days to months of another nearby large earthquake. On July 18, 2010, two earthquakes (M 6.9 and M 7.3) struck about $25 \mathrm{~km}$ to the southwest of the August 4, 2010, earthquake. In November 2000, three earthquakes of M 7.8+ occurred over a 2-day period approximately $275 \mathrm{~km}$ to the northeast of the August 4, 2010, earthquake. The first event (M 8.0) caused at least two fatalities, left many people left homeless, and caused widespread damage. The second two events resulted in additional minor damage. 
08/10/2010 05:23:44 UTC

usp000hhuc

$17.561^{\circ} \mathrm{S}, 168.028^{\circ} \mathrm{E}$

\section{7.3 - Vanuatu}

\section{Depth 25.0 km}

\section{Electronic Poster Available}

The August 10, 2010, M 7.3 Vanuatu earthquake occurred as the result of shallow reverse faulting on or near the plate boundary between the Australia and Pacific plates in the Coral Sea region of the southwest Pacific. In the region of the earthquake, the Australia plate moves to the east-northeast relative to the Pacific plate at a velocity of about $85 \mathrm{~mm} / \mathrm{yr}$. The Australia plate thrusts underneath the Pacific plate at the Vanuatu Trench and dips to the east-northeast. The location, depth, focal mechanism solutions, and finite-fault modeling of globally distributed seismic data for the August $10^{\text {th }}$ event are consistent with the earthquake resulting from reverse faulting associated with subduction along the Australia-Pacific plate boundary.

This earthquake was located approximately $500 \mathrm{~km}$ to the south of a sequence of large subduction thrust earthquakes that occurred in October of 2009. On October 7, 2009, two earthquakes of M 7.7 and M 7.8 occurred 15 minutes apart. After these events, a M 7.4 aftershock struck approximately 1 hour later, and two aftershocks (M 6.6 and M 6.8) occurred on the following day. On May 27, 2010, a M 7.1 earthquake occurred $100 \mathrm{~km}$ farther to the north of the October 2009 sequence. More broadly, the Vanuatu region experiences a very high level of earthquake activity, with almost 50 events of M 7 or larger recorded since 1973.

\section{8/12/2010 11:54:15 UTC}

\section{usp000hj05}

\section{$1.260^{\circ} \mathrm{S}, 77.312^{\circ} \mathrm{W}$}

\section{7.1 - Ecuador}

Depth 206.7 km

\section{Electronic Poster Available}

The August 12, 2010, M 7.1 Ecuador earthquake occurred as the result of normal faulting at an intermediate depth, approximately $200 \mathrm{~km}$ beneath central Ecuador within the lithosphere of the subducted Nazca plate. Focal mechanism solutions indicate that rupture occurred on either a steeply dipping normal fault or a shallowly dipping normal fault. Slip on a fault of either orientation would accommodate the down-dip extension of the Nazca slab that is implied by the normal-component of the faulting solution. At the location of the earthquake, the oceanic Nazca plate moves east relative to the South America plate at a rate of about $70 \mathrm{~mm} / \mathrm{yr}$, subducting at the Peru-Chile Trench west of the Ecuadoran coast and sinking into the mantle beneath South America. Like most earthquakes of Ecuador and western South America, this event was caused by strains generated by the ongoing subduction process. This earthquake occurred as normal faulting within a segment of the subducted plate that has produced frequent earthquakes with focal depths of 160 to $200 \mathrm{~km}$ beneath the Earth's surface. A M 6.7 earthquake in 1971 was situated $60 \mathrm{~km}$ to the southwest of the August 12, 2010, earthquake at a depth of $170 \mathrm{~km}$.

Earthquakes like this event, with focal depths between 70 and $300 \mathrm{~km}$, are commonly termed "intermediate-depth" earthquakes. Intermediate-depth earthquakes represent deformation within subducted slabs rather than at the shallow plate interface between subducting and overriding tectonic plates. They typically cause less damage on the ground surface above their foci than is the case with similar-magnitude shallow-focus earthquakes, but large intermediate-depth earthquakes may be felt at great distance from their epicenters. "Deep-focus" earthquakes, those with focal depths greater than $300 \mathrm{~km}$, also occur in the subducted Nazca plate farther east from the Peru-Chile Trench, beneath western Brazil and central Argentina. Earthquakes have been reliably located to depths of about $650 \mathrm{~km}$ in this region.

The Peru-Chile Trench is an area that hosts large earthquakes quite regularly. Within $400 \mathrm{~km}$ of the August $12^{\text {th }}$ earthquake, there have been six other earthquakes with magnitudes of $7+$ over the preceding 40 years. The largest of these events was a M 7.7 earthquake in December 1979, off the coast of northern Ecuador roughly $200 \mathrm{~km}$ to the northwest of the August $12^{\text {th }}$ event. That earthquake, associated with thrust faulting on the interface between the Nazca and South America plates, resulted in more than 600 fatalities and 20,000 injuries. 


\section{$43.530^{\circ} \mathrm{S}, 172.120^{\circ} \mathrm{E}$}

\section{7.0 - South Island of New Zealand \\ Depth 12.0 km}

\section{Electronic Poster Available}

The September 3, 2010, M 7.0 South Island, New Zealand earthquake occurred as a result of shallow strike-slip faulting within the crust of the Pacific plate, near the eastern foothills of the Southern Alps at the western edge of the Canterbury Plains. The earthquake struck approximately $50 \mathrm{~km}$ to the west-northwest of Christchurch, the largest population center in the region, and about $80-90 \mathrm{~km}$ to the south and east of the current expression of the Australia-Pacific plate boundary through the island (the Alpine and Hope faults). Focal mechanism solutions indicate that rupture occurred on either a right-lateral west-striking fault or a left-lateral south-striking fault. At the location of the earthquake, the Pacific and Australia plates accommodate about $35 \mathrm{~mm} / \mathrm{yr}$ of relative motion. The earthquake, though removed from the plate boundary itself, likely reflects right-lateral motion on one of a number of regional faults related to the overall relative motion of these plates and may be related to the overall southern propagation of the Marlborough fault system in recent geologic time. Finite-fault modeling of globally distributed seismic data and geological field mapping have since confirmed that the earthquake occurred on a series of right-lateral faults.

The September 3, 2010, earthquake occurred approximately $50 \mathrm{~km}$ to the southeast of a M 7.1, surface-rupturing event in Arthur's Pass, on March 9, 1929, which caused damage but injured no one. More recently, two earthquakes, M 6.7 and M 5.9, occurred in June 1994 approximately $40 \mathrm{~km}$ to the northwest of the 2010 event, but did not cause any known fatalities or significant damage.

\section{9/29/2010 17:11:25 UTC usp000hmbq $4.920^{\circ} \mathrm{S}, 133.783^{\circ} \mathrm{E}$ \\ M 7.0 - Near the South Coast of Papua, Indonesia Depth 26.0 km}

\section{Electronic Poster Available}

The September 29, 2010, M 7.0 earthquake near the south coast of Papua, Indonesia, occurred as a result of shallow normal faulting along a section of the broad plate boundary system in eastern Indonesia to the northwest of the Aru Islands. Focal mechanism solutions indicate that rupture occurred on either a north- or south-striking, moderately dipping normal fault.

Eastern Indonesia is characterized by complex tectonics in which motions of numerous small plates are accommodating large-scale convergence among the Australia, Sunda, Pacific, and Philippine Sea plates. The September $29^{\text {th }}$ earthquake lies near the boundary between the proposed Banda Sea microplate and the Australia plate proper, which is oriented approximately north-northeast and accommodates divergent motion between these plates. The focal mechanism solution of the earthquake is consistent with its occurrence on such a boundary, though due to the complexity of tectonics in this region, any specific association with a causative fault structure must be regarded as speculative, pending further study. At a broad scale, the Australia plate moves northward with respect to the Sunda plate at a velocity of approximately $77 \mathrm{~mm} / \mathrm{yr}$ in the region of the earthquake. In more detail, it has been estimated that the Banda Sea microplate moves westward with respect to the Australia plate at a velocity of about $15 \mathrm{~mm} / \mathrm{yr}$.

The September $29^{\text {th }}$ earthquake was preceded approximately 27 seconds earlier by a smaller, M 6.2 event, from nearly the same epicenter. Eastern Indonesia is a tectonically active area with frequent moderate and large earthquakes. The region within $300 \mathrm{~km}$ of the September $29^{\text {th }}$ event experienced more than 30 earthquakes larger than M 6 in the past half century.

10/25/2010 14:42:22 UTC usp000hnj4

\section{$3.484^{\circ} \mathrm{S}, 100.114^{\circ} \mathrm{E}$}

\section{7.8 - Kepulauan Mentawai region, Indonesia \\ Depth 20.1 km}

The October 25, 2010, M 7.8 Pulau Pagai Selatan (Mentawai), Sumatra, earthquake occurred as the result of shallow thrust faulting on or near the subduction interface plate boundary between the Australia and Sunda plates. At the location of this earthquake, the Australia plate moves north-northeast relative to the Sunda plate at a velocity of about 57-69 mm/yr. On the basis of the currently available faulting mechanism information and earthquake depth it is likely that this earthquake occurred along the plate interface. 
While commonly plotted as points on maps, earthquakes of this size are more appropriately described as slip over a larger fault area. Thrust-faulting events of the size of the October 25, 2010, earthquake are typically about 120x50 km (length x width); modeling of this earthquake implies similar dimensions, predominantly up-dip of the hypocenter.

The subduction zone adjacent to the region of this event last slipped during the M 8.5 and 7.9 earthquakes of September 2007, and the October $25^{\text {th }}$ event appears to have occurred near the up-dip edge of the rupture zones of those earthquakes. The October $25^{\text {th }}$ earthquake is the latest in a sequence of large ruptures along the Sunda megathrust, including a M 9.1 earthquake that ruptured to within $800 \mathrm{~km}$ north of this earthquake in December 2004; a M 8.6 earthquake $700 \mathrm{~km}$ to the north between Nias and Simeulue in March 2005; and a M 7.6 earthquake $300 \mathrm{~km}$ to the north near Padang in September 2009. The October $25^{\text {th }}$ earthquake also occurred near the southern edge of a M 8.7-8.9 rupture in 1797 and within the rupture area of a M 8.9-9.1 earthquake in 1833.

\section{2/21/2010 17:19:40 UTC Usp000hr97 \\ $26.892^{\circ} \mathrm{N}, 143.726^{\circ} \mathrm{E}$}

\section{7.4 - Bonin Islands, Japan region Depth $14.0 \mathrm{~km}$}

\section{Electronic Poster Available}

The December 21, 2010, M 7.4 earthquake in the Bonin Islands near Japan occurred as the result of shallow normal faulting within the Pacific plate, in the region of the boundary between the Pacific plate and the Philippine Sea plate. Focal mechanism solutions indicate that rupture occurred on either a north-northwest- or an east-southeast-striking, moderately dipping normal fault. Of these two possible fault orientations, finite-fault modeling of globally recorded seismic data is more consistent with slip on the east-southeast-striking fault. In the epicentral region of the earthquake, the Pacific plate moves west relative to the Philippine Sea plate at a velocity of about $40 \mathrm{~mm} / \mathrm{yr}$. The Pacific plate subducts beneath the Philippine Sea plate at the Izu Trench just west of the December $21^{\text {st }}$ earthquake and is seismically active to a depth of about $560 \mathrm{~km}$. The stresses that generated the December $21^{\text {st }}$ earthquake result from the bending of the Pacific plate as it begins to subduct beneath the Philippine Sea plate.

The Izu-Bonin and Mariana Island Arcs of the Pacific:Philippine Sea plate boundary region experience frequent moderate and strong earthquakes. In the past quarter century alone, the $1,000-\mathrm{km}$ section of the plate boundary centered on the epicenter of the December $21^{\text {st }}$ earthquake has produced 27 earthquakes of M 6+, two with magnitudes larger than 7.0. Roughly half of the moderate and large events in this region occur as intermediate-depth earthquakes (70-300 km below the Earth's surface) or deep-focus earthquakes (greater than $300 \mathrm{~km}$ below the Earth's surface). The December $21^{\text {st }}$ earthquake, however, occurred within $20 \mathrm{~km}$ of the Earth's surface and would be classified as a "shallow-focus" earthquake. The largest nearby event was a 400-km-deep M 7.4 earthquake in August 2000 roughly $250 \mathrm{~km}$ northwest of the December $21^{\text {st }}$ event, with no recorded casualties or damage.

12/25/2010 13:16:37 UTC

\section{$19.775^{\circ} \mathrm{S}, 167.895^{\circ} \mathrm{E}$}

\section{7.3 - Vanuatu region \\ Depth $16.0 \mathrm{~km}$}

\section{Electronic Poster Available}

The December 25, 2010, M 7.3 Vanuatu region earthquake occurred as the result of shallow normal faulting within the Australia plate, in the region of the boundary between the Australia plate and the Pacific plate. Focal mechanism solutions indicate that rupture occurred on either a north- or south-southeast-striking, moderately dipping normal fault. Of these two possible fault orientations, finite-fault modeling of globally recorded seismic data is more consistent with slip on the south-southeaststriking fault. In the epicentral region of the earthquake, the Australia plate moves east-northeast relative to the Pacific plate at a velocity of about $80 \mathrm{~mm} / \mathrm{yr}$. The Australia plate subducts beneath the Pacific plate at the New Hebrides Trench, just east of the December $25^{\text {th }}$ earthquake, and is seismically active to a depth of $300 \mathrm{~km}$. The stresses that generated the earthquake result from the bending of the Australia plate as it subducts beneath the Pacific plate.

The western margin of the Pacific plate that lies to the east of the New Hebrides Trench is commonly viewed as being subdivided into several microplates that move with respect to each other at rates of a few centimeters per year, whose differential motions help to accommodate the overall convergence between the Australia and Pacific plates. These include the New Hebrides microplate local to this earthquake. 
The New Hebrides Arc region of the Australia/New Hebrides plate boundary experiences numerous strong earthquakes. In the past quarter century, the 1,000-km section of the arc centered on the epicenter of the December $25^{\text {th }}$ earthquake has produced 19 earthquakes of M 7+, the largest having M 7.7.

\section{1: 20 Events}

\section{1/01/2011 09:56:58 UTC usp000hsdc}

\section{$26.794^{\circ} \mathrm{S}, 63.079^{\circ} \mathrm{W}$}

\section{7.0 - Santiago Del Estero, Argentina \\ Depth 576.8 km}

\section{Electronic Poster Available}

The January 1, 2011, M 7.0 earthquake near Santiago Des Estero, Argentina, occurred as the result of deep normal faulting, approximately $570 \mathrm{~km}$ beneath northern Argentina within the subducted lithosphere of the oceanic Nazca plate. Focal mechanism solutions indicate that rupture occurred on either a steep, southeast-striking fault or on a shallow, north-striking fault. Slip on a fault of either orientation would accommodate the down-dip extension of the Nazca slab that is implied by the normalcomponent of the faulting solution. At the location of the earthquake, the Nazca plate moves east relative to the South America plate at a velocity of about $70 \mathrm{~mm} / \mathrm{yr}$. The Nazca plate is overridden by the South America plate at the Peru-Chile Trench, west of the Chilean coast, and sinks into the mantle beneath South America. This earthquake occurred as normal faulting within a segment of the subducted plate that has produced frequent earthquakes with focal depths of $500 \mathrm{~km}$ to $625 \mathrm{~km}$ beneath the Earth's surface. In the past quarter century, two other events of M 7+ have occurred in the segment of the subducted Nazca plate that lies beneath northern Argentina. Neither produced recorded damage or casualties.

Earthquakes that have focal depths greater than $300 \mathrm{~km}$ are commonly termed "deep-focus" earthquakes. Deep-focus earthquakes cause less damage on the ground surface above their foci than similar-magnitude shallow-focus earthquakes, but large deep-focus earthquakes may be felt at great distance from their epicenters. The largest recorded deep-focus earthquake prior to this January 2011 earthquake was a M 8.2 event that occurred at a depth of $630 \mathrm{~km}$ within the subducted Nazca plate beneath South America near the northern Bolivian border in 1994. A larger event has since occurred-namely the M 8.3 earthquake that occurred at a depth of $600 \mathrm{~km}$ within the subducted Pacific plate beneath the Sea of Okhotsk offshore of northeastern Russia in 2013. The M 8.3 Sea of Okhotsk earthquake was felt all over Asia, as far away as Moscow, and across the Pacific Ocean along the western seaboard of the United States (though at distant locations, individuals reporting having felt the event were likely very favorably situated for the perception of small ground motions). The M 8.2 Bolivian deep-focus earthquake in 1994 had similarly been reported by individuals in North America at great distance from the epicenter.

Over the past century, 82 earthquakes with a magnitude of M 7+ have occurred at depths greater than $300 \mathrm{~km}$ globally; 4 of these were located in the same region as the January $1^{\text {st }}$ event. The largest nearby event at these depths was a M 7.3 earthquake in June 1991, just $20 \mathrm{~km}$ to the west and $20 \mathrm{~km}$ shallower than the January $1^{\text {st }}$ event.

\section{1/02/2011 20:20:17 UTC usp000hsfq}

\section{$38.354^{\circ} \mathrm{S}, 73.275^{\circ} \mathrm{W}$}

\section{7.2 - Araucania, Chile}

\section{Depth $24.0 \mathrm{~km}$}

\section{Electronic Poster Available}

The January 2, 2011, M 7.2 Araucania, Chile earthquake occurred as the result of shallow thrust faulting on or near the subduction interface between the Nazca and South America tectonic plates. At the location of this event, the Nazca plate moves east-northeast relative to South America at a velocity of about $74 \mathrm{~mm} / \mathrm{yr}$. The Nazca plate, oceanic in origin, subducts eastward beneath the South America plate at a shallow angle from the Peru-Chile Trench. It is seismically active to depths of approximately $200 \mathrm{~km}$ adjacent to the epicenter of the January $2^{\text {nd }}$ earthquake, though farther north seismicity continues to depths exceeding $600 \mathrm{~km}$.

The January $2^{\text {nd }}$ earthquake occurred at the southern end of the aftershock region of the damaging M 8.8 Maule megathrust earthquake of February 27, 2010, and can also be considered an aftershock of that event. The subduction zone between the Nazca and South America plates has a long history of large megathrust earthquakes, including the largest event ever recorded, a M 9.5 event in 1960, which ruptured a fault mostly to the south of the January $2^{\text {nd }}$ earthquake. 
01/13/2011 16:16:41 UTC

usp000ht15

$20.622^{\circ} \mathrm{S}, 168.459^{\circ} \mathrm{E}$

M 7.0 - Loyalty Islands

Depth 9.0 km

\section{Electronic Poster Available}

The January 13, 2011, M 7.0 Loyalty Islands earthquake occurred as the result of shallow normal faulting within the Australia plate, in the region of the boundary between the Australia plate and the Pacific plate. Focal mechanism solutions indicate that rupture occurred on either a steeply dipping, southeast-striking normal fault or on a more shallowly dipping, northweststriking fault. At the location of the earthquake, the Australia plate moves east-northeast relative to the Pacific plate at a velocity of about $80 \mathrm{~mm} / \mathrm{yr}$ The Australia plate subducts beneath the Pacific plate at the New Hebrides Trench immediately east of the January $13^{\text {th }}$ earthquake and is seismically active to a depth of $300 \mathrm{~km}$. The stresses that generated the earthquake result from the bending of the Australia plate during this subduction beneath the Pacific plate. Slip on a fault aligned with either nodal plane of the focal mechanism solution is consistent with this intraplate setting.

The western margin of the Pacific plate that lies to the east of the New Hebrides Trench is commonly viewed as being subdivided into several microplates that move relative to each other at rates of a few centimeters per year, whose differential motions help to accommodate the overall convergence between the Australia and Pacific plates. These include the New Hebrides microplate local to this earthquake.

The New Hebrides Arc region of the Australia/New Hebrides plate boundary experiences numerous strong earthquakes. In the past quarter century, the 1,000-kilometer section of the arc centered near the epicenter of the January $13^{\text {th }}$ earthquake has produced 19 earthquakes of M 7+. The largest was a M 7.7 earthquake near the southern end of this section in May 1995, which caused no recorded damage or casualties.

\section{1/18/2011 20:23:23 UTC usp000htb4}

\section{$28.732^{\circ} \mathrm{N}, 63.928^{\circ} \mathrm{E}$}

\section{7.2 - Southwestern Pakistan}

\section{Depth 68.0 km}

\section{Electronic Poster Available}

The January 18, 2011, M 7.2 earthquake of southwestern Pakistan occurred as a result of shallow normal faulting within the lithosphere of the subducted Arabia plate. Focal mechanism solutions indicate that rupture occurred on either a steeply dipping normal fault striking southwest, or on a moderately dipping normal fault striking east-northeast. Slip on a fault aligned with either nodal plane is consistent with the intraplate setting of this event.

The present-day tectonic environment of Pakistan is determined by the motions of the Arabia and India plates north-northeast with respect to the Eurasia plate at velocities of 35-40 mm/yr at the location of this earthquake. Arabia plate lithosphere is subducted beneath the Eurasia plate at the Makran Coast of Pakistan and Iran and becomes progressively deeper to the north. The subducted Arabia plate is seismically active to depths of about $160 \mathrm{~km}$. The frequency of moderate and large earthquakes within the subducted Arabia plate is not high compared with the frequency of such events in some other subducted plates worldwide, but several earthquakes have occurred within this slab in the region of the January $18^{\text {th }}$ event over the past 30 years, including a M 7 event $200 \mathrm{~km}$ to the southwest in April 1983 that resulted in no recorded casualties or damage.

03/09/2011 02:45:20 UTC

\section{usp000hvhj}

\section{$38.440^{\circ} \mathrm{N}, 142.840^{\circ} \mathrm{E}$}

\section{7.3 - Near the east coast of Honshu, Japan \\ Depth $32.0 \mathrm{~km}$}

\section{Electronic Poster Available}

The March 9, 2011, M 7.3 earthquake near the east coast of Honshu, Japan, occurred as a result of shallow thrust faulting on or near the subduction zone interface plate boundary between the Pacific and North America plates. At the location of this earthquake, the Pacific plate moves approximately westward relative to the North America plate at a velocity of $83 \mathrm{~mm} / \mathrm{yr}$. The Pacific plate thrusts underneath Japan at the Japan Trench, east of the March $9^{\text {th }}$ earthquake, and dips to the west beneath Eurasia. The location, depth, focal mechanism solutions, and finite-fault modeling of globally distributed seismic data for the March $9^{\text {th }}$ earthquake are consistent with the event resulting from thrust faulting associated with subduction along this plate boundary. Note that some authors 
divide this region into several microplates that together define the relative motions between the larger Pacific, North America and Eurasia plates; these include the Okhotsk and Amur microplates that are part of North America and Eurasia, respectively.

The Japan Trench subduction zone has hosted nine events of M 7+ since 1973. The largest of these was a M 7.8 earthquake approximately $230 \mathrm{~km}$ to the north of the March $9^{\text {th }}$ event, in December 1994, which caused 3 fatalities and almost 700 injuries. In June 1978, a M 7.7 earthquake $75 \mathrm{~km}$ to the southwest caused 22 fatalities and more than 400 injuries. In December 2008, a sequence of four moderate earthquakes (M 5.3-5.8) occurred within $20 \mathrm{~km}$ of the March $9^{\text {th }}$ event. In the first 12 hours following the March $9^{\text {th }}$ earthquake, the region has experienced more than a dozen aftershocks of M 5+, the largest being M 5.7.

03/11/2011 05:46:24 UTC usp000hvnu

\section{$38.297^{\circ} \mathrm{N}, 142.372^{\circ} \mathrm{E}$}

\section{9.1 - Near the east coast of Honshu, Japan \\ Depth 29.0 km \\ Electronic Poster Available}

The March 11, 2011, M 9.1 Tohoku earthquake, which occurred near the northeast coast of Honshu, Japan, resulted from shallow thrust faulting on the subduction zone plate boundary between the Pacific and North America plates. At the location of this earthquake, the Pacific plate moves roughly westward relative to the North America plate at a velocity of $83 \mathrm{~mm} / \mathrm{yr}$, and begins its westward descent beneath Japan at the Japan Trench, east of the March $11^{\text {th }}$ earthquake. Note that some authors divide this region into several microplates that together define the relative motions between the larger Pacific, North America and Eurasia plates; these include the Okhotsk and Amur microplates that are part of North America and Eurasia, respectively.

The location, depth (about $25 \mathrm{~km}$ ), and focal mechanism solutions of the March $11^{\text {th }}$ earthquake are consistent with the event having occurred on the subduction zone plate boundary. Modeling of the rupture of this earthquake indicates that the fault moved as much as 50-60 m, and slipped over an area approximately $400 \mathrm{~km}$ long (along strike) by $150 \mathrm{~km}$ wide (in the downdip direction). The rupture zone is roughly centered on the earthquake epicenter along strike, while peak slips were up-dip of the hypocenter, towards the Japan Trench axis. The March $11^{\text {th }}$ earthquake was preceded by a series of large foreshocks over the previous 2 days, beginning on March 9 with a M 7.4 event approximately $40 \mathrm{~km}$ from the epicenter of the March $11^{\text {th }}$ earthquake, and continuing with another three earthquakes greater than M 6 on the same day.

The Japan Trench subduction zone has hosted nine events of M 7+ since 1973. The largest of these, a M 7.8 earthquake approximately $260 \mathrm{~km}$ to the north of the March $11^{\text {th }}$ epicenter, caused 3 fatalities and almost 700 injuries in December 1994. In June 1978, a M 7.7 earthquake $35 \mathrm{~km}$ to the southwest of the March $11^{\text {th }}$ epicenter caused 22 fatalities and more than 400 injuries. Large offshore earthquakes have occurred in the same subduction zone in 1611, 1896, and 1933 that each produced devastating tsunami waves on the Sanriku Coast of Pacific northeast Japan. That coastline is particularly vulnerable to tsunami waves because it has many deep coastal embayments that amplify tsunami waves and cause great wave inundations. The M 7.6 subduction earthquake of 1896 created tsunami waves as high $38 \mathrm{~m}$ and caused 27,000 fatalities. The M 8.6 earthquake of March 2, 1933, produced tsunami waves as high as $29 \mathrm{~m}$ on the Sanriku Coast and caused more than 3,000 fatalities. Unlike the recent M 9.0 earthquake, the 1933 earthquake did not occur as the result of thrust faulting on the subduction zone plate interface, but rather within the Pacific plate just seaward of the Japan Trench.

The March 11, 2011, earthquake was much larger than other post-1900 plate boundary thrust fault earthquakes in the southern Japan Trench, none of which attained M 8. A similarly sized predecessor may have occurred on July 13, 869, when the Sendai area was swept by a large tsunami that Japanese scientists have identified from written records and a sand sheet.

Continuing readjustments of stress and related aftershocks are expected in the region of this earthquake. The exact location and timing of future aftershocks cannot be specified. Numbers of aftershocks will continue to be highest on and near to fault-segments on which rupture occurred at the time of the mainshock. The frequency of aftershocks will tend to decrease with elapsed time from the time of the mainshock, but the general decrease of activity may be punctuated by episodes of higher aftershock activity. Beyond the ongoing aftershock sequence, the earthquakes in Japan have not significantly raised the probability of future major earthquakes. While the probability of future large earthquakes far from northern Honshu has not increased, neither has it decreased; large global earthquakes will likely continue to occur just as we have observed in the past. 
03/11/2011 06:15:40 UTC

usp000hvpa

\section{$36.281^{\circ} \mathrm{N}, 141.111^{\circ} \mathrm{E}$}

\section{7.9 - Near the East Coast of Honshu, Japan \\ Depth 42.6 km}

The March 11, 2011, M 7.9 earthquake off the east coast of Honshu, Japan, about 140 km northeast from Tokyo, occurred as a result of shallow thrust faulting on or near the subduction zone plate boundary between the Pacific and North America plates. At the location of this earthquake, the Pacific plate moves roughly westward relative to the North America plate at a velocity of $71 \mathrm{~mm} / \mathrm{yr}$ and begins its westward descent beneath Japan at the Japan Trench, east of the March $11^{\text {th }}$ earthquake. Note that some authors divide this region into several microplates that together define the relative motions between the larger Pacific, North America and Eurasia plates; these include the Okhotsk and Amur microplates that are part of North America and Eurasia, respectively.

The March $11^{\text {th }}$ M 7.9 earthquake occurred approximately 30 minutes after the devastating March 11, 2011, M 9.1 Tohoku earthquake, and can be considered an aftershock at the southern end of the rupture area of that event. Over the 2 days preceding the March $11^{\text {th }}$ mainshock, a series of large foreshocks had occurred, beginning on March 9 with a M 7.3 event approximately $40 \mathrm{~km}$ from the epicenter of the March $11^{\text {th }}$ M 9.1 earthquake, and continuing with another three earthquakes greater than M 6 on the same day. Prior to March 9, the Japan Trench subduction zone had hosted nine events of M 7+ since 1973.

While commonly plotted as points on maps, earthquakes of this size are more appropriately described as slip over a larger fault area. Thrust-faulting events of the size of the March 11, 2011, M 7.9 earthquake are typically about $135 \times 60 \mathrm{~km}$ (length x width); interference from the previous M 9.1 event makes modeling its source dimensions complicated, and as such a slip model is not available at this time.

\section{3/11/2011 06:25:50 UTC usp000hvpg $38.059^{\circ} \mathrm{N}, 144.640^{\circ} \mathrm{E}$}

\section{7.7 - Off the east coast of Honshu, Japan Depth 18.6 km}

The March 11, 2011, M 7.7 earthquake near the east coast of Honshu, Japan, occurred as a result of shallow normal faulting within the oceanic lithosphere of the Pacific plate, approximately $60 \mathrm{~km}$ east of the Japan Trench. Focal mechanism solutions indicate that rupture occurred on either a north- or south-striking, moderately dipping normal fault. Slip on a fault aligned with either nodal plane is consistent with the intraplate setting of this event. At the location of this earthquake, the Pacific plate moves roughly westward relative to the North America plate at a velocity of $70 \mathrm{~mm} / \mathrm{yr}$, and begins its westward descent beneath Japan at the Japan Trench. Note that some authors divide this region into several microplates that together define the relative motions between the larger Pacific, North America and Eurasia plates; these include the Okhotsk and Amur microplates that are part of North America and Eurasia, respectively.

This earthquake occurred approximately 40 minutes after the devastating March 11, 2011, M 9.1 Tohoku earthquake. This 06:25 UTC earthquake can be considered an aftershock of the 05:46 M 9.1 event, despite occurring on a different fault structure (on a normal fault directly east of the subduction zone, rather than on the subduction zone interface). Over the 2 days preceding the March $11^{\text {th }}$ mainshock, a series of large foreshocks had occurred, beginning on March 9 with a M 7.3 event approximately $40 \mathrm{~km}$ from the epicenter of the March $11^{\text {th }}$ M 9.1 earthquake, and continuing with another three earthquakes greater than M 6 on the same day. Prior to March 9, the Japan Trench subduction zone had hosted nine events of M 7+ since 1973.

While commonly plotted as points on maps, earthquakes of this size are more appropriately described as slip over a larger fault area. Normal-faulting events of the size of the March 11, 2011, M 7.7 earthquake are typically about 90x35 km (length x width); interference from the previous M 9.1 event makes modeling its source dimensions complicated, and as such a slip model is not available at this time.

\section{4/07/2011 14:32:43 UTC Usp000hzf6 $38.253^{\circ} \mathrm{N}, 141.640^{\circ} \mathrm{E}$}

\section{7.1 - Near the east coast of Honshu, Japan Depth 42.0 km}

The April 7, 2011, M 7.1 earthquake near the east coast of Honshu, Japan, occurred as a result of shallow reverse faulting on or near the subduction zone plate boundary between the Pacific and North America plates. Focal mechanism solutions indicate that rupture occurred on either a north-northeast- or south-southwest-striking, moderately dipping reverse fault. At 
the location of this earthquake, the Pacific plate moves roughly westward relative to the North America plate at a velocity of $83 \mathrm{~mm} / \mathrm{yr}$, and begins its westward descent beneath Japan at the Japan Trench, east of the April $7^{\text {th }}$ earthquake. Note that some authors divide this region into several microplates that together define the relative motions between the larger Pacific, North America and Eurasia plates; these include the Okhotsk and Amur microplates that are part of North America and Eurasia, respectively.

The epicenter and focal depth of the April $7^{\text {th }}$ earthquake are consistent with the event having occurred very close to the main interface thrust fault of the subduction zone plate boundary. Preliminary focal mechanism solutions, however, imply slip on a fault with steeper dip than that of the main interface thrust fault, which may imply that an intraplate source is most likely. In such an intraplate scenario, slip may have occurred on a fault aligned with either nodal plane of the focal mechanism solution.

The April 7th earthquake can be considered an aftershock of the March 11, 2011, M 9.1 Tohoku earthquake. The aftershock sequence of that event has been ongoing since March 11 and has included 58 earthquakes of M 6+ up until April 7, 2011;2 of these were M 7+ (M 7.7 and M 7.9, both on March 11). Over the 2 days preceding the March $11^{\text {th }}$ mainshock, a series of large foreshocks had occurred, beginning on March $9^{\text {th }}$ with a M 7.3 event approximately $40 \mathrm{~km}$ from the epicenter of the March $11^{\text {th }}$ M 9.1 earthquake, and continuing with another three earthquakes greater than M 6 on the same day. Prior to March 9, 2011, the Japan Trench subduction zone had hosted nine events of M 7+ since 1973.

\section{6/24/2011 03:09:39 UTC usp000j3mq} $52.008^{\circ} \mathrm{N}, 171.859^{\circ} \mathrm{W}$

\section{7.3 - Fox Islands, Aleutian Islands, Alaska Depth 52.0 km}

\section{Electronic Poster Available}

The June 24, 2011, M 7.2 Fox Islands (Aleutian Islands, Alaska) earthquake occurred as a result of normal faulting within the downgoing Pacific slab as it thrusts beneath the North America plate at the Aleutian Trench, in the subduction zone extending to the southwest from Alaska. At the location of the event, the Pacific plate converges with North America at a velocity of about $71 \mathrm{~mm} / \mathrm{yr}$ in a northwest direction, subducting at the Aleutian Trench south of the June $24^{\text {th }}$ earthquake. Though the June $24^{\text {th }}$ earthquake is near this regional subduction thrust interface, its depth (currently estimated as $52 \mathrm{~km}$, though moment tensors place the event deeper) and focal mechanism solution (indicating either very shallow or near-vertical normal faulting) both suggest that the earthquake occurred within the subducting plate, beyond the down-dip edge of the coupled zone between North America and the Pacific plates. Slip on a fault aligned with either nodal plane of the focal mechanism solution is consistent with this intraplate setting.

Historically, the section of the Aleutian Arc in the vicinity of the June $24^{\text {th }}$ earthquake is less active than other parts of this subduction zone, though it has hosted 11 events of M 6+ since the early 1970s, all shallower than the June $24^{\text {th }}$ earthquake. Few instrumentally recorded earthquakes at the depth of the June $24^{\text {th }}$ event have been as large as M 6 , though two nearby events of M 7+ near the beginning of the $20^{\text {th }}$ century were also thought to have occurred within the subducting Pacific slab. The shallow subduction zone up-dip of the June $24^{\text {th }}$ earthquake ruptured in the M 8.6 central Aleutians earthquake of 1957, which spawned a large and damaging tsunami locally and also impacted the shores of Hawaii and California.

Increased attention to this event is due to the fact that the recent M 9 Tohoku, Japan, earthquake was preceded two days earlier by a nearby M 7.3 foreshock. While both of those Japanese earthquakes occurred on the subduction thrust plate boundary between the Pacific and North America plates, the June $24^{\text {th }}$ Fox Islands earthquake is likely to have occurred within the lithosphere of the downgoing Pacific slab, and thus any link to future events on the plate boundary itself is less clear.

Statistically, any large earthquake raises the probability that other events may occur nearby (typically within two fault lengths, or approximately $100 \mathrm{~km}$ in this case). While the probability of a larger earthquake occurring in the near future close to the June $24^{\text {th }}$ event cannot be precisely evaluated, such probabilities are typically low.

\section{7/06/2011 19:03:18 UTC Usp000j48h}

\subsection{2 $\mathrm{S}, 176.204^{\circ} \mathrm{W}$}

\section{7.6 - Kermadec Islands region}

\section{Depth 17.0 km}

\section{Electronic Poster Available}

The July 6, 2011, M 7.6 Kermadec Islands region earthquake occurred as the result of shallow normal faulting near the Kermadec Trench where the Pacific plate begins its descent into the mantle beneath the eastern edge of the Australia plate. Focal mechanism solutions indicate that rupture occurred on either a north-northeast- or a south-southeast-striking, moderately dipping 
normal fault. Of these two possible fault orientations, finite-fault modeling of globally recorded seismic data is more consistent with slip on the south-southeast-striking fault. At the location of this earthquake, the Pacific plate is converging with Australia in a westward direction at a velocity of about $61 \mathrm{~mm} / \mathrm{yr}$. The focal mechanism solution and depth (about $20 \mathrm{~km}$ ) of the event suggest that it ruptured a normal fault within the shallow oceanic lithosphere of the Pacific plate; the location suggests a source slightly to the west of the trench, within the downgoing slab, rather than to the east and in the outer rise region.

While commonly plotted as points on maps, earthquakes of this size are more appropriately described as slip over a larger fault area. Normal-faulting events of the size of the July 6, 2011, earthquake are typically about $85 \times 35 \mathrm{~km}$ (length $\mathrm{x}$ width); modeling of this earthquake implies dimensions of about $110 \times 40 \mathrm{~km}$, predominantly surrounding the hypocenter and to the northwest.

The July $6^{\text {th }}$ earthquake struck in an oceanic region with few nearby populations, approximately $550 \mathrm{~km}$ south of Tonga and $650 \mathrm{~km}$ north of New Zealand. This region of the Tonga-Kermadec subduction zone experiences high levels of seismic activity, with nearly 50 events of M 6.5+ over the past 38 years, and 4 of M 7.5+. Two of these, M 7.8 and M 8.2 earthquakes on the same day in 1976, occurred about $150 \mathrm{~km}$ west-northwest of the July $6^{\text {th }}$ event. A M 7.8 event in 1978 struck nearly $200 \mathrm{~km}$ to the southwest, and a M 8.3 event occurred in October 1986 about $130 \mathrm{~km}$ to the north. None of these events have recorded damage or casualties.

\section{7/10/2011 00:57:10 UTC Usp000j4gp \\ $38.040^{\circ} \mathrm{N}, 143.287^{\circ} \mathrm{E}$ \\ M 7.0 - Off the east coast of Honshu, Japan \\ Depth $23.0 \mathrm{~km}$}

\section{Electronic Poster Available}

The July 10, 2011, M 7.0 earthquake off the east coast of Honshu, Japan, occurred as the result of shallow strike-slip faulting close to the boundary between the Pacific and North America plates, in the subduction zone region where the Pacific plate converges with and sinks beneath Japan and Eurasia to the west. Focal mechanism solutions indicate that rupture occurred on either a right-lateral northwest-striking fault or a left-lateral east-northeast-striking fault. At the location of the July $10^{\text {th }}$ event, the Pacific plate moves west-northwestward with respect to North America and northern Japan at a rate of approximately $83 \mathrm{~mm} / \mathrm{yr}$. Note that some authors divide this region into several microplates that together define the relative motions between the larger Pacific, North America and Eurasia plates; these include the Okhotsk and Amur microplates that are part of North America and Eurasia, respectively.

The epicenter and focal mechanism solutions of this earthquake, together with a preliminary depth estimate of $23 \mathrm{~km}$, suggest that the earthquake occurred within the subducting Pacific lithosphere, rather than on the overlying subduction plate interface itself or within the overriding North America plate. Slip on a fault aligned with either nodal plane of the focal mechanism solution is consistent with this intraplate setting. The July $10^{\text {th }}$ event struck about $80 \mathrm{~km}$ to the east-southeast of the March 11, 2011, M 9.1 Tohoku earthquake, near the southern end of major rupture associated with that larger event. The July $10^{\text {th }}$ earthquake can be considered an aftershock of the damaging March 11 ${ }^{\text {th }}$ event. Since March 11, more than 688 aftershocks with magnitudes greater than 5 have occurred, and 67 of these had M 6+, with aftershocks occurring both as interplate events on the subduction plate interface and as intraplate events within the overriding North America plate or the subducting Pacific plate. These aftershocks reflect the adjustment of stresses in the plate boundary region in response to the March $11^{\text {th }}$ mainshock.

\section{8/20/2011 16:55:02 UTC usp000j6r4}

\section{$18.260^{\circ} \mathrm{S}, 168.069^{\circ} \mathrm{E}$}

\section{7.2 - Vanuatu}

\section{Depth 32.0 km}

\section{Electronic Poster Available}

The August 20, 2011 (16:55:02 UTC), M 7.2 Vanuatu earthquake was the first of two M 7+ events that occurred on the same day in this region, a result of shallow thrust faulting on or near the subduction zone plate boundary between the Australia and Pacific plates in the Coral Sea region of the southwest Pacific. Near the epicenter of these earthquakes, the Australia plate moves to the east-northeast relative to the Pacific plate at a velocity of about $83 \mathrm{~mm} / \mathrm{yr}$, and begins its eastward descent beneath the arc at the New Hebrides Trench to the west of the August $20^{\text {th }}$ earthquakes. The subducting Australia plate is seismically active to depths of about $350 \mathrm{~km}$ beneath the islands.

The M 7.2 earthquake (16:55 UTC) preceded the M 7.1 event (18:19 UTC) by 84 minutes, and was located approximately $6 \mathrm{~km}$ away horizontally, and $12 \mathrm{~km}$ apart in depth — each offset within location uncertainties of typical global earthquakes. The 
two events also had approximately the same focal mechanism solution. The latter earthquake was almost certainly triggered by the earlier event. Seismologists sometimes refer to a pair of similarly sized earthquakes that occur at nearly the same time and location as an earthquake "doublet."

These earthquakes are located approximately $80 \mathrm{~km}$ to the south of a M 7.3 earthquake that occurred in August 2010, and $600 \mathrm{~km}$ to the south of a sequence of large subduction thrust earthquakes that occurred in October 2009. The Vanuatu region experiences a very high level of earthquake activity, with almost 50 events of M 7 or larger recorded since 1973.

08/20/2011 18:19:23 UTC

\section{$18.287^{\circ} \mathrm{S}, 168.132^{\circ} \mathrm{E}$}

\section{7.1 - Vanuatu}

\section{Depth $28.0 \mathrm{~km}$}

\section{Electronic Poster Available}

The August 20, 2011 (18:19:24 UTC), M 7.1 Vanuatu earthquake was the second of two M 7+ events that occurred on the same day in this region, a result of shallow thrust faulting on or near the subduction zone plate boundary between the Australia and Pacific plates in the Coral Sea region of the southwest Pacific. Near the epicenters of these earthquakes, the Australia plate moves to the east-northeast relative to the Pacific plate at a velocity of about $83 \mathrm{~mm} / \mathrm{yr}$, and begins its eastward descent beneath the arc at the New Hebrides Trench to the west of the August $20^{\text {th }}$ events. The subducting Australia plate is seismically active to depths of about $350 \mathrm{~km}$ beneath the islands.

The M 7.2 earthquake (August 20, 2011, 16:55 UTC) preceded the M 7.1 event (August 20, 2011, 18:19 UTC) by 84 minutes, and was located approximately $6 \mathrm{~km}$ away horizontally, and $12 \mathrm{~km}$ apart in depth - each offset within location uncertainties of typical global earthquakes. The two events also had approximately the same focal mechanism solution. The latter earthquake was almost certainly triggered by the earlier event. Seismologists sometimes refer to a pair of similarly sized earthquakes that occur at nearly the same time and location as an earthquake "doublet."

These earthquakes are located approximately $80 \mathrm{~km}$ to the south of a M 7.3 earthquake that occurred in August 2010, and $600 \mathrm{~km}$ to the south of a sequence of large subduction thrust earthquakes that occurred in October 2009. The Vanuatu region experiences a very high level of earthquake activity, with almost 50 events of M 7 or larger recorded since 1973.

\section{8/24/2011 17:46:11 UTC usp000j6z8 \\ $18.287^{\circ} \mathrm{S}, 168.132^{\circ} \mathrm{E}$ \\ M 7.0 - Northern Peru Depth 147.0 km}

\section{Electronic Poster Available}

The August 24, 2011, M 7.0 Peru earthquake occurred as the result of normal faulting at an intermediate depth, approximately $150 \mathrm{~km}$ beneath northern Peru, within the subducting Nazca slab. Focal mechanism solutions indicate that rupture occurred on either a north- or south-striking, moderately dipping normal fault. Slip on a fault of either orientation would accommodate the down-dip extension of the Nazca slab that is implied by the normal-component of the faulting solution. At the location of the earthquake, the Nazca plate moves roughly east-northeast relative to the South America plate at a velocity of $67 \mathrm{~mm} / \mathrm{yr}$. The event struck near the boundary between these two plates, where the former sinks beneath the latter. The Nazca plate is seismically active east-northeast of the August $24^{\text {th }}$ epicenter to depths of greater than $600 \mathrm{~km}$; the stresses generating this earthquake may result from the bending of the plate as it transitions from a sub-horizontal region west-southwest of the epicenter to sink at steeper dips towards the mantle transition zone.

The section of the subducting Nazca plate within $100 \mathrm{~km}$ of the epicenter of the August 24, 2011, earthquake has hosted moderate earthquakes in the past, with seven earthquakes of $\mathrm{M} 6+$ in the past quarter century, though none have been as large as the August $24^{\text {th }}$ event. The most recent nearby earthquake was a M 6.4 event just over $10 \mathrm{~km}$ to the east in August 2008 that had no recorded damage or casualties.

Earthquakes like this event, with focal depths between 70 and $300 \mathrm{~km}$, are commonly termed "intermediate-depth" earthquakes. Intermediate-depth earthquakes represent deformation within subducted slabs rather than at the shallow plate interface between subducting and overriding tectonic plates. They typically cause less damage on the ground surface above their foci than is the case with similar-magnitude shallow-focus earthquakes, but large intermediate-depth earthquakes may be felt at great distance from their epicenters. "Deep-focus" earthquakes, those with focal depths greater than $300 \mathrm{~km}$, also occur in the subducted Nazca plate farther east from the Peru-Chile Trench, beneath western Brazil and central Argentina. Earthquakes have been reliably located to depths of about $650 \mathrm{~km}$ in this region. 
09/03/2011 22:55:40 UTC

usp000j7jb

\section{$20.585^{\circ} \mathrm{S}, 169.696^{\circ} \mathrm{E}$}

\section{7.0 - Vanuatu}

\section{Depth 185.1 km}

\section{Electronic Poster Available}

The September 3, 2011, M 7.0 Vanuatu earthquake occurred as the result of oblique-reverse faulting at an intermediate depth, approximately $135 \mathrm{~km}$ beneath the Earth's surface at the southern extent of the Vanuatu islands. Focal mechanism solutions indicate that rupture occurred on either a steeply dipping reverse fault or a moderately dipping oblique-reverse fault. Slip on a fault of either orientation would accommodate the down-dip compression of the Australia slab that is implied by the reverse component of the faulting solution. At the location of this earthquake, the Australia plate moves roughly east-northeast relative to the Pacific at a velocity of $79 \mathrm{~mm} / \mathrm{yr}$, subducting beneath the Vanuatu island chain from the New Hebrides Trench to the west of this earthquake. The September $3^{\text {rd }}$ event occurred near the boundary between these two plates as a result of faulting within the subducting Australia slab, and was driven by the stresses generated by the bending of the plate as it sinks deeper into the mantle. The subducted slab is seismically active east of the September $3^{\text {rd }}$ epicenter to depths close to $300 \mathrm{~km}$.

This section of the subducting Australia plate has hosted numerous moderate and large earthquakes in the past, with 14 earthquakes of M 6.5+ within $100 \mathrm{~km}$ of the September $3^{\text {rd }}$ event over the past quarter century. The largest was a M 7.2 earthquake $80 \mathrm{~km}$ to the south and $50 \mathrm{~km}$ shallower in 1979. The recent M 7.1 and M 7.0 Vanuatu earthquakes of August 20, 2011, occurred more than $300 \mathrm{~km}$ to the northwest of the September $3^{\text {rd }}$ quake, along the shallow plate boundary interface, rather than within the subducting plate.

Earthquakes like this event, with focal depths between 70 and $300 \mathrm{~km}$, are commonly termed "intermediate-depth" earthquakes. Intermediate-depth earthquakes represent deformation within subducted slabs rather than at the shallow plate interface between subducting and overriding tectonic plates. They typically cause less damage on the ground surface above their foci than is the case with similar-magnitude shallow-focus earthquakes, but large intermediate-depth earthquakes may be felt at great distance from their epicenters.

\section{9/15/2011 19:31:04 UTC usp000j83e $21.559^{\circ} \mathrm{S}, 179.369^{\circ} \mathrm{W}$}

\section{7.3 - Fiji Region}

\section{Depth 644.6 km}

\section{Electronic Poster Available}

The September 15, 2011, M 7.3 earthquake near Fiji occurred as the result of oblique reverse faulting, approximately $645 \mathrm{~km}$ beneath the Earth's surface in the South Pacific Ocean, within the subducting Pacific slab. Focal mechanism solutions indicate reverse slip occurred on either a northeast-striking, near-vertical fault or on a northwest-striking, moderately dipping fault. Slip on a fault of either orientation would accommodate the down-dip compression of the Pacific slab that is implied by the reverse component of the faulting solution. At the location of this earthquake, the Pacific plate moves approximately due west relative to the interior of the Australia plate at a rate of $75 \mathrm{~mm} / \mathrm{yr}$. The Pacific plate begins its westward descent beneath the eastern edge of the Australia plate at the Tonga Trench (to the east of this earthquake), and is seismically active west of the September $15^{\text {th }}$ epicenter to depths of greater than $650 \mathrm{~km}$. The geometry of the Pacific plate at depth is known to be quite complex, and may involve interactions between the Pacific plate proper and one or more relict slab fragments. The stresses generating the September $15^{\text {th }}$ earthquake likely result from the slow deformation within the interior of one of these slabs, near the base of the mantle transition zone.

The subducting Pacific plate beneath Fiji, which initiates its westward descent beneath the eastern edge of the Australia plate at the Tonga Trench, is one of the most seismically active regions in the world. Over the past 37 years, more than 3,000 deep-focus earthquakes have occurred within $200 \mathrm{~km}$ of the September $15^{\text {th }}$ event. Of these, 14 had magnitudes of M 6.5+. The largest was a M 7.7 earthquake in August 2002, which occurred about $15 \mathrm{~km}$ to the southwest and $50 \mathrm{~km}$ shallower than the September $15^{\text {th }}$ event; that $\mathrm{M} 7.7$ earthquake had no recorded casualties or damage.

Earthquakes that have focal depths greater than $300 \mathrm{~km}$ are commonly termed "deep-focus" earthquakes. Deep-focus earthquakes cause less damage on the ground surface above their foci than similar-magnitude shallow-focus earthquakes, but large deep-focus earthquakes may be felt at great distance from their epicenters. The largest recorded deep-focus earthquake prior to this September 2011 earthquake was a M 8.2 event that occurred at a depth of $630 \mathrm{~km}$ within the subducted Nazca plate beneath South America near the northern Bolivian border in 1994. A larger event has since occurred-namely the M 8.3 earthquake that occurred at a depth of $600 \mathrm{~km}$ within the subducted Pacific plate beneath the Sea of Okhotsk offshore of northeastern Russia in 
2013. The M 8.3 Sea of Okhotsk earthquake was felt all over Asia, as far away as Moscow, and across the Pacific Ocean along the western seaboard of the United States (though at distant locations, individuals reporting having felt the event were likely very favorably situated for the perception of small ground motions). The M 8.2 Bolivian deep-focus earthquake in 1994 had similarly been reported by individuals in North America at great distance from the epicenter.

Over the past century, 83 earthquakes with a magnitude of M 7+ have occurred at depths greater than $300 \mathrm{~km}$ globally; 26 of these were located in the same region as the September 15, 2011, event. The largest nearby event at these depths was a M 7.7 earthquake in August 19, 2002 (11:01:01 UTC), just $10 \mathrm{~km}$ to the south-southeast and $65 \mathrm{~km}$ shallower than the September 2011 event.

\section{0/21/2011 17:57:16 UTC Usp000j9nm}

\section{$28.998^{\circ} \mathrm{S}, 176.183^{\circ} \mathrm{W}$}

\section{7.4 - Kermadec Islands region Depth 33.0 km \\ Electronic Poster Available}

The October 21, 2011, M 7.4 Kermadec Islands region earthquake occurred as the result of shallow reverse faulting near the Kermadec Trench where the Pacific plate begins its descent into the mantle beneath the eastern edge of the Australia plate. Focal mechanism solutions indicate that rupture occurred on either a south- or northeast-striking, moderately dipping reverse fault. Of these two possible fault orientations, finite-fault modeling of globally recorded seismic data is more consistent with slip on the northeast-striking fault. At the location of this earthquake, the Pacific plate is converging with Australia in a westward direction at a velocity of about $61 \mathrm{~mm} / \mathrm{yr}$. The preliminary mechanism and depth of the event suggest it ruptured a reverse fault within the subducting oceanic lithosphere of the Pacific plate, rather than on the overlying thrust interface between the Pacific and Australia plates.

The October $21^{\text {st }}$ earthquake struck in an oceanic region with few nearby populations, approximately $500 \mathrm{~km}$ south of Tonga and $700 \mathrm{~km}$ north of New Zealand. This region of the Tonga-Kermadec subduction zone experiences high levels of seismic activity, with nearly 50 events of M 6.5+ over the past 38 years, and 5 of M 7.5+. Two of these, M 7.8 and M 8.2 earthquakes on the same day in 1976, occurred about $100 \mathrm{~km}$ west-northwest of the October $21^{\text {st }}$ event; a M 7.8 event in 1978 struck nearly $250 \mathrm{~km}$ to the southwest, and a M 8.3 event occurred in October 1986 about $80 \mathrm{~km}$ to the north. None of these events have recorded damage or casualties.

In July of this year, a M 7.6 event occurred approximately $45 \mathrm{~km}$ to the south-southwest of the October $21^{\text {st }}$ earthquake, breaking a normal fault within the subducting Pacific plate also very close to the Kermadec Trench. This event was notable because it triggered a large number of thrust faulting aftershocks to the west of the plate boundary, on or close to the interface between the Pacific and Australia plates. The October $21^{\text {st }}$ earthquake may be related to that aftershock sequence.

10/23/2011 10:41:23 UTC usp000j9rr

$38.691^{\circ} \mathrm{N}, 43.497^{\circ} \mathrm{E}$

\section{7.1 - Eastern Turkey}

\section{Depth $18.0 \mathrm{~km}$}

\section{Electronic Poster Available}

Turkey is a tectonically active country that experiences frequent destructive earthquakes. On a broad scale, the seismotectonics of the region near the October 23, 2011, earthquake are controlled by the collision of the Arabia plate and Eurasia plates; at the location of this event, the Arabia plate converges with Eurasia in a northerly direction at a rate of approximately $24 \mathrm{~mm} / \mathrm{yr}$. West of the October 23, 2011, earthquake, tectonics are dominated by strike-slip faulting on the East (in southern Turkey) and North (in northern Turkey) Anatolian fault zones. These large, translational fault systems extend across much of central and western Turkey and accommodate the western motion of the Anatolian block as it is being squeezed by the converging Arabia and Eurasia plates. In the area of Lake Van and farther east, tectonics are dominated by the Bitlis suture zone (in eastern Turkey) and Zagros fold and thrust belt (towards Iran). The October 23, 2011, earthquake occurred in a broad region of convergence beyond the eastern extent of Anatolian strike-slip tectonics. The focal mechanism solution of this earthquake is consistent with oblique-reverse faulting similar to mapped faults in the region. Of the two possible fault orientations of the focal mechanism solution, finite-fault modeling of globally recorded seismic data is more consistent with slip on the west-striking (north-dipping) reverse fault.

This earthquake is a reminder of the many deadly seismic events that Turkey has suffered in the recent past. The devastating Izmit earthquake of 1999 (M 7.6) ruptured a section of the North Anatolian fault 1,000 km to the west of the October $23^{\text {rd }}$ 
event and caused 17,000 fatalities and 50,000 injuries, and left 500,000 people homeless. Approximately $70 \mathrm{~km}$ from this earthquake, a M 7.3 earthquake occurred in November 1976 destroying several villages near the Turkey and Iran border and resulted in several thousand fatalities. A M 7.8 earthquake struck Erzincan in 1939, with an estimated 33,000 fatalities.

\section{2/14/2011 05:04:58 UTC usp000jc5z}

\section{$7.518^{\circ} \mathrm{S}, 146.767^{\circ} \mathrm{E}$}

\section{7.1 - Eastern New Guinea region, Papua New Guinea Depth 135.0 km}

\section{Electronic Poster Available}

The December 14, 2011, M 7.1 eastern New Guinea region earthquake occurred as a result of oblique normal faulting at an intermediate depth, approximately $135 \mathrm{~km}$ beneath eastern Papua New Guinea, near the northern edge of the Australia plate. Focal mechanism solutions indicate that rupture occurred on either a near-vertical normal fault or a shallowly dipping normal fault. At the location of the earthquake, the Australia plate moves towards the east-northeast relative to the Pacific plate at a velocity of about $100 \mathrm{~mm} / \mathrm{yr}$. Earthquakes in this geographical region are generally associated with the large-scale convergence of these two major plates, and with the complex interactions of several associated microplates, most notably the South Bismarck plate, the Solomon Sea microplate, and the Woodlark plate.

The depth of the December $14^{\text {th }}$ earthquake implies that it occurred in subducted or foundered lithosphere. Although there is still not complete geophysical consensus on the location and configuration of subducted plates in the region, the location of the earthquake is consistent with it occurring in a subducted fragment of the Solomon Sea microplate that is bent about an approximately east-west axis and subducting both to the north and to the south or southwest. In northern Papua New Guinea, approximately $80 \mathrm{~km}$ to the north of the December $14^{\text {th }}$ event, clear north-directed subduction of the Solomon Sea microplate beneath the South Bismarck plate occurs, with the associated Wadati-Benioff zone active to depths of more than $600 \mathrm{~km}$ beneath the Bismarck Sea to the northeast of New Guinea. The location of the December $14^{\text {th }}$ earthquake places it in the gently south-southwestdipping segment of the Solomon Sea microplate. Slip on a fault aligned with either nodal plane of the focal mechanism solution is consistent with this intraplate setting.

Papua New Guinea experiences a high rate of seismic activity, with almost 50 events of M 6+ occurring within $250 \mathrm{~km}$ of the December $14^{\text {th }}$ event since 1973. Nearby (within $100 \mathrm{~km}$ ), only one large earthquake has occurred at depths greater than $100 \mathrm{~km}$ - a M 7.3 earthquake $60 \mathrm{~km}$ to the west at $180 \mathrm{~km}$ depth in 1963.

Earthquakes like the December 14th event, with focal depths between 70 and $300 \mathrm{~km}$, are commonly termed "intermediatedepth" earthquakes. Intermediate-depth earthquakes represent deformation within subducted slabs rather than at the shallow plate interface between subducting and overriding tectonic plates. They typically cause less damage on the ground surface above their foci than is the case with similar-magnitude shallow-focus earthquakes, but large intermediate-depth earthquakes may be felt at great distance from their epicenters. "Deep-focus" earthquakes, those with focal depths greater than $300 \mathrm{~km}$, also occur in beneath Papua New Guinea and the Bismarck Sea to the northeast.

\section{2: 16 Events}

\section{1/10/2012 18:36:59 UTC Usp000jdar}

\section{$2.452^{\circ} \mathrm{N}, 93.209^{\circ} \mathrm{E}$}

\section{7.2 - Off the West Coast of Northern Sumatra}

\section{Depth $19.0 \mathrm{~km}$}

\section{Electronic Poster Available}

The January 10, 2012, M 7.2 earthquake off the west coast of northern Sumatra, Indonesia, occurred as a result of shallow strike-slip faulting within the oceanic lithosphere of the Indo-Australia plate, approximately $100 \mathrm{~km}$ to the southwest of the major subduction zone that defines the plate boundary between the Indo-Australia and Sunda plates offshore Sumatra. Focal mechanism solutions indicate that rupture occurred on either a right-lateral east-striking fault or a left-lateral south-striking fault. Finite-fault modeling of globally recorded seismic data for this earthquake is not able to distinguish between these two possibilities. At the location of this earthquake, the Indo-Australia plate moves north-northeast relative to the Sunda plate at a velocity of about $52 \mathrm{~mm} / \mathrm{yr}$. 
While they are rare, large strike-slip earthquakes are not unprecedented in this region of the Indo-Australia plate. Since the massive M 9.1 earthquake that ruptured a 1,300-km-long segment of the Sumatran megathrust plate boundary in December 2004, two M 6.2 strike-slip events have occurred within $50 \mathrm{~km}$ of the January $10^{\text {th }}$ event, on April 19, 2006, and October 4, 2007. These events seem to align with fabric of the sea floor in the diffuse boundary zone between the India and Australia plates.

02/02/2012 13:34:40 UTC

usp000jeag

\section{$17.766^{\circ} \mathrm{S}, 167.134^{\circ} \mathrm{E}$}

\section{7.1 - Vanuatu}

\section{Depth 23.0 km}

\section{Electronic Poster Available}

The February 2, 2012, M 7.1 earthquake near Vanuatu in the southwest Pacific Ocean occurred as a result of shallow, oblique normal faulting within the lithosphere of the Australia plate. Focal mechanism solutions indicate that oblique rupture occurred on either a northeast- or south-southeast-striking, moderately dipping normal fault. The earthquake epicenter is located just $15 \mathrm{~km}$ to the west of the New Hebrides Trench, the bathymetric expression of the boundary between the Australia and Pacific plates, where lithosphere of the Australia plate subducts into the mantle beneath the North Fiji Basin. Slip on a fault aligned with either nodal plane of the focal mechanism solution is consistent with this intraplate setting. At the location of this earthquake, the Australia plate moves east-northeast with respect to the Pacific plate at a velocity of approximately $84 \mathrm{~mm} / \mathrm{yr}$.

The Vanuatu region frequently experiences earthquakes of this size; about a dozen earthquakes of M 7 or larger have occurred within $250 \mathrm{~km}$ of the February $2^{\text {nd }}$ event over the past 30 years. However, they generally occur on the megathrust interface to the east, and few have been outboard (seaward) of the trench. A M 7.3 normal faulting earthquake did occur to the west of the New Hebrides Trench, about $225 \mathrm{~km}$ to the south of the February $2^{\text {nd }}$ event, on December 25, 2010.

03/20/2012 18:02:47 UTC usp000jghj

\section{$16.662^{\circ} \mathrm{N}, 98.188^{\circ} \mathrm{W}$}

\section{7.4 - Oaxaca, Mexico}

\section{Depth 20.0 km}

\section{Electronic Poster Available}

The March 20, 2012, M 7.4 earthquake of Oaxaca, Mexico, occurred as a result of shallow thrust faulting on or near the plate boundary interface between the Cocos and North America plates. The depth, focal mechanism solutions, and finite-fault modeling of globally recorded seismic data for the earthquake are consistent with its occurrence on the subduction zone interface between these plates, approximately $100 \mathrm{~km}$ northeast of the Middle America Trench, where the Cocos plate begins its descent into the mantle beneath Mexico. In the region of this earthquake, the Cocos plate moves approximately northeastward at a rate of $60 \mathrm{~mm} / \mathrm{yr}$.

Historically, several significant earthquakes have occurred along the southern coast of Mexico. In 1932, a M 8.4 thrust earthquake struck in the region of Jalisco, several hundred kilometers to the northwest of the March $20^{\text {th }}$ event. On October 9, 1995, a M 8.0 earthquake struck in the Colima-Jalisco region, resulted in at least 49 fatalities and left 1,000 people homeless. The deadliest nearby earthquake occurred on September 19, 1985, in the Michoacan region $470 \mathrm{~km}$ to the northwest of the March $20^{\text {th }}$ event. This M 8.0 earthquake resulted in at least 9,500 fatalities, injured about 30,000 people, and left 100,000 people homeless. In 2003, a M 7.6 earthquake in Colima, Mexico, $640 \mathrm{~km}$ to the northwest of the March $20^{\text {th }}$ event, resulted in 29 fatalities, destroyed more than 2,000 homes and left more than 10,000 people homeless.

03/25/2012 22:37:06 UTC

\section{usp000jgsw}

\section{$35.183^{\circ} \mathrm{S}, 71.792^{\circ} \mathrm{W}$}

\section{7.1 - Maule, Chile}

\section{Depth 40.7 km}

\section{Electronic Poster Available}

The March 25, 2012, M 7.1 Maule, Chile earthquake occurred as the result of shallow thrust faulting on or near the subduction interface between the Nazca and South America plates. At the location of this event, the Nazca plate moves east-northeast relative to South America at a velocity of about $74 \mathrm{~mm} / \mathrm{yr}$. The Nazca plate, oceanic in origin, subducts eastward beneath the 
South America plate at a shallow angle from the Peru-Chile Trench. It is seismically active to depths of approximately $200 \mathrm{~km}$ adjacent to the epicenter of the March 25th earthquake, though farther north seismicity continues to depths exceeding $600 \mathrm{~km}$.

The March $25^{\text {th }}$ earthquake occurred within the aftershock zone of the damaging M 8.8 Maule earthquake of February 27, 2010, and can also be considered an aftershock of that event. The subduction zone between the Nazca and South America plates has a long history of large megathrust earthquakes, including the largest event ever recorded, a M 9.5 earthquake in 1960, which ruptured a fault mostly to the south of the March $25^{\text {th }}$ earthquake.

\section{4/11/2012 08:38:36 UTC usp000jhh2}

\section{$2.311^{\circ} \mathrm{N}, 93.063^{\circ} \mathrm{E}$}

\section{8.6 - Off the west coast of northern Sumatra}

\section{Depth 20.0 km}

\section{Electronic Poster Available}

The April 11, 2012 (08:38:37 UTC), M 8.6 earthquake off the west coast of northern Sumatra, Indonesia, occurred as a result of strike-slip faulting within the oceanic lithosphere of the Indo-Australia plate, the first of two M 8+ earthquakes in this region on the same day. This first event was located $100 \mathrm{~km}$ to the southwest of the major subduction zone that defines the plate boundary between the India:Australia and Sunda plates offshore Sumatra. At this location, the India:Australia plates move northnortheast relative to the Sunda plate at a velocity of about $52 \mathrm{~mm} / \mathrm{yr}$.

Large strike-slip earthquakes are not unprecedented in the diffuse boundary region separating the India and Australia plates, southwest of the Sumatra subduction zone. Since the massive M 9.1 earthquake that ruptured a 1,300-km-long segment of the Sumatran megathrust plate boundary in December 2004, three earlier large strike-slip events had occurred within $50 \mathrm{~km}$ of the first large April 11, 2012, event. These earthquakes occurred on April 19, 2006 (M 6.2), October 4, 2007 (M 6.2), and January 10, 2012 (M 7.2). Focal mechanism solutions of the three earlier earthquakes and the two great earthquakes of April 11, 2012, are consistent in implying that each earthquake could have occurred as the result of left-lateral slip on a north-northeaststriking fault or right-lateral slip on a west-northwest-striking fault. The two different orientations of strike-slip faulting are both possible under the same tectonic stress field; perpendicular strike-slip faults that are both compatible with the same stress field are called "conjugate faults." Studies since these major events have shown that faults of both orientations were involved in their rupture processes, breaking a network of conjugate faults over an area of about 200x200 km in size in the Wharton Basin.

\section{4/11/2012 10:43:10 UTC usp000jhjb \\ $0.773^{\circ} \mathrm{N}, 92.452^{\circ} \mathrm{E}$}

\section{8.2 - Off the west coast of northern Sumatra}

\section{Depth 25.1 km}

\section{Electronic Poster Available}

The April 11, 2012 (10:43:09 UTC), M 8.2 earthquake off the west coast of northern Sumatra, Indonesia, occurred as a result of strike-slip faulting within the oceanic lithosphere of the Indo-Australia plate, the second of two M 8+ earthquakes in this region on the same day. This second event was located $200 \mathrm{~km}$ to the southwest of the major subduction zone that defines the plate boundary between the India:Australia and Sunda plates offshore Sumatra. At this location, the India:Australia plates move north-northeast relative to the Sunda plate at a velocity of about $52 \mathrm{~mm} / \mathrm{yr}$.

Large strike-slip earthquakes are not unprecedented in the diffuse boundary region separating the India and Australia plates, southwest of the Sumatra subduction zone. Since the massive M 9.1 earthquake that ruptured a 1,300-km-long segment of the Sumatran megathrust plate boundary in December 2004, three earlier large strike-slip events had occurred within $50 \mathrm{~km}$ of the first large April 11, 2012, event. These earthquakes occurred on April 19, 2006 (M 6.2), October 4, 2007 (M 6.2), and January 10, 2012 (M 7.2). Focal mechanism solutions of the three earlier earthquakes and the two great earthquakes of April 11, 2012, are consistent in implying that each earthquake could have occurred as the result of left-lateral slip on a north-northeaststriking fault or right-lateral slip on a west-northwest-striking fault. The two different orientations of strike-slip faulting are both possible under the same tectonic stress field; perpendicular strike-slip faults that are both compatible with the same stress field are called "conjugate faults." Studies since these major events have shown that faults of both orientations were involved in their rupture processes, breaking a network of conjugate faults over an area of about 200x200 km in size in the Wharton Basin. 
04/12/2012 07:15:48 UTC

usp000jhr6

$28.696^{\circ} \mathrm{N}, 113.104^{\circ} \mathrm{W}$

M 7.0 - Baja California, Mexico

Depth 13.0 km

The April 12, 2012, M 7.0 earthquake of Baja California, Mexico, occurred as the result of shallow transform faulting along the principal plate boundary between the North America and Pacific plates in the Gulf of California. Focal mechanism solutions indicate that rupture occurred on either a left-lateral northeast-striking fault or a right-lateral northwest-striking transform; the latter is consistent with plate boundary motion. At the location of the earthquake, the Pacific plate moves northwest relative to the North America plate at about $46 \mathrm{~mm} / \mathrm{yr}$. The plate boundary though the Gulf of California consists of a series of northwesttrending strike-slip (transform) faults that are separated by pull-apart basins. Farther north, this plate boundary system becomes the San Andreas Fault. The April $12^{\text {th }}$ mainshock occurred along a strike-slip segment of the plate boundary.

Historically, this is an area with a high level of seismicity, with six earthquakes of M 6.5+ occurring since 2000 . These include the M 6.9 earthquake in Sonora, Mexico, on August 3, 2009, which was $35 \mathrm{~km}$ to the northeast of the April 12, 2012, event. The last M 7+ earthquake in the vicinity of the April 12, 2012, event occurred on April 4, 2010 (M 7.2), approximately $35 \mathrm{~km}$ south of the Mexico-USA border and $440 \mathrm{~km}$ north of the April $12^{\text {th }}$ event. The 2010 earthquake caused at least 2 fatalities and 233 injuries.

08/14/2012 02:59:38 UTC

\section{usp000jq9h}

\section{$49.784^{\circ} \mathrm{N}, 145.126^{\circ} \mathrm{E}$}

M 7.7 - Sea of Okhotsk

Depth 583.2 km

\section{Electronic Poster Available}

The August 14, 2012, M 7.7 earthquake near Poronaysk, Russia, occurred as a result of oblique reverse faulting within the subducting Pacific plate, approximately $580 \mathrm{~km}$ beneath the Sea of Okhotsk offshore of northeast Russia. Focal mechanism solutions indicate that reverse slip occurred on either a steep, southwest-striking fault or on a moderately dipping, northeast-striking fault. At the location of the earthquake, the Pacific plate moves towards the west-northwest relative to the North America plate at a velocity of about $81 \mathrm{~mm} / \mathrm{yr}$. The earthquake ruptured a fault in the interior of the inclined subduction zone that dips to the west-northwest beneath the Kuril Islands and Kamchatka, having begun its descent into the mantle at the Kuril-Kamchatka Trench. The event resulted from stresses generated by the slow distortion of the subducting plate as it descends through the mantle, rather than on the thrust interface that constitutes the boundary between the Pacific and overlying North America plates; the latter is active only near the Earth's surface, while the subducting Pacific plate is active to depths greater than $650 \mathrm{~km}$ in this region. Slip on a fault aligned with either nodal plane of the focal mechanism solution is consistent with this intraplate setting.

Earthquakes that have focal depths greater than $300 \mathrm{~km}$ are commonly termed "deep-focus" earthquakes. Deep-focus earthquakes cause less damage on the ground surface above their foci than similar-magnitude shallow-focus earthquakes, but large deep-focus earthquakes may be felt at great distance from their epicenters. The largest recorded deep-focus earthquake prior to this August 2012 earthquake was a M 8.2 event that occurred at a depth of $630 \mathrm{~km}$ within the subducted Nazca plate beneath South America near the northern Bolivian border in 1994. A larger event has since occurred-namely the M 8.3 earthquake that occurred at a depth of $600 \mathrm{~km}$ within the subducted Pacific plate beneath the Sea of Okhotsk offshore of northeastern Russia in 2013. The M 8.3 Sea of Okhotsk earthquake was felt all over Asia, as far away as Moscow, and across the Pacific Ocean along the western seaboard of the United States (though at distant locations, individuals reporting having felt the event were likely very favorably situated for the perception of small ground motions). The M 8.2 Bolivian deep-focus earthquake in 1994 had similarly been reported by individuals in North America at great distance from the epicenter.

Over the past century, 84 earthquakes with a magnitude of M 7+ have occurred at depths greater than $300 \mathrm{~km}$ globally; 7 of these were located in the same region as the August 14, 2012, event. The largest nearby event at these depths was another M 7.7 earthquake in July 2008, several hundred kilometers to the northeast and $50 \mathrm{~km}$ deeper than the August $14^{\text {th }}$ event, with no recorded damage or casualties. 
08/27/2012 04:37:19 UTC

usp000jqvm

$12.278^{\circ} \mathrm{N}, 8^{8.528^{\circ} \mathrm{W}}$

M 7.3 - Offshore El Salvador

Depth 28.0 km

\section{Electronic Poster Available}

The August 27, 2012, M 7.3 earthquake offshore El Salvador occurred as the result of shallow thrust faulting on or near the boundary between the Cocos and Caribbean plates. At the epicenter of this earthquake, the Cocos plate moves north-northeast relative to the Caribbean plate at a velocity of about $73 \mathrm{~mm} / \mathrm{yr}$ and subducts beneath Central America at the Middle America Trench southwest of the August $27^{\text {th }}$ earthquake.

This plate boundary region has experienced more than 20 earthquakes of M 6+ over the past 40 years; 3 of these had magnitudes greater than 7. The largest of these were a M 7.7 earthquake in September 1992, approximately $140 \mathrm{~km}$ to the southeast of the August $26^{\text {th }}$ earthquake, and another M 7.7 earthquake in January 2001, $85 \mathrm{~km}$ to the north of the August $26^{\text {th }}$ event. The 1992 earthquake spawned a large and damaging tsunami along the coastline of Central America, particularly in Nicaragua and Costa Rica, and resulted in more than 100 fatalities. That earthquake has been labeled a tsunami earthquake, characterized by the unusually large tsunami it caused in relation to the size of the earthquake. The 2001 earthquake offshore of El Salvador resulted in more than 850 fatalities, many of which were caused by large landslides in multiple El Salvador cities.

\section{8/31/2012 12:47:33 UTC usp000jr83}

$10.838^{\circ} \mathrm{N}, 126.704^{\circ} \mathrm{E}$

\section{7.6 - Philippine Island region}

\section{Depth $28.0 \mathrm{~km}$}

\section{Electronic Poster Available}

The August 31, 2012, M 7.6 earthquake off the east coast of the Philippines occurred as a result of shallow reverse faulting within the oceanic lithosphere of the Philippine Sea plate. Focal mechanism solutions indicate that rupture occurred on either a north-northwest- or south-southwest-striking, moderately dipping reverse fault. Of these two possible fault orientations, finitefault modeling of globally recorded seismic data is more consistent with slip on the northwest-striking fault. At the location of the earthquake, the Philippine Sea plate moves west-northwest at a velocity of about $100 \mathrm{~mm} / \mathrm{yr}$ with respect to the Sunda plate. The preliminary location of the earthquake indicates that this is an intraplate event, $50 \mathrm{~km}$ or more to the east of this subduction zone plate boundary between these two plates.

While commonly plotted as points on maps, earthquakes of this size are more appropriately described as slip over a larger fault area. Reverse-faulting events of the size of the August 31, 2012, earthquake are typically about 90x45 km (length $\mathrm{x}$ width); modeling of this earthquake implies dimensions of about $60 \times 60 \mathrm{~km}$, predominantly surrounding the hypocenter.

While this region of the Philippines experiences moderate to large earthquakes fairly frequently - approximately 40 events of M 6+ have occurred over the past 40 years within $250 \mathrm{~km}$ of the August 31, 2012, earthquake - large events outboard of the subduction zone are rare. While several moderate-sized events have occurred in this intraplate region, most have been the result of normal faulting within the shallower $(<15 \mathrm{~km})$ oceanic lithosphere, rather than deeper $(>30 \mathrm{~km})$ reverse faulting similar to the August $31^{\text {st }}$ event. The largest nearby event regardless of mechanism was the October $1975 \mathrm{M} 7.6$ earthquake, approximately $200 \mathrm{~km}$ to the north of the August $31^{\text {st }}$ event, which resulted in at least one fatality.

09/05/2012 14:42:07 UTC

\section{usp000jrsw}

\section{$10.086^{\circ} \mathrm{N}, 85.305^{\circ} \mathrm{W}$}

\section{7.6 - Costa Rica}

\section{Depth $35.0 \mathrm{~km}$}

\section{Electronic Poster Available}

The September 5, 2012, M 7.6 earthquake beneath the Nicoya Peninsula, Costa Rica, occurred as the result of shallow thrust faulting on or near the subduction zone interface between the Cocos and Caribbean plates. At the location of this earthquake, the Cocos plate moves north-northeast with respect to the Caribbean plate at a velocity of about $77 \mathrm{~mm} / \mathrm{yr}$, and subducts beneath Central America at the Middle America Trench west of the September $5^{\text {th }}$ earthquake. 
While commonly plotted as points on maps, earthquakes of this size are more appropriately described as slip over a larger fault area. Thrust-faulting events of the size of the August 31, 2012, earthquake are typically about 90x45 km (length $\mathrm{x}$ width); modeling of this earthquake implies dimensions of about $80 \times 90 \mathrm{~km}$, predominantly surrounding and up-dip of the hypocenter.

Over the past 40 years, the region within $250 \mathrm{~km}$ of the September $5^{\text {th }}$ earthquake has experienced approximately 30 M 6+ earthquakes; two of these were larger than M 7, neither of which caused documented fatalities. The first of these two historic M 7+ events was a M 7.2 earthquake in August 1978, $9 \mathrm{~km}$ to the north-northeast of the September $5^{\text {th }}$ event; the second had a magnitude of 7.3 and struck a region just over $50 \mathrm{~km}$ to the east-southeast in March 1990. The M 7.8 earthquake of October 5, 1950, occurred in the general area of the September $5^{\text {th }}$ earthquake, although the hypocenter of the earlier earthquake is not known to high precision. The 1950 earthquake caused damage in northwestern Costa Rica and in the Valle Central of Costa Rica, but no casualties were reported. The nearest earthquake to cause fatalities in recent history was the M 6.5 April 1973 earthquake, which occurred at shallow depth approximately $80 \mathrm{~km}$ to the northeast; the 1973 event resulted in 26 fatalities and more that 100 injuries.

\section{9/30/2012 16:31:35 UTC usp000jta1 \\ $1.929^{\circ} \mathrm{N}, 76.362^{\circ} \mathrm{W}$}

\section{7.3 - Colombia}

\section{Depth 170.0 km}

\section{Electronic Poster Available}

The September 30, 2012, M 7.3 earthquake west of Isnos, Colombia, occurred as a result of normal faulting at an intermediate depth, approximately $170 \mathrm{~km}$ beneath southwestern Colombia within the subducting Nazca slab. Focal mechanism solutions indicate that rupture occurred on either an east- or southwest-striking normal fault. The earthquake ruptured a fault in the interior of the inclined subduction zone that dips to the east-southeast beneath South America, having begun its descent into the mantle at the Colombian-Ecuador Trench offshore of Colombia and Ecuador. The event resulted from stresses generated by the slow distortion of the subducting plate as it descends through the mantle, rather than on the thrust interface that constitutes the boundary between the Nazca and overlying South America plates; the latter is active only near the Earth's surface, while the subducting Nazca plate generates intraplate earthquakes to depths of $200 \mathrm{~km}$ or more in this region. Slip on a fault aligned with either nodal plane of the focal mechanism solution is consistent with this intraplate setting. At the location of this event, the Nazca plate moves east-northeast with respect to the South America plate at a rate of approximately $60 \mathrm{~mm} / \mathrm{yr}$.

Earthquakes like this event, with focal depths between 70 and $300 \mathrm{~km}$, are commonly termed "intermediate-depth" earthquakes. Intermediate-depth earthquakes represent deformation within subducted slabs rather than at the shallow plate interface between subducting and overriding tectonic plates. They typically cause less damage on the ground surface above their foci than is the case with similar-magnitude shallow-focus earthquakes, but large intermediate-depth earthquakes may be felt at great distance from their epicenters. "Deep-focus" earthquakes, those with focal depths greater than $300 \mathrm{~km}$, also occur in the subducted Nazca plate farther east from the Peru-Chile Trench, beneath central Colombia, western Brazil, and central Argentina. Earthquakes have been reliably located to depths of about $650 \mathrm{~km}$ in this region.

Earthquakes of this depth in this region of the Nazca plate are fairly common; 13 similar events deeper than $100 \mathrm{~km}$ have occurred over the past 40 years, within $500 \mathrm{~km}$ of the September $30^{\text {th }}$ earthquake. The largest was a M 7.1 earthquake at a depth of $206 \mathrm{~km}$ in August 2010, $380 \mathrm{~km}$ to the south of the September $30^{\text {th }}$ event, that caused only slight damage to the surrounding area.

\section{0/28/2012 03:04:08 UTC usp000juhz $52.742^{\circ} \mathrm{N}, 132.131^{\circ} \mathrm{W}$ \\ M 7.8 - Haida Gwaii, Canada \\ Depth 14.0 km}

\section{Electronic Poster Available}

The October 28, 2012 (October 27 at the location of the epicenter), M 7.7 earthquake offshore of the island of Haida Gwaii, Canada, occurred as a result of shallow, oblique-thrust faulting near the plate boundary between the Pacific and North America plates. At the location of this earthquake, the Pacific plate moves approximately north-northwest with respect to the North America plate at a velocity of about $50 \mathrm{~mm} / \mathrm{yr}$. This earthquake is likely associated with relative motion across the Queen Charlotte fault system offshore of British Columbia, Canada. Studies of tectonics in this region suggest plate motions are taken up by strike-slip faulting parallel to the plate boundary, accompanied by lesser amounts of thrust motion to accommodate the oblique nature of the plate motion vector between the two plates relative to the orientation of the main plate boundary fault 
structure. This oblique component of plate motion may involve either underthrusting of the western edge of the Pacific plate beneath North America, or be accommodated by crustal faults within the North America plate. The October $28^{\text {th }}$ earthquake is consistent with either scenario. Its rupture extended approximately $100-150 \mathrm{~km}$ along strike, along the shallow extent of the source fault. Slip amounts reached upwards of $5 \mathrm{~m}$, in a patch predominantly to the south of the epicenter. Aftershocks clearly delineate the rupture.

While commonly plotted as points on maps, earthquakes of this size are more appropriately described as slip over a larger fault area. Reverse-faulting events of the size of the October 28, 2012, earthquake are typically about 130x40 km (length $\mathrm{x}$ width); modeling of this earthquake implies dimensions of about 140x30 km, predominantly up-dip of and bilaterally from the hypocenter.

This region of the Pacific-North America plate boundary has hosted seven earthquakes of M $6+$ over the past 40 years, the largest of which was a M 6.6 earthquake in November 2009, $80 \mathrm{~km}$ to the southeast of the 2012 earthquake that caused no documented damage. In 1949, a M 8.1 earthquake occurred closer to the Pacific-North America plate boundary, likely as a result of strike-slip faulting, approximately $100 \mathrm{~km}$ northwest of the October $28^{\text {th }}$ earthquake, near the northern extent of Haida Gwaii region (formerly Queen Charlotte Islands).

\section{1/07/2012 16:35:46 UTC usp000jv5f}

\section{$14.083^{\circ} \mathrm{N}, 91.916^{\circ} \mathrm{W}$}

\section{7.4 - Offshore Guatemala \\ Depth $24.0 \mathrm{~km}$}

\section{Electronic Poster Available}

The November 7, 2012, M 7.4 earthquake south of Champerico, Guatemala, occurred as a result of shallow thrust faulting on or near the subduction zone interface between the subducting Cocos plate and the overlying Caribbean and North America plates, near their triple junction. At the location of this earthquake, the Cocos plate moves north-northeast relative to the Caribbean and North America plates at a velocity of about $70-80 \mathrm{~mm} / \mathrm{yr}$ and subducts beneath Central America at the Middle America Trench southwest of the November $7^{\text {th }}$ earthquake.

Over the past 40 years, the region within $250 \mathrm{~km}$ of the November $7^{\text {th }}$ earthquake has experienced 50 earthquakes with M 6+; 2 of these were larger than M 7. The first was a M 7.1 in December of 1983, in approximately the same location as the November $7^{\text {th }}$ event, and resulted in no documented fatalities. The second had a magnitude of 7.2, and struck about $100 \mathrm{~km}$ to the northwest offshore Mexico in September 1993. One known fatality was associated with the 1993 event. A M 6.8 earthquake in October 1979, $120 \mathrm{~km}$ to the east-southeast of the November $7^{\text {th }}$ earthquake, resulted in seven fatalities in Guatemala.

\section{2/07/2012 08:18:23 UTC usp000jwjn}

\section{$37.889^{\circ} \mathrm{N}, 144.090^{\circ} \mathrm{E}$}

\section{7.3 - Off the east coast of Honshu, Japan}

\section{Depth 31.0 km}

\section{Electronic Poster Available}

The December 7, 2012, M 7.3 earthquake east of Sendai, Japan, occurred as a result of shallow oblique reverse faulting within the oceanic lithosphere of the Pacific plate, approximately $20 \mathrm{~km}$ east of the plate boundary between the Pacific and North America plates that marks the location where the Pacific plate subducts beneath Japan. Focal mechanism solutions indicate that oblique rupture occurred on either a northeast- or southeast-striking, moderately dipping reverse fault. Slip on a fault aligned with either nodal plane is consistent with this intraplate setting. At the epicenter of this earthquake, the Pacific plate moves west-northwestward relative to the North America plate at a velocity of about $83 \mathrm{~mm} / \mathrm{yr}$. Note that some authors divide this region into several microplates that together define the relative motions between the larger Pacific, North America and Eurasia plates; these include the Okhotsk and Amur microplates that are part of North America and Eurasia, respectively.

The plate boundary region surrounding the December 7, 2012, earthquake hosts moderate to large earthquakes regularly -12 events of M 7 or larger have occurred within $250 \mathrm{~km}$ of this earthquake over the past 40 years. These historic events include the damaging M 9.0 Tohoku earthquake of March 11, 2011, which ruptured a large portion of the subduction zone plate interface to the west of the December $7^{\text {th }}$ event, and which spawned a major tsunami that caused significant devastation along the Honshu Coast. A series of aftershocks of that 2011 megathrust event also occurred to the east of the plate boundary within the Pacific plate, including a M 7.6 normal faulting earthquake $60 \mathrm{~km}$ to the northeast of the December $7^{\text {th }}$ event. 
12/10/2012 16:53:08 UTC

\section{$6.540^{\circ} \mathrm{S}, 129.815^{\circ} \mathrm{E}$}

\section{7.1 - Banda Sea}

\section{Depth 155.0 km}

\section{Electronic Poster Available}

The December 10, 2012, M 7.1 earthquake northwest of Saumlaki, Indonesia, occurred as a result of predominantly strikeslip faulting at intermediate depth, $170 \mathrm{~km}$ beneath the southeastern Banda Sea near the complex plate boundary between the Australia and Sunda plates. Focal mechanism solutions indicate that rupture occurred on either a left-lateral northeast-striking fault or a right-lateral northwest-striking fault. At the location of this earthquake, the Australia plate moves towards the northnortheast with respect to Sunda at a velocity of about $76 \mathrm{~mm} / \mathrm{yr}$. Motion between the two plates is dominantly convergent, and sections of the Australia plate have subducted beneath Sunda; the December $10^{\text {th }}$ earthquake likely represents faulting within the interior of that subducted slab. Slip on a fault aligned with either nodal plane of the focal mechanism solution is consistent with this intraplate setting.

Eastern Indonesia and the islands of the Banda Sea are no strangers to moderate to large earthquakes - the region within $250 \mathrm{~km}$ of the December $10^{\text {th }}$ event has hosted more than 50 earthquakes of M 6+ over the past 40 years. Six of those events have been greater than M 7, including a M 7.0 earthquake in November of 1998, which was $105 \mathrm{~km}$ to the southwest of the December 10, 2012, event, and a M 7.2 earthquake in December 1992, which was $65 \mathrm{~km}$ to the east. None of these M 7+ earthquakes are known to have caused significant damage or fatalities.

Earthquakes like this event, with focal depths between 70 and $300 \mathrm{~km}$, are commonly termed "intermediate-depth" earthquakes. Intermediate-depth earthquakes represent deformation within subducted slabs rather than at the shallow plate interface between subducting and overriding tectonic plates. They typically cause less damage on the ground surface above their foci than is the case with similar-magnitude shallow-focus earthquakes, but large intermediate-depth earthquakes may be felt at great distance from their epicenters. "Deep-focus" earthquakes, those with focal depths greater than $300 \mathrm{~km}$, also occur beneath the Banda Sea to the northwest. Earthquakes have been reliably located to depths of about $500 \mathrm{~km}$ in this region.

\section{3: 19 Events}

\section{1/05/2013 08:58:19 UTC} usp000jxum

\section{$55.394^{\circ} \mathrm{N}, 134.650^{\circ} \mathrm{W}$}

\section{7.5 - Southeastern Alaska}

\section{Depth 10.0 km}

\section{Electronic Poster Available}

The January 5, 2013, M 7.5 earthquake off the west coast of southeastern Alaska occurred as a result of shallow strikeslip faulting on or near the plate boundary between the Pacific and North America plates. At the location of this earthquake, the Pacific plate is moving north-northwestward with respect to the North America plate at a velocity of about $51 \mathrm{~mm} / \mathrm{yr}$. This earthquake is likely associated with right-lateral relative motion across the Queen Charlotte fault system offshore of Alaska and British Columbia, Canada, which forms the major expression of the Pacific-North America plate boundary in this region.

While commonly plotted as points on maps, earthquakes of this size are more appropriately described as slip over a larger fault area. Strike-slip events of the size of the January 5, 2013, earthquake are typically about $120 \times 20 \mathrm{~km}$ (length x width); modeling of this earthquake implies dimensions of about $80 \times 20 \mathrm{~km}$, predominantly north of the hypocenter.

The surrounding area of the plate boundary has hosted eight earthquakes of M 6+ over the past 40 years. In 1949 , a M 8.1 strike-slip earthquake nucleated in the Pacific-North America plate boundary region approximately $200 \mathrm{~km}$ to the southeast of the January $5^{\text {th }}$ event, and the causative fault ruptured close to, or into, the January $5^{\text {th }}$ source region. In October 2012 , the M 7.8 Haida Gwaii earthquake occurred in the plate boundary region approximately $330 \mathrm{~km}$ to the southeast of the January $5^{\text {th }}$ earthquake, and was associated with oblique thrust faulting. The January 5, 2013, earthquake is related to the earthquake three months previously, and is an expression of deformation along the same plate boundary system. The January $5^{\text {th }}$ event ruptured a fault approximately $50 \mathrm{~km}$ in length with $7-8 \mathrm{~m}$ of slip. 
02/06/2013 01:12:25 UTC

usc000f1s0

$10.738^{\circ} \mathrm{S}, 165.138^{\circ} \mathrm{E}$

\section{8.0 - 76 km West of Lata, Solomon Islands}

\section{Depth 24.0 km}

\section{Electronic Poster Available}

The February 6, 2013 (01:12:25 UTC), M 8.0 earthquake in the Santa Cruz Islands occurred as a result of shallow thrust faulting on or near the plate boundary interface between the Australia and Pacific plates. In the region of this earthquake, the Australia plate converges with and subducts beneath the Pacific plate, moving towards the east-northeast at a rate of approximately $94 \mathrm{~mm} / \mathrm{yr}$.

The February $6^{\text {th }}$ earthquake is located approximately $700-750 \mathrm{~km}$ east-southeast of the M 8.1 Solomon Islands earthquake of April 1, 2007, and the M 7.1 Solomon Islands earthquake of January 3, 2010. It is over 900 km to north-northwest of the February 2, 2012, M 7.1 Vanuatu earthquake, and approximately 200-300 km north of a series of earthquakes in October 2009 along the Vanuatu Trench that included two earthquakes larger than M 7 (M 7.8, M 7.4).

While commonly plotted as points on maps, earthquakes of this size are more appropriately described as slip over a larger fault area. Thrust-faulting events of the size of the February 6, 2013, earthquake are typically about $155 \times 65 \mathrm{~km}$ (length x width); modeling of this earthquake implies dimensions of about $120 \times 70 \mathrm{~km}$, predominantly surrounding and up-dip of the hypocenter.

The February 6, 2013, earthquake is located adjacent to a complex section of the Australia-Pacific plate boundary, where the Solomon Trench to the west is linked to the New Hebrides (Vanuatu) Trench to the south by a short segment of dominantly strike-slip plate motion. The February $6^{\text {th }}$ earthquake is located at the northern end of the New Hebrides (Vanuatu) segment. To the north and west of this event, the plate boundary changes in character, is oriented more west-to-east, and connects the segment ruptured by this event with the continuation of the subduction zone along the Solomon Islands.

Over the month leading up to the February $6^{\text {th }}$ earthquake, dozens of earthquakes were recorded in the epicentral region; more than $40 \mathrm{M} \mathrm{4.5+} \mathrm{events} \mathrm{occurred} \mathrm{in} \mathrm{the} \mathrm{preceding} 7$ days alone, 7 of which were larger than M 6. Faulting mechanisms for these earthquakes suggest a mixture of strike-slip, normal, and thrust-faulting events. Within an hour of the February $6^{\text {th }} \mathrm{M} 8.0$ mainshock, there were also two large aftershocks with magnitudes greater than M 7.

\section{2/06/2013 01:23:19 UTC usc000f1se}

\section{$11.254^{\circ} \mathrm{S}, 164.932^{\circ} \mathrm{E}$}

\section{7.1 - 114 km west-southwest of Lata, Solomon Islands}

\section{Depth 10.0 km}

The February 6, 2013 (01:23:19 UTC), M 7.1 earthquake in the Santa Cruz Islands occurred as a result of shallow normal faulting within the oceanic lithosphere of the Australia plate, just west of the New Hebrides Trench where the Australia plate begins its eastward subduction beneath the western edge of the Pacific plate. Focal mechanism solutions indicate that rupture occurred on either a northwest- or south-southeast-striking, moderately dipping normal fault. Slip on a fault aligned with either nodal plane is consistent with this intraplate setting. At the location of this earthquake, the Australia plate moves towards the east-northeast with respect to the Pacific plate at a velocity of approximately $94 \mathrm{~mm} / \mathrm{yr}$. This event can be considered an aftershock of the damaging M 8.0 Santa Cruz Islands earthquake that occurred earlier on the same day, $50 \mathrm{~km}$ to the northeast.

This earthquake is located adjacent to a complex section of the Australia-Pacific plate boundary, where the Solomon Trench to the west is linked to the New Hebrides (Vanuatu) Trench to the south by a short segment of dominantly strike-slip plate motion. The February $6^{\text {th }}$ earthquakes are located at the northern end of the New Hebrides (Vanuatu) segment. To the north and west of this event, the plate boundary changes in character, is oriented more west-to-east, and connects the segment ruptured by this event with the continuation of the subduction zone along the Solomon Islands.

The February $6^{\text {th }}$ M 7.1 earthquake occurred only 20 minutes after and approximately $50 \mathrm{~km}$ southwest of the M 8.0 Santa Cruz Islands earthquake. Over the month leading up to the February $6^{\text {th }}$ events, dozens of earthquakes were recorded in the epicentral region; more than $40 \mathrm{M} 4.5+$ occurred in the preceding 7 days alone, 7 of which were larger than M 6. Faulting mechanisms for these earthquakes suggest a mixture of strike-slip, normal, and thrust-faulting events. Within an hour of the February $6^{\text {th }}$ M 8.0 mainshock, there were two large aftershocks with magnitudes greater than M 7, this M 7.1 being the first of the two. None of these events have been associated with recorded damage or casualties. 
02/06/2013 01:54:14 UTC

usc000f1ts

\section{$10.479^{\circ} \mathrm{S}, 165.772^{\circ} \mathrm{E}$}

\section{7.0 - 27 km north-northwest of Lata, Solomon Islands \\ Depth 8.8 km}

The February 6, 2013 (01:54:15 UTC), M 7.0 earthquake in the Santa Cruz Islands occurred as a result of shallow strikeslip faulting within the oceanic lithosphere of the Pacific plate, above the northern edge of the subduction zone interface between the Australia and Pacific plates. Focal mechanism solutions indicate that rupture occurred on either a right-lateral northeaststriking fault or a left-lateral northwest-striking fault. Slip on a fault aligned with either nodal plane is consistent with this intraplate setting. At the location of this earthquake, the Australia plate moves towards the east-northeast with respect to the Pacific plate at a velocity of about $94 \mathrm{~mm} / \mathrm{yr}$. This event can be considered an aftershock of the damaging M 8.0 Santa Cruz Islands earthquake that occurred earlier on the same day, $75 \mathrm{~km}$ to the southwest.

This earthquake is located adjacent to a complex section of the Australia-Pacific plate boundary, where the Solomon Trench to the west is linked to the New Hebrides (Vanuatu) Trench to the south by a short segment of dominantly strike-slip plate motion. The February $6^{\text {th }}$ earthquake is located at the northern end of the New Hebrides (Vanuatu) segment. To the north and west of this event, the plate boundary changes in character, is oriented more west-to-east, and connects the segment ruptured by this event with the continuation of the subduction zone along the Solomon Islands.

Though close to the subduction zone plate boundary in the region, the depth and focal mechanism solutions of this M 7.0 earthquake indicate intraplate faulting within the overlying Pacific plate, rather than deeper thrust faulting directly related to the subduction process. The event was likely driven by the stresses generated by the earlier M 8.0 mainshock. Over the month leading up to the February $6^{\text {th }}$ earthquakes, dozens of earthquakes were recorded in the epicentral region; over $40 \mathrm{M} 4.5+$ events occurred in the preceding 7 days alone, 7 of which were larger than M 6. Faulting mechanisms for these earthquakes suggest a mixture of strike-slip, normal, and thrust-faulting events. Within an hour of the February $6^{\text {th }} \mathrm{M} 8.0$ mainshock, there were two large aftershocks with magnitudes greater than M 7, this M 7.0 being the second of the two. None of these events have been associated with recorded damage or casualties.

02/08/2013 15:26:38 UTC usc000f40j

\section{$10.932^{\circ} \mathrm{S}, 166.021^{\circ} \mathrm{E}$}

\section{7.1 - $31 \mathrm{~km}$ southeast of Lata, Solomon Islands}

\section{Depth 21.0 km}

The February 8, 2013, M 7.1 earthquake in the Santa Cruz Islands occurred as a result of shallow strike-slip faulting within the oceanic lithosphere of the Pacific plate, above the subduction zone interface between the Australia and Pacific plates. Focal mechanism solutions indicate that rupture occurred on either a right-lateral west-striking fault or a left-lateral north-striking fault. Finite-fault modeling of globally recorded seismic data for this earthquake is not able to distinguish between these two possibilities. At the location of this earthquake, the Australia plate moves towards the east-northeast with respect to the Pacific plate at a velocity of about $94 \mathrm{~mm} / \mathrm{yr}$. This event can be considered an aftershock of the damaging M 8.0 Santa Cruz Islands earthquake that occurred 2 days previously, $50 \mathrm{~km}$ to the northeast.

The February 8th earthquake is located adjacent to a complex section of the Australia-Pacific plate boundary, where the Solomon Trench to the west is linked to the New Hebrides (Vanuatu) Trench to the south by a short segment of dominantly strike-slip plate motion. The February $8^{\text {th }}$ earthquake is located at the northern end of the New Hebrides (Vanuatu) segment. To the north and west of this event, the plate boundary changes in character, is oriented more west-to-east, and connects the segment ruptured by this event with the continuation of the subduction zone along the Solomon Islands.

Though close to the subduction zone plate boundary in the region, the depth and focal mechanism solutions of this $\mathrm{M} 7.1$ earthquake indicate intraplate faulting within the overlying Pacific plate, rather than deeper thrust faulting directly related to the subduction process. The event was likely driven by the stresses generated by the earlier M 8.0 mainshock, similar to the M 7.0 February $6^{\text {th }}, 01: 54$ UTC aftershock, $60 \mathrm{~km}$ to the northwest. 
04/06/2013 04:42:35 UTC usb000g13s

$3.513^{\circ} \mathrm{S}, 138.477^{\circ} \mathrm{E}$

\section{7.0 - 240 km east of Enarotali, Indonesia}

\section{Depth $66.0 \mathrm{~km}$}

\section{Electronic Poster Available}

The April 6, 2013, M 7.0 earthquake beneath Irian Jaya, Indonesia, occurred as a result of oblique normal faulting at an intermediate depth, approximately $70 \mathrm{~km}$ beneath New Guinea. Focal mechanism solutions indicate that rupture occurred on either a north-northwest- or southwest-striking, moderately dipping normal fault. Of these two possible fault orientations, finitefault modeling of globally recorded seismic data is more consistent with slip on the southwest-striking fault. At the location of this earthquake, the Pacific and Australia plates are converging at a rate of approximately $110 \mathrm{~mm} / \mathrm{yr}$ in an east-northeast-westsouthwest direction, resulting in the southward subduction of the Pacific plate beneath New Guinea at the New Guinea Trench, north of the island. The depth and faulting mechanism of the April $6^{\text {th }}$ earthquake indicate that it likely ruptured a fault within the subducting Pacific lithosphere rather than on the shallower thrust interface between the two plates.

This region of New Guinea frequently experiences moderate to large earthquakes; several dozen events with magnitudes greater than 6 have occurred within $250 \mathrm{~km}$ of the April $6^{\text {th }}$ earthquake over the past 40 years. Many of those events were shallow expressions of microplate interactions at the complicated boundary between the Pacific and Australia plates in this region. The January 19, 1981, M 6.7 earthquake, $140 \mathrm{~km}$ to the southeast, struck at a depth of $20 \mathrm{~km}$ and caused approximately 1,300 fatalities. In July of 1976, a M 7.1 earthquake $210 \mathrm{~km}$ to the east-southeast struck just a few kilometers beneath the surface and resulted in around 6,000 fatalities. In contrast, intermediate-depth earthquakes like the April $6^{\text {th }}$ event are much less hazardous and do not generally cause significant damage or fatalities, though large intermediate-depth (70-300 km) and deep-focus (depth $>300 \mathrm{~km}$ ) earthquakes may be felt at great distances from their epicenters.

\section{4/16/2013 10:44:20 UTC usb000g7x7}

\section{$28.107^{\circ} \mathrm{N}, 62.053^{\circ} \mathrm{E}$}

\section{7.7 - $83 \mathrm{~km}$ east of Khash, Iran Depth 80.0 km}

\section{Electronic Poster Available}

The April 16, 2013, M 7.7 earthquake east of Khash, Iran, occurred as a result of normal faulting at an intermediate depth in the Arabia plate lithosphere, approximately $80 \mathrm{~km}$ beneath the surface in southeastern Iran. Focal mechanism solutions indicate that rupture occurred on either a southwest or east-striking, moderately dipping normal fault. Slip on a fault of either orientation would accommodate the down-dip extension of the Arabia slab that is implied by the normal-component of the faulting solution. Regional tectonics are dominated by the collisions of the Arabia and India plates with Eurasia; at the longitude of this event, the Arabia plate is converging towards the north-northeast at a rate of approximately $37 \mathrm{~mm} / \mathrm{yr}$ with respect to the Eurasia plate. Arabia plate lithosphere is subducted beneath the Eurasia plate at the Makran Coast of Pakistan and Iran, and becomes progressively deeper to the north. The subducted Arabia plate is seismically active to depths of about $160 \mathrm{~km}$.

The frequency of moderate and large earthquakes within the subducted Arabia plate is not high compared with similar events in some other subducted plates worldwide, but several earthquakes have occurred within this slab in the region of the April $16^{\text {th }}$ event over the past 40 years, including a M 6.7 event $50 \mathrm{~km}$ to the south in 1983. In January 2011, a M 7.2 earthquake occurred approximately $200 \mathrm{~km}$ to the east, in a similar tectonic environment to that of the April $16^{\text {th }}$ earthquake.

Earthquakes like this event, with focal depths between 70 and $300 \mathrm{~km}$, are commonly termed "intermediate-depth" earthquakes. Intermediate-depth earthquakes represent deformation within subducted slabs rather than at the shallow plate interface between subducting and overriding tectonic plates. They typically cause less damage on the ground surface above their foci than is the case with similar-magnitude shallow-focus earthquakes, but large intermediate-depth earthquakes may be felt at great distance from their epicenters. 


\section{4/19/2013 03:05:52 UTC usb000gbf8 $46.224^{\circ} \mathrm{N}, 150.783^{\circ} \mathrm{E}$ \\ M 7.2 - 251 km east-northeast of Kuril'sk, Russia Depth 110.0 km}

\section{Electronic Poster Available}

The April 19, 2013, M 7.2 earthquake east-northeast of Kuril'sk, Russia, occurred as a result of oblique normal faulting at an intermediate depth, approximately $110 \mathrm{~km}$ beneath the Kuril Islands within the subducting lithosphere of the Pacific plate. Focal mechanism solutions indicate that rupture occurred on either a near-vertical, southwest-striking normal fault, or on a shallow, southeast-striking normal fault. At the location of this earthquake, the Pacific plate converges with the North America plate (and the smaller Okhotsk microplate) towards the west-northwest at a velocity of about $82 \mathrm{~mm} / \mathrm{yr}$, and subducts beneath the Kuril Islands at the Kuril-Kamchatka Trench about $160 \mathrm{~km}$ to the southeast of the April $19^{\text {th }}$ event. The depth of this earthquake, and its oblique-faulting mechanism, indicate that it involved intraplate faulting within the subducting slab, rather than being an interplate thrust event on the shallower seismogenic zone between the two tectonic plates. Slip on a fault aligned with either nodal plane of the focal mechanism solution is consistent with this intraplate setting.

The Kuril-Kamchatka Arc has frequent moderate to large earthquakes and has hosted more than three-dozen M 6.5+ events within $250 \mathrm{~km}$ of the April $19^{\text {th }}$ earthquake over the past 40 years. None are known to have caused shaking-related fatalities. The largest of these was the November 2006 M 8.3 interplate thrust event, approximately $200 \mathrm{~km}$ to the east of the April $19^{\text {th }}$ earthquake. However, while the Pacific slab is seismically active in this region to depths of almost $700 \mathrm{~km}$, just one of these nearby M 6.5+ events has occurred at depths greater than $70 \mathrm{~km}$ - a M 6.7 event in October 1994, $130 \mathrm{~km}$ to the southwest.

Earthquakes like this event, with focal depths between 70 and $300 \mathrm{~km}$, are commonly termed "intermediate-depth" earthquakes. Intermediate-depth earthquakes represent deformation within subducted slabs rather than at the shallow plate interface between subducting and overriding tectonic plates. They typically cause less damage on the ground surface above their foci than is the case with similar-magnitude shallow-focus earthquakes, but large intermediate-depth earthquakes may be felt at great distance from their epicenters. "Deep-focus" earthquakes, those with focal depths greater than $300 \mathrm{~km}$, also occur in the subducted Pacific plate beneath the Sea of Okhotsk to the northwest. Earthquakes have been reliably located to depths of about $600 \mathrm{~km}$ in this region.

\section{5/23/2013 17:19:04 UTC usb000h3k3}

\subsection{5 $\mathrm{S}, 177.109^{\circ} \mathrm{W}$}

\section{7.4 - $282 \mathrm{~km}$ southwest of Vaini, Tonga Depth 173.7 km \\ Electronic Poster Available}

The May 23, 2013, M 7.4 earthquake southwest of Vaini, Tonga, occurred as a result of normal faulting at an intermediate depth within subducted Pacific lithosphere, approximately $170 \mathrm{~km}$ beneath the Pacific Ocean. Focal mechanism solutions indicate that rupture occurred on either a near-vertical, north-striking normal fault, or on a shallow, south-striking normal fault. At the location of this earthquake, the Pacific and Australia plates are converging at a velocity of about $73 \mathrm{~mm} / \mathrm{yr}$ in an eastwest direction, resulting in the westward subduction of the Pacific plate beneath Tonga at the Tonga-Kermadec Trench, $200 \mathrm{~km}$ west of the earthquake. The depth and faulting mechanism of the May $23^{\text {rd }}$ earthquake indicate that it ruptured a fault within the subducting Pacific lithosphere rather than on the shallower thrust interface between the two plates. Slip on a fault aligned with either nodal plane of the focal mechanism solution is consistent with this intraplate setting.

The Tonga-Kermadec Arc has frequent moderate to large earthquakes and has hosted more than a dozen M 6.5+ earthquakes within $500 \mathrm{~km}$ of the May $23^{\text {rd }}$ earthquake over the past 40 years. Most of these also occurred at intermediate depths; the largest was a M 7.7 earthquake in October 1997, approximately $110 \mathrm{~km}$ to the north-northeast of the May 23, 2013, event. None are known to have caused significant damage.

Earthquakes like this event, with focal depths between 70 and $300 \mathrm{~km}$, are commonly termed "intermediate-depth" earthquakes. Intermediate-depth earthquakes represent deformation within subducted slabs rather than at the shallow plate interface between subducting and overriding tectonic plates. They typically cause less damage on the ground surface above their foci than is the case with similar-magnitude shallow-focus earthquakes, but large intermediate-depth earthquakes may be felt at great distance from their epicenters. "Deep-focus" earthquakes, those with focal depths greater than $300 \mathrm{~km}$, also occur in the subducted Pacific plate beneath the Lau Ridge and South Fiji Basin to the west. Earthquakes have been reliably located to depths of about $650 \mathrm{~km}$ in this region. 
05/24/2013 05:44:48 UTC

\section{$54.874^{\circ} \mathrm{N}, 153.281^{\circ} \mathrm{E}$}

\section{8.3 - Sea of Okhotsk}

\section{Depth 598.1 km}

\section{Electronic Poster Available}

The May 24, 2013, M 8.3 earthquake beneath the Sea of Okhotsk, Russia, occurred as a result of deep normal faulting at a depth of approximately $600 \mathrm{~km}$. Focal mechanism solutions indicate that rupture occurred on either a near-vertical, northstriking normal fault, or on a shallow, south-striking normal fault. At the location of this earthquake, the Pacific and North America plates are converging at a velocity of about $78 \mathrm{~mm} / \mathrm{yr}$ in a west-northwest-east-southeast direction, resulting in the subduction of the Pacific plate beneath Eurasia at the Kuril-Kamchatka Trench. Note that some authors divide this region into several microplates that together define the relative motions among the larger Pacific, North America and Eurasia plates; these include the Okhotsk and Amur microplates that are part of North America and Eurasia, respectively. The depth and faulting mechanism of the May $24^{\text {th }}$ earthquake indicate that it ruptured a fault deep within the subducting Pacific lithosphere rather than on the shallow thrust interface between the two plates. Slip on a fault aligned with either nodal plane of the focal mechanism solution is consistent with this intraplate setting.

This deep section of the Pacific slab beneath the Sea of Okhotsk has hosted several large earthquakes in the past-four M 6+ events within $200 \mathrm{~km}$ of the May $24^{\text {th }}$ event since 1988 . These included a M 7.7 earthquake in July $2008,115 \mathrm{~km}$ to the southwest at a depth of $630 \mathrm{~km}$, and a M 7.3 event in November 2008, $95 \mathrm{~km}$ to the southeast at a depth of $490 \mathrm{~km}$. Neither of these events resulted in documented casualties or damage. The Pacific slab in the region of the May $24^{\text {th }}$ earthquake is seismically active to depths of greater than $650 \mathrm{~km}$.

Earthquakes that have focal depths greater than $300 \mathrm{~km}$ are commonly termed "deep-focus" earthquakes. Deep-focus earthquakes cause less damage on the ground surface above their foci than similar-magnitude shallow-focus earthquakes, but large deep-focus earthquakes may be felt at great distance from their epicenters. Prior to this event, the largest recorded deep-focus earthquake was a M 8.2 event that occurred at a depth of $630 \mathrm{~km}$ within the subducted Nazca plate beneath South America near the northern Bolivian border in 1994. The May 2013 Okhotsk earthquake is approximately 1.5 times larger than the Bolivian event. The Okhotsk earthquake was felt all over Asia, as far away as Moscow, and across the Pacific Ocean along the western seaboard of the United States (though at distant locations, individuals reporting having felt the event were likely very favorably situated for the perception of small ground motions). The M 8.2 Bolivian deep-focus earthquake in 1994 had similarly been reported by individuals in North America at great distance from the epicenter.

Over the past century, 85 earthquakes with a magnitude of M 7+ have occurred at depths greater than $300 \mathrm{~km}$ globally; 8 of these were located in the same region as the May 24, 2013, event. The largest nearby event at these depths was a M 7.7 earthquake in July 2008, just $100 \mathrm{~km}$ to the south and $40 \mathrm{~km}$ deeper than the May 24, 2013, event.

\section{7/07/2013 18:35:30 UTC usb000i89z}

\section{$3.923^{\circ} \mathrm{S}, 153.920^{\circ} \mathrm{E}$}

\section{7.3 - 115 km east-northeast of Taron, Papua New Guinea Depth 385.5 km}

\section{Electronic Poster Available}

The M 7.3 July 7, 2013, earthquake northeast of Papua New Guinea occurred as a result of normal faulting approximately $380 \mathrm{~km}$ deep beneath the Pacific Ocean within the subducted Australia plate. Focal mechanism solutions indicate that rupture occurred on either a northwest or south-striking, moderately dipping normal fault. The Australia plate subducts beneath the Pacific plate at the New Britain Trench, $200 \mathrm{~km}$ to the south of this event, and moves towards the north-northeast at a rate of $103 \mathrm{~mm} / \mathrm{yr}$. The depth and faulting mechanism of the July $7^{\text {th }}$ earthquake are consistent with the event resulting from internal (intraplate) deformation of the subducted slab, rather than as an interplate event on the shallow plate boundary interface. Slip on a fault aligned with either nodal plane of the focal mechanism solution is consistent with this intraplate setting. Crustal tectonics of the New Britain region are commonly described in terms of relative motions of microplates that are situated at the boundary of the Australia and Pacific plates.

The New Britain Trench region frequently experiences large earthquakes; this subduction zone is one of the most seismically active regions of the world. Deep earthquakes $(>300 \mathrm{~km})$ are reasonably common as well; several M 6.5+ earthquakes have occurred within $250 \mathrm{~km}$ of the July $7^{\text {th }}$ event over the past 40 years, including a M 6.8 event in an almost identical location in June 1995. Because of their great depths, none are known to have caused damage. The Australia slab in the region of the July 7, 2013, earthquake is seismically active to depths of greater than $400 \mathrm{~km}$. 
Earthquakes that have focal depths greater than $300 \mathrm{~km}$ are commonly termed "deep-focus" earthquakes. Deep-focus earthquakes cause less damage on the ground surface above their foci than similar-magnitude shallow-focus earthquakes, but large deep-focus earthquakes may be felt at great distance from their epicenters. The largest recorded deep-focus earthquake recorded to date is a M 8.3 event that occurred at a depth of $600 \mathrm{~km}$ within the subducted Pacific plate beneath the Sea of Okhotsk offshore of northeastern Russia in May 2013. The M 8.3 Okhotsk earthquake was felt all over Asia, as far away as Moscow, and across the Pacific Ocean along the western seaboard of the United States (though at distant locations, individuals reporting having felt the event were likely very favorably situated for the perception of small ground motions). The M 8.2 Bolivian deepfocus earthquake in 1994 had similarly been reported by individuals in North America at great distance from the epicenter.

Over the past century, 86 earthquakes with a magnitude of M 7+ have occurred at depths greater than $300 \mathrm{~km}$ globally; two of these were located in the same region as the July 7, 2013, event. The largest was a M 7.2 earthquake in April 1972, about $100 \mathrm{~km}$ to the southeast and $40 \mathrm{~km}$ deeper than the July 2013 event.

07/15/2013 14:03:39 UTC usb000ief9

$60.868^{\circ} \mathrm{S}, 25.144^{\circ} \mathrm{W}$

M 7.3 - 218 km south-southeast of Bristol Island, South Sandwich Islands

Depth $11.0 \mathrm{~km}$

\section{Electronic Poster Available}

The July 15, 2013, M 7.3 South Sandwich Islands earthquake occurred as a result of either east-west left-lateral or northsouth right-lateral strike-slip motion at shallow oceanic crustal depths. Of these two possible fault orientations, finite-fault modeling of globally recorded seismic data is more consistent with slip on the east-striking (left-lateral) fault. The earthquake occurred about $100 \mathrm{~km}$ east of a complex plate triple junction between the South America, Antarctica, and Sandwich plates. The South America plate currently subducts beneath the Sandwich plate at a rate of about $13 \mathrm{~mm} / \mathrm{yr}$ while sliding past the Antarctica plate with left-lateral motion along the South Sandwich fracture zone at a rate of about $14 \mathrm{~mm} / \mathrm{yr}$. Given the strike-slip nature and location of the event, the earthquake likely resulted from relative motion between the South America and Antarctica plates. Several large earthquakes have occurred along this portion of the plate boundary, including events of M 7.4 in January 2006 and M 7.5 in October 1973.

\section{8/30/2013 16:25:02 UTC usb000jdt7}

\section{$51.537^{\circ} \mathrm{N}, 175.230^{\circ} \mathrm{W}$}

\section{7.0 - 101 km southwest of Atka, Alaska Depth 29.0 km}

\section{Electronic Poster Available}

The August 30, 2013, M 7.0 earthquake southeast of Adak, Alaska, occurred as the result of shallow thrust faulting on or near the subduction zone interface between the Pacific and North America plates. At the location of this event, the Pacific plate moves towards the northwest relative to the North America plate at a velocity of about $73 \mathrm{~mm} / \mathrm{yr}$, beginning its descent into the mantle at the Aleutian Trench approximately $130 \mathrm{~km}$ south of the August $30^{\text {th }}$ earthquake. The depth and mechanism of this earthquake are consistent with it occurring along the megathrust interface between these two plates.

The Aleutians Arc has frequent large earthquakes; two dozen events of M 6.5+ have occurred over the last century within $250 \mathrm{~km}$ of the August $30^{\text {th }}$ earthquake. The largest of these was a M 8.6 earthquake in March 1957, whose hypocenter was located just $15 \mathrm{~km}$ south of the August $30^{\text {th }}$ earthquake. Aftershocks associated with the 1957 event extended for more than 1,000 km along the arc, roughly from the International Date Line in the west to Unimak Island in the east. The 1957 earthquake also resulted in a large tsunami that was observed throughout the Pacific Basin, and caused damage locally along the Aleutian Arc and in Hawaii. Other large nearby events include the May 1986 M 8.0 earthquake $40 \mathrm{~km}$ to the southeast, and the June 1996 M 7.9 earthquake $150 \mathrm{~km}$ to the west. Neither of these more recent events is known to have caused fatalities or significant damage. 


\section{9/24/2013 11:29:47 UTC usb000jyiv}

\section{$26.951^{\circ} \mathrm{N}, 65.501^{\circ} \mathrm{E}$}

\section{7.7 - 61 km north-northeast of Awaran, Pakistan Depth 15.0 km}

\section{Electronic Poster Available}

The September 24, 2013, M 7.7 earthquake in south-central Pakistan occurred as the result of oblique strike-slip type motion at shallow crustal depths. The location, focal mechanism solutions, and finite-fault modeling of the earthquake are consistent with left-lateral (southwest-striking) rupture within the Eurasia plate above the Makran subduction zone. The event occurred within the transition zone between northward subduction of the Arabia plate beneath the Eurasia plate and northward collision of the India plate with the Eurasia plate. The epicenter of the event is $69 \mathrm{~km}$ north of Awaran, Pakistan, and $270 \mathrm{~km}$ north of Karachi, Pakistan (population 11.6 million).

On a broad scale, the tectonics of southern and central Pakistan reflect a complex plate boundary where the India plate slides northward relative to the Eurasia plate in the east, and the Arabia plate subducts northward beneath the Eurasia plate in the Makran (western Pakistan). These motions typically result in north-south to northeast-southwest strike-slip motion at the location of the September $24^{\text {th }}$ earthquake that is primarily accommodated on the Chaman fault, with the earthquake potentially occurring on one of the southernmost strands of this fault system. Further, more in-depth studies will be required to identify the precise fault associated with this event.

While commonly plotted as points on maps, earthquakes of this size are more appropriately described as slip over a larger fault area. Strike-slip events of the size of the September 24, 2013, earthquake are typically about 160x20 km (length x width); modeling of this earthquake implies dimensions of about 200x20 km, predominantly up-dip and southwest of the hypocenter.

Although seismically active, this portion of the Eurasia plate boundary region has not experienced large damaging earthquakes in the recent history. Over the past 40 years, only one significant event (M 6.1), which killed six, has occurred within $200 \mathrm{~km}$ of the September 2013 event, in July 1990.

\section{9/25/2013 16:42:43 UTC usb000jzma \\ $15.838^{\circ} \mathrm{S}, 74.511^{\circ} \mathrm{W}$}

\section{7.1 - 46 km south-southeast of Acari, Peru \\ Depth 40.0 km}

\section{Electronic Poster Available}

The Peru earthquake of September 25, 2013, occurred as the result of shallow thrust faulting on or near the boundary between the South America plate and the subducting Nazca plate. The Nazca plate subducts beneath the South America plate at the Peru-Chile Trench offshore of western South America, and the thrust interface between the two plates dips east-northeast beneath the South American continent. At the location of the earthquake, the Nazca plate moves to the east-northeast with respect to the South America plate at a velocity of about $70 \mathrm{~mm} / \mathrm{yr}$.

The boundary region between the Nazca and South America plates experiences a large number of earthquakes. The region within $250 \mathrm{~km}$ of the epicenter of the earthquake of September 25 has experienced 17 previous earthquakes of M 6+ since 1973. The largest of these, the M 8.4 earthquake of June 23, 2001, occurred along the plate boundary to the south. It resulted in at least 74 fatalities and destroyed more than 17,000 homes. The M 7.7 earthquake of November 12, 1996, resulted in at least 14 fatalities and left 12,000 people homeless. It occurred along the plate boundary to the north of the September $25^{\text {th }}$ epicenter.

\section{0/15/2013 00:12:32 UTC usb000kdb4}

\section{$9.880^{\circ} \mathrm{N}, 124.117^{\circ} \mathrm{E}$}

\section{7.1 - 4 km southeast of Sagbayan, Philippines Depth $19.0 \mathrm{~km}$}

\section{Electronic Poster Available}

The October 15, 2013, M 7.1 earthquake near the city of Catigbian on Bohol Island, Philippines, occurred as the result of shallow reverse faulting on a moderately inclined fault dipping either to the northwest or to the southeast. Finite-fault modeling of globally recorded seismic data for this earthquake is not able to distinguish between these two possibilities. The depth of the event indicates that it ruptured a fault within the crust of the Sunda plate, rather than on the deeper subduction zone plate boundary interface. At the location of this earthquake, the Philippine Sea plate moves towards the west-northwest with respect to the 
Sunda plate at a rate of approximately $100 \mathrm{~mm} / \mathrm{yr}$, subducting beneath the Philippines several hundred kilometers to the east of the October $15^{\text {th }}$ earthquake at the Philippine Trench.

The Philippines straddle a region of complex tectonics at the intersection of three major tectonic plates (the Philippine Sea, Sunda, and Eurasia plates). As such, the islands frequently experience large and damaging earthquakes, and the region within $500 \mathrm{~km}$ of the October $15^{\text {th }}$ earthquake has hosted 19 events of M 6+, a dozen of which have been shallow (0-70 km). One of these, a M 6.8 earthquake $70 \mathrm{~km}$ to the east of the October 15, 2013, event in 1990, caused several casualties.

10/25/2013 17:10:19 UTC

usc000kn4n

\section{$37.156^{\circ} \mathrm{N}, 144.661^{\circ} \mathrm{E}$}

\section{7.1 - Off the east coast of Honshu, Japan \\ Depth 35.0 km \\ Electronic Poster Available}

The October 25, 2013, M 7.1 earthquake offshore of Honshu, Japan, occurred as the result of normal faulting in the shallow oceanic crust of the Pacific plate. The earthquake occurred outboard (east) of the Japan Trench, which marks the sea-floor expression of the subduction zone plate boundary between the Pacific and North America plates, and is immediately up-dip of the source region of the March 2011 M 9.0 Tohoku earthquake. At the location of this earthquake, the Pacific plate moves westward with respect to the North America plate at a rate of $83 \mathrm{~mm} / \mathrm{yr}$ before subducting beneath the island of Honshu. Note that some authors divide this region into several microplates that together define the relative motions between the larger Pacific, North America and Eurasia plates; these include the Okhotsk and Amur microplates that are part of North America and Eurasia, respectively.

The location, depth, and focal mechanism solutions of the October 25, 2013, event are consistent with normal faulting rupture near the outer-arc high of the Japan Trench. Of the two possible fault orientations of the focal mechanism solution, finitefault modeling of globally recorded seismic data is more consistent with slip on the north-northeast-striking fault. In this region, normal faulting is encouraged by the bending of the Pacific plate as it enters the subduction zone and by stresses transferred from the locked subduction thrust interface to the west. Since the March 2011 Tohoku earthquake, two large events of M 7.7 and M 7.3 have occurred in the vicinity of the October 25, 2013, earthquake. The M 7.7 event, on March 11, 2011, was also a normal faulting event near the outer-arc high and occurred $95 \mathrm{~km}$ north of the October $25^{\text {th }}$ event. The M 7.3 event, on December 7 , 2012, was a more complex earthquake resulting from thrust motion near the trench $100 \mathrm{~km}$ to the northwest of the October $25^{\text {th }}$ earthquake. Ten additional events, ranging in magnitude from M 6.1 to 6.4, have occurred over the same time period in this region east of the Japan Trench.

\section{1/17/2013 09:04:55 UTC usb00010gq $60.274^{\circ} \mathrm{S}, 46.401^{\circ} \mathrm{W}$}

\section{7.7 - Scotia Sea}

\section{Depth 10.0 km}

\section{Electronic Poster Available}

The November 17, 2013, M 7.7 earthquake in the Scotia Sea, to the northwest of the South Orkney Islands, occurred as the result of either left-lateral strike-slip faulting on an east-west oriented plane, or right-lateral faulting on a north-south-oriented plane. The location of the event adjacent to the east-west-oriented plate boundary between the Antarctica and Scotia plates implies that the left-lateral faulting scenario is most likely. Finite-fault modeling of globally recorded seismic data is also more consistent with slip on the east-striking (left-lateral) fault. At the location of this earthquake, the Antarctica plate moves eastward with respect to to the Scotia plate at a velocity of about $6 \mathrm{~mm} / \mathrm{yr}$.

The November $17^{\text {th }}$ earthquake is the latest in a series of moderate to large earthquakes to strike the same region over the previous several days. The sequence began with a M 6.1 event on November 13 approximately $50 \mathrm{~km}$ to the west of the November $17^{\text {th }}$ quake. On November 15, a M 6.8 earthquake struck very close to the preceding M 6.1 event. Since then, nine aftershocks were recorded in the area, ranging from M 4.7 to M 5.4, near the previous earthquakes and in the same approximate location as the November $17^{\text {th }}$ event.

While commonly plotted as points on maps, earthquakes of this size are more appropriately described as slip over a larger fault area. Strike-slip events of the size of the November 17, 2013, earthquake are typically about 160x20 km (length x width); modeling of this earthquake implies dimensions of about $280 \times 40 \mathrm{~km}$, predominantly surrounding and southeast of the hypocenter. 
Though the region surrounding the Scotia Sea frequently experiences earthquakes, the majority occur around the subduction zone adjacent to the South Sandwich Islands, to the east of the November $17^{\text {th }}$ earthquake. Only two events of M 6+ have occurred within $250 \mathrm{~km}$ of this earthquake over the past 40 years - a M 6.0 earthquake $230 \mathrm{~km}$ to the west in September 1979 and a M 7.6 earthquake $160 \mathrm{~km}$ to the east in August 2003. These two events involved normal and oblique normal faulting, respectively, associated with the same plate boundary. Neither is known to have caused damage or fatalities.

\section{1/25/2013 06:27:33 UTC usb00015zn $53.945^{\circ} \mathrm{S}, 55.003^{\circ} \mathrm{W}$}

\section{7.0 - Falkland Islands region \\ Depth 11.8 km \\ Electronic Poster Available}

The November 25, 2013, M 7.0 earthquake southwest of the Falkland Islands in the South Atlantic Ocean occurred as the result of strike-slip faulting, on either a left-lateral fault striking east-northeast-west-southwest, or a right-lateral fault striking north-northwest-south-southeast. The location of the earthquake, near the east-northeast-west-southwest-trending plate boundary between the South America and Scotia tectonic plates, suggests it is likely associated with left-lateral faulting along this margin. At the location of this earthquake, the Scotia plate moves east-northeast with respect to South America at a velocity of about $9.5 \mathrm{~mm} / \mathrm{yr}$.

The November 25, 2013, 06:27:33 earthquake was the largest of five M 5+ events that occurred in a similar area over an approximate 2-hour period, including a M 5.6 earthquake 24 seconds prior to the M 7.0 mainshock. Though this region experiences moderately sized earthquakes relatively frequently-15 M 5+ events have occurred within $250 \mathrm{~km}$ of the November $25^{\text {th }}$ earthquake over the past 40 years - large events have been fairly uncommon over the same time period. The largest nearby earthquake over the same time period was a M 6.6 event in September 1993, $210 \mathrm{~km}$ to the east of the November $25^{\text {th }}$ earthquake.

\section{4: 12 Events}

\section{4/01/2014 23:46:47 UTC usc000nzvd $19.610^{\circ} \mathrm{S}, 70.769^{\circ} \mathrm{W}$ \\ M 8.2 - 94 km northwest of Iquique, Chile \\ Depth 25.0 km \\ Electronic Poster Available}

The April 1, 2014, M 8.2 earthquake off the west coast of northern Chile occurred as the result of thrust faulting at shallow depths near the Chilean coast. At the location of the earthquake, the Nazca plate subducts eastward beneath the South America plate at a velocity of $72 \mathrm{~mm} / \mathrm{yr}$. The location and mechanism of the earthquake are consistent with slip on the primary plate boundary interface, or megathrust, between these two major plates. Subduction along the Peru-Chile Trench to the west of Chile has led to uplift of the Andes Mountain Range and has produced some of the largest earthquakes in the world, including the damaging 2010 M 8.8 Maule earthquake in central Chile, and the largest earthquake on record, the 1960 M 9.5 earthquake in southern Chile.

The April $1^{\text {st }}$ earthquake occurred in a region of historic seismic quiescence, which is termed the northern Chile or Iquique seismic gap. Historical records indicate that an earthquake of about M 8.8 occurred within the Iquique gap in 1877, which was preceded immediately to the north by an earthquake of about M 8.8 in 1868.

A recent increase in seismicity rates has occurred in the vicinity of the April $1^{\text {st }}$ earthquake. A M 6.7 earthquake with similar faulting mechanism occurred on March 16, 2014, and was followed by more than 60 earthquakes of M 4+ and 26 earthquakes of M 5+. The March $16^{\text {th }}$ earthquake was also followed by three M 6.2 events on March 17, March 22, and March 23. The spatial distribution of seismicity following the March $16^{\text {th }}$ event migrated spatially to the north through time, starting near $20^{\circ} \mathrm{S}$ and moving to about $19.5^{\circ} \mathrm{S}$. The initial location of the April $1^{\text {st }}$ earthquake places the event near the northern end of this seismic sequence.

While commonly plotted as points on maps, earthquakes of this size are more appropriately described as slip over a larger fault area. Thrust-faulting events of the size of the April 1, 2014, earthquake are typically about 200x80 km (length x width); modeling of this earthquake implies dimensions of about $80 \times 80 \mathrm{~km}$, predominantly down-dip of the hypocenter. This indicates there is a substantial section of the seismic gap that remains unruptured. 
Other recent large plate boundary ruptures bound the seismic gap in which the April $1^{\text {st }}$ event occurred, including the 2001 M 8.4 Peru earthquake adjacent to the south coast of Peru to the north and the 2007 M 7.7 Tocopilla, Chile, and 1995 M 8.1 Antofagasta, Chile, earthquakes to the south, all of which had many associated fatalities and damages. Other nearby events along the plate boundary interface include a M 7.4 earthquake in 1967 as well as a M 7.7 earthquake in 2005 in the deeper portion of the subduction zone beneath inland Chile.

\section{4/03/2014 02:43:13 UTC Usc000p27i $20.571^{\circ} \mathrm{S}, 70.493^{\circ} \mathrm{W}$}

\section{7.7 - 53 km southwest of Iquique, Chile Depth 22.4 km}

\section{Electronic Poster Available}

The April 3, 2014, M 7.7 earthquake off the west coast of northern Chile occurred as the result of thrust faulting at shallow depths, approximately $23 \mathrm{~km}$ south of the city of Iquique. At the location of the event, the Nazca plate subducts eastward beneath the South America plate at a velocity of about $73 \mathrm{~mm} / \mathrm{yr}$. The location and mechanism of the earthquake are consistent with slip on the plate boundary interface, or megathrust, between these two major plates. Subduction along the Peru-Chile Trench to the west of Chile has led to uplift of the Andes Mountain Range and has produced some of the largest earthquakes in the world, including the damaging M 8.8 Maule earthquake in central Chile in 2010, and the largest earthquake on record, the M 9.5 earthquake in southern Chile in 1960.

The April $3^{\text {rd }}$ earthquake is an aftershock of the M 8.2 Iquique earthquake that occurred on April 1, 2014, approximately $110 \mathrm{~km}$ to the north of the April $3^{\text {rd }}$ event. The M 8.2 event triggered a tsunami with measured heights near $2 \mathrm{~m}$ along the northern Chile and southern Peru coasts. Since the M 8.2 event, 47 aftershocks ranging from M 4.2 to this M 7.7 event have occurred, including a M 6.4 earthquake on April 2. The current seismic sequence was preceded by a foreshock sequence that began on March 16, 2014, with a M 6.7 earthquake close to the epicenter of the April $1^{\text {st }}$ M 8.2 event.

This segment of the subduction zone, known as the Iquique or northern Chile seismic gap, last ruptured during an earthquake of about M 8.8 in 1877. Other recent large plate boundary ruptures bound this seismic gap, including the $2001 \mathrm{M} 8.4$ Peru earthquake adjacent to the south coast of Peru to the north, and the 2007 M 7.7 Tocopilla, Chile, and 1995 M 8.1 Antofagasta, Chile, earthquakes to the south.

While commonly plotted as points on maps, earthquakes of this size are more appropriately described as slip over a larger fault area. Thrust-faulting events of the size of the April 3, 2014, earthquake are typically about 100x50 km (length x width); modeling of this earthquake implies dimensions of about $70 \times 60 \mathrm{~km}$, predominantly down-dip of the hypocenter, and immediately south of the M 8.2 rupture 2 days earlier. These two ruptures have not filled the seismic gap; a substantial section remains unruptured, particularly to the south of the April $3^{\text {rd }}$ event.

\section{4/11/2014 07:07:23 UTC Usc000pft9}

\section{$6.586^{\circ} \mathrm{S}, 155.048^{\circ} \mathrm{E}$}

\section{7.1 - 56 km west-southwest of Panguna, Papua New Guinea Depth $60.5 \mathrm{~km}$}

The April 11, 2014, M 7.1 earthquake southwest of Panguna, Papua New Guinea, occurred as the result of shallow thrust faulting on or near the subduction zone interface between the subducting Australia plate and overriding Pacific plate. At the location of the earthquake, the Australia plate moves towards the east-northeast at a rate of $102 \mathrm{~mm} / \mathrm{yr}$ with respect to the Pacific plate, and begins its subduction into the mantle beneath Bougainville Island at the New Britain Trench south of the earthquake. The moment tensor and depth of the earthquake are consistent with thrust-type motion on the interface between these two plates. Note that at the location of the earthquake, some researchers consider the edge of the Australia plate to be divided into several microplates that take up the overall convergence between the Australia and Pacific plates. Here, the Solomon Sea microplate moves slightly faster and more northeasterly relative to the Pacific plate than does the Australia plate due to sea-floor spreading in the Woodlark Basin several hundred kilometers to the south of the April $11^{\text {th }}$ earthquake.

In the Papua New Guinea region, the boundary between the Australia and Pacific plates is very active seismically; $35 \mathrm{M}$ $7+$ events have occurred within $250 \mathrm{~km}$ of the April 11, 2014, earthquake over the past century. None are known to have caused any shaking-related fatalities. The largest was a M 8.0 event $175 \mathrm{~km}$ to the northwest of the April 11, 2014, earthquake, and was one of two M 8+ earthquakes $140 \mathrm{~km}$ apart in July 1971. The M 8.1 Solomon Islands earthquake in April 2007, which caused a devastating tsunami, was $300 \mathrm{~km}$ southeast of the April 11, 2014, event.

A M 6.5 aftershock occurred at 08:16 UTC approximately $25 \mathrm{~km}$ to the southeast of the M 7.1 mainshock. Like the mainshock, the moment tensor and depth of the aftershock are consistent with thrust faulting on the Australia-Pacific plate boundary interface. 


\section{4/12/2014 20:14:39 UTC Usc000phx5}

\section{$11.270^{\circ} \mathrm{S}, 162.148^{\circ} \mathrm{E}$}

\section{7.6 - 93 km south-southeast of Kirakira, Solomon Islands Depth 22.6 km}

\section{Electronic Poster Available}

The April 12, 2014, M 7.6 Solomon Islands earthquake occurred as the result of shallow, nearly pure strike-slip faulting, likely on a northwest-southeast-oriented left-lateral fault on or near the plate boundary between the Australia and Pacific plates. At the location of the earthquake, the Australia plate converges with and slips past the Pacific plate at a rate of $95 \mathrm{~mm} / \mathrm{yr}$. The April $12^{\text {th }}$ earthquake occurred along a portion of this plate boundary that transitions from thrust to transform tectonics between the New Britain Trench to the northwest and the New Hebrides Trench farther east. The earthquake occurred about $100 \mathrm{~km}$ south-southeast of Kirakira, Solomon Islands.

While commonly plotted as points on maps, earthquakes of this size are more appropriately described as slip over a larger fault area. Strike-slip events of the size of the April 12, 2014, earthquake are typically about 140x20 km (length x width); modeling of this earthquake implies dimensions of about $120 \times 50 \mathrm{~km}$, predominantly surrounding and up-dip of the hypocenter.

The region of the April $12^{\text {th }}$ earthquake is very seismically active, with 27 earthquakes of M 6+ occurring within $100 \mathrm{~km}$ and 62 events of M 7+ occurring within $500 \mathrm{~km}$ since 1900. The majority of these earthquakes are grouped to the northwest around the Solomon Islands and to the east near Vanuatu and the Santa Cruz Islands. Notable earthquake within $100 \mathrm{~km}$ include a doublet of M 7.0 events in November 1978 events of M 7.1 in 1931 and 1937, and a M 7.2 event in 1910. The most recent local event prior to the April $12^{\text {th }}$ earthquake was a M 6.0 event on April 4, 2014, $94 \mathrm{~km}$ to the northwest. The April $12^{\text {th }}$ earthquake also occurred about $950 \mathrm{~km}$ to the southeast of an earthquake sequence south of Bougainville Island, Papua New Guinea that began with a M 6.1 event on April 11,2014. On February 6, 2013, a M 8.0 earthquake struck offshore of the Santa Cruz Islands about $340 \mathrm{~km}$ east of the April $12^{\text {th }}$ event. The 2013 earthquake triggered a regional tsunami of about $1.5 \mathrm{~m}$ and was followed by an aftershock of M 7.0 and two aftershocks of M 7.1.

\section{4/13/2014 12:36:19 UTC usc000piqj $11.463^{\circ} \mathrm{S}, 162.051^{\circ} \mathrm{E}$}

\section{7.4 - $112 \mathrm{~km}$ south of Kirakira, Solomon Islands Depth $39.0 \mathrm{~km}$ \\ Electronic Poster Available}

The April 13, 2014, M 7.4 Solomon Islands earthquake occurred as the result of shallow, nearly pure reverse slip on an approximately east-west-oriented fault near the oceanic trench that marks the plate boundary between the Australia and Pacific plates. Focal mechanism solutions indicate that rupture occurred on a moderately dipping reverse fault striking to the westnorthwest or to the east. Finite-fault modeling of globally recorded seismic data for this earthquake is not able to distinguish between these two possibilities. At the location of the earthquake, the Australia plate converges with and slips past the Pacific plate at a velocity of about $95 \mathrm{~mm} / \mathrm{yr}$. The April $13^{\text {th }}$ earthquake occurred along a portion of this plate boundary that transitions from thrust to transform tectonics between the New Britain Trench to the northwest and the New Hebrides Trench farther east. The earthquake occurred about $110 \mathrm{~km}$ south-southeast of Kirakira, Solomon Islands.

The April $13^{\text {th }}$ earthquake occurred less than 24 hours and approximately $20 \mathrm{~km}$ to the southwest of a M 7.7 strike-slip earthquake on April 12, 2014. While the April $12^{\text {th }}$ strike-slip earthquake likely represented Australia-Pacific plate boundary faulting, the April $13^{\text {th }}$ earthquake is located south of the plate boundary at a depth of approximately $35 \mathrm{~km}$, and as such, may represent tearing of the Australia plate to accommodate the abrupt change in Australia plate interaction with the Pacific plate (subduction to the north and west; left-lateral translation to the east).

The region of the April $13^{\text {th }}$ earthquake is very seismically active, with 28 earthquakes of M $6+$ occurring within $100 \mathrm{~km}$ and 62 events of M 7+ occurring within $500 \mathrm{~km}$ since 1900. The majority of these earthquakes are grouped to the northwest around the Solomon Islands and to the east near Vanuatu and the Santa Cruz Islands. Notable earthquakes within $100 \mathrm{~km}$ include a doublet of M 7.0 events in November 1978 events of M 7.1 in 1931 and 1937, and a M 7.2 earthquake in 1910. The most recent local event prior to the April $12^{\text {th }}$ earthquake was a M 6.0 event on April 4, 2014, $94 \mathrm{~km}$ to the northwest. The April $12^{\text {th }}$ earthquake also occurred about $950 \mathrm{~km}$ to the southeast of an earthquake sequence south of Bougainville Island, Papua New Guinea that began with a M 6.1 event on April 11, 2014. On February 6, 2013, a M 8.0 earthquake struck offshore of the Santa Cruz Islands about $340 \mathrm{~km}$ east of the April $12^{\text {th }}$ event. The 2013 earthquake triggered a regional tsunami of about $1.5 \mathrm{~m}$ and was followed by an aftershock of M 7.0 and two aftershocks of M 7.1. 


\section{4/18/2014 14:27:24 UTC Usb000pq41 $17.397^{\circ} \mathrm{N}, 100.972^{\circ} \mathrm{W}$}

\section{7.2 - 33 km east-southeast of Petatlan, Mexico Depth $24.0 \mathrm{~km}$}

\section{Electronic Poster Available}

The April 18, 2014, M 7.2 earthquake near the Pacific Coast of Mexico occurred as the result of shallow reverse faulting in the state of Guerrero, $265 \mathrm{~km}$ southwest of Mexico City. The initial location, depth, and mechanism of the April $18^{\text {th }}$ earthquake are broadly consistent with slip on or near the plate boundary interface between the subducting Cocos oceanic plate and the North America plate. The broad-scale tectonics of the Pacific Coast of Mexico are controlled by the northeastward subduction of the Cocos plate beneath the North America plate at a rate of approximately $65 \mathrm{~mm} / \mathrm{yr}$.

Earthquakes are a common occurrence along the Middle America subduction zone. The April $18^{\text {th }}$ earthquake occurred northwest of the rupture area of the 1957 M 7.8 Guerrero earthquake, and since 1975, 23 events of $\mathrm{M}>6.0$ have occurred within $200 \mathrm{~km}$ of the April $18^{\text {th }}$ earthquake, including events of M 8.0 and M 7.6 (September 1985), M 7.2 (October 1981), and M 7.5 (March 1979), all to the northwest of the April $18^{\text {th }}$ epicenter. The 1981 and 1979 events caused nine and five shaking-related fatalities, respectively. The 1985 M 8.0 earthquake, $195 \mathrm{~km}$ to the northwest of the April 2014 event, led to more than 9,500 fatalities, mostly in Mexico City, and generated small, local tsunamis. That event was influential in initiating efforts to establish earthquake early warning systems in Mexico City.

The April $18^{\text {th }}$ earthquake occurred within the "Guerrero Seismic Gap"-an approximately 200-km-long segment of the Cocos-North America plate boundary identified to have experienced no significant earthquakes since 1911 when a M 7.6 event occurred. The plate interface in this region is known to be locked, and an earthquake of M 8.1-8.4 is thought possible if the entire gap ruptures in a single event.

\section{4/19/2014 13:28:00 UTC usb000pr89}

\section{$6.755^{\circ} \mathrm{S}, 155.024^{\circ} \mathrm{E}$}

\section{7.5 - 70 km southwest of Panguna, Papua New Guinea Depth 43.4 km}

\section{Electronic Poster Available}

The M 7.5, April 19, 2014, earthquake southwest of Panguna, Papua New Guinea, occurred as the result of shallow thrust faulting on or near the subduction zone interface between the Australia plate and overriding Pacific plate. At the location of the earthquake, the Australia plate moves towards the east-northeast at a velocity of about $102 \mathrm{~mm} / \mathrm{yr}$ with respect to the Pacific, and begins its subduction into the mantle beneath Bougainville Island at the New Britain Trench south of the earthquake. The moment tensor and depth of the event are consistent with thrust-type motion on the interface between these two plates. Note that at the location of the earthquake, some researchers consider the edge of the Australia plate to be divided into several microplates that take up the overall convergence between the Australia and Pacific plates. Here the Solomon Sea microplate moves slightly faster and more northeasterly relative to the Pacific plate than does the Australia plate due to sea-floor spreading in the Woodlark Basin several hundred kilometers to the south of the April $19^{\text {th }}$ earthquake.

This event is the latest in an ongoing sequence of seismicity in the same region over the previous week, which began with M 7.1 and M 6.5 earthquakes on April 11, just to the northeast and southeast of the April $19^{\text {th }}$ earthquake, respectively. Over the intervening 8 days, 45 earthquakes of M 4.5+ occurred nearby, including a M 6.6 event about 12 hours before the April $19^{\text {th }}$ earthquake.

While commonly plotted as points on maps, earthquakes of this size are more appropriately described as slip over a larger fault area. Thrust-faulting events of the size of the April 19, 2014, earthquake are typically about 80x40 km (length x width); modeling of this earthquake implies dimensions of about $50 \times 50 \mathrm{~km}$, predominantly surrounding and northwest of the hypocenter.

In the Papua New Guinea region, the boundary between Australia and Pacific plates is very active seismically; $35 \mathrm{M} 7+$ events have occurred within $250 \mathrm{~km}$ of the April 19, 2014 earthquake over the past century. None are known to have caused any shaking-related fatalities. The largest was a M 8.0 event $175 \mathrm{~km}$ to the northwest of the April 19, 2014, earthquake, one of two M 8+ earthquakes $140 \mathrm{~km}$ apart in July 1971. The M 8.1 Solomon Islands earthquake in April 2007, which caused a devastating tsunami, was $300 \mathrm{~km}$ southeast of the April 19, 2014, event. 
06/23/2014 20:53:09 UTC

usc000rki5

$51.849^{\circ} \mathrm{N}, 178.735^{\circ} \mathrm{E}$

\section{7.9 - 19 km southeast of Little Sitkin Island, Alaska \\ Depth $109.0 \mathrm{~km}$}

\section{Electronic Poster Available}

The June 23, 2014, earthquake near Little Sitkin Island, Alaska, occurred as the result of oblique normal faulting at intermediate depth, approximately $110 \mathrm{~km}$ beneath the Aleutian Islands to the north of the Aleutian Trench. Focal mechanism solutions indicate that rupture occurred on either a near-vertical fault or a shallowly dipping fault. Finite-fault modeling of globally recorded seismic data for this earthquake is not able to distinguish between these two possibilities. At the location of this event, the Pacific plate subducts northward beneath the North America plate at a velocity of about $59 \mathrm{~mm} / \mathrm{yr}$. The mechanism, location, and depth of the June $23^{\text {rd }}$ event indicate that the earthquake likely occurred within the subducting Pacific plate, several kilometers beneath the slab interface.

The region of the June $23^{\text {rd }}$ event is very seismically active, with 26 events of M 7+ having occurred within $250 \mathrm{~km}$ since 1900. Notable events include a M 8.4 earthquake in 1906, a M 8.7 earthquake in 1965, and a M 7.9 earthquake in 1996. Unlike the June $23^{\text {rd }}$ event, many of these events occurred at shallower depths, likely along the plate boundary interface.

Earthquakes like this event, with focal depths between 70 and $300 \mathrm{~km}$, are commonly termed "intermediate-depth" earthquakes. Intermediate-depth earthquakes represent deformation within subducted slabs rather than at the shallow plate interface between subducting and overriding tectonic plates. They typically cause less damage on the ground surface above their foci than is the case with similar-magnitude shallow-focus earthquakes, but large intermediate-depth earthquakes may be felt at great distance from their epicenters. "Deep-focus" earthquakes, those with focal depths greater than $300 \mathrm{~km}$, do not occur in the subducted Pacific plate beneath the Aleutian Islands. The deepest reliably located earthquake in this region occurred at a depth of $300 \mathrm{~km}$.

\section{0/09/2014 02:14:31 UTC usb000sk6k}

\section{$32.108^{\circ} \mathrm{S}, 110.811^{\circ} \mathrm{W}$}

\section{7.0 - Southern East Pacific Rise}

\section{Depth 16.5 km}

\section{Electronic Poster Available}

The October 9, 2014, M 7.0 earthquake near the Southern East Pacific Rise occurred as the result of shallow, oblique reverse faulting in the complex plate boundary region at the intersection of the Pacific, Nazca and Antarctic plates, nearly $600 \mathrm{~km}$ to the south of Easter Island. Focal mechanism solutions indicate that oblique rupture occurred on a moderately dipping reverse fault striking to the west-northwest or to the east. Of these two possible fault orientations, finite-fault modeling of globally recorded seismic data is more consistent with slip on the east-striking reverse fault. At the location of the earthquake, about $100 \mathrm{~km}$ to the east of the East Pacific Rise, the Nazca plate diverges from the Pacific at a velocity of about $150 \mathrm{~mm} / \mathrm{yr}$ in a direction slightly south of due east. Some authors identify a small microplate, called the Juan Fernandez plate, in this region; the October $9^{\text {th }}$ earthquake occurred near the northern boundary of this tectonic block with the broader Nazca plate.

Moderate-sized earthquakes are common in this region of the East Pacific Rise, though events of this size have been rare over the past century. Fifteen other M 6+ earthquakes have occurred within $500 \mathrm{~km}$ of the 2014 event over the preceding century-until October 9, 2014, none had been larger than a M 7.0 earthquake that occurred in March 1920, $400 \mathrm{~km}$ due south of the October 9, 2014, earthquake. Because of the remote location far from population centers that might be vulnerable to earthquake shaking, none of these events are known to have caused damage. The M 7.1 2014 event was followed by a M 6.6 aftershock 18 minutes later.

\section{0/14/2014 03:51:34 UTC usb000sIwn \\ $12.526^{\circ} \mathrm{N}, 88.123^{\circ} \mathrm{W}$}

\section{7.3 - 74 km south of Intipuca, El Salvador Depth $40.0 \mathrm{~km}$}

\section{Electronic Poster Available}

The October 14, 2014, M 7.3 earthquake off the coast of El Salvador occurred as the result of shallow normal faulting in the Central America subduction zone. Focal mechanism solutions indicate that rupture occurred on either a steeply 
northeast-dipping fault or on a fault dipping shallowly to the southwest. The location, depth (40 km), and faulting mechanism of the earthquake are consistent with its occurrence either within the subducting oceanic Cocos plate, or in the accretionary wedge of the overriding Caribbean plate, rather than on the main subduction zone thrust. Finite-fault modeling of globally recorded seismic data for this earthquake is not able to distinguish between these two possibilities. At the location of this event, the Cocos plate is converging with the Caribbean plate at a rate of about $73 \mathrm{~mm} / \mathrm{yr}$ in an east-northeast direction. The approximate depth of the subducted Cocos plate at the location of the earthquake is $50 \mathrm{~km}$.

The portion of the Middle America subduction zone bordering El Salvador and Nicaragua, locus of the October $14^{\text {th }}$ earthquake, is very seismically active, with events of M 7.3 (2012), M 7.7 (2001), M 7.7 (1992), and M 7.3 (1982) all having occurred within $200 \mathrm{~km}$ of the October $14^{\text {th }}$ earthquake in the past 35 years. The $2001 \mathrm{M} 7.7$ earthquake involved normal faulting with similar orientation to the October $14^{\text {th }}$ event, and likely occurred within the subducting Cocos plate. It caused substantial damage in El Salvador and Guatemala, with the majority of fatalities caused by a triggered landslide. The 2001 earthquake also triggered aftershocks in the overriding Caribbean plate, including a M 6.6 event in the vicinity of San Salvador.

\section{1/01/2014 18:57:22 UTC Usc000stdc $19.690^{\circ} \mathrm{S}, 177.759^{\circ} \mathrm{W}$}

\section{7.1 - 144 km northeast of Ndoi Island, Fiji Depth $434.0 \mathrm{~km}$ \\ Electronic Poster Available}

The November 1, 2014, M 7.1 earthquake occurred as the result of deep reverse faulting approximately $435 \mathrm{~km}$ beneath the Pacific Ocean, within the lithosphere of the subducted Pacific slab. Focal mechanism solutions indicate that rupture occurred on either a near-vertical reverse fault or a shallowly dipping thrust fault. Slip on a fault of either orientation would accommodate the down-dip compression of the Pacific slab that is implied by the reverse component of the faulting solution. At the location of the earthquake, the Pacific plate moves approximately westward with respect to the Australia plate at a rate of about $78 \mathrm{~mm} / \mathrm{yr}$, subducting in to the mantle at the Tonga Trench, about $300 \mathrm{~km}$ to the east of the November $1^{\text {st }}$ earthquake.

The approximately 3000-km-long Australia-Pacific plate boundary in this region extends from south of Macquarie Island to the Samoa Islands. It includes an oceanic transform (the Macquarie Ridge); two oppositely verging subduction zones (Puysegur and Hikurangi); a transpressive continental transform, the Alpine fault, through South Island, New Zealand; and the TongaKermadec subduction zone north of New Zealand, the northward continuation of the Hikurangi subduction zone. At the northern end of the Tonga-Kermadec subduction zone, north of the November $1^{\text {st }}$ earthquake, the boundary curves sharply westward and changes along a 700-km-long segment from trench-normal subduction, to oblique subduction, to a left lateral transform-like structure.

The subducting Pacific plate beneath Fiji is one of the most seismically active regions in the world. Over the past century, nearly $100 \mathrm{M} 6.5+$ deep-focus earthquakes have occurred within $250 \mathrm{~km}$ of the November $1^{\text {st }}$ event. Of these, 13 had magnitudes of M 7+. The largest was a M 7.8 earthquake about $50 \mathrm{~km}$ to the northwest and $50 \mathrm{~km}$ deeper in January 1919.

Earthquakes that have focal depths greater than $300 \mathrm{~km}$ are commonly termed "deep-focus" earthquakes. Deep-focus earthquakes cause less damage on the ground surface above their foci than similar-magnitude shallow-focus earthquakes, but large deep-focus earthquakes may be felt at great distance from their epicenters. The largest recorded deep-focus earthquake to date was the M 8.3 event that occurred at a depth of $600 \mathrm{~km}$ within the subducted Pacific plate beneath the Sea of Okhotsk offshore of northeastern Russia in 2013. The M 8.3 Okhotsk earthquake was felt all over Asia, as far away as Moscow, and across the Pacific Ocean along the western seaboard of the United States (though at distant locations, individuals reporting having felt the event were likely very favorably situated for the perception of small ground motions). The M 8.2 Bolivian deep-focus earthquake in 1994 had similarly been reported by individuals in North America at great distance from the epicenter.

Over the past century, 87 earthquakes with a magnitude of M 7+ have occurred at depths greater than $300 \mathrm{~km}$ globally; 28 of these were located in the same region as the November 1, 2014, event.

\section{1/15/2014 02:31:41 UTC usc000sxh8}

\section{$1.893^{\circ} \mathrm{N}, 126.522^{\circ} \mathrm{E}$}

\section{7.1 - 154 km northwest of Kota Ternate, Indonesia Depth $45.0 \mathrm{~km}$ \\ Electronic Poster Available}

The November 15, 2014, M 7.1 earthquake northwest of Kota Ternate, Indonesia, occurred within the shallow oceanic crust of the Sunda plate, in the complex plate boundary region of eastern Indonesia, about $300 \mathrm{~km}$ to the west of the major plate 
boundary between the Sunda and Pacific plates. Faulting mechanism solutions for the event indicate that it activated a reverse faulting structure, dipping either steeply towards the northwest, or more gently towards the southeast, in line with the general trend of earthquakes in the region. Slip on a fault aligned with either nodal plane is consistent with the intraplate setting of this event.

Tectonics in eastern Indonesia are extremely complex and are dominated by the mostly convergent interactions of the Pacific, Australia, Philippine Sea, and Sunda plates, with some authors labeling the most proximate edge of the Pacific plate here as a separate tectonic block called the Caroline plate. The edges of the Sunda and Australia plates are also often subdivided into smaller tectonic blocks, including the Molucca Sea and Birds Head microplates immediately to the south and east of the November 2014 earthquake, respectively. In this context, the November 2014 event most closely aligns with the boundary between the broader Sunda plate and the Birds Head microplate. At depth beneath this earthquake and the Molucca Sea in general, the inverted-U-shaped Halmahera plate, which has no surface expression, also plays a role in regional tectonics. At the location of the November $15^{\text {th }}$ earthquake, the Sunda and Philippine Sea plates are converging in an east-west direction at a rate of approximately $109 \mathrm{~mm} / \mathrm{yr}$.

This area of the Molucca Sea frequently hosts moderate to large earthquakes; nearly 120 M 6+ events have occurred within $250 \mathrm{~km}$ of the November 15, 2014, earthquake in the last century, two dozen of which were M 7+. The largest, a M 8.1 event in 1932, struck along the same microplate boundary structure approximately $190 \mathrm{~km}$ to the south of the 2014 event. Despite the large number of events in the region, few have been damaging because of their oceanic setting. The exception was a M 7.5 earthquake that struck $90 \mathrm{~km}$ to the south of the 2014 event in January 2007and caused four fatalities.

\section{5: 19 Events}

\section{2/13/2015 18:59:12 UTC usb000tp5q}

\section{$52.649^{\circ} \mathrm{N}, 31.902^{\circ} \mathrm{W}$}

\section{7.1 - northern Mid-Atlantic Ridge \\ Depth 16.7 km \\ Electronic Poster Available}

The February 13, 2015, M 7.1 northern Mid-Atlantic Ridge earthquake occurred as the result of right-lateral strike-slip faulting on or near a transform fault forming part of the North America:Eurasia plate boundary. At the location of this earthquake, the North America plate moves approximately westward at a rate of $21 \mathrm{~mm} / \mathrm{yr}$ with respect to Eurasia. The preliminary location and mechanism of the earthquake are consistent with its occurrence on the Charlie-Gibbs Transform (the seismically active section of the Charlie-Gibbs fracture zone), though more detailed analyses of the event will be required to definitively determine the causative fault.

Moderate to large earthquakes in this region of the north Atlantic are common-over the past century, five other earthquakes of M 6.3-7.0 have occurred within $250 \mathrm{~km}$ of the February 13, 2015, event, likely along the same fracture zone. The largest of these was a M 7.0 event on February 13, 1967. Because of their strike-slip mechanisms and locations in the remote North Atlantic, none of these historic events are known to have caused damage.

\section{2/27/2015 13:45:05 UTC usc000ttkd}

\section{$7.297^{\circ} \mathrm{S}, 122.535^{\circ} \mathrm{E}$}

\section{7.0 - $130 \mathrm{~km}$ north of Nebe, Indonesia Depth $552.1 \mathrm{~km}$}

\section{Electronic Poster Available}

The February 27, 2015, M 7.0 earthquake north of Nebe, Indonesia, occurred as the result of oblique strike-slip faulting within the subducted Australia plate, $550 \mathrm{~km}$ beneath the Flores Sea. Focal mechanism solutions for the earthquake indicate that rupture occurred on either a left-lateral fault with a moderately dipping, northeast-striking plane, or on a right lateral fault dipping steeply towards the southwest. The earthquake is located at the eastern end of the Australia slab that was originally subducted at the Sunda-Java Trench, several hundred kilometers to the south of the event (and at the surface of the Earth). At the location of the earthquake, the Australia plate moves approximately northward with respect to the Sunda plate at a rate of $74 \mathrm{~mm} / \mathrm{yr}$. The February 27, 2015, earthquake occurred in response to stresses generated by the slow distortion of the Australia 
plate at depth, rather than on the shallower interface with the overriding Sunda plate. Slip on a fault aligned with either nodal plane of the focal mechanism solution is consistent with this intraplate setting.

Earthquakes that have focal depths greater than $300 \mathrm{~km}$ are commonly termed "deep-focus" earthquakes. Deep-focus earthquakes cause less damage on the ground surface above their foci than is the case with similar-magnitude shallow-focus earthquakes, but large deep-focus earthquakes may be felt at great distance from their epicenters. The largest recorded deepfocus earthquake was a M 8.3 event that occurred at a depth of $600 \mathrm{~km}$ within the subducted Pacific plate beneath the Sea of Okhotsk, offshore of northeastern Russia, in 2013. The M 8.3 Okhotsk earthquake was felt all over Asia, as far away as Moscow, and across the Pacific Ocean along the western seaboard of the United States (though at distant locations, individuals reporting having felt the event were likely very favorably situated for the perception of small ground motions). The M 8.2 Bolivian deepfocus earthquake in 1994 had similarly been reported by individuals in North America at great distance from the epicenter.

Over the past century, 88 earthquakes with a magnitude of M 7+ have occurred at depths greater than $300 \mathrm{~km} ; 4$ of these were located in the same region as the Februry 27, 2015 event. The largest nearby event at these depths was a M 7.9 earthquake in June 1996, just $18 \mathrm{~km}$ to the north and $40 \mathrm{~km}$ deeper than the February 2015 event.

\section{3/29/2015 23:48:31 UTC us10001rvu}

\section{$4.729^{\circ} \mathrm{S}, 152.562^{\circ} \mathrm{E}$}

\section{7.5 - 53 km southeast of Kokopo, Papua New Guinea Depth $41.0 \mathrm{~km}$}

\section{Electronic Poster Available}

The March 29, 2015, M 7.5 earthquake southeast of Kokopo, Papua New Guinea, occurred as the result of thrust faulting on or near the plate boundary interface between the subducting Australia and overriding Pacific plates. At the location of the earthquake, the Australia plate moves towards the east-northeast at a velocity of $105 \mathrm{~mm} / \mathrm{yr}$ with respect to the Pacific plate, and begins its subduction into the mantle beneath New Britain and New Ireland at the New Britain Trench south of the earthquake. The moment tensor and depth of the event are consistent with thrust-type motion on the interface between these two plates. Note that at the location of the earthquake, some researchers consider the edges of the Australia and Pacific plates to be divided into several microplates that take up the overall convergence between Australia and the Pacific, including the Solomon Sea and South Bismark microplates local to this event. The Solomon Sea microplate moves slightly faster and more northeasterly with respect to the Pacific plate than does the Australia plate due to sea-floor spreading in the Woodlark Basin several hundred kilometers to the south of the March $29^{\text {th }}$ earthquake, facilitating the classic subduction evident beneath New Britain and New Ireland.

While commonly plotted as points on maps, earthquakes of this size are more appropriately described as slip over a larger fault area. Thrust-faulting events of the size of the March 29, 2015, earthquake are typically about 80x40 km (length x width); modeling of this earthquake implies dimensions of about $100 \times 70 \mathrm{~km}$, predominantly up-dip of the hypocenter.

The plate boundary between the Australia and Pacific plates in the Papua New Guinea region is very active seismically; 36 M $7+$ events have occurred within $250 \mathrm{~km}$ of the March 29, 2015, earthquake over the past century. Few are known to have caused shaking-related fatalities because of the remoteness of the region, though a M 8.0 earthquake in November 2000-one of three similarly sized events over a 2-day period - did cause several deaths. The largest nearby earthquake was a M 8.1 event, $70 \mathrm{~km}$ to the east of the March 29, 2015, earthquake, and was one of two M 8+ earthquakes $140 \mathrm{~km}$ apart in July 1971.

\section{4/25/2015 06:11:25 UTC Us20002926}

\section{$28.230^{\circ} \mathrm{N}, 84.731^{\circ} \mathrm{E}$}

\section{7.8 - 3 km east of Khudi, Nepal Depth $8.2 \mathrm{~km}$}

\section{Electronic Poster Available}

The April 25, 2015, M 7.8 Nepal earthquake occurred as the result of thrust faulting on or near the main thrust interface between the subducting India plate and the overriding Eurasia plate to the north. At the location of this earthquake, approximately $80 \mathrm{~km}$ to the northwest of the Nepalese capital of Kathmandu, the India plate is converging with Eurasia at a rate of $45 \mathrm{~mm} / \mathrm{yr}$ towards the north-northeast - a fraction of which (about $18 \mathrm{~mm} / \mathrm{yr}$ ) is driving the uplift of the Himalayan Mountain Range. The preliminary location, size and focal mechanism solutions of the April $25^{\text {th }}$ earthquake are consistent with its occurrence on the decollément associated with the Main Himalayan Thrust, which defines the subduction thrust interface between the India and Eurasia plates.

While commonly plotted as points on maps, earthquakes of this size are more appropriately described as slip over a larger fault area. Thrust-faulting events of the size of the April 25, 2015, earthquake are typically about 100x50 km (length x width); 
early modeling of this earthquake implies dimensions of about 120x80 km, directed from the hypocenter eastward, and towards Kathmandu. As a result, substantial seismic energy was generated by faulting very close to the city.

The boundary region of the India and Eurasia plates has a history of large and great-sized earthquakes. Four events of M 6 or larger have occurred within $250 \mathrm{~km}$ of the April 25, 2015, earthquake over the past century. One, a M 6.9 earthquake in August 1988, $240 \mathrm{~km}$ to the southeast of the April $25^{\text {th }}$ event, caused close to 1,500 fatalities. The largest, a M 8.0 event known as the 1934 Nepal-Bihar earthquake, ruptured a large section of the fault to the east of this 2015 event, in a similar location to the 1988 earthquake. It severely damaged Kathmandu, and is thought to have caused about 10,600 fatalities. Prior to the $20^{\text {th }}$ century, a large earthquake in 1833 is thought to have ruptured a similar area as the 2015 event.

\section{5/05/2015 01:44:06 UTC us20002bnf}

\section{$5.462^{\circ} \mathrm{S}, 151.875^{\circ} \mathrm{E}$}

\section{7.5 - 130 km south-southwest of Kokopo, Papua New Guinea Depth $55.0 \mathrm{~km}$}

\section{Electronic Poster Available}

The May 5, 2015, M 7.5 earthquake south-southwest of Kokopo, Papua New Guinea, occurred as the result of thrust faulting on or near the plate boundary interface between the subducting Australia and overriding Pacific plates. At the location of the earthquake, the Australia plate moves towards the east-northeast at a velocity of $105 \mathrm{~mm} / \mathrm{yr}$ with respect to the Pacific plate, and begins its subduction into the mantle beneath New Britain at the New Britain Trench, south-southeast of the earthquake. The moment tensor and depth of the event are consistent with thrust-type motion on the interface between these two plates. Note that at the location of the earthquake, some researchers consider the edges of the Australia and Pacific plates to be divided into several microplates that take up the overall convergence between the Australia and Pacific plates, including the Solomon Sea and South Bismark microplates local to this event. The Solomon Sea microplate moves slightly faster and more northeasterly with respect to the Pacific plate than does the Australia plate due to sea-floor spreading in the Woodlark Basin several hundred kilometers to the southeast of the May $5^{\text {th }}$ earthquake, facilitating the classic subduction evident beneath New Britain.

While commonly plotted as points on maps, earthquakes of this size are more appropriately described as slip over a larger fault area. Thrust-faulting events of the size of the May 5, 2015, earthquake are typically about 70x40 km (length x width); modeling of this earthquake implies dimensions of about $60 \times 50 \mathrm{~km}$, predominantly northeast of the hypocenter.

The plate boundary between the Australia and Pacific plates in the Papua New Guinea region is very active seismically; 36 M 7+ events have occurred within $250 \mathrm{~km}$ of the May 5, 2015, earthquake over the past century. Few are known to have caused shaking-related fatalities because of the remoteness of the region, though a M 8.0 earthquake in November 2000 - one of three similarly sized events over a 2-day period — did cause several deaths. The largest nearby earthquake was a M 8.1 event, $150 \mathrm{~km}$ to the east-northeast of the May 5, 2015, earthquake, one of two M 8+ earthquakes $140 \mathrm{~km}$ apart in July 1971. The May 2015 earthquake is only $10 \mathrm{~km}$ to the east-northeast of the November 17, 2000, M 7.8 earthquake, which was also a thrust-faulting event on the plate boundary interface.

The May $5^{\text {th }}$ earthquake was also preceded by a series of moderate to large earthquakes on this portion of the plate boundary over the preceding several weeks, beginning with a M 7.5 event on March 29, 2015, $110 \mathrm{~km}$ to the northeast of the May 5, 2015, earthquake. Between these two large events, 25 other earthquakes of M 5+ have occurred in the same area; including M 6.7 and M 6.8 events just to the northwest of the May $5^{\text {th }}$ earthquake, on April 30 and May 1, respectively.

\section{5/07/2015 07:10:19 UTC us20002das}

\section{$7.218^{\circ} \mathrm{S}, 154.557^{\circ} \mathrm{E}$}

\section{7.1 - 143 km southwest of Panguna, Papua New Guinea Depth $10.0 \mathrm{~km}$}

\section{Electronic Poster Available}

The May 7, 2015, M 7.1 earthquake southwest of Panguna, Papua New Guinea, occurred as the result of normal faulting within the Australia plate, a few tens of kilometers to the southwest of the plate boundary where Australia begins its subduction beneath the Pacific plate at the New Britain Trench. At the location of the earthquake, the Australia plate moves towards the east-northeast at a velocity of $103 \mathrm{~mm} / \mathrm{yr}$ with respect to the Pacific plate. The moment tensor and location of the event are consistent with its occurrence near what has been termed the outer rise region outboard of the subduction zone, rather than farther to the north on the plate boundary (thrust) interface, on a normal fault dipping shallowly to the northeast or steeply to the southwest. Finite-fault modeling of globally recorded seismic data for this earthquake is not able to distinguish between these two possibilities. Note that at the location of the earthquake, some researchers consider the edges of the Australia and Pacific plates 
to be divided into several microplates that take up the overall convergence between the Australia and Pacific plates, including the Solomon Sea microplate local to this event. The Solomon Sea microplate moves slightly faster and more northeasterly with respect to the Pacific plate than does the Australia plate due to sea-floor spreading in the Woodlark Basin a few hundred kilometers to the southeast of the May $7^{\text {th }}$ earthquake, facilitating the classic subduction evident beneath New Britain and the Solomon Islands.

While commonly plotted as points on maps, earthquakes of this size are more appropriately described as slip over a larger fault area. Normal-faulting events of the size of the May 7, 2015, earthquake are typically about $45 \times 20 \mathrm{~km}$ (length x width).

The plate boundary between the Australia and Pacific plates in the Papua New Guinea region is very active seismically; $26 \mathrm{M} 7+$ events have occurred within $250 \mathrm{~km}$ of the May 7, 2015, earthquake over the past century. Most occurred on the subduction zone thrust interface to the north of this event, and few are known to have caused shaking-related fatalities because of the remoteness of the region. Just one of these large nearby events was the result of normal faulting to the south of the plate boundary - a M 7.0 earthquake in October 1987, $15 \mathrm{~km}$ to the southwest of the May 7, 2015, event.

The May 7 earthquake was also preceded by a series of moderate to large earthquakes on the portion of the plate boundary several hundred kilometers to the northwest over the previous 6 weeks, beginning with a M 7.5 event on March 29, 2015, and continuing with another M 7.5 earthquake on May 5, 2015. The May $7^{\text {th }}$ earthquake is also $75 \mathrm{~km}$ to the southwest of a M 7.5 earthquake in April 2014, just offshore of the North Solomon Islands.

\section{5/12/2015 07:05:19 UTC us20002ejl}

\section{$27.809^{\circ} \mathrm{N}, 86.066^{\circ} \mathrm{E}$}

\section{7.3 - 19 km southeast of Kodari, Nepal Depth $15.0 \mathrm{~km}$}

\section{Electronic Poster Available}

The May 12, 2015, M 7.3 Nepal earthquake (southeast of Zham, China) occurred as the result of thrust faulting on or near the decollément associated with the Main Himalayan Thrust, which defines the interface between the underthrusting India plate and the overriding Eurasia plate to the north. At the location of this earthquake, approximately $80 \mathrm{~km}$ to the east-northeast of the Nepalese capital of Kathmandu, the India plate is converging with Eurasia at a rate of $45 \mathrm{~mm} / \mathrm{yr}$ towards the north-northeasta fraction of which (about $18 \mathrm{~mm} / \mathrm{yr}$ ) is driving the uplift of the Himalayan Mountain Range. The May 12, 2015, event is the largest aftershock to date of the M 7.8 April 25, 2015, Nepal earthquake - known as the Gorkha earthquake — which was located $150 \mathrm{~km}$ to the west, and which ruptured much of the decollément between the hypocenters of these two earthquakes.

While commonly plotted as points on maps, earthquakes of this size are more appropriately described as slip over a larger fault area. Thrust-faulting events of the size of the May 12, 2015, earthquake are typically about $55 \times 30 \mathrm{~km}$ (length $\mathrm{x}$ width). The April 25, 2015, M 7.8 mainshock had approximate dimensions of about 120x80 km, directed from its hypocenter eastward, and towards Kathmandu. The May 12, 2015, earthquake is located just beyond the eastern end of that rupture, with dimensions of about $40 \times 20 \mathrm{~km}$.

The boundary region of the India and Eurasia plates has a history of large and great earthquakes. Prior to April 25, four events of M 6 or larger had occurred within $250 \mathrm{~km}$ of this area over the past century. One, a M 6.9 earthquake in August $1988,140 \mathrm{~km}$ to the south-southeast of the May $12^{\text {th }}$ event, caused close to 1,500 fatalities. The largest, a M 8.0 event known as the 1934 Nepal-Bihar earthquake, ruptured a large section of the fault to the south of this May 2015 event, and east of the April 2015 mainshock, in a similar location to the 1988 earthquake. It severely damaged Kathmandu, and is thought to have caused about 10,600 fatalities. Prior to the $20^{\text {th }}$ century, a large earthquake in 1833 is thought to have ruptured a similar area as the April 25, 2015, event. To date, there have been almost $100 \mathrm{M} 3+$ aftershocks of the Gorkha earthquake. In the first 2 hours after the May $12^{\text {th }}$ event, 6 further aftershocks have occurred to the southwest and southeast of that earthquake.

05/30/2015 11:23:02 UTC us20002ki3

\section{$27.839^{\circ} \mathrm{N}, 140.493^{\circ} \mathrm{E}$}

\section{7.8 - 189 km west-northwest of Chichi-shima, Japan \\ Depth $664.0 \mathrm{~km}$}

\section{Electronic Poster Available}

The May 30, 2015, M 7.8 earthquake west-northwest of Chichi-shima, Japan, occurred as the result of oblique normal faulting at a depth greater than $660 \mathrm{~km}$ beneath the Pacific Ocean. The earthquake is located within the interior of the Pacific plate that subducts beneath Japan starting at the Izu Trench, several hundred kilometers to the east of the event (and at the surface of the Earth). Focal mechanism solutions indicate that rupture occurred on a normal fault dipping either steeply to the 
west-southwest, or shallowly to the southeast. At the location of the earthquake, the Pacific plate moves approximately westward with respect to the Philippine Sea plate at a rate of $39 \mathrm{~mm} / \mathrm{yr}$. This earthquake occurred in response to stresses generated by the slow distortion of the Pacific plate at depth, rather than occurring on the interface between the Pacific plate and the overriding Philippine Sea plate. Slip on a fault aligned with either nodal plane of the focal mechanism solution is consistent with this intraplate setting.

Earthquakes that have focal depths greater than $300 \mathrm{~km}$ are commonly termed "deep-focus" earthquakes. Deep-focus earthquakes cause less damage on the Earth's surface above their foci than is the case with similar-magnitude shallow-focus earthquakes. Large deep-focus earthquakes may be felt at great distance from their epicenters. The largest recorded deep-focus earthquake was a 2013 M 8.3 earthquake that occurred at a depth of $600 \mathrm{~km}$ within the subducted Pacific plate beneath the Sea of Okhotsk, offshore of northeastern Russia. The M 8.3 Okhotsk earthquake was felt all over Asia, as far away as Moscow, and across the Pacific Ocean along the western seaboard of the United States (though at distant locations, individuals reporting having felt the event were likely very favorably situated for the perception of small ground motions). The M 8.2 Bolivian deepfocus earthquake in 1994 had similarly been reported by individuals in North America at great distance from the epicenter.

Over the past century, 89 earthquakes with a magnitude of M 7+ have occurred at depths greater than $300 \mathrm{~km} ; 3$ of these were located in the same region as the May 30, 2015, event. The largest nearby event at these depths was a M 7.3 earthquake in 1968, several hundred kilometers to the south of this earthquake.

\section{6/17/2015 12:51:32 UTC us20002qn7}

\section{$35.364^{\circ} \mathrm{S}, 17.160^{\circ} \mathrm{W}$}

\section{7.0 - Southern Mid-Atlantic Ridge}

\section{Depth $10.0 \mathrm{~km}$}

\section{Electronic Poster Available}

The June 17, 2015, M 7.0 southern Mid-Atlantic Ridge earthquake occurred as the result of left-lateral strike-slip faulting on or near a transform fault forming part of the South America:Africa (Nubia) plate boundary. At the location of this earthquake, the South America plate moves approximately westward at a rate of $33 \mathrm{~mm} / \mathrm{yr}$ with respect to the Nubia plate. While historical earthquakes have occurred in the same region and likely on the same fault as this earthquake, the fracture zone does not appear to be named.

Moderate to large earthquakes in this region of the south Atlantic are common—over the past century, 16 other earthquakes of M 6.0-6.6 have occurred within $250 \mathrm{~km}$ of the June 17, 2015, event, both along the same fracture zone and in association with other shorter fracture zones to the south. The June 17, 2015, event represents the largest in the region over that time period; the next largest was a M 6.6 event in February 2005, $130 \mathrm{~km}$ to the south. None of these earthquakes are known to have caused damage. Their remoteness from populated land minimizes the potential hazard from shaking damage, and their strike-slip faulting mechanisms produce relatively small vertical tectonic displacement of the sea-floor, which minimizes the risk of their producing destructive tsunami.

\section{7/18/2015 02:27:33 UTC us20002yaw \\ $10.401^{\circ} \mathrm{S}, 165.141^{\circ} \mathrm{E}$}

\section{7.0 - 83 km west-northwest of Lata, Solomon Islands Depth $11.0 \mathrm{~km}$}

\section{Electronic Poster Available}

The July 18, 2015, M 7.0 normal faulting earthquake northwest of Lata, in the Solomon Islands, occurred on either an east-west-striking fault dipping moderately to the north, or on a southeast-northwest-striking fault dipping more steeply towards the southwest. At the location of this earthquake, the Australia plate moves towards the east-northeast at a rate of $95 \mathrm{~mm} / \mathrm{yr}$ with respect to the Pacific plate. The location and mechanism of this event are consistent with its occurrence within the oceanic crust of the Pacific plate, $500 \mathrm{~km}$ to the northeast of the major local plate boundary between the Australia and Pacific plates, and directly above the northern edge of the Australia slab that subducts from the North New Hebrides Trench to the east beneath the Santa Cruz Islands. Slip on a fault aligned with either nodal plane of the focal mechanism solution is consistent with this intraplate setting.

The Australia:Pacific plate boundary system from the Solomon Islands towards Vanuatu is one of the most seismically active regions of the planet, and the area frequently hosts major earthquakes. Eighteen other M 7+ events have occurred within $250 \mathrm{~km}$ of the July 18, 2015, earthquake over the preceding century. The July 2015 earthquake occurred at the northern end of the earthquake sequence associated with the February 6, 2013, M 8.0 earthquake, which struck $45 \mathrm{~km}$ to the south of the July 18, 2015, event. The M 8.0 earthquake and associated tsunami caused several fatalities and injuries and significantly damaged local islands. 
07/27/2015 21:41:21 UTC

us200030kn

$2.629^{\circ} \mathrm{S}, 138.528^{\circ} \mathrm{E}$

\section{7.0 - 228 km west of Abepura, Indonesia}

Depth 48.0 km

\section{Electronic Poster Available}

The July 27, 2015, M 7.0 earthquake near Abepura, Indonesia, occurred as the result of reverse faulting on a fault plane dipping moderately either to the northeast or southwest. The earthquake occurred in a broad zone of convergence between the Pacific and Australia plates, whose boundary in this region is divided by some authors into a series of microplates that together take up the relative motions between the larger plates. The epicenter of the July $27^{\text {th }}$ event lies close to the boundaries among the Maoke, Woodlark, and Caroline microplates. At this location, the Pacific plate moves towards the southwest with respect to the Australia plate, at a rate of approximately $111 \mathrm{~mm} / \mathrm{yr}$. To the north of the event, the Pacific (Caroline) plate subducts to the southwest beneath Australia (Maoke and Woodlark) at the New Guinea Trench, and the location and mechanism of the July 27, 2015, earthquake are consistent with its occurrence on or near that slab interface at depth. Finite-fault modeling of globally recorded seismic data is more consistent with slip on a fault dipping moderately to the southwest, within the subducted lithosphere of the Caroline plate (just below the plate boundary).

The Australia:Pacific plate boundary through Papua New Guinea experiences frequent moderate to large earthquakes, and has hosted 29 other events of M 6.5+ over the prior century. The largest was a M 7.7 earthquake $150 \mathrm{~km}$ to the east-southeast of the July $27^{\text {th }}$ event in January 1971. All of these earthquakes reflect the complex tectonics of the region, exhibiting reverse faulting mechanisms associated with Pacific subduction, as well as transform, reverse, and normal faulting mechanisms associated with upper plate deformation. None are known to have caused significant damage, likely because of the sparse population of the region.

\section{9/16/2015 22:54:32 UTC us20003k7a}

\section{$31.573^{\circ} \mathrm{S}, 71.674^{\circ} \mathrm{W}$}

\section{8.3 - 48 km west of Illapel, Chile Depth 22.4 km}

\section{Electronic Poster Available}

The September 16, 2015, M 8.3 earthquake west of Illapel, Chile, occurred as the result of thrust faulting on the interface between the Nazca and South America plates in central Chile. At the location of this event, the Nazca plate is moving towards the east-northeast at a velocity of $74 \mathrm{~mm} / \mathrm{yr}$ with respect to South America, and begins its subduction beneath the continent at the Peru-Chile Trench, $85 \mathrm{~km}$ to the west of the September $16^{\text {th }}$ earthquake. The size, location, depth and mechanism of this event are all consistent with its occurrence on the megathrust interface in this region.

While commonly plotted as points on maps, earthquakes of this size are more appropriately described as slip over a larger fault area. Thrust-faulting events of the size of the September 16, 2015, earthquake are typically about 230x100 km (length x width).

Chile has a long history of massive earthquakes, including the 2010 M 8.8 Maule earthquake in central Chile, which ruptured an approximately 400-km-long section of the plate boundary south of this 2015 event (and to the south of the Juan Fernandez Ridge, which enters the trench immediately south of the 2015 earthquake). This subducton zone also hosted the largest earthquake on record, the 1960 M 9.5 earthquake in southern Chile. Over the century prior to the September 16, 2015, earthquake, the region within $400 \mathrm{~km}$ of this event hosted 15 other M 7+ earthquakes.

09/16/2015 23:18:41 UTC Us20003k7w

$31.562^{\circ} \mathrm{S}, 71.426^{\circ} \mathrm{W}$

\section{7.0 - 25 km west-northwest of Illapel, Chile}

\section{Depth 28.4 km}

\section{Electronic Poster Available}

The September 16, 2015, M 7.0 earthquake (UTC 23:18) west of Illapel, Chile, occurred as the result of thrust faulting on the interface between the Nazca and South America plates in central Chile, and is an aftershock of the UTC 22:54 M 8.3 earthquake of the same date. The epicenters of these two events are separated by about $25 \mathrm{~km}$. At the location of the M 7.0 event, the Nazca plate is moving towards the east-northeast at a velocity of $74 \mathrm{~mm} / \mathrm{yr}$ with respect to South America, and begins 
its subduction beneath the continent at the Peru-Chile Trench to the west of the September $16^{\text {th }}$ earthquakes. The size, location, depth and mechanism of this event are all consistent with its occurrence on the megathrust interface in this region.

Chile has a long history of massive earthquakes, including the M 8.8 Maule earthquake in central Chile in 2010, which ruptured an approximately 400-km-long section of the plate boundary south of this 2015 event (and to the south of the Juan Fernandez Ridge, which enters the trench immediately south of the 2015 earthquake). This subducton zone also hosted the largest earthquake on record, the 1960 M 9.5 earthquake in southern Chile. Over the century prior to the September 16, 2015, earthquake, the region within $400 \mathrm{~km}$ of this event has hosted 15 other M 7+ earthquakes.

\section{0/20/2015 21:52:02 UTC us10003q0q}

\section{$14.860^{\circ} \mathrm{S}, 167.303^{\circ} \mathrm{E}$}

\section{7.1 - 34 km northeast of Port-Olry, Vanuatu Depth 135.0 km \\ Electronic Poster Available}

The October 20, 2015, M 7.1 Vanuatu earthquake occurred as the result of oblique-reverse faulting at an intermediate depth, approximately $130 \mathrm{~km}$ beneath the Pacific Ocean and $100 \mathrm{~km}$ to the east of the New Hebrides Trench, within the lithosphere of the subducting Australia plate. Focal mechanism solutions indicate that oblique rupture occurred on either a west-northwest- or south-striking, moderately dipping fault. Slip on a fault aligned with either nodal plane is consistent with the intraplate setting of this event. At the location of the earthquake, the Australia plate moves east-northeast relative to the Pacific plate, subducting beneath the New Hebrides Arc and North Fiji Basin at a velocity of about $88 \mathrm{~mm} / \mathrm{yr}$. The plate boundary in this region is often subdivided into a collection of small tectonic microplates that together accommodate the convergence of the much larger Australia and Pacific plates. The subducted Australia plate is seismically active to a depth of about $300 \mathrm{~km}$ in the region of this earthquake.

Earthquakes like this one, with focal depths between 70 and $300 \mathrm{~km}$, are commonly termed "intermediate-depth" earthquakes. Intermediate-depth earthquakes represent deformation within subducted slabs rather than at the shallow plate interfaces between subducting and overriding tectonic plates. They typically cause less damage on the ground surface above their foci than is the case with similar-magnitude shallow-focus earthquakes, but large intermediate-depth earthquakes may be felt at great distance from their epicenters.

The Vanuatu region experiences a very high level of earthquake activity, and 27 earthquakes of $\mathrm{M} 7+$ have occurred within $400 \mathrm{~km}$ of the October $20^{\text {th }}$ event over the preceding 40 years. Five of these earthquakes occurred at intermediate depths. The largest nearby event at these depths was a M 7.2 earthquake in July 1990, $60 \mathrm{~km}$ to the southeast of the October 20, 2015, event.

10/26/2015 09:09:42 UTC Us10003re5

\section{$36.524^{\circ} \mathrm{N}, 70.368^{\circ} \mathrm{E}$}

\section{7.5 - 45 km east of Farkhar, Afghanistan \\ Depth $231.0 \mathrm{~km}$ \\ Electronic Poster Available}

The October 26, 2015, M 7.5 earthquake near the Hindu Kush region of Afghanistan (southwest of Jarm) occurred as the result of reverse faulting at an intermediate depth, approximately $210 \mathrm{~km}$ below the Hindu Kush Range in northeastern Afghanistan. Focal mechanism solutions indicate that rupture occurred on either a steep, south-dipping reverse fault or a shallow, northdipping thrust fault. Of these two possible fault orientations, finite-fault modeling of globally recorded seismic data is more consistent with slip on the steep south-dipping fault. At the location of the earthquake, the India subcontinent moves northward and collides with Eurasia at a velocity of about $37 \mathrm{~mm} / \mathrm{yr}$.

Active faults and their resultant earthquakes in northern Pakistan and adjacent parts of India and Afghanistan are the direct result of the convergence between the India and Eurasia plates. This collision causes uplift that produces the highest mountain peaks in the world, including the Himalayan, the Karakoram, the Pamir, and the Hindu Kush Ranges.

While commonly plotted as points on maps, earthquakes of this size are more appropriately described as slip over a larger fault area. Reverse-faulting events of the size of the October 26, 2015, earthquake are typically about $70 \mathrm{x} 40 \mathrm{~km}$ (length $\mathrm{x}$ width); modeling of this earthquake implies dimensions of about $30 \times 30 \mathrm{~km}$, predominantly west of the hypocenter.

Earthquakes like this event, with focal depths between 70 and $300 \mathrm{~km}$, are commonly termed "intermediate-depth" earthquakes. Intermediate-depth earthquakes represent deformation within subducted lithosphere rather than at the shallow plate interfaces between subducting and overriding tectonic plates. They typically cause less damage on the ground surface above their foci than is the case with similar-magnitude shallow-focus earthquakes, but large intermediate-depth earthquakes may be 
felt at great distance from their epicenters. "Deep-focus" earthquakes, those with focal depths greater than $300 \mathrm{~km}$, also occur beneath the northeastern part of Afghanistan. Earthquakes have been reliably located to depths of just over $300 \mathrm{~km}$ in this region.

Seven other M 7+ earthquakes have occurred within $250 \mathrm{~km}$ of this event over the preceding century, the most recent being a M 7.4 earthquake in March 2002 just $20 \mathrm{~km}$ to the west of the October 26, 2015, event, and with a similar depth and thrust fault orientation. The 2002 event caused more than 150 fatalities and the damage or destruction of over 400 houses in relation to an associated landslide. A M 7.4 event in December 1983 at a similar depth just $8 \mathrm{~km}$ to the south of the October 26, 2015, earthquake resulted in 26 fatalities, hundreds of injuries and extensive damage in the region. The most deadly recent event in the region occurred $330 \mathrm{~km}$ to the southeast of the October 26, 2015, earthquake, in the Kashmir region of Pakistan on October 8, 2005. This 2005 event killed at least 86,000 people and caused extensive damage. The 2005 event was shallow ( $26 \mathrm{~km}$ ) and was caused by geologic forces that are distinctly different than those driving deep earthquakes in the Hindu Kush region.

\section{1/24/2015 22:45:38 UTC us100040ww $10.536^{\circ} \mathrm{S}, 70.965^{\circ} \mathrm{W}$ \\ M 7.6 - 175 km west-northwest of Iberia, Peru Depth $606.2 \mathrm{~km}$}

\section{Electronic Poster Available}

The November 24, 2015 (22:45 UTC), M 7.6 earthquake was the first of two similarly sized events near the Peru-Brazil border in southeast Peru. Both earthquakes occurred as the result of normal faulting at a depth of approximately $600 \mathrm{~km}$, almost $1,000 \mathrm{~km}$ east of the Peru-Chile Trench within the subducted oceanic lithosphere of the Nazca plate. Focal mechanism solutions indicate that rupture occurred on either a north- or south-southeast-striking, moderately dipping normal fault. Slip on a fault of either orientation would accommodate the down-dip extension of the Nazca slab that is implied by the normal component of the faulting solution. At the location of the earthquakes, the Nazca plate subducts to the east under the South America plate at a velocity of about $69 \mathrm{~mm} / \mathrm{yr}$.

The 22:45 UTC event preceded another M 7.6 earthquake (22:50 UTC) by 5 minutes; the events were separated by approximately $55 \mathrm{~km}$ horizontally — more than typical location uncertainties of global earthquakes — and just $12 \mathrm{~km}$ vertically. The two events also had approximately the same focal mechanism solution. The latter earthquake was almost certainly triggered by the earlier event. Seismologists sometimes refer to a pair of similarly sized earthquakes that occur at nearly the same time and location as an earthquake "doublet."

As it descends eastward from the Peru-Chile Trench off the west coast of Peru, the Nazca plate is seismically active down to depths of about $200 \mathrm{~km}$. Between depths of 200 and $500 \mathrm{~km}$, where the Nazca plate subducts beneath eastern Peru, very few earthquakes are produced. Beneath Peru and Brazil in the border region near the November 24th earthquakes, the subducted Nazca plate is again seismically active between depths of about 500 and $650 \mathrm{~km}$. The deep part of the Nazca plate, in which the November $24^{\text {th }}$ earthquakes occurred, took $10 \mathrm{Myr}$ or more to descend from the point at which it initially thrust under the South America plate.

Earthquakes that have focal depths greater than $300 \mathrm{~km}$ are commonly termed "deep-focus" earthquakes. Deep-focus earthquakes cause less damage on the ground surface above their foci than similar-magnitude shallow-focus earthquakes, but large deep-focus earthquakes may be felt at great distance from their epicenters. The largest recorded deep-focus earthquake was a M 8.3 event that occurred at a depth of $600 \mathrm{~km}$ within the subducted Pacific plate beneath the Sea of Okhotsk offshore of northeastern Russia in 2013. The M 8.3 Okhotsk earthquake was felt all over Asia, as far away as Moscow, and across the Pacific Ocean along the western seaboard of the United States (though at distant locations, individuals reporting having felt the event were likely very favorably situated for the perception of small ground motions). Prior to 2013, the largest recorded deep-focus earthquake was a M 8.2 event that occurred at a depth of $630 \mathrm{~km}$ within the subducted Nazca plate near the northern Bolivian border in 1994, approximately $500 \mathrm{~km}$ southeast of the November 24, 2015, events. The M 8.2 Bolivian deep-focus earthquake in 1994 had similarly been reported by individuals in North America at great distance from the epicenter.

Over the past century, 90 earthquakes of M 7+ have occurred at depths greater than $300 \mathrm{~km}$ globally; 13 of these were located in the same region as the November 24, 2015, events. The largest nearby event at these depths was the aforementioned M 8.2 Bolivia earthquake. The most recent large event in the immediate vicinity of the November 24, 2015, events was a M 7.0 earthquake in October 1990, $15 \mathrm{~km}$ to the southeast. 


\section{1/24/2015 22:50:54 UTC us100040x6 $10.061^{\circ} \mathrm{S}, 71.018^{\circ} \mathrm{W}$}

\section{7.6 - 211 km south of Tarauaca, Brazil Depth 620.6 km}

\section{Electronic Poster Available}

The November 24, 2015 (22:50 UTC), M 7.6 earthquake was the second of two similarly sized events near the Peru-Brazil border in southeast Peru. Both earthquakes occurred as the result of normal faulting at a depth of approximately $600 \mathrm{~km}$, almost $1,000 \mathrm{~km}$ east of the Peru-Chile Trench within the subducted oceanic lithosphere of the Nazca plate. Focal mechanism solutions indicate that rupture occurred on either a north- or south-southeast-striking, moderately dipping normal fault. Slip on a fault of either orientation would accommodate the down-dip extension of the Nazca slab that is implied by the normal component of the faulting solution. At the location of the earthquakes, the Nazca plate subducts to the east under the South America plate at a velocity of about $69 \mathrm{~mm} / \mathrm{yr}$.

The 22:50 UTC event followed another M 7.6 earthquake (22:45 UTC) by 5 minutes; the events were separated by approximately $55 \mathrm{~km}$ horizontally - more than typical location uncertainties of global earthquakes - and just $12 \mathrm{~km}$ vertically. The two events also had approximately the same focal mechanism solution. The latter earthquake was almost certainly triggered by the earlier event. Seismologists sometimes refer to a pair of similarly sized earthquakes that occur at nearly the same time and location as an earthquake "doublet."

As it descends eastward from the Peru-Chile Trench off the west coast of Peru, the Nazca plate is seismically active down to depths of about $200 \mathrm{~km}$. Between depths of 200 and $500 \mathrm{~km}$, where the Nazca plate subducts beneath eastern Peru, very few earthquakes are produced. Beneath Peru and Brazil in the border region near the November $24^{\text {th }}$ earthquakes, the subducted Nazca plate is again seismically active between depths of about 500 and $650 \mathrm{~km}$. The deep part of the Nazca plate, in which the November $24^{\text {th }}$ earthquakes occurred, took 10 million years or more to descend from the point at which it initially thrust under the South America plate.

Earthquakes that have focal depths greater than $300 \mathrm{~km}$ are commonly termed "deep-focus" earthquakes. Deep-focus earthquakes cause less damage on the ground surface above their foci than similar-magnitude shallow-focus earthquakes, but large deep-focus earthquakes may be felt at great distance from their epicenters. The largest recorded deep-focus earthquake to date was the M 8.3 event that occurred at a depth of $600 \mathrm{~km}$ within the subducted Pacific plate beneath the Sea of Okhotsk offshore of northeastern Russia in 2013. The M 8.3 Okhotsk earthquake was felt all over Asia, as far away as Moscow, and across the Pacific Ocean along the western seaboard of the United States (though at distant locations, individuals reporting having felt the event were likely very favorably situated for the perception of small ground motions). Prior to 2013, the largest recorded deep-focus earthquake was a M 8.2 event that occurred at a depth of $630 \mathrm{~km}$ within the subducted Nazca plate near the northern Bolivian border in 1994, approximately $500 \mathrm{~km}$ southeast of the November 24, 2015, events. The M 8.2 Bolivian deep-focus earthquake in 1994 had similarly been reported by individuals in North America at great distance from the epicenter.

Over the past century, 90 earthquakes of M 7+ have occurred at depths greater than $300 \mathrm{~km}$ globally; 13 of these were located in the same region as the November 24, 2015, events. The largest nearby event at these depths was the aforementioned M 8.2 Bolivia earthquake. The most recent large event in the immediate vicinity of the November 24, 2015, events was a M 7.0 earthquake in October 1990, $15 \mathrm{~km}$ to the southeast.

\section{2/04/2015 22:25:00 UTC us100043z2}

\section{$47.617^{\circ} \mathrm{S}, 85.091^{\circ} \mathrm{E}$}

\section{7.1 - Southeast Indian Ridge}

\section{Depth 35.0 km}

\section{Electronic Poster Available}

The M 7.1 earthquake in the southern Indian Ocean on December 4, 2015, occurred as the result of oblique normal faulting within the oceanic crust of the Antarctica plate, nearly $700 \mathrm{~km}$ south of the Australia:Antarctica plate boundary in this region, which is defined by the Southeast Indian Ridge. At the location of the earthquake, the Antarctica plate is moving approximately southwestward at a rate of $66 \mathrm{~mm} / \mathrm{yr}$ with respect to Australia. Focal mechanism solutions indicate that rupture occurred on an oblique normal fault moderately dipping towards either the west or the southeast. Slip on a fault aligned with either of these nodal planes is consistent with this intraplate setting.

Earthquakes off the axis of the Southeast Indian Ridge in this region are quite rare; no other events larger than M 5 are known to have occurred within $400 \mathrm{~km}$ of the December 4, 2015, event over the previous century. Within $750 \mathrm{~km}$, seismicity is predominantly focused on the ridge, with some off-ridge earthquakes on the southward extensions of the Vlamingh and 
Geelvinck Fracture Zones to the northwest of the December 4, 2015, event. Just two M 6+ earthquakes have occurred within $750 \mathrm{~km}$ over the past century — a M 6.0 earthquake on the ridge in 2002, $670 \mathrm{~km}$ to the northwest of the 2015 event, and a M 6.1 earthquake near the Vlamingh fracture zone in 1984, $690 \mathrm{~km}$ to the northwest of the 2015 event.

\section{2/07/2015 07:50:07 UTC us100044k6}

\section{$38.227^{\circ} \mathrm{N}, 72.752^{\circ} \mathrm{E}$}

\section{7.2 - 106 km west of Murghob, Tajikistan Depth 22.0 km}

\section{Electronic Poster Available}

The December 7, 2015, M 7.2 earthquake in Tajikistan occurred as the result of strike-slip faulting within the crust of the Eurasia plate. Focal mechanism solutions indicate that rupture occurred on either a northwest-southeast-striking right-lateral fault, or on a southwest-northeast-striking left-lateral fault. Of these two possible fault orientations, finite-fault modeling of globally recorded seismic data is more consistent with slip on the southwest-striking (left-lateral) fault. At the location of this earthquake, the India plate is moving northward with respect to Eurasia at a rate of approximately $38 \mathrm{~mm} / \mathrm{yr}$.

The December 7, 2015, earthquake is located several hundred kilometers north of the India:Eurasia plate boundary, in the Pamir Mountains. The collision of these two plates drives the tectonics of the broad region surrounding the Himalayan Mountains and the Tibetan Plateau, and causes uplift that produces the highest mountain peaks in the world including the Himalayan, the Karakoram, the Pamir, and the Hindu Kush Ranges.

The location of the December 7, 2015, earthquake is close to Saraz Lake, which was formed in February 1911 when a nearby M 7.3 earthquake triggered a landslide that dammed the Murghab River. Over the past century, 18 other earthquakes of M 6.5 or larger have occurred within $250 \mathrm{~km}$ of the December 7, 2015, earthquake. Given the remoteness of the region, earthquakes here rarely cause shaking-related fatalities; however, secondary hazards such as landsliding have caused damage and fatalities in the past.

\section{Regional Tectonic Summaries}

Most, though not all, earthquakes discussed in the previous section occur in areas for which regional seismotectonic posters have been prepared. These posters contain regional maps and tectonic summaries that help give context to the event-specific summaries. They provide a basis for better understanding regional tectonic complexity and how earthquakes are related to broader tectonic features. The posters are available for downloading at http://earthquake.usgs.gov/earthquakes/world/seismicity_maps/, but for convenience, regional tectonic summaries of the information given in the posters are included in this section.

\section{North America}

\section{Aleutian Arc and Vicinity}

Benz, H.M., Dart, R.L., Villaseñor, Antonio, Hayes, G.P., Tarr, A.C., Furlong, K.P., and Rhea, Susan, 2011, Seismicity of the Earth 1900-2010 Aleutian Arc and vicinity: U.S. Geological Survey Open-File Report 20101083-B, scale 1:5,000,000, http://pubs.usgs.gov/of/2010/1083/b/.

The Aleutian Arc extends approximately 3,000 km from the Gulf of Alaska in the east to the Kamchatka Peninsula in the west. It marks the region where the Pacific plate subducts into the mantle beneath the North America plate. This subduction is responsible for the generation of the Aleutian Islands and the deep offshore Aleutian Trench.

The curvature of the arc results in a westward transition of relative plate motion from trench-normal (compressional) in the east to trench-parallel (translational) in the west, accompanied by westward variations in seismic activity, volcanism, and overriding plate composition. The Aleutian Arc is generally divided into three regions: the western, central, and eastern Aleutians. Relative to a fixed North America plate, the Pacific plate is moving northwest at a rate that increases from about $60 \mathrm{~mm} / \mathrm{yr}$ at the arc's eastern edge to $76 \mathrm{~mm} / \mathrm{yr}$ near its western terminus. The eastern Aleutian Arc extends from the Alaskan Peninsula in the east to the Fox Islands in the west. Motion along this section of the arc is characterized by arc-perpendicular convergence and 
Pacific plate subduction beneath thick continental lithosphere. This region exhibits intense volcanic activity and has a history of megathrust earthquakes.

The central Aleutian Arc extends from the Andreanof Islands in the east to the Rat Islands in the west. Here, motion is characterized by westward-increasing oblique convergence and Pacific plate subduction beneath thin oceanic lithosphere. Along this portion of the arc, the Wadati-Benioff zone is well defined to depths of approximately $200 \mathrm{~km}$. Despite the obliquity of convergence, active volcanism and megathrust earthquakes are also present along this margin.

The western Aleutians, stretching from the western end of the Rat Islands in the east to the Commander Islands, Russia, in the west, are tectonically different from the central and eastern portions of the arc. The increasing component of transform motion between the Pacific and North America plates is evidenced by diminishing active volcanism; the last active volcano is located on Buldir Island, in the far western portion of the Rat Island chain. Additionally, this portion of the subduction zone has not hosted large earthquakes or megathrust events in recorded history. Instead, the largest earthquakes in this region are generally shallow, predominantly strike-slip events with magnitudes between M 5 and M 6. Deeper earthquakes do occur, albeit rather scarcely and with small magnitudes $(\mathrm{M}<4)$, down to approximately $50 \mathrm{~km}$.

Most of the seismicity along the Aleutian Arc results from thrust faulting that occurs along the interface between the Pacific and North America plates, extending from near the base of the trench to depths of 40 to $60 \mathrm{~km}$. Slip along this interface is responsible for generating devastating earthquakes. Deformation also occurs within the subducting slab in the form of intermediate-depth earthquakes that can reach depths of $250 \mathrm{~km}$. Normal-faulting events occur in the outer rise region of the Aleutian Arc resulting from the bending of the oceanic Pacific plate as it enters the Aleutian Trench. Additionally, deformation of the overriding North America plate generates shallow crustal earthquakes.

The Aleutian Arc is a seismically active region, evidenced by the many moderate to large earthquakes occurring each year. Since 1900, this region has hosted 12 large earthquakes (M 7.5+) including the May 7, 1986, M 8.0 Andreanof Islands earthquake, the June 10, 1996, M 7.9 Andreanof Islands earthquake, and the November 17, 2003, M 7.8 Rat Islands earthquake. Six of these great earthquakes (M 8.3 or larger) have occurred along the Aleutian Arc that together have ruptured almost the entire shallow megathrust contact. The first of these major earthquakes occurred on August 17, 1906, near the island of Amchitka (M 8.3) in the western Aleutian Arc. Unlike the other megathrust earthquakes along the arc, this event is thought to have been an intraplate event occurring in the shallow slab beneath the subduction zone interface.

The first megathrust event along the arc during the $20^{\text {th }}$ century was the November 10, 1938, M 8.6 Shumagin Islands earthquake. This event ruptured an approximately $300-\mathrm{km}$-long stretch of the arc from the southern end of Kodiak Island to the northern end of the Shumagin Islands and generated a small tsunami that was recorded as far south as Hawaii.

The April 1, 1946, M 8.6 Unimak Island earthquake, located in the central Aleutian Arc, was characterized by slow rupture followed by a devastating Pacific-wide tsunami that was observed as far south as the shores of Antarctica. Although damage from earthquake shaking was not severe locally, tsunami run-up heights were recorded as high as $42 \mathrm{~m}$ on Unimak Island and tsunami waves in Hilo, Hawaii, also resulted in casualties. The slow rupture of this event has made it difficult to constrain the focal mechanism solution and depth of the earthquake, though it is thought to have been an interplate thrust earthquake.

The next megathrust earthquake occurred along the central portion of the Aleutian Arc near the Andreanof Islands on March 9, 1957, with a magnitude of M 8.6. The rupture length of this event was approximately 1,200 km, making it the longest observed aftershock zone of all the historical Aleutian Arc events. Although only limited seismic data from this event are still available, significant damage and tsunamis were observed on the islands of Adak and Unimak with tsunami heights of approximately $13 \mathrm{~m}$.

The easternmost megathrust earthquake was the March 28, 1964, M 9.2 Prince William Sound earthquake, currently the second-largest recorded earthquake in the world. The event had a rupture length of roughly $700 \mathrm{~km}$ extending from Prince William Sound in the northeast to the southern end of Kodiak Island in the southwest. Extensive damage was recorded in Kenai, Moose Pass, and Kodiak, but significant shaking was felt over a large region of Alaska, parts of western Yukon Territory, and British Columbia, Canada. Property damage was the largest in Anchorage, as a result of both the mainshock shaking and the ensuing landslides. This megathrust earthquake also triggered a devastating tsunami that caused damage along the Gulf of Alaska, the west coast of the United States, and in Hawaii.

The westernmost Aleutians megathrust earthquake followed a year later on February 4, 1965. This M 8.7 Rat Islands earthquake was characterized by roughly $600 \mathrm{~km}$ of rupture. Although this event is quite large, damage was minimal because of the region's remote and sparsely inhabited location. A relatively small tsunami was recorded throughout the Pacific Ocean with run-up heights up to $10.7 \mathrm{~m}$ on Shemya Island and flooding on Amchitka Island.

Although the Aleutian Arc is highly active, seismicity is rather discontinuous, with two regions that have not experienced a large (M 8.0+) earthquake in the past century: the Commander Islands in the western Aleutians and the Shumagin Islands in the east. Because of the dominantly transform motion along the western arc, the Commander Islands could rupture in a moderate to large strike-slip earthquake in the future. The Shumagin Islands region may also have high potential for hosting a large rupture in the future, though it has been suggested that little strain is being accumulated along this section of the subduction zone, thus associated hazards may be reduced. 
East of the Aleutian Arc along the Gulf of Alaska, crustal earthquakes occur as a result of transmitted deformation and stress associated with the northwestward convergence of the Pacific plate that collides a block of oceanic and continental material into the North America plate. In 2002, the Denali fault ruptured in a sequence of earthquakes that commenced with the October $23^{\text {rd }}$ M 6.7 Nenana Mountain right-lateral strike-slip earthquake and culminated with the November $3^{\text {rd }}$ M 7.9 Denali earthquake which started as a thrust earthquake along a then unrecognized fault and continued with a larger right-lateral strikeslip event along the Denali and Totschunda faults.

\title{
Offshore British Columbia - Southeastern Alaska and Vicinity
}

\author{
Hayes, G.P., Smoczyk, G.M., Ooms, J.G., McNamara, D.E., Furlong, K.P., Benz, H.M., and Villaseñor, Antonio, \\ 2014, Seismicity of the Earth 1900-2013 Offshore British Columbia-southeastern Alaska and vicinity: \\ U.S. Geological Survey Open-File Report 2010-1083-0, 1 sheet, scale 1:3,500,000, http://pubs.usgs.gov/ \\ of/2010/1083/o/.
}

The tectonics of the Pacific margin of North America between Vancouver Island and south-central Alaska are dominated by the northwest motion of the Pacific plate with respect to the North America plate at a velocity of approximately $50 \mathrm{~mm} / \mathrm{yr}$. In the south of this mapped region, convergence between the northern extent of the Juan de Fuca plate (also known as the Explorer microplate) and North America plate dominates. North from the Explorer, Pacific, and North America plate triple junction, Pacific:North America motion is accommodated along the approxmately 650-km-long Queen Charlotte fault system. Offshore of Haida Gwaii and to the southwest, the obliquity of the Pacific:North America plate motion vector creates a transpressional regime, and a complex mixture of strike-slip and convergent (underthrusting) tectonics. North of the Haida Gwaii Islands, plate motion is roughly parallel to the plate boundary, resulting in almost pure dextral strike-slip motion along the Queen Charlotte fault. To the north, the Queen Charlotte fault splits into multiple structures, continuing offshore of southwestern Alaska as the Fairweather fault, and branching east into the Chatham Strait and Denali faults through the interior of Alaska. The plate boundary north and west of the Fairweather fault ultimately continues as the Alaska-Aleutians subduction zone, where Pacific plate lithosphere subducts beneath the North America plate at the Aleutians Trench. The transition is complex, and involves intraplate structures such as the Transition fault. The Pacific margin offshore of British Columbia is one of the most active seismic zones in North America and has hosted a number of large earthquakes historically.

At the southern extent of the mapped region offshore of Vancouver Island lies a complex triple junction between the Pacific, North America, and Juan de Fuca plates (which includes the Explorer and Winona microplates). The Winona microplate experiences little relative motion with respect to North America. Similarly, at its northern extent, the Explorer microplate tracks North America plate motion, but is subducting at a rate of 2 centimeters per year $(\mathrm{cm} / \mathrm{yr})$ near its southern extent adjacent to the Nootka fault. Farther south the main body of the oceanic Juan de Fuca plate converges with and subducts beneath the continental North America plate at a rate of 4.0-4.5 cm/yr. The Explorer microplate is heavily deformed by internal dextral faulting, experiencing frequent moderate-sized earthquakes. During the period from 1973 to 2013, this approximately 30-km-wide area experienced close to 50 earthquakes of M 5+. The largest of these was a M 6.7 event that occurred on April 6, 1992. On January 5, 2008, M 6.6 and M 6.4 earthquakes struck in this same region just 40 minutes apart, and were separated by less than $20 \mathrm{~km}$ along a southeast-northwest trend that is sub-parallel to the motion of the Pacific plate. Like many other similar events in the region, no damage or casualties were reported for these earthquakes.

The Queen Charlotte fault trends northwestward from the triple junction region, accommodating approximately $5.5 \mathrm{~cm} / \mathrm{yr}$ of dextral strike-slip motion along the Pacific:North America plate boundary. The majority of earthquakes associated with the Queen Charlotte fault are purely dextral strike-slip in nature, though occasional earthquakes exhibit a significant thrust component, such as the 1970 M 6.8 event and the 2012 M 7.8 event. Because the Pacific:North America plate motion vector adjacent to the islands of Haida Gwaii is oblique to the plate boundary, the Pacific plate underthrusts the Queen Charlotte terrace and the western margin of the North America plate. The convergent component of the plate vector is accommodated by relative motion between the Pacific plate and the Queen Charlotte terrace, though it is unclear from geophysical evidence how far the Pacific plate extends beneath the North America plate.

The largest earthquake observed along the Queen Charlotte fault was a M 8.0 strike-slip event in 1949, located approximately $25 \mathrm{~km}$ west of the north tip of Haida Gwaii. This earthquake created a minor far-field tsunami, an uncommon occurrence for strike-slip faulting. The 1970 M 6.8 earthquake that ruptured about $30 \mathrm{~km}$ south of the southern tip of Haida Gwaii was one of the first large magnitude events in the area to be recognized as having a significant thrust component. More recently the M 7.8 Haida Gwaii earthquake struck adjacent to the south-central portion of the islands on October 28, 2012, and was characterized by oblique thrust faulting, triggering a locally significant tsunami. Only 4 months later on January 5, 2013, a large strike-slip earthquake (M 7.5) occurred a few hundred kilometers farther north, near the junction of the Fairweather and Queen Charlotte faults. No major structural damage or casualties were reported for either of these recent events. 
Continuing north, dextral Queen Charlotte fault motion extends into the Fairweather fault and other inland structures such as the Chatham Strait and Denali faults. The Fairweather fault is a continuation of the Queen Charlotte fault that eventually dies out as it comes onshore into Alaska. The average slip rate of the Fairweather fault is believed to be $4.6 \pm 2.0 \mathrm{~cm} / \mathrm{yr}$, oriented northwestward. On July 9, 1958, the Fairweather fault experienced its largest documented earthquake, a M 7.8 event that caused a massive landslide and subsequent water wave in Lituya Bay. The wave caused by the landslide stripped away trees and ground soil up to a height of $520 \mathrm{~m}$, and caused five fatalities.

The Chatham Strait fault trends north-northwest from its origin at the Queen Charlotte fault and Fairweather fault junction. This structure does not appear to be accommodating a significant fraction of plate motion and has not hosted any significant historic seismic activity. Farther north the Chatham Strait fault turns northwestward, transitioning into the Denali fault, which continues through continental North America. The Denali fault had been relatively quiet historically until the 2002 earthquake sequence, when a M 6.6 event was followed 11 days later by a M 7.8 earthquake that ruptured an approximately $340-\mathrm{km}$ section of the fault system on November 3, 2002. Despite the large size of the November event, its remote location meant only a small amount of structural damage was observed, with no fatalities and few injuries reported. For three decades prior to the 2002 event, seismicity along the Denali fault was characterized by an average of four $M \geq 3$ events per year. However, in the 8 months leading up to the mainshock, microseismicity along the Denali fault increased significantly, and 80 small events were recorded.

Near the northern termination of the Fairweather fault, the west-northwest-trending Transition fault marks the boundary between the Yakutat terrane and Pacific plate. The Yakutat terrane is a 15- to 30-km-thick igneous plateau that began to subduct at a low angle beneath continental North America 30 to 35 million years ago. Though the Yakutat terrane subducts at a slightly slower rate than that of the Pacific plate, its convergence direction has a slightly more westerly trend, causing compressional deformation along the Transition fault to increase towards the northwest. Extending southward from the Transition fault, the Gulf of Alaska shear zone has experienced a high rate of seismicity historically, with earthquakes reaching M 7+. The Gulf of Alaska shear zone is believed to have formed along an old fracture zone or spreading fabric in the oceanic crust, and is an example of intraplate seismicity reflecting high stresses generated by nearby plate boundary processes, in this case immediately to the north, between the Yakutat terrane and Pacific plate. The Gulf of Alaska shear zone hosted a sequence of large earthquakes between 1987 and 1992, consisting of five events of M 6.8 or larger (three of which were M 7.8, M 7.9, and M 7.9).

Within the greater Queen Charlotte fault region (excluding the Alaska-Aleutians subduction zone), more than 150 earthquakes of M 5+ have occurred between 1973 and 2013, with only a small fraction of these events rupturing at depths greater than $25 \mathrm{~km}$ and none deeper than $35 \mathrm{~km}$. Earthquake epicenters along the Queen Charlotte fault express an east-west asymmetry, with the majority of seismicity occurring towards the eastern slope of the marine terrace near the definition of the Queen Charlotte fault trace. This can be explained by an east-dipping fault plane, evident in moment tensor data for moderate to large earthquakes within the transform fault zone.

\title{
Mexico and Vicinity
}

\author{
Benz, H.M., Dart, R.L., Villaseñor, Antonio, Hayes, G.P., Tarr, A.C., Furlong, K.P., and Rhea, Susan, 2011, \\ Seismicity of the Earth 1900-2010 Mexico and vicinity: U.S. Geological Survey Open-File Report 2010-1083-F, \\ scale 1:8,000,000, http://pubs.usgs.gov/of/2010/1083/f/.
}

Located atop three of the large tectonic plates, Mexico is one of the world's most seismologically active regions. The relative motion of these crustal plates causes frequent earthquakes and occasional volcanic eruptions.

Most of the Mexican landmass is on the westward-moving North America plate. The Pacific Ocean floor south of Mexico is being carried northeastward by the underlying Cocos plate. Because oceanic crust is relatively dense, when the Pacific Ocean floor encounters the lighter continental crust of the Mexican landmass, the ocean floor is subducted beneath the North America plate creating the deep Middle America Trench along Mexico's southern coast. Also as a result of this convergence, the westward-moving Mexico landmass is slowed and crumpled, creating the mountain ranges of southern Mexico and earthquakes near Mexico's southern coast. As the oceanic crust is pulled downward, it melts; the molten material is then forced upward through weaknesses in the overlying continental crust. This process has created a region of volcanoes across south-central Mexico known as the Cordillera Neovolcánica.

The area west of the Gulf of California, including Mexico's Baja California Peninsula, is moving northwestward with the Pacific plate at about $95 \mathrm{~mm} / \mathrm{yr}$. Here, the Pacific and North America plates grind past each other creating strike-slip faulting, the southern extension of California's San Andreas Fault. In the past, this relative plate motion pulled Baja California away from the coast forming the Gulf of California and is the cause of earthquakes in the Gulf of California region today.

Mexico has a long history of destructive earthquakes and volcanic eruptions. In September 1985, a M 8.1 earthquake killed more than 9,500 people in Mexico City. In southern Mexico, Volcán de Colima and El Chichón erupted in 2005 and 1982, respectively. Paricutín volcano, west of Mexico City, began venting smoke in a cornfield in 1943; a decade later this new 
volcano had grown to a height of $424 \mathrm{~m}$. Popocatépetl and Ixtaccíhuatl volcanos ("smoking mountain" and "white lady," respectively), southeast of Mexico City, occasionally vent gas that can be clearly seen from the City, a reminder that volcanic activity is ongoing. In 1994 and 2000, Popocatépetl renewed its activity, forcing the evacuation of nearby towns and causing seismologists and government officials to be concerned about the effect a large-scale eruption might have on the heavily populated region. Popocatépetl volcano last erupted in 2010.

\title{
Caribbean Plate and Vicinity
}

\author{
Benz, H.M., Tarr, A.C., Hayes, G.P., Villaseñor, Antonio, Furlong, K.P., Dart, R.L., and Rhea, Susan, 2011, \\ Seismicity of the Earth 1900-2010 Caribbean plate and vicinity: U.S. Geological Survey Open-File Report \\ 2010-1083-A, scale 1:8,000,000, http://pubs.usgs.gov/of/2010/1083/a/.
}

Extensive diversity of tectonic regimes characterizes the perimeter of the Caribbean plate, involving no fewer than four major adjacent plates (North America, South America, Nazca, and Cocos). Inclined zones of deep earthquakes (Wadati-Benioff zones), deep ocean trenches, and arcs of volcanoes clearly indicate subduction of oceanic lithosphere along the Central American and Atlantic Ocean margins of the Caribbean plate, while shallow seismicity and focal mechanism solutions of major shocks in Guatemala, northern Venezuela, and the Cayman Ridge and Cayman Trench indicate transform fault and pull-apart basin tectonics.

The depth profile panels on this map portray earthquakes that extend from the Middle America Trench axis in the west to depths as great as $300 \mathrm{~km}$ beneath Guatemala, and from the Lesser Antilles Trench axis in the east to depths of approximately $200 \mathrm{~km}$ beneath Guadeloupe and the northeast Caribbean. In contrast, seismicity along the segments of the Caribbean plate margins from Guatemala to Hispaniola and from Trinidad to western Venezuela is indicative of transform fault tectonics.

Along the northern margin of the Caribbean plate, the North America plate moves west, relative to the Caribbean plate, at approximately $20 \mathrm{~mm} / \mathrm{yr}$, resulting in major transcurrent faults and troughs. Farther east, the North America plate subducts beneath the Caribbean plate resulting in surface expression of the deep Puerto Rico Trench and a zone of intermediate-depth earthquakes in the subducted slab.

The plate boundary curves around Puerto Rico and the northern Lesser Antilles where the plate motion vector of the Caribbean plate relative to the North and South America plates is less oblique, resulting in active island arc tectonics. The North and South America plates subduct beneath the Caribbean plate along the Lesser Antilles Trench at rates of about $20 \mathrm{~mm} / \mathrm{yr}$; consequently, there are both intermediate-depth earthquakes within the subducted South America plate and a chain of active volcanoes along the island arc.

The southern Caribbean plate boundary along with the South America plate strikes east-west across Trinidad and western Venezuela and is characterized by major strike-slip faults and shallow seismicity, resulting from relative plate motion of about $20 \mathrm{~mm} / \mathrm{yr}$. Farther to the west, a broad zone of convergent deformation trends southwest across western Venezuela and central Columbia. Plate boundaries are not well defined across northern South America, but there is a transition from Caribbean:South America convergence in the east to Nazca:South America convergence in the west, described in more detail below. The transition zone is characterized by high seismic hazard.

The Nazca-Caribbean plate boundary offshore of Columbia is characterized by convergence (Nazca plate subducting under South America plate) at about $65 \mathrm{~mm} / \mathrm{yr}$. The January 6, 1906, M 8.5 megathrust subduction earthquake occurred on a shallowdipping interface of this plate boundary segment. The 1906 earthquake occurred in the Colombia-Ecuador region, with a seismic moment (Mo; equivalent to radiated energy) of $6 \times 10^{28}$ dyne-cm, and a moment magnitude (Mw) of 8.5. The nucleation point of this earthquake is indicated on the map.

Along the western coast of Central America, the Cocos plate subducts beneath the Caribbean plate at rates of $72-81 \mathrm{~mm} / \mathrm{yr}$, resulting in a relatively high seismic hazard and a chain of numerous active volcanoes; here intermediate-focus earthquakes occur within the subducted Cocos plate to depths of nearly $300 \mathrm{~km}$. 


\section{South America}

\section{South America, Nazca Plate Region}

Hayes, G.P., Smoczyk, G.M., Benz, H.M., Villaseñor, Antonio, and Furlong, K.P., 2015, Seismicity of the Earth 1900-2013, Seismotectonics of South America (Nazca Plate Region): U.S. Geological Survey Open-File Report 2015-1031-E, 1 sheet, scale 1:14,000,000, http://pubs.usgs.gov/of/2015/1031/e/.

The South American Arc extends over 7,000 km, from the Chilean margin triple junction offshore of southern Chile, to its intersection with the Panama fracture zone, offshore of the southern coast of Panama in Central America. It marks the plate boundary between the subducting Nazca plate and the South America plate, where the oceanic crust and lithosphere of the Nazca plate begin their descent into the mantle beneath South America. The convergence associated with this subduction process is responsible for the uplift of the Andes Mountains, and for the active volcanic chain present along much of this deformation front. Relative to a fixed South America plate, the Nazca plate moves slightly north of eastward at a rate varying from approximately $80 \mathrm{~mm} / \mathrm{yr}$ in the south, to approximately $65 \mathrm{~mm} / \mathrm{yr}$ in the north. Although the rate of subduction varies little along the entire arc, there are complex changes in the geologic processes along the subduction zone that dramatically influence volcanic activity, crustal deformation, and earthquake generation and occurrence all along the western edge of South America.

Most of the large earthquakes in South America are constrained to shallow depths of 0-70 km as a result of both crustal and interplate deformation. Crustal earthquakes are caused by deformation and mountain building in the overriding South America plate and generate earthquakes as deep as approximately $50 \mathrm{~km}$. Interplate earthquakes occur due to slip along the dipping interface between the Nazca and the South America plates. Interplate earthquakes in this region are frequent and often large, and occur between depths of approximately 10 and $60 \mathrm{~km}$. Since 1900, numerous M 8+ earthquakes have occurred on this subduction zone interface that were followed by devastating tsunamis, including the 1960 M 9.5 earthquake in southern Chile, the largest instrumentally recorded earthquake in the world. Other notable shallow tsunami-generating earthquakes include the 1906 M 8.5 earthquake near Esmeraldas, Ecuador; the 1922 M 8.5 earthquake near Coquimbo, Chile; the 2001 M 8.4 Arequipa, Peru, earthquake; the 2007 M 8.0 earthquake near Pisco, Peru; and the 2010 M 8.8 Maule, Chile, earthquake located just north of the 1960 event.

Large intermediate-depth earthquakes (those occurring between depths of approximately 70 and $300 \mathrm{~km}$ ) are relatively limited in size and spatial extent in South America, and occur within the Nazca plate as a result of internal deformation within the subducting plate. These earthquakes generally cluster beneath northern Chile and southwestern Bolivia, and to a lesser extent beneath northern Peru and southern Ecuador, with depths from 110 to $130 \mathrm{~km}$. Most of these earthquakes occur adjacent to the bend in the coastline between Peru and Chile. The most recent large intermediate-depth earthquake in this region was the 2005 M 7.8 Tarapaca, Chile, earthquake.

Earthquakes can also be generated to depths greater than $600 \mathrm{~km}$ as a result of continued internal deformation of the subducting Nazca plate. Deep-focus earthquakes in South America are not observed from a depth range of approximately $300-500 \mathrm{~km}$. Instead, deep earthquakes in this region occur at depths of 500-650 km and are concentrated into two zones: one that runs beneath the Peru-Brazil border and another that extends from central Bolivia to central Argentina. These earthquakes generally do not exhibit large magnitudes. An exception to this was the 1994 Bolivian earthquake in northwestern Bolivia. This M 8.2 earthquake occurred at a depth of $631 \mathrm{~km}$, which until recently was the largest deep-focus earthquake instrumentally recorded (superseded in May 2013 by a M 8.3 earthquake $610 \mathrm{~km}$ beneath the Sea of Okhotsk, Russia), and was felt widely throughout South and North America.

Subduction of the Nazca plate is geometrically complex and influences the geology and seismicity of the western edge of South America. The intermediate depth regions of the subducting Nazca plate can be segmented into five sections based on their angle of subduction beneath the South America plate. Three segments are characterized by steeply dipping subduction; the other two by near-horizontal subduction. The Nazca plate beneath northern Ecuador, southern Peru to northern Chile, and southern Chile descend into the mantle at angles of $25^{\circ}$ to $30^{\circ}$. In contrast, the slab beneath southern Ecuador to central Peru, and under central Chile, is subducting at a shallow angle of approximately $10^{\circ}$ or less. In these regions of "flat-slab" subduction, the Nazca plate moves horizontally for several hundred kilometers before continuing its descent into the mantle, and is shadowed by an extended zone of crustal seismicity in the overlying South America plate. Although the South America plate exhibits a chain of active volcanism resulting from the subduction and partial melting of the Nazca oceanic lithosphere along most of the arc, these regions of inferred shallow subduction correlate with an absence of volcanic activity.

The tectonics of the Antarctica triple junction in southern Chile (Chile triple junction), are controlled by the interactions of the Antarctica, South America, and Scotia plates. Immediately south of the Chile triple junction, the Antarctica plate subducts beneath South America at a rate of approximately $16 \mathrm{~mm} / \mathrm{yr}$. There have been no moderate to large earthquakes associated with this convergence over the past century. Moving south and east through Patagonia, plate motions between the South America and 
the Scotia plates are predominantly left-lateral, at rates of $5-10 \mathrm{~mm} / \mathrm{yr}$. This plate boundary hosted two M 7.8 earthquakes in December 1949, near the Chile-Argentina border in Tierra del Fuego. Farther south, the Antarctica plate moves towards the east with respect to the Scotia plate at rates of less than $10 \mathrm{~mm} / \mathrm{yr}$, decreasing towards the south. Several M 6-6.5 earthquakes have been observed in the Drake Passage region over the past half century, all with left-lateral strike-slip faulting mechanisms.

\section{Europe}

\section{Mediterranean Sea and Vicinity}

Herman, M.W., Hayes, G.P., Smoczyk, G.M., Turner, Rebecca, Turner, Bethan, Jenkins, Jennifer, Davies, Sian, Parker, Amy, Sinclair, Allison, Benz, H.M., Furlong, K.P., and Villaseñor, Antonio, 2015, Seismicity of the Earth 1900-2013, Mediterranean Sea and vicinity: U.S. Geological Survey Open-File Report 2010-1083-0, scale 1:10,000,000, https://pubs.er.usgs.gov/publication/ofr201010830.

The Mediterranean region is seismically active due to the convergence of the Nubia (Africa) plate with the Eurasia plate. Present-day Nubia-Eurasia motion ranges from about $4 \mathrm{~mm} / \mathrm{yr}$ (in a northwest-southeast direction) in the western Mediterranean to about $10 \mathrm{~mm} / \mathrm{yr}$ (north-south) in the eastern Mediterranean. The Nubia-Eurasia plate boundary is complex, and includes extensional and translational zones in addition to convergent regimes. This convergence began at approximately 50 million years ago (Ma) and was associated with the closure of the Tethys Sea; the Mediterranean Sea is all that remains of the Tethys. The highest rates of seismicity in the Mediterranean region are found along the Hellenic subduction zone of southern Greece and the North Anatolian fault zone of northwestern Turkey.

At the western margin of the Mediterranean region (in the eastern Atlantic Ocean), oblique Nubia-Eurasia collision is accommodated by right-lateral strike-slip faulting along the Azores-Gibraltar seismic zone and into the Gulf of Cadiz. One of the more prominent historical (pre-instrumental) earthquakes within this region was the November 1, 1755, Lisbon earthquake, with an estimated magnitude of 8.0. This event generated a tsunami that swept up the Portuguese coast, inundating coastal villages and the city of Lisbon, leading to a death toll of about 60,000.

In the region near the Alboran Sea, between Spain and Morocco, shallow earthquakes are characterized by a wide range of faulting mechanisms, though extensional to strike-slip mechanisms prevail. The region's tectonic activity cannot be simply explained by the collision of the Eurasia and Nubia plates. It has been suggested that deeper lithospheric processes are controlling some of the deformation observed at the surface. Seismicity to depths of $600+\mathrm{km}$ beneath southern Spain is considered evidence of remnant subduction that still influences present-day tectonics.

The Atlas Belt extends along northern Africa and hosts normal and thrust earthquakes with the same west-east strike orientation as the Nubia-Eurasia plate boundary as well as strike-slip earthquakes oblique to the plate boundary orientation. Along the North Africa coast, earthquakes form a narrow band and the region in northern Algeria between Oran and Algiers is particularly active. On May 21, 2003, a M 6.8 earthquake in Algiers killed 2,266 people and injured 10,261.

Beneath northeastern Sicily and southern Italy, subduction occurs beneath the Tyrrhenian Sea at the Calabrian Arc, with seismic activity observed to depths of $500 \mathrm{~km}$. Despite a slow convergence rate at the Calabrian Arc $(0.8-1.1 \mathrm{~mm} / \mathrm{yr})$, this region has generated some of the most devastating historical earthquakes in Europe, including the 1693 Sicily earthquake that destroyed numerous towns along Sicily's east coast. The Messina Strait is an extensional back-arc structure between Sicily and Italy, which hosted a M 7.0 earthquake on December 28, 1908, that caused 72,000 fatalities. To date, it is the deadliest documented European earthquake.

The seismicity of Italy is dominated by earthquakes within the northwest-southeast-trending Apennine mountain chain, which extends from the Gulf of Taranto in the south, to the southern edge of the Po Basin in the north. The Apennine Mountains formed as a consequence of thrusting above a west-dipping subduction zone, where the Adriatic Sea descends beneath the Italian peninsula. It is still debated whether the Adriatic Sea is a northern promontory of the Nubia plate or a separate block moving independently of the Nubia and Eurasia plates.

The eastern side of the Apennine chain is dominantly compressional, with associated thrusting earthquakes. On the western side of the Apennines, east-west extension occurs due to gravitational collapse of the mountain belt, resulting in normal faulting seismicity. The most damaging instrumentally recorded earthquake in this region occurred on January 13, 1915, near the town of Avezzano, which killed tens of thousands.

Deformation within the Alpine Mountain belt is also associated with compression in response to the collision of northern Italy with Eurasia. The eastern Alps are particularly seismically active, with many shallow earthquakes occurring on north-dipping thrust faults, such as the M 6.5 Friuli earthquake in northeast Italy on May 6, 1976, that killed approximately 1,000 people. 
Near Crete, the Nubia plate subducts at a rate of almost $40 \mathrm{~mm} / \mathrm{yr}$ beneath the Aegean Sea along the Hellenic Arc. Shallowfocus earthquakes $(<70 \mathrm{~km})$ are common in this region, and most earthquakes northwest of Crete have reverse or strike-slip mechanisms, accommodating the convergent motion at the subducting front. Northeast of Crete, normal and strike-slip earthquakes arise from extension associated with regional back-arc spreading above the subducting Mediterranean oceanic crust. Beneath the southern Aegean Sea, and particularly under the Greek volcanic arc, several large intermediate-depth earthquakes $(>70 \mathrm{~km})$ have also occurred. These deeper earthquakes are thought to have occurred as a consequence of subducting oceanic lithosphere sinking under its weight into the mantle.

The 1903 Kythira and 1926 Rhodes earthquakes, with estimated magnitudes of approximately 7.0, are among the largest earthquakes instrumentally recorded in the Mediterranean region. Historical sources and archeological studies suggest that earthquakes occurring near Crete in $365 \mathrm{AD}$ and $1303 \mathrm{AD}$ may have been much larger than any Hellenic Arc earthquake of the $20^{\text {th }}$ century.

Along the eastern margin of the Mediterranean (near Turkey), the Sea of Marmara is a transition zone between the extensional regime of the back-arc of the Hellenic subduction system to the west, and the strike-slip regime of the North Anatolian fault to the east. The North Anatolian fault accommodates much of the right-lateral strike-slip motion between the Anatolian Block and Eurasia plate. Between 1939 and 1999, a sequence of 11 M 6.7+ strike-slip earthquakes propagated westward along the North Anatolian fault. The most recent and farthest west of these earthquakes was the August 17, 1999, M 7.6 Izmit earthquake, which killed approximately 17,000 people.

At the southern edge of the Anatolian Block lies the east-west trending Cyprian Arc, which hosts moderate levels of seismicity. The Cyprian Arc represents the convergent boundary between the Anatolian Block to the north and the Nubia plate to the south. The boundary is thought to join with the East Anatolian fault zone in eastern Turkey; however, no certain geometry or sense of relative motion along the entire boundary is widely accepted.

Along the eastern margin of the Mediterranean region, there is complex interaction between the Nubia, Arabia and Eurasia plates. The Red Sea Rift is a spreading center between the Nubia and Arabia plates, with a spreading rate of approximately 10 $\mathrm{mm} / \mathrm{yr}$ near its northern end, and $16 \mathrm{~mm} / \mathrm{yr}$ near its southern end. Seismicity rate and size of earthquakes has been relatively small along the spreading center, but the rifting process has produced a series of volcanic systems across western Saudi Arabia.

Farther north, the Red Sea Rift terminates at the southern boundary of the Dead Sea Transform. The Dead Sea Transform is a strike-slip fault that accommodates left-lateral motion between the Nubia and Arabia plates. Historically, earthquake activity along the Dead Sea Transform has been a significant hazard in the densely populated Levant region (eastern Mediterranean). For example, the November 1759 Near East earthquake is thought to have killed somewhere between 2,000 and 20,000 people. The northern termination of the Dead Sea Transform occurs within a complex tectonic region of southeast Turkey, where interaction of the Nubia and Arabia plates and the Anatolian Block occurs. This involves translational motion of the Anatolia Block westward, with a speed of approximately $25 \mathrm{~mm} / \mathrm{yr}$ with respect to Eurasia, in order to accommodate closure of the Mediterranean Basin.

\section{Africa}

\section{East African Rift}

Hayes, G.P., Jones, E.S., Stadler, T.J., Barnhart, W.D., McNamara, D.E., Benz, H.M., Furlong, K.P., and Villaseñor, Antonio, 2014, Seismicity of the Earth 1900-2013 East African Rift: U.S. Geological Survey OpenFile Report 2010-1083-P, 1 sheet, scale 1:8,500,000, http://pubs.usgs. gov/of/2010/1083/p/.

The East African Rift system (EARS) is a 3,000-km-long Cenozoic-age continental rift extending from the Afar triple junction, between the horn of Africa and the Middle East, to western Mozambique. Sectors of active extension occur from the Indian Ocean, west to Botswana and the Democratic Republic of the Congo. It is the only rift system in the world that is active on a continent-wide scale, providing geologists with a view of how continental rifts develop over time into oceanic spreading centers like the Mid-Atlantic Ridge.

Rifting in East Africa is not all coeval; volcanism and faulting have been ongoing phenomena on the continent since the Eocene (about $45 \mathrm{Ma}$ ). The rifting began in northern East Africa, and led to the separation of the Nubia (Africa) and Arabia plates in the Red Sea and Gulf of Aden, and in the Lake Turkana area at the Kenya-Ethiopia border. A Paleogene mantle superplume beneath East Africa caused extension within the Nubia plate, as well as a first-order topographic high known as the African superswell which now includes most of the eastern and southern sectors of the Nubia plate. Widespread volcanism erupted onto much of the rising plateau in Ethiopia during the Eocene-Oligocene (45-29 Ma), with chains of volcanoes forming along the rift separating Africa and Arabia. Since the initiation of rifting in northeastern Africa, the system has propagated over $3,000 \mathrm{~km}$ to the south and southwest, and it experiences seismicity as a direct result of the extension and active magmatism. 
Today, extension and magmatism are localizing in distinct eastern, western, and southwestern branches marking the edges of two or more microplates between the subparallel zones of extension in East Africa. The borders of the microplates (known as Victoria and Rovuma) with the Nubia plate to the west and Somalia plate to the east now represent the most seismically active zones on the continent where normal faulting earthquakes occur on a monthly basis. They are also the sites of volcanotectonic earthquakes. Along the rift, models of sparse GPS data and earthquake-slip vectors predict average spreading rates of 1-4 $\mathrm{mm} / \mathrm{yr}$, increasing from north to south in the western branch, and increasing from south to north in the east.

Seismicity in the East African Rift is widespread, but displays a distinct pattern. Seismicity is characterized by mainly shallow (about $40 \mathrm{~km}$ ) normal faults (earthquakes rupturing as a direct result of extension of the crust), and volcano-tectonic earthquakes. The majority of events occur in the 10-25-km depth range. This pattern is widespread throughout the EARS, and provides insight into the relationship between depth of earthquakes, the deformation of continental lithosphere, and magmatic processes in many sectors of the rift.

The three limbs of the Afar triple junction zone experience major earthquakes, as well as frequent volcanic eruptions and dike intrusions. The magnitude of earthquakes during volcano-tectonic events is usually less than $\mathrm{M} 6$, but large volumes of magma accommodating plate opening may occur during these intense, smaller magnitude swarms. The largest earthquakes recorded in this area occurred in a swarm, along a section of the evolving Arabia-Nubia plate boundary in Afar in August 1989. Studies of this earthquake swarm show that the events occurred as a result of slip on conjugate normal faults bounding the narrow Dobi graben. The swarm, made up of $25 \mathrm{M} \geq 4.2$ earthquakes, occurred over 48 hours beginning 11:17 UTC August 20, 1989. The events were all shallower than $15 \mathrm{~km}$ as a result of the thin crust beneath the triple junction compared to the surrounding continental crust. Conversely, the deepest earthquake ever recorded on the African continent (about $62 \mathrm{~km}$ ) also occurred beneath the Afar triple junction on November 8, 1978. This M 4.9 earthquake occurred beneath an active spreading segment, and was probably associated with the movement of magma at depth during the rifting episode.

The western branch is divided into three main segments - the northern and middle segments border the Nubia-Victoria microplate boundary, and the southern segment borders the Nubia-Rovuma boundary. The northern segment comprises the West Nile region (WNR), and Lakes Albert, Kivu, and Edward (LAKE); the middle segment includes Lakes Tanganyika and Rukwa (LT, LR); and the southern segment encompasses Lake Malawi and central Mozambique (LM). The two largest instrumentally recorded events in Africa occurred about $300 \mathrm{~km}$ north of Lake Albert in the WNR, in an area of Mesozoic (250-65 Ma) rifting. These M 7.1 earthquakes struck 4 days apart in May 1990, both at about $15 \mathrm{~km}$ depth. Their tectonic relationship to the Albert rift system or Mesozoic faults remains unclear. The most recent major earthquake to strike the region occurred on February 22, 2006. This M 7.0 event struck at a depth of $11 \mathrm{~km}$ in west-central Mozambique around midnight local time, killing 2 and injuring 15. The earthquake was felt in Mozambique, Zimbabwe, Swaziland, South Africa, and Zambia, but no major structural damage was reported.

The eastern branch is a discontinuous system of rifts, most of which have experienced magmatism since their onset. From north to south, these are the Ethiopian Rift (ER), the Kenya Rift (KR), the northern Tanzania divergence (NTD), and the Davie Ridge (DR). The Kenya Rift experienced a major M 6.9 earthquake in 1928, but has hosted only small magnitude swarms since then. As in the Afar and Ethiopian rift sectors where magma supply appears to be abundant, dike intrusions in the Kenya Rift accommodate extensional strain at lower stress levels than are required to cause slip along large fault systems bounding the rift. This generally results in relatively smaller earthquakes. Seismicity near the northern Tanzania Divergence marks the diffuse, volcanically active Victoria-Somalia plate boundary. Consistent with the widespread magmatism in this rift sector, earthquake magnitudes are generally less than M 6 and are the result of normal faulting. The Davie Ridge marks the Rovuma-Somalia plate boundary in the oceanic lithosphere of the western Indian Ocean basin. On May 14, 1985, two M 6.0-6.3 earthquakes struck this area, less than $100 \mathrm{~km}$ off the coast of northern Mozambique.

\section{Middle East}

\section{Middle East and Vicinity}

Jenkins, Jennifer, Turner, Bethan, Turner, Rebecca, Hayes, G.P., Sinclair, Alison, Davies, Sian, Parker, A.L., Dart, R.L., Tarr, A.C., Villaseñor, Antonio, and Benz, H.M., compilers, 2013, Seismicity of the Earth 1900-2010 Middle East and vicinity (ver 1.1, Jan. 28, 2014): U.S. Geological Survey Open-File Report 2010-1083-K, scale 1:7,000,000, http://pubs.usgs.gov/of/2010/1083/k/.

No fewer than four major tectonic plates (Arabia, Eurasia, India, and Nubia) and one smaller tectonic block (Anatolia) are responsible for seismicity and tectonics in the Middle East and surrounding region. Geologic development of the region is a consequence of a number of first-order plate tectonic processes that include subduction, large-scale transform faulting, compressional mountain building, and crustal extension. 
Mountain building in northern Pakistan and Afghanistan is the result of compressional tectonics, associated with collision of the India plate moving northward at a rate of $40 \mathrm{~mm} / \mathrm{yr}$ with respect to the Eurasia plate. Continental thickening of the northern and western edge of the India subcontinent has produced the highest mountains in the world, including the Himalayan, Karakorum, Pamir, and Hindu Kush Ranges. Earthquake activity and faulting found in this region, as well as adjacent parts of Afghanistan and India, are due to collisional plate tectonics.

Beneath the Pamir-Hindu Kush Mountains of northern Afghanistan, earthquakes occur to depths as great as $200 \mathrm{~km}$ as a result of remnant lithospheric subduction. Shallower crustal earthquakes in the Pamir-Hindu Kush Mountains occur primarily along the Main Pamir Thrust and other active Quaternary faults, which accommodate much of the region's crustal shortening. The western and eastern margins of the Main Pamir Thrust display a combination of thrust and strike-slip mechanisms.

Along the western margin of the Tibetan Plateau, in the vicinity of southeastern Afghanistan and western Pakistan, the India plate translates obliquely relative to the Eurasia plate, resulting in a complex fold-and-thrust belt known as the Sulaiman Range. Faulting in this region includes strike-slip, reverse-slip, and oblique-slip motion and often results in shallow, destructive earthquakes. The relatively fast moving left-lateral, strike-slip Chaman fault system in southeastern Afghanistan accommodates translational motion between the India and Eurasia plates. In 1505, a segment of the Chaman fault system near Kabul, Afghanistan, ruptured causing widespread destruction of Kabul and surrounding villages. In the same region, the more recent May 30 , 1935, M 7.6 Quetta, Pakistan, earthquake occurred within the Kirthar range, killing between 30,000 and 60,000 people.

Off the south coast of Pakistan and southeast coast of Iran, the Makran Trench is the present-day surface expression of active subduction of the Arabia plate beneath the continental Eurasia plate, which converge at a rate of approximately $20 \mathrm{~mm} / \mathrm{yr}$. Although the Makran subduction zone has a relatively slow convergence rate, it has produced large devastating earthquakes and tsunamis. For example, the November 27, 1945, M 8.0 megathrust earthquake produced a tsunami within the Gulf of Oman and Arabia Sea, killing over 4,000 people. Northwest of this active subduction zone, collision of the Arabia and Eurasia plates forms the approximately 1,500-km-long fold and thrust belts of the Zagros Mountains, which cross the whole of western Iran and extend into northeastern Iraq. Collision of the Arabia and Eurasia plates also causes crustal shortening in the Alborz Mountains and Kopet Dag in northern Iran. Eastern Iran undergoes destructive earthquakes that originate on both strike-slip and reverse faults. For example, the September 16, 1978, M 7.4 earthquake, along the northwest edge of the Dasht-e-Lut Basin, killed at least 15,000 people. Though smaller, the M 6.5 December 26, 2008, Bam earthquake, near the southwestern edge of the Dasht-eLut Basin, resulted in more than 25,000 deaths.

Along the eastern margin of the Mediterranean region there is complex interaction among the Nubia, Arabia, and Eurasia plates. The Red Sea Rift is a spreading center between the Nubia and Arabia plates, with a spreading rate of approximately $10 \mathrm{~mm} / \mathrm{yr}$ near its northern end and $16 \mathrm{~mm} / \mathrm{yr}$ near its southern end. Seismicity rate and size of earthquakes have been relatively small along the spreading center, but the rifting process has produced a series of volcanic systems across western Saudi Arabia.

Farther north, the Red Sea Rift terminates at the southern boundary of the Dead Sea Transform Fault. The Dead Sea Transform is a strike-slip fault that accommodates differential motion between the Nubia and Arabia plates. Though both the Nubia plate, to the west, and the Arabia plate, to the east, are moving in a north-northeast direction, the Arabia plate is moving slightly faster, resulting in the left-lateral, strike-slip motion along this segment of the plate boundary. Historically, earthquake activity along the Dead Sea Transform has been a significant hazard in the densely populated Levant region (eastern Mediterranean). For example, the November 1759 Near East earthquake is thought to have killed somewhere between 2,000 and 20,000 people. The northern termination of the Dead Sea Transform occurs within a complex tectonic region of southeast Turkey, where interaction of the Nubia and Arabia plates and the Anatolia block occurs. This involves translational motion of the Anatolia block westward, with a speed of approximately $25 \mathrm{~mm} / \mathrm{yr}$ with respect to Eurasia, in order to accommodate closure of the Mediterranean Basin.

The right-lateral, strike-slip North Anatolia fault in northern Turkey accommodates much of the westward motion between the Anatolia block and Eurasia plate. Between 1939 and 1999, a series of devastating M 7.0+ strike-slip earthquakes propagated westward along the North Anatolia fault system. The westernmost of these earthquakes was the August 17, 1999, M 7.6 Izmit earthquake, near the Sea of Marmara, which killed approximately 17,000 people.

At the southern edge of the Anatolia block lies the east-west-trending Cyprian Arc with associated levels of moderate seismicity. The Cyprian Arc represents the convergent boundary between the Anatolia block to the north and the Nubia plate to the south. The boundary is thought to join the East Anatolia fault zone in eastern Turkey; however, no certain geometry or sense of relative motion along the entire boundary is widely accepted. 


\section{Asia}

\section{Himalaya and Vicinity}

Turner, Bethan, Jenkins, Jennifer, Turner, Rebecca, Parker, A.L., Sinclair, Alison, Davies, Sian, Hayes, G.P., Villaseñor, Antonio, Dart, R.L., Tarr, A.C., Furlong, K.P., and Benz, H.M., 2013, Seismicity of the Earth 1900-2010 Himalaya and vicinity (ver.1.1, Jan. 28, 2014): U.S. Geological Survey Open-File Report 2010-1083-J, scale 1:9,000,000, http://pubs.usgs.gov/of/2010/1083/j/.

Seismicity in the Himalaya primarily results from the continental collision of the India and Eurasia plates, which are converging at a relative rate of $40-50 \mathrm{~mm} / \mathrm{yr}$. Approximately half of this convergence is accommodated across the Himalaya. Northward under-thrusting of India beneath Eurasia generates numerous earthquakes and consequently makes this area one of the most seismically hazardous regions on Earth. The surface expression of the plate boundary is marked by the foothills of the north-south-trending Sulaiman Range in the west, the Indo-Burmese Arc in the east, and the east-west-trending Himalaya Front in the north of India.

The India-Eurasia plate boundary is a diffuse boundary, which in the region near the north of India lies within the limits of the Indus-Tsangpo (also called the Yarlung-Zangbo) suture zone to the north and the Main Frontal Thrust to the south. The Indus-Tsangpo suture zone is located roughly $200 \mathrm{~km}$ north of the Himalaya Front and is defined by an exposed ophiolite chain along its southern margin. The narrow $(<200 \mathrm{~km})$ Himalaya Front includes numerous east-west-trending parallel structures. This region has the highest rates of seismicity and largest earthquakes in the Himalaya region, caused mainly by movement on thrust faults. Examples of significant earthquakes, in this densely populated region, caused by reverse-slip movement include the 1934 M 8.1 Bihar, the 1905 M 7.5 Kangra, and the 2005 M 7.6 Kashmir earthquakes. The latter two resulted in the highest death tolls for Himalaya earthquakes seen to date, together killing over 100,000 people and leaving millions homeless. The largest instrumentally recorded Himalaya earthquake occurred on August 15, 1950, in Assam, eastern India. This M 8.6 right-lateral, strike-slip earthquake was widely felt over a broad area of central Asia, causing extensive damage to villages in the epicentral region.

The Tibetan Plateau is situated north of the Himalaya, stretching approximately 1,000 km north-south and 2,500 km eastwest, and is geologically and tectonically complex with several sutures which are hundreds of kilometers long and generally trend east-west. The Tibetan Plateau is cut by a number of large $(>1,000 \mathrm{~km})$ east-west-trending left-lateral strike-slip faults, including the Kunlun, Haiyuan, and the Altyn Tagh. Right-lateral strike-slip faults (comparable in size to the left-lateral faults) in this region include the Karakorum, Red River, and Sagaing. Secondary north-south-trending normal faults also cut the Tibetan Plateau. Thrust faults are found towards the north and south of the Tibetan Plateau. Collectively, these faults accommodate crustal shortening associated with the ongoing collision of the India and Eurasia plates, with thrust faults accommodating northsouth compression, and normal and strike-slip faults accommodating east-west extension.

Along the western margin of the India plate, in the vicinity of southeastern Afghanistan and western Pakistan, the India plate translates obliquely relative to the Eurasia plate, resulting in a complex fold-and-thrust belt known as the Sulaiman Range. Faulting in this region includes strike-slip, reverse-slip and oblique-slip motion and often results in shallow, destructive earthquakes. The active, left-lateral, strike-slip Chaman fault is the fastest moving fault in the region. In 1505, a segment of the Chaman fault near Kabul, Afghanistan, ruptured causing widespread destruction. In the same region the more recent May 30, 1935, M 7.6 Quetta earthquake, which occurred in the Sulaiman Range in Pakistan, killed as many as 35,000 people.

On the northwestern side of the Tibetan Plateau, beneath the Pamir-Hindu Kush Mountains of northern Afghanistan, earthquakes occur at depths as great as $200 \mathrm{~km}$ as a result of remnant lithospheric subduction (see cross sections). Shallow crustal earthquakes also occur in this region near the Main Pamir Thrust and other active Quaternary faults. The Main Pamir Thrust, north of the Pamir Mountains, is an active shortening structure. The northern portion of the Main Pamir Thrust produces many shallow earthquakes, whereas its western and eastern borders display a combination of thrust and strike-slip mechanisms (Fan and others, 1994). On February 18, 1911, the M 7.4 Sarez earthquake ruptured in the Central Pamir Mountains, killing numerous people and triggering a landside, which blocked the Murghab River.

Farther north, the Tian Shan is a seismically active intra-continental mountain belt, which extends $2,500 \mathrm{~km}$ in an eastnortheast-west-northwest orientation north of the Tarim Basin. This belt is defined by numerous east-west-trending thrust faults, creating a compressional basin-and-range landscape. It is generally thought that regional stresses associated with the collision of the India and Eurasia plates are responsible for faulting in the region. The region has had three major earthquakes (>M 7.6) at the start of the $20^{\text {th }}$ century, including the 1902 Atushi earthquake, which killed an estimated 5,000 people. The range is cut through in the west by the 700-km-long, northwest-southeast-striking, Talas-Ferghana active right-lateral, strike-slip fault system. Though the system has produced no major earthquakes in the last 250 years, paleoseismic studies indicate that it has the potential to produce M 7.0+ earthquakes and it is thought to represent a significant hazard. 
The northern portion of the Tibetan Plateau itself is largely dominated by the motion on three large left-lateral, strikeslip fault systems: the Altyn Tagh, Kunlun and Haiyuan. The Altyn Tagh fault is the longest of these strike-slip faults and it is thought to accommodate a significant portion of plate convergence. However, this system has not undergone significant historical earthquakes, though paleoseismic studies show evidence of prehistoric M 7.0-8.0 events. Thrust faults link with the Altyn Tagh at its eastern and western termini. The Kunlun fault, south of the Altyn Tagh, is seismically active, producing large earthquakes such as the November 8, 1997, M 7.6 Manyi earthquake and the November 14, 2001, M 7.8 Kokoxili earthquake. The Haiyuan fault, in the far northeast, generated the December 16, 1920, M 7.8 earthquake that killed approximately 200,000 people and the May 22, 1927, M 7.6 earthquake that killed 40,912 people.

The Longmen Shan thrust belt, along the eastern margin of the Tibetan Plateau, is an important structural feature and forms a transitional zone between the complexly deformed Songpan-Garze fold belt and the relatively undeformed Sichuan Basin. On May 12, 2008, the thrust belt produced the reverse slip, M 7.9 Wenchuan earthquake, killing over 87,000 people and causing the equivalent of billions of U.S. dollars in damages and landslides, which dammed several rivers and lakes.

Southeast of the Tibetan Plateau are the right-lateral, strike-slip Red River and the left-lateral, strike-slip XianshuiheXiaojiang fault systems. The Red River fault underwent large-scale, left-lateral ductile shear during the Tertiary period before changing to its present-day right-lateral slip rate of approximately $5 \mathrm{~mm} / \mathrm{yr}$. This fault has produced several earthquakes $>\mathrm{M} 6.0$ including the January 4, 1970, M 7.5 earthquake in Tonghai which killed over 10,000 people. Since the start of the $20^{\text {th }}$ century, the Xianshuihe-Xiaojiang fault system has generated several M 7.0+ earthquakes including the M 7.5 Luhuo earthquake which ruptured on April 22, 1973. Some studies suggest that due to the high slip rate on this fault, future large earthquakes are highly possible along the $65-\mathrm{km}$ stretch between Daofu and Qianning and the 135-km stretch that runs through Kangding.

Shallow earthquakes within the Indo-Burmese Arc predominantly occur on a combination of strike-slip and reverse faults, including the Sagaing, Kabaw, and Dauki faults. Between 1930 and 1956, six M 7.0+ earthquakes occurred near the right-lateral Sagaing fault, resulting in severe damage in Burma, including the generation of landslides, liquefaction, and the loss of 610 lives. Deep earthquakes $(>300 \mathrm{~km})$ have also been known to occur in this region; these are thought to be due to the subduction of the eastward-dipping India plate, though whether subduction is currently active is debated. Within the pre-instrumental period, the large Shillong earthquake occurred on June 12, 1897, causing widespread destruction.

\section{Japan and Vicinity}

\section{Rhea, S., Tarr, A.C., Hayes, G., Villaseñor, A., and Benz, H.M., 2010, Seismicity of the Earth 1900-2007, Japan and vicinity: U.S. Geological Survey Open-File Report 2010-1083-D, 1 map sheet, scale 1:5,000,000, http://pubs. usgs.gov/of/2010/1083/d/.}

Japan and its island possessions lie across four major tectonic plates: Pacific plate; North America plate; Eurasia plate; and Philippine Sea plate. The Pacific plate is subducted into the mantle, beneath Hokkaido and northern Honshu, along the eastern margin of the Okhotsk microplate, a proposed subdivision of the North America plate. Farther south, the Pacific plate is subducted beneath volcanic islands along the eastern margin of the Philippine Sea plate. This 2,200-km-long zone of subduction of the Pacific plate is responsible for the creation of the deep offshore Ogasawara and Japan Trenches as well as parallel chains of islands and volcanoes, typical of circumpacific island arcs. Similarly, the Philippine Sea plate is itself subducting under the Eurasia plate along a zone, extending from Taiwan to southern Honshu, which comprises the Ryukyu Islands and the Nansei-Shoto Trench.

Subduction zones at the Japanese Island Arcs are geologically complex and produce numerous earthquakes from multiple sources. Deformation of the overriding plates generates shallow crustal earthquakes, whereas slip at the interface of the plates generates interplate earthquakes that extend from near the base of the trench to depths of 40 to $60 \mathrm{~km}$. At greater depths, Japanese Arc earthquakes occur within the subducting Pacific and Philippine Sea plates and can reach depths of nearly $700 \mathrm{~km}$. Since 1900, two great earthquakes occurred off Japan and three north of Hokkaido. They are the M 8.4 1933 Sanriku-oki earthquake, the M 8.3 2003 Tokachi-oki earthquake, the M 8.41958 Etorofu earthquake, the M 8.5 1963 Kuril earthquake, and the M 8.3 1994 Shikotan earthquake.

Several relevant tectonic elements, plate boundaries and active volcanoes, provide a context for the seismicity in the Japan region. The plate boundaries are known most accurately along the axis of the trenches and are more diffuse or speculative in the Sea of Japan, China, and Russia. The active volcanic arcs follow the Izu, Volcano, and Ryukyu Island chains and the main Japanese Islands parallel to the Japan Trench. 


\title{
Kuril-Kamchatka Arc and Vicinity
}

\author{
Rhea, S., Tarr, A.C., Hayes, G., Villaseñor, A., Furlong, K.P., and Benz, H.M., 2010, Seismicity of the Earth \\ 1900-2007, Kuril-Kamchatka Arc and vicinity: U.S. Geological Survey Open-File Report 2010-1083-C, 1 map \\ sheet, scale 1:5,000,000, http://pubs.usgs.gov/of/2010/1083/c/.
}

The Kuril-Kamchatka Arc extends approximately 2,100 km from Hokkaido, Japan, along the Kuril Islands and the Pacific coast of the Kamchatka Peninsula to its intersection with the Aleutian Arc near the Commander Islands, Russia. It marks the region where the Pacific plate subducts into the mantle beneath the Okhotsk microplate, part of the larger North America plate. This subduction is responsible for the generation of the Kuril Islands chain, active volcanoes located along the entire arc, and the deep offshore Kuril-Kamchatka Trench. Relative to a fixed North America plate, the Pacific plate is moving towards the northwest at a rate that increases from $75 \mathrm{~mm} / \mathrm{yr}$ near the northern end of the arc to $83 \mathrm{~mm} / \mathrm{yr}$ in the south.

Plate motion is predominantly convergent along the Kuril-Kamchatka Arc with obliquity increasing towards the southern section of the arc. The subducting Pacific plate is relatively old, particularly adjacent to Kamchatka where its age is greater than $100 \mathrm{Ma}$. Consequently, the Wadati-Benioff zone is well defined to depths of approximately $650 \mathrm{~km}$. The central section of the arc comprises an oceanic island arc system, which differs from the continental arc systems of the northern and southern sections. Oblique convergence in the southern Kuril Arc results in the partitioning of stresses into both trench-normal thrust earthquakes and trench-parallel strike-slip earthquakes, and the westward translation of the Kuril forearc. This westward migration of the Kuril forearc currently results in collision between the Kuril Arc in the north and the Japan Arc in the south, resulting in the deformation and uplift of the Hidaka Mountains in central Hokkaido.

The Kuril-Kamchatka Arc is considered one of the most seismically active regions in the world. Deformation of the overriding North America plate generates shallow crustal earthquakes, whereas slip at the subduction zone interface between the Pacific and North America plates generates interplate earthquakes that extend from near the base of the trench to depths of 40 to $60 \mathrm{~km}$. At greater depths, Kuril-Kamchatka Arc earthquakes occur within the subducting Pacific plate and can reach depths of approximately $650 \mathrm{~km}$.

This region has frequently experienced large (M 7+) earthquakes over the past century. Since 1900, a dozen great earthquakes (M 8 or larger) have occurred along the arc, with mechanisms that include interplate thrust faulting, and intraplate faulting. Damaging tsunamis followed several of the large interplate megathrust earthquakes. These events include the February 3 , 1923, M 8.4 Kamchatka earthquake; the November 6, 1958, M 8.4 Etorofu earthquake; and the September 25, 2003, M 8.3 Hokkaido earthquake. A large M 8.5 megathrust earthquake occurred on October 13, 1963, off the coast of Urup, an island along the southern Kuril Arc, which generated a large tsunami in the Pacific Ocean and the Sea of Okhotsk and caused run-up wave heights of up to 4-5 m along the Kuril Arc. The largest megathrust earthquake to occur along the entire Kurile-Kamchatka Arc in the $20^{\text {th }}$ century was the November 4, 1952, M 9.0 event. This earthquake was followed by a devastating tsunami with run-up wave heights as high as $12 \mathrm{~m}$ along the coast of Paramushir, a small island immediately south of Kamchatka, causing significant damage to the city of Severo-Kurilsk.

On October 4, 1994, a great (M 8.3) intraplate event occurred within the subducted oceanic lithosphere off the coast of Shikotan Island causing intense ground shaking, landslides, and a tsunami with run-up heights of up to $10 \mathrm{~m}$ on the island.

The most recent megathrust earthquake in the region was the November 15, 2006, M 8.3 Kuril Island event, located in the central section of the arc. Prior to this rupture, this part of the subduction zone had been recognized as a seismic gap spanning from the northeastern end of the 1963 rupture zone to the southwestern end of the 1952 rupture. Two months after the 2006 event, a great (M 8.1) normal faulting earthquake occurred on January 13, 2007, in the adjacent outer rise region of the Pacific plate. It has been suggested that the 2007 event may have been caused by the stresses generated from the 2006 earthquake.

\section{Philippine Sea Plate and Vicinity}

\author{
Smoczyk, G.M., Hayes, G.P., Hamburger, M.W., Benz, H.M., Villaseñor, Antonio, and Furlong, K.P., 2013, \\ Seismicity of the Earth 1900-2012 Philippine Sea plate and vicinity: U.S. Geological Survey Open-File Report \\ 2010-1083-M, scale 1:10,000,000, http://pubs.usgs.gov/of/2010/1083/m/.
}

The Philippine Sea plate is bordered by the larger Pacific and Eurasia plates, and by the smaller Sunda plate. The Philippine Sea plate is unusual in that its borders are nearly all zones of plate convergence. The Pacific plate is subducted into the mantle, south of Japan, beneath the Izu-Bonin and Mariana Island Arcs, which extend more than 3,000 km along the eastern margin of the Philippine Sea plate. This subduction zone is characterized by rapid plate convergence and high-level seismicity extending to depths of more than $600 \mathrm{~km}$. In spite of this extensive zone of plate convergence, the plate interface has been associated with few great $(M>8.0)$ "megathrust" earthquakes. This low seismic energy release is thought to result from weak coupling along 
the plate interface. This convergent plate margin is also associated with unusual zones of back-arc extension (along with resulting seismic activity) that decouple the volcanic island arcs from the remainder of the Philippine Sea plate.

South of the Mariana Island Arc, the Pacific plate is subducted beneath the Yap Islands along the Yap Trench. Similarly, the northwestern margin of the Philippine Sea plate is subducting beneath the Eurasia plate along a convergent zone, extending from southern Honshu (north of the map area) to the northeastern coast of Taiwan, manifested by the Ryukyu Islands and the NanseiShoto extension: the Okinawa Trough. At Taiwan, the plate boundary is characterized by a zone of arc-continent collision, whereby the northern end of the Luzon Island Arc is colliding with the buoyant crust of the Eurasia continental margin offshore China.

Along its western margin, the Philippine Sea plate is associated with a zone of oblique convergence with the Sunda plate. This highly active convergent plate boundary extends along both sides of the Philippines, from Luzon in the north to Sulawesi in the south. The tectonic setting of the Philippines is unusual in several respects: it is characterized by opposite-facing subduction systems on its east and west sides; the archipelago is cut by a major transform fault, the Philippine fault; and the arc complex itself is marked by volcanism, faulting, and high seismic activity. Subduction of the Philippine Sea plate occurs at the eastern margin of the archipelago along the Philippine Trench and its northern extension, the East Luzon Trough. The East Luzon Trough is thought to be an unusual example of a subduction zone in the process of formation, as the Philippine Trench system gradually extends northward. On the west side of Luzon, the Sunda plate subducts eastward along a series of trenches, including the Manila Trench in the north, the smaller and less well-developed Negros Trench in the central Philippines, and the Sulu and Cotabato Trenches in the south. At its northern and southern terminations, subduction at the Manila Trench is interrupted by arc-continent collision between the northern Philippine Island Arc and the Eurasian continental margin between the Sulu-Borneo Block (Sunda plate) and Luzon at the island of Mindoro. The Philippine Fault, which extends over 1,200 km within the Philippine Arc, is seismically active. The fault has been associated with major historical earthquakes, including the destructive M 7.6 Luzon earthquake of 1990. Several other active intra-arc fault systems are associated with moderate-to-high seismic activity, including the Cotabato Fault and the Verde Passage-Sibuyan Sea fault.

Relative plate motion near the Philippines (about $80 \mathrm{~mm} / \mathrm{yr}$ ) is oblique to the plate boundary along the two plate margins of central Luzon, where it is partitioned into orthogonal plate convergence in the subduction zones and nearly pure translational motion along the Philippine fault. Profiles B and C reveal evidence of opposing inclined seismic zones at intermediate depth (roughly $70-300 \mathrm{~km}$ ) and complex tectonics at the surface along the Philippine fault.

Several relevant tectonic elements, plate boundaries and active volcanoes, provide a context for the seismicity in this region. The plate boundaries are well-constrained along the axis of the trenches and more diffuse or speculative in the South China Sea and Lesser Sunda Islands. The active volcanic arcs follow the Izu, Volcano, Mariana, and Ryukyu Island chains, and the main Philippine Islands, all of which are parallel to the Manila, Negros, Cotabato, and Philippine Trenches, respectively.

Seismic activity related to the motions of the Philippine Sea plate has produced seven great (M 8+) earthquakes and 250 large (M 7+) events. Among the most destructive events were the 1923 Kanto earthquake, the 1948 Fukui earthquake, and the 1995 Kobe (Japan) earthquake (99,000, 5,100, and 6,400 casualties, respectively); the 1935 and the 1999 Chi-Chi (Taiwan) earthquakes (3,300 and 2,500 casualties, respectively); and the 1976 M 7.6 Moro Gulf and 1990 M 7.6 Luzon (Philippines) earthquakes (7,100 and 2,400 casualties, respectively). Some events are too small to show on the map. There have also been several tsunami-generating events in the region, including the Moro Gulf earthquake, whose tsunami resulted in more than 5,000 deaths.

\section{Java and Vicinity}

Jones, E.S., Hayes, G.P., Bernardino, Melissa, Dannemann, F.K., Furlong, K.P., Benz, H.M., and Villaseñor, Antonio, 2014, Seismicity of the Earth 1900-2012 Java and vicinity: U.S. Geological Survey Open-File Report 2010-1083-N, 1 sheet, scale 1:5,000,000, http://pubs.usgs.gov/of/2010/1083/n/.

The Sunda convergent margin extends for 5,600 km from the Bay of Bengal and the Andaman Sea, both located northwest of the map area, towards the island of Sumba in the southeast, and then continues eastward as the Banda Arc system. This tectonically active margin is a result of the India and Australia plates converging with and subducting beneath the Sunda plate at a rate of approximately 50 to $70 \mathrm{~mm} / \mathrm{yr}$. The main physiographic feature associated with this convergent margin is the Sunda-Java Trench, which stretches for 3,000 km parallel to the Java and Sumatra land masses and terminates at $120^{\circ} \mathrm{E}$. The convergence of the Indo-Australia and Sunda plates produces two active volcanic arcs: Sunda, which extends from 105 to $122^{\circ} \mathrm{E}$ and Banda, which extends from 122 to $128^{\circ} \mathrm{E}$. The Sunda Arc results solely from relatively simple oceanic plate subduction, while the Banda Arc represents the transition from oceanic subduction to continental collision, where a complex, broad deforming zone is found. 
Based on modern activity, the Banda Arc can be divided into three distinct zones: an inactive section, the Wetar Zone, bound by two active segments, the Flores Zone in the west and the Damar Zone in the east. The lack of volcanism in the Wetar Zone is attributed to the collision of Australia with the Sunda plate. The absence of gap in volcanic activity is underlain by a gap in intermediate-depth seismicity, which is in contrast to nearly continuous, deep seismicity below all three sections of the arc. The Flores Zone is characterized by down-dip compression in the subducted slab at intermediate depth and late Quaternary uplift of the forearc. These unusual features, along with GPS data interpretations indicate that the Flores Zone marks the transition between subduction of oceanic crust in the west and the collision of continental crust in the east.

The Java section of the Sunda Arc is considered relatively aseismic historically when compared to the highly seismically active Sumatra section, despite both areas being located along the same active subduction margin. Shallow (0-20 km) events have occurred historically in the overlying Sunda plate, causing damage to local and regional communities. A recent example was the May 26, 2006, M 6.3 left-lateral strike-slip event that occurred at a depth of $10 \mathrm{~km}$ in central Java, and caused over 5,700 fatalities. Intermediate-depth $(70-300 \mathrm{~km})$ earthquakes frequently occur beneath Java as a result of intraplate faulting within the Australia slab. Deep (300-650 km) earthquakes occur beneath the Java Sea and the back-arc region to the north of Java. Similar to other intermediate-depth events, these earthquakes are also associated with intraslab faulting. However, this subduction zone exhibits a gap in seismicity from 250 to $400 \mathrm{~km}$, interpreted as the transition between extensional and compressional slab stresses. Historical examples of large intraplate events include the 1903 M 8.1 event, 1921 M 7.5 event, 1977 M 8.3 event, and August 2007 M 7.5 event.

Large thrust earthquakes close to the Java Trench are typically interplate faulting events along the slab interface between the Australia and Sunda plates. These earthquakes also generally have high tsunamigenic potential due to their shallow hypocentral depths. In some cases, these events have demonstrated slow moment-release and have been defined as 'tsunami' earthquakes, where rupture is large in the weak crustal layers very close to the sea floor. These events are categorized by tsunamis that are significantly larger than predicted by the earthquake's magnitude. The most notable tsunami earthquakes in the Java region occurred on June 2, 1994 (M 7.8) and July 17, 2006 (M 7.7). The 1994 event produced a tsunami with wave run-up heights of $13 \mathrm{~m}$, killing over 200 people. The 2006 event produced a tsunami of up to $15 \mathrm{~m}$, and killed 730 people. Although both of these tsunami earthquakes were characterized by rupture along thrust faults, they were followed by an abundance of normal faulting aftershocks. These aftershocks are interpreted to result from extension within the subducting Australia plate, whereas the mainshocks represented interplate faulting between the Australia and Sunda plates.

\section{Sumatra and Vicinity}

Hayes, G.P., Bernardino, Melissa, Dannemann, Fransiska, Smoczyk, Gregory, Briggs, Richard, Benz, H.M.,
Furlong, K.P., and Villaseñor, Antonio, 2013, Seismicity of the Earth 1900-2012 Sumatra and vicinity: U.S.
Geological Survey Open-File Report 2010-1083-L, scale 1:6,000,000, http://pubs.usgs.gov/of/2010/1083/I/.

The plate boundary southwest of Sumatra, Indonesia, is part of a long tectonic collision zone that extends over 8,000 km from Papua, New Guinea, in the east, to the Himalaya Front in the west. The Sumatra-Andaman part of the collision zone forms a subduction-zone megathrust boundary, the Sunda Arc (Sunda-Java Trench), which accommodates convergence between the Indo-Australia and Sunda plates. This convergence is responsible for the intense seismicity and volcanism in Sumatra. Plateboundary-related deformation is also not restricted to the subduction zone and overriding plate; the subducting Indo-Australia plate actually comprises two somewhat independent plates (India plate and Australia plate), with small amounts of motion relative to one another, which are joined along a broad, actively deforming region producing seismicity up to several hundred kilometers west of the trench. This deformation is exemplified by the recent April 2012 earthquake sequence, which includes the April 11, 2012, M 8.6 and M 8.2 strike-slip events and their subsequent aftershocks.

The relative motion between the Indo-Australia and Sunda plates is rapid, decreasing from roughly $63 \mathrm{~mm} / \mathrm{yr}$ near the southern tip of Sumatra (Australia plate relative to Sunda plate) to $44 \mathrm{~mm} / \mathrm{yr}$ north of Andaman Islands (India relative to Sunda) and rotating counterclockwise to the northwest, so that relative motion near Jakarta is nearly trench-normal but becomes nearly trench-parallel near Burma. As a result of the rotation of relative plate motion along the strike of the arc and the interaction of multiple tectonic plates, several interrelated tectonic elements compose the Sumatra-Andaman part of the plate boundary. Most strain accumulation and release occurs along the Sunda megathrust of the main subduction zone, where lithosphere of the subducting Indo-Australia plate is in contact with the overlying Sunda plate down to a depth of $60 \mathrm{~km}$. Strain release associated with deformation within the subducting slab is evidenced by deeper earthquakes that extend to depths of less than $300 \mathrm{~km}$ on Sumatra and $150 \mathrm{~km}$ or less along the Andaman Islands. The increasingly oblique convergence between these two plates moving northwest along the arc is accommodated by crustal seismicity along a series of transform and normal faults. The Sumatra fault, a major transform structure that bisects Sumatra, accommodates the northwest-increasing lateral component of relative plate motion. East of the Andaman Islands, back-arc spreading in the Andaman Sea produces a zone of distributed normal and 
strike-slip faulting. Similar to the Sumatra fault, the Sagaing fault near Burma also accommodates the strike-slip component of oblique plate motion.

Paleoseismic studies using coral reefs as a proxy for relative land level changes associated with earthquake displacement suggest that the Sunda Arc has repeatedly ruptured during relatively large events in the past, with records extending as far back as the 10th century. In northern Simeulue Island, the southern terminus of the 2004 megathrust earthquake rupture area, a cluster of megathrust earthquakes occurred over a 56-year period between A.D. 1390 and 1455 resulting in uplift substantially greater than that caused by the 2004 event. Studies that look at large sheeted deposits of sand on land interpreted as the transport of debris from a tsunami wave also indicate that this region has gone through significant tsunamis in the past, albeit infrequently.

Prior to 2004, the most recent megathrust earthquakes along the Sunda Arc were in 1797 (M 8.7-8.9), 1833 (M 8.9-9.1), and 1861 (M 8.5). Since 2004, much of the Sunda megathrust between the northern Andaman Islands and Enggano Island, a distance of more than $2,000 \mathrm{~km}$, has ruptured in a series of large subduction zone earthquakes - most rupturing the plate boundary south of Banda Aceh. The great M 9.1 earthquake of December 26, 2004, which produced a devastating tsunami, ruptured much of the boundary between Burma and Simeulue Island offshore Banda Aceh. Immediately to the south of the great 2004 earthquake, the M 8.6 Nias Island earthquake of March 28, 2005, ruptured a 400-km section between Simeulue and Batu Islands. Farther south in the Mentawai Islands, two earthquakes on September 12, 2007, of M 8.5 and M 7.9 occurred in the southern portion of the estimated 1797 and 1833 rupture zone, which extends from approximately Enggano Island to the northern portion of Siberut Island. Smaller earthquakes have also been locally important: a M 7.6 rupture within the subducting plate caused considerable damage in Padang in 2009, and a M 7.8 rupture on October 25, 2010, occurred on the shallow portion of the megathrust to the west of the Mentawai Islands, and caused a substantial tsunami on the west coast of those islands.

In addition to the current seismic hazards along this portion of the Sunda Arc, this region is also recognized as having one of the highest volcanic activity levels in the world. One of the most dramatic eruptions in human history was the Krakatau eruption on August 26-27, 1883, a volcano just to the southeast of the island of Sumatra, which resulted in more than 35,000 casualties.

Subduction and seismicity along the plate boundary adjacent to Java is fundamentally different from that of the SumatranAndaman section. Relative motion along the Java Arc is trench-normal (approximately $65-70 \mathrm{~mm} / \mathrm{yr}$ ) and does not exhibit the same strain partitioning and back-arc strike-slip faulting that are observed along the Sumatra margin. Neither has the Java subduction zone hosted similar large-magnitude megathrust events to those of its neighbor, at least in documented history. Although this region is not as seismically active as the Sumatra region, the Java Arc has hosted low- to intermediate-magnitude extensional earthquakes and deep-focus (300-700 km) events and exhibits a similar if not higher volcanic hazard. This part of the arc has also hosted two large, shallow tsunami earthquakes in the recent past that resulted in high tsunami run-ups along the southern Java coast.

\section{Australia/Oceania}

\section{Australia Plate and Vicinity}

Benz, H.M., Herman, Matthew, Tarr, A.C., Hayes, G.P., Furlong, K.P., Villasenor, Antonio, Dart, R.L., and Rhea, Susan, 2011, Seismicity of the Earth 1900-2010 Australia plate and vicinity: U.S. Geological Survey Open-File Report 2010-1083-G, scale 1:15,000,000, http://pubs.usgs.gov/of/2010/1083/g/.

The boundary of the Australia plate includes all fundamental plate boundary components: mid-ocean ridges, subduction zones, arc-continent collisions, and large-offset transform faults. Along the southern edge of the plate, the mid-ocean ridge separates the Australia and Antarctica plates and its behavior is straightforward. In contrast, the other boundary segments that ring the Australia plate represent some of the most seismically active elements of the global plate boundary system, and some of the most rapidly evolving plate interactions. As a result, there are some very complex structures that host many large and great earthquakes.

Subduction dominates the convergence of the eastern boundary of the Australia plate with the Pacific plate. The relative plate velocity increases northward from $35 \mathrm{~mm} / \mathrm{yr}$ at New Zealand to $100 \mathrm{~mm} / \mathrm{yr}$ at the Solomon Islands. Near New Zealand, the 3,000-km-long plate boundary changes structure rapidly along its length and includes an oceanic transform, two subduction zones, and a transpressive continental transform fault (Alpine fault).

In the New Zealand continental block, large earthquakes tend to occur within the accretionary wedge (for example, the 1931 M 7.8 Hawke's Bay event that killed 256 people), but the Alpine fault is also capable of generating M 7.5 earthquakes. North of New Zealand, the Pacific plate subducts westward at the Kermadec and Tonga Trenches. Many large earthquakes are 
generated by subduction processes in the accretionary wedge, on the descending slab interface, and, less frequently, on the outer rise of the Pacific plate. On September 29, 2009, an outer rise M 8.1 normal fault event occurred south of Samoa, generating a tsunami that killed at least 180 people.

On the eastern edge of the north plate boundary, the Australia plate subducts eastward under the Pacific plate. Large earthquakes are dominantly due to subduction processes, such as the April 1, 2007, M 8.1 interplate event in the Solomon Islands that generated a tsunami killing at least 40 people. The northern boundary of the Australia plate is dominated by convergence with the Eurasia and Pacific plates, accommodatedby subduction in western Indonesia, incipient arc-continent collision in eastern Indonesia, and prolonged arc-continent collision in New Guinea.

From Sumatra to Sumba, the Australia plate is subducting northward at $65 \mathrm{~mm} / \mathrm{yr}$ under the Eurasia plate. The Sunda subduction zone hosts many large and great earthquakes related to the subduction process, including three great interplate megathrust events near Sumatra: the 2007 M 8.5 event killed 25 people, the 2005 M 8.6 event killed over 1,800 people, and the 2004 M 9.3 event was the third largest ever recorded and killed over 175,000 people. The 1977 Sumba M 8.0 event is also noteworthy because it was one of the largest normal fault earthquakes ever recorded, causing a tsunami that killed at least 100 people.

From Sumba to the Timor trough, the northern Australia continental margin collides with the volcanic arc to the north. There is seismic evidence for a descending slab under the Banda Sea, but it is rupturing from the buoyant continental lithosphere. GPS measurements indicate that the surface lithosphere of the Banda Sea is now moving with the Australia plate rather than the Eurasia plate. Large earthquakes are common in eastern Indonesia, but interplate megathrust events are rare because of the disconnection of the slab. The 1938 M 8.5 Banda Sea earthquake, an intermediate-depth thrust event, caused a tsunami, but no deaths were reported. In New Guinea, arc-continent collision between the Australia and Pacific plates has been progressing for $25 \mathrm{Ma}$, and the regions near the edges of the impinging Australia continental margin include relatively short-lived segments with diverse deformational styles that outline blocks of undeformed lithosphere. Large thrust fault and strike-slip earthquakes are associated with the collision.

\section{New Guinea and Vicinity}

\section{Benz, H.M., Herman, Matthew, Tarr, A.C., Hayes, G.P., Furlong, K.P., Villaseñor, Antonio, Dart, R.L., and Rhea, Susan, 2011, Seismicity of the Earth 1900-2010 New Guinea and vicinity: U.S. Geological Survey Open-File Report 2010-1083-H, scale 1:8,000,000, http://pubs.usgs.gov/of/2010/1083/h/.}

There have been 22 M 7.5+ earthquakes recorded in the New Guinea region since 1900. The dominant earthquake mechanisms are thrust and strike-slip, associated with the arc-continent collision and the relative motions between numerous local microplates. The largest earthquake in the region was a M 8.2 shallow thrust fault event in the northern Papua province of Indonesia that killed 166 people in 1996.

The Australia-Pacific plate boundary is over 4,000 km long on the northern margin, from the Sunda (Java) Trench in the west to the Solomon Islands in the east. The eastern section is over 2,300 km long, extending west from northeast of the Australian continent and the Coral Sea until it intersects the east coast of Papua New Guinea. The boundary is dominated by the general northward subduction of the Australia plate.

Along the South Solomon Trench, the Australia plate converges with the Pacific plate at a rate of approximately $95 \mathrm{~mm} / \mathrm{yr}$ towards the east-northeast. Seismicity along the trench is dominantly related to subduction tectonics, and large earthquakes are common; there have been 13 M 7.5+ earthquakes recorded since 1900. On April 1, 2007, a M 8.1 interplate megathrust earthquake occurred at the western end of the trench, generating a tsunami and killing at least 40 people. This was the third M 8.1 megathrust event associated with this subduction zone in the past century; the other two occurred in 1939 and 1977.

Farther east at the New Britain Trench, the relative motions of several microplates surrounding the Australia-Pacific boundary, including north-south-oriented sea-floor spreading in the Woodlark Basin south of the Solomon Islands, maintain the general northward subduction of Australia-affiliated lithosphere beneath Pacific-affiliated lithosphere. Most of the large and great earthquakes east of New Guinea are related to this subduction; such earthquakes are particularly concentrated at the cusp of the trench south of New Ireland. Thirty-three M 7.5+ earthquakes have been recorded since 1900, including 3 shallow thrust fault M 8.1 events in 1906, 1919, and 2007.

The western end of the Australia-Pacific plate boundary is perhaps the most complex portion of this boundary, extending 2,000 km from Indonesia and the Banda Sea to eastern New Guinea. The boundary is dominantly convergent along an arc-continent collision segment spanning the width of New Guinea, but the regions near the edges of the impinging Australia continental margin also include relatively short segments of extensional, strike-slip, and convergent deformation. The dominant convergence is accommodated by shortening and uplift across a 250-350-km-wide band of northern New Guinea, as well as by slow southward verging subduction of the Pacific plate north of New Guinea at the New Guinea Trench. Here, the Australia-Pacific plate relative velocity is approximately $110 \mathrm{~mm} / \mathrm{yr}$ towards the northeast, leading to the 2-8- $\mathrm{mm} / \mathrm{yr}$ uplift of the New Guinea Highlands. 
Whereas the northern band of deformation is relatively diffuse east of the Indonesia-Papua New Guinea border, in western New Guinea there are at least two small $\left(<100,000 \mathrm{~km}^{2}\right)$ blocks of relatively undeformed lithosphere. The westernmost of these is the Birds Head Peninsula microplate in Indonesia's West Papua province, bounded on the south by the Seram Trench. The Seram Trench was originally interpreted as an extreme bend in the Sunda subduction zone, but is now thought to represent a southward-verging subduction zone between Birds Head and the Banda Sea.

The western portion of the northern Australia plate boundary extends approximately 4,800 km from New Guinea to Sumatra and primarily separates Australia from the Eurasia plate, including the Sunda block. This portion is dominantly convergent and includes subduction at the Sunda (Java) Trench, and a young arc-continent collision.

In the east, this boundary extends from the Kai Islands to Sumba along the Timor trough, offset from the Sunda Trench by $250 \mathrm{~km}$ south of Sumba. Contrary to earlier tectonic models in which this trough was interpreted as a subduction feature continuous with the Sunda subduction zone, it is now thought to represent a subsiding deformational feature related to the collision of the Australia plate continental margin and the volcanic arc of the Eurasia plate, initiating in the last 5-8 million years (Myr). Before collision began, the Sunda subduction zone extended eastward to at least the Kai Islands, evidenced by the presence of a northward-dipping zone of seismicity beneath Timor Leste. A more detailed examination of the seismic zone along its eastern segment reveals a gap in intermediate-depth seismicity under Timor and seismic mechanisms that indicate an eastward-propagating tear in the descending slab as the negatively buoyant oceanic lithosphere detaches from positively buoyant continental lithosphere. On the surface, GPS measurements indicate that the region around Timor is currently no longer connected to the Eurasia plate, but instead is moving at nearly the same velocity as the Australia plate, another consequence of collision.

Large earthquakes in eastern Indonesia occur frequently but interplate megathrust events related to subduction are rare; this is likely due to the disconnection of the descending oceanic slab from the continental margin. There have been nine M 7.5+ earthquakes recorded from the Kai Islands to Sumba since 1900. The largest was the great Banda Sea earthquake of 1938 (M 8.5), an intermediate-depth thrust faulting event that did not cause significant loss of life.

\section{Eastern Margin of the Australian Plate}

Benz, H.M., Herman, Matthew, Tarr, A.C., Furlong, K.P., Hayes, G.P., Villaseñor, Antonio, Dart, R.L., and Rhea, Susan, 2011, Seismicity of the Earth 1900-2010 eastern margin of the Australia plate: U.S. Geological Survey Open-File Report 2010-1083-I, scale 1:8,000,000, http://pubs.usgs.gov/of/2010/1083/i/.

The eastern margin of the Australia plate is one of the most seismically active areas of the world due to high rates of convergence between the Australia and Pacific plates. In the region of New Zealand, the 3,000-km-long Australia-Pacific plate boundary extends from south of Macquarie Island to the southern Kermadec Island chain. It includes an oceanic transform (the Macquarie Ridge), two oppositely verging subduction zones (Puysegur and Hikurangi), and a transpressive continental transform, the Alpine Fault through South Island, New Zealand.

Australia-Pacific relative velocity is approximately $35 \mathrm{~mm} / \mathrm{yr}$ along the three plate boundary segments south of the Hikurangi subduction zone. The transpressive nature of the Alpine Fault leads to the rapid ( $>4 \mathrm{~mm} / \mathrm{yr}$ ) uplift of the Southern Alps. At the Puysegur subduction zone, starting in southwest New Zealand, the Australia plate descends obliquely to the northeast under South Island. To the east of North Island, subduction polarity is reversed at the Hikurangi Trench, where the Pacific plate sinks to the west. The convergence rate at the Hikurangi subduction zone increases northward from 35 to $60 \mathrm{~mm} / \mathrm{yr}$.

Since 1900, there have been 15 M 7.5+ earthquakes recorded near New Zealand. Nine of these, and the four largest, occurred along or near the Macquarie Ridge, including the 1989 M 8.2 event on the ridge itself, and the 2004 M 8.1 event $200 \mathrm{~km}$ to the west of the plate boundary, reflecting intraplate deformation. The largest recorded earthquake in New Zealand itself was the 1931 M 7.8 Hawke's Bay earthquake, which killed 256 people. The last M 7.5+ earthquake along the Alpine Fault was 170 years ago; studies of the faults' strain accumulation suggest that similar events are likely to occur again.

North of New Zealand, the Australia-Pacific boundary stretches east of Tonga and Fiji to $250 \mathrm{~km}$ south of Samoa. For $2,200 \mathrm{~km}$ the trench is approximately linear, and includes two segments where old (>120 Myr) Pacific oceanic lithosphere rapidly subducts westward (Kermadec and Tonga). At the northern end of the Tonga Trench, the boundary curves sharply westward and changes along a 700-km-long segment from trench-normal subduction, to oblique subduction, to a left lateral transform-like structure.

Australia-Pacific convergence rates increase northward from $60 \mathrm{~mm} / \mathrm{yr}$ at the southern Kermadec Trench to $90 \mathrm{~mm} / \mathrm{yr}$ at the northern Tonga Trench; however, significant back arc extension (or equivalently, slab rollback) causes the consumption rate of subducting Pacific lithosphere to be much faster. The spreading rate in the Lau-Havre trough, west of the Kermadec Trench, increases northward from 8 to $20 \mathrm{~mm} / \mathrm{yr}$. The southern tip of this spreading center is propagating into the North Island of New Zealand, rifting it apart. In the southern Lau Basin, west of the Tonga Trench, the spreading rate increases northward from 60 to $90 \mathrm{~mm} / \mathrm{yr}$, and in the northern Lau Basin, multiple spreading centers result in an extension rate as high as $160 \mathrm{~mm} / \mathrm{yr}$. The overall 
subduction velocity of the Pacific plate is the vector sum of Australia-Pacific velocity and back arc spreading velocity; thus it increases northward along the Kermadec Trench from 70 to $100 \mathrm{~mm} / \mathrm{yr}$, and along the Tonga Trench from 150 to $240 \mathrm{~mm} / \mathrm{yr}$.

The Kermadec-Tonga subduction zone generates many large earthquakes on the interface between the descending Pacific and overriding Australia plates, within the two plates themselves and, less frequently, near the outer rise of the Pacific plate east of the trench. Since 1900, $40 \mathrm{M} 7.5+$ earthquakes have been recorded, mostly north of $30^{\circ} \mathrm{S}$. However, it is unclear whether any of the few historic M 8+ events that have occurred close to the plate boundary were underthrusting events on the plate interface, or were intraplate earthquakes. On September 29, 2009, one of the largest normal fault (outer rise) earthquakes ever recorded (M 8.1) occurred south of Samoa, $40 \mathrm{~km}$ east of the Tonga Trench, generating a tsunami that killed at least 180 people.

Across the North Fiji Basin and to the west of the Vanuatu Islands, the Australia plate again subducts eastward beneath the Pacific, at the North New Hebrides Trench. At the southern end of this trench, east of the Loyalty Islands, the plate boundary curves east into an oceanic transform-like structure analogous to the one north of Tonga.

Australia-Pacific convergence rates increase northward from 80 to $90 \mathrm{~mm} / \mathrm{yr}$ along the North New Hebrides Trench, but the Australia plate consumption rate is increased by extension in the back arc and in the North Fiji Basin. Back arc spreading occurs at a rate of $50 \mathrm{~mm} / \mathrm{yr}$ along most of the subduction zone, except near about $15^{\circ} \mathrm{S}$, where the D'Entrecasteaux Ridge intersects the trench and causes localized compression of $50 \mathrm{~mm} / \mathrm{yr}$ in the back arc. Therefore, the Australia plate subduction velocity ranges from $120 \mathrm{~mm} / \mathrm{yr}$ at the southern end of the North New Hebrides Trench, to $40 \mathrm{~mm} / \mathrm{yr}$ at the D'Entrecasteaux Ridge/ Trench intersection, to $170 \mathrm{~mm} / \mathrm{yr}$ at the northern end of the trench.

Large earthquakes are common along the North New Hebrides Trench and have mechanisms associated with subduction tectonics, though occasional strike-slip earthquakes occur near the subduction of the D'Entrecasteaux ridge. Within the subduction zone 34 M 7.5+ earthquakes have been recorded since 1900. On October 7, 2009, a large interplate thrust fault earthquake (M 7.6) in the northern North New Hebrides subduction zone was followed 15 minutes later by an even larger interplate event (M 7.8) $60 \mathrm{~km}$ to the north. It is likely that the first event triggered the second of the so-called earthquake "doublet."

\section{References}

Benz, H.M., Dart, R.L., Villaseñor, Antonio, Hayes, G.P., Tarr, A.C., Furlong, K.P., and Rhea, Susan, 2011, Seismicity of the Earth 1900-2010 Aleutian Arc and vicinity: U.S. Geological Survey Open-File Report 2010-1083-B, scale 1:5,000,000, http://pubs.usgs.gov/of/2010/1083/b/.

Benz, H.M., Dart, R.L., Villaseñor, Antonio, Hayes, G.P., Tarr, A.C., Furlong, K.P., and Rhea, Susan, 2011, Seismicity of the Earth 1900-2010 Mexico and vicinity: U.S. Geological Survey Open-File Report 2010-1083-F, scale 1:8,000,000, http:// pubs.usgs.gov/of/2010/1083/f/.

Benz, H.M., Herman, Matthew, Tarr, A.C., Furlong, K.P., Hayes, G.P., Villaseñor, Antonio, Dart, R.L., and Rhea, Susan, 2011, Seismicity of the Earth 1900-2010 eastern margin of the Australia plate: U.S. Geological Survey Open-File Report 20101083-I, scale 1:8,000,000, http://pubs.usgs.gov/of/2010/1083/i/.

Benz H.M., Herman, Matthew, Tarr, A.C., Hayes, G.P., Furlong, K.P., Villasenor, Antonio, Dart, R.L., and Rhea, Susan, 2011, Seismicity of the Earth 1900-2010 Australia plate and vicinity: U.S. Geological Survey Open-File Report 2010-1083-G, scale 1:15,000,000, http://pubs.usgs.gov/of/2010/1083/g/.

Benz, H.M., Herman, Matthew, Tarr, A.C., Hayes, G.P., Furlong, K.P., Villaseñor, Antonio, Dart, R.L., and Rhea, Susan, 2011, Seismicity of the Earth 1900-2010 New Guinea and vicinity: U.S. Geological Survey Open-File Report 2010-1083-H, scale 1:8,000,000, http://pubs.usgs.gov/of/2010/1083/h/.

Benz, H.M., Tarr, A.C., Hayes, G.P., Villaseñor, Antonio, Furlong, K.P., Dart, R.L., and Rhea, Susan, 2011, Seismicity of the Earth 1900-2010 Caribbean plate and vicinity: U.S. Geological Survey Open-File Report 2010-1083-A, scale 1:8,000,000, http://pubs.usgs.gov/of/2010/1083/a/.

DeMets, Charles, Gordon, R.G. and Argus, D.F., 2010, Geologically current plate motions: Geophysical Journal International, v. 181 , no. 1 , p. $1-80$.

Di Giacomo, D., Storchak, D.A., Safronova, N., Ozgo, P., Harris, J., Verney, R. and Bondár, I., 2014, A New ISC service: The bibliography of seismic events: Seismological Research Letters, v. 85, no. 2, p. 354-360, accessed July 2016 at http://dx.doi. org/10.1785/0220130143. 
Hayes, G.P., Bernardino, Melissa, Dannemann, Fransiska, Smoczyk, Gregory, Briggs, Richard, Benz, H.M., Furlong, K.P., and Villaseñor, Antonio, 2013, Seismicity of the Earth 1900-2012 Sumatra and vicinity: U.S. Geological Survey Open-File Report 2010-1083-L, scale 1:6,000,000, http://pubs.usgs.gov/of/2010/1083/1/.

Hayes, G.P., Jones, E.S., Stadler, T.J., Barnhart, W.D., McNamara, D.E., Benz, H.M., Furlong, K.P., and Villaseñor, Antonio, 2014, Seismicity of the Earth 1900-2013 East African Rift: U.S. Geological Survey Open-File Report 2010-1083-P, 1 sheet, scale 1:8,500,000, http://pubs.usgs.gov/of/2010/1083/p/.

Hayes, G.P., Smoczyk, G.M., Benz, H.M., Villaseñor, Antonio, and Furlong, K.P., 2015, Seismicity of the Earth 1900-2013, Seismotectonics of South America (Nazca Plate Region): U.S. Geological Survey Open-File Report 2015-1031-E, 1 sheet, scale 1:14,000,000, http://pubs.usgs.gov/of/2015/1031/e/.

Hayes, G.P., Smoczyk, G.M., Ooms, J.G., McNamara, D.E., Furlong, K.P., Benz, H.M., and Villaseñor, Antonio, 2014, Seismicity of the Earth 1900-2013 Offshore British Columbia-southeastern Alaska and vicinity: U.S. Geological Survey Open-File Report 2010-1083-O, 1 sheet, scale 1:3,500,000, http://pubs.usgs.gov/of/2010/1083/o/.

Herman, M.W., Hayes, G.P., Smoczyk, G.M., Turner, Rebecca, Turner, Bethan, Jenkins, Jennifer, Davies, Sian, Parker, Amy, Sinclair, Allison, Benz, H.M., Furlong, K.P., and Villaseñor, Antonio, 2015, Seismicity of the Earth 1900-2013, Mediterranean Sea and vicinity: U.S. Geological Survey Open-File Report 2010-1083-Q, scale 1:10,000,000, https://pubs.er.usgs.gov/ publication/ofr20101083Q.

Jenkins, Jennifer, Turner, Bethan, Turner, Rebecca, Hayes, G.P., Sinclair, Alison, Davies, Sian, Parker, A.L., Dart, R.L., Tarr, A.C., Villaseñor, Antonio, and Benz, H.M., compilers, 2013, Seismicity of the Earth 1900-2010 Middle East and vicinity (ver 1.1, Jan. 28, 2014): U.S. Geological Survey Open-File Report 2010-1083-K, scale 1:7,000,000, http://pubs.usgs.gov/ of $/ 2010 / 1083 / \mathrm{k} /$.

Jones, E.S., Hayes, G.P., Bernardino, Melissa, Dannemann, F.K., Furlong, K.P., Benz, H.M., and Villaseñor, Antonio, 2014, Seismicity of the Earth 1900-2012 Java and vicinity: U.S. Geological Survey Open-File Report 2010-1083-N, 1 sheet, scale 1:5,000,000, http://pubs.usgs.gov/of/2010/1083/n/.

Rhea, S., Tarr, A.C., Hayes, G., Villaseñor, A., and Benz, H.M., 2010, Seismicity of the Earth 1900-2007, Japan and vicinity: U.S. Geological Survey Open-File Report 2010-1083-D, 1 map sheet, scale 1:5,000,000, http://pubs.usgs.gov/ of $/ 2010 / 1083 / \mathrm{d} /$.

Rhea, S., Tarr, A.C., Hayes, G., Villaseñor, A., Furlong, K.P., and Benz, H.M., 2010, Seismicity of the Earth 1900-2007, KurilKamchatka Arc and vicinity: U.S. Geological Survey Open-File Report 2010-1083-C, 1 map sheet, scale 1:5,000,000, http:// pubs.usgs.gov/of/2010/1083/c/.

Smoczyk, G.M., Hayes, G.P., Hamburger, M.W., Benz, H.M., Villaseñor, Antonio, and Furlong, K.P., 2013, Seismicity of the Earth 1900-2012 Philippine Sea plate and vicinity: U.S. Geological Survey Open-File Report 2010-1083-M, scale 1:10,000,000, http://pubs.usgs.gov/of/2010/1083/m/.

Turner, Bethan, Jenkins, Jennifer, Turner, Rebecca, Parker, A.L., Sinclair, Alison, Davies, Sian, Hayes, G.P., Villaseñor, Antonio, Dart, R.L., Tarr, A.C., Furlong, K.P., and Benz, H.M., 2013, Seismicity of the Earth 1900-2010 Himalaya and vicinity (ver.1.1, Jan. 28, 2014): U.S. Geological Survey Open-File Report 2010-1083-J, scale 1:9,000,000, http://pubs.usgs.gov/ of $/ 2010 / 1083 / \mathrm{j} /$.

U.S. Geological Survey National Earthquake Information Center Comprehensive Catalog, accessed July 2016 at http:// earthquake.usgs.gov/earthquakes/search/. 
Publishing support provided by:

Denver and Lafayette Publishing Service Centers

For more information concerning this publication, contact:

Director, Geologic Hazards Science Center

U.S. Geological Survey

Box 25046, Mail Stop 966

Denver, CO 80225-0046

(303) $273-8500$

Or visit the USGS Geologic Hazards Science Center Web site at: https://geohazards.usgs.gov/ 
